american american brazilian brazilian

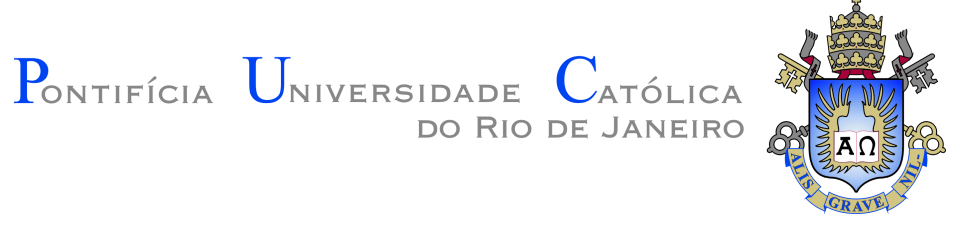

Renata Bulcão Nofal

Modelagem, simulação e estimação de parâmetros da decomposição térmica do alúmen de potássio

Dissertação de Mestrado

Dissertação apresentada como requisito parcial para obtenção do grau de Mestre pelo Programa de Pósgraduação em Engenharia de Materiais e de Processos Químicos e Metalúrgicos do Departamento de Engenharia Química e de Materiais do Centro Técnico Científico da PUC-Rio.

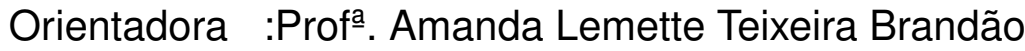
Co-orientador:Prof. Rodrigo Fernandes Magalhães de Souza 
Renata Bulcão Nofal

\title{
Modelagem, simulação e estimação de parâmetros da decomposição térmica do alúmen de potássio
}

\begin{abstract}
Dissertação apresentada como requisito parcial para obtenção do grau de Mestre pelo Programa de Pósgraduação em Engenharia de Materiais e de Processos Químicos e Metalúrgicos do Departamento de Engenharia Química e de Materiais do Centro Técnico Científico da PUC-Rio. Aprovada pela Comissão Examinadora abaixo assinada.
\end{abstract}

$$
\begin{array}{r}
\text { Profa. Amanda Lemette Teixeira Brandão } \\
\text { Orientadora } \\
\text { Departamento de Engenharia Química e de Materiais - } \\
\text { PUC-Rio }
\end{array}
$$

Prof. Rodrigo Fernandes Magalhães de Souza Co-orientador Departamento de Engenharia Química e de Materiais PUC-Rio

\section{Dr. Bruno Francisco Oechsler PEQ/COPPE - UFRJ}

Prof. Dr. Roberto de Ribeiro Avillez Departamento de Engenharia Química e de Materiais PUC-Rio

Prof. Márcio da Silveira Carvalho Coordenador Setorial do Centro Técnico Científico PUC-Rio 
Todos os direitos reservados. É proibida a reprodução total ou parcial do trabalho sem autorização da universidade, do autor e do orientador.

Renata Bulcão Nofal

Graduou-se em Engenharia Química pela Pontifícia Universidade Católica do Rio de Janeiro (Rio de Janeiro, Brasil).

Ficha Catalográfica

Nofal, Renata Bulcão

Modelagem, simulação e estimação de parâmetros da decomposição térmica do alúmen de potássio / Renata Bulcão Nofal; orientadora: Amanda Lemette Teixeira Brandão; co-orientador: Rodrigo Fernandes Magalhães de Souza. -2018.

119 f: il. color. ; $30 \mathrm{~cm}$

Dissertação (mestrado) - Pontifícia Universidade Católica do Rio de Janeiro, Departamento de Engenharia Química e de Materiais.

Inclui bibliografia

1. Engenharia Química - Teses. 2. Engenharia de Materiais - Teses. 3. Modelagem;. 4. Estimação de Parâmetros;. 5. Enxame de Partículas;. 6. Alúmen de Potássio;. 7. Decomposição Térmica.. I. Brandão, Amanda Lemette Teixeira. II. Souza,Rodrigo Fernandes Magalhães. III. Pontifícia Universidade Católica do Rio de Janeiro. Departamento de Engenharia Química e de Materiais. IV. Título. 


\section{Agradecimentos}

Aos meus pais e melhores amigos, Marcia e Salim Nofal.

À minha orientadora, Amanda Brandão, pela paciência, apoio e orientação ao longo desse processo.

Ao meu co-orientador, Rodrigo Souza, pela amizade desde os tempos de IC e pela confiança ao longo dos anos e trabalhos.

Aos professores do DEQM pela ajuda em momentos de desespero ao longo desse e outros trabalhos, em especial o Professor Roberto de Avillez e a Professora Maria Isabel Pais.

Ao Professor Eduardo Brocchi, pela mentoria e confiança desde a iniciação científica.

Ao técnico Henrique Meira, pelo apoio, perseverança, coragem, ajuda, disponibilidade, estímulo, motivação, e eu poderia passar mais várias páginas aqui...

Aos meus amigos maravilhosos que me aguentaram em tempos de crise, com as menções especiais:

Artur Serpa, que consegue ser rocha e almofada, não tenho nem mais palavras para você. Não existe prestígio que pague sua amizade.

Ana Dourado e Julia Cardoso, que viraram mais minha família e porto seguro nos últimos anos que qualquer outra coisa. Juntas nós somos a mistura perfeita de desespero, determinação e humor. Eu não teria terminado esse trabalho sem vocês.

Felipe Argento, Felipe Bizzo, Juliana Sette e Zeca Carvalho, por ficarem do meu lado, me apoiando, sempre.

Ao Conselho Nacional de Desenvolvimento Científico e Tecnológico (CNPq) pelo apoio financeiro. 


\section{Resumo}

Nofal, Renata Bulcão; Brandão, Amanda Lemette Teixeira; Souza,Rodrigo Fernandes Magalhães. Modelagem, simulação e estimação de parâmetros da decomposição térmica do alúmen de potássio. Rio de Janeiro, 2018. 119p. Dissertação de Mestrado - Departamento de Engenharia Química e de Materiais, Pontifícia Universidade Católica do Rio de Janeiro.

O potássio é um íon essencial para a nutrição de plantas, geralmente fornecido sob a forma de cloretos e sulfatos. De acordo com a disponibilidade e demanda brasileira de fertilizantes agrícolas, a importação de compostos portadores desse elemento químico é mandatória para atender a enorme demanda por esse nutriente. Assim, iniciativas que buscam fontes alternativas de potássio tornam-se cada vez mais interessantes e economicamente atraentes. Uma rota potencial está associada com a digestão com ácido sulfúrico de minerais portadores de glauconita e operações unitárias sequenciais para recuperar compostos de alumínio, ferro, magnésio e potássio. No contexto deste processo químico, o alúmen de potássio dodecahidrato aparece como um produto intermediário relevante que permite a recuperação seletiva de potássio e alumínio através de decomposição térmica seguida de solubilização em água e filtração. Com base no que foi dito, o presente trabalho investiga a cinética da decomposição do alúmen de potássio dodecahidratado sob condições não-redutoras e redutoras, e um novo modelo matemático é proposto para descrever a perda de massa ao longo do tempo. Uma abordagem estocástica, com o uso do método de otimização enxame de partículas, é empregada para estimar os parâmetros desconhecidos do modelo. As previsões do modelo são validadas por dados experimentais obtidos via análise termogravimétrica dinâmica em diferentes atmosferas de reação (inerte e oxidante), e com a presença ou não de agente redutor (finos de coque metalúrgico). Com os parâmetros do modelo validado, é possível usar o mesmo para monitorar as composições mássicas de todos os compostos presentes no meio assim como empregar o modelo futuramente para monitoramento online uma vez que sua simulação leva menos do que $1 \mathrm{~s}$ para simular 20 min de decomposição térmica.

\section{Palavras-chave}

Modelagem; Estimação de Parâmetros; Enxame de Partículas; Alúmen de Potássio; Decomposição Térmica. 


\section{Abstract}

Nofal, Renata Bulcão; Brandão, Amanda Lemette Teixeira (Advisor); Souza,Rodrigo Fernandes Magalhães (Co-Advisor). Modeling, simulation and parameter estimation of thermal decomposition of potassium alum. Rio de Janeiro, 2018. 119p. Dissertação de Mestrado - Departamento de Engenharia Química e de Materiais, Pontifícia Universidade Católica do Rio de Janeiro.

Potassium is an essential ion for plant nutrition, usually supplied in the form of chlorides and sulfates. According to Brazilian availability and demand of agriculture fertilizers, the importation of compounds carrying this chemical element is mandatory in order to fulfill the huge demand for this nutrient. So initiatives looking for alternative sources of potassium become increasingly interesting and economically attractive. A potential route is associated with the sulfuric digestion of glauconite-bearing greensands and sequential unit operations in order to recover aluminum, iron, magnesium and potassium compounds. In the context of this chemical process, the potassium alum dodecahydrate appears as a relevant intermediate product that allows the selective recovery of potassium and aluminum through thermal decomposition followed by solubilization in water and filtration. Based on what was said, the present work investigates the kinetics of potassium alum dodecahydrate decomposition under nonreductive and reductive conditions, and a novel mathematical model is proposed to describe the weight loss during time. A stochastic approach approach, using particle swarm optimization method, is employed to estimate the unknown model parameters. The model predictions are validated by experimental data obtained through dynamic thermogravimetric analysis at different reaction atmospheres (inert and oxidant), and with the presence or not of reducing agent (metallurgical coke breeze). With the validated model parameters, it is possible to use them to monitor the mass compositions of all compounds present in the process as well as to use the model for future online monitoring since its simulation takes less than $1 \mathrm{~s}$ to simulate $20 \mathrm{~min}$ of decomposition thermal.

\section{Keywords}

Modeling; Parameter Estimation; Particle Swarm; Potassium Alum; Thermal Decomposition. 


\section{Sumário}

american american brazilian brazilian

$\begin{array}{lr}\text { Lista de figuras } & 9\end{array}$

$\begin{array}{lr}\text { Lista de tabelas } & 14\end{array}$

1 Introdução $\quad 17$

$\begin{array}{lll}1.1 & \text { Organização do trabalho } & 20\end{array}$

2 Revisão Bibliográfica $\quad 21$

2.1 Sulfato de potássio empregado em fertilizantes 21

2.2 Rotas de produção do Sulfato de potássio 23

2.2.1 O Processo Mannheim (a partir de $\mathrm{KCl}$ e $\mathrm{H}_{2} \mathrm{SO}_{4}$ ) 24

2.2.2 Método Hargreaves $\quad 25$

2.2.3 Método com emprego de $\mathrm{KCl}$ e outros sulfatos 26

2.2.4 Rota de processamento da Glauconita 26

2.3 Processo Bayer e obtenção da alumina 29

2.4 Termodinâmica de reações químicas envolvendo sulfatos 30

2.4.1 Termodinâmica da decomposição térmica na presença de agente redutor $\quad 32$

2.5 Cinética da decomposição térmica do alúmen de potássio 36

2.6 Termogravimetria, calorimetria exploratória diferencial e análise térmica diferencial 38

2.6.1 TG e DTG 38

2.6.2 Métodos de estimação experimental de energia de ativação 39

2.7 Estimação de parâmetros $\quad 40$

2.7.1 Método de otimização Enxame de Partículas 41

2.7.2 Interpretação estatística dos parâmetros estimados e da qualidade de predição do modelo $\quad 43$

2.8 Comentários finais $\quad 45$

3 Metodologia $\quad 47$

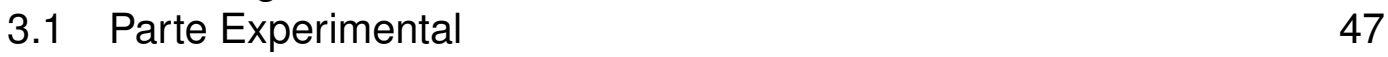

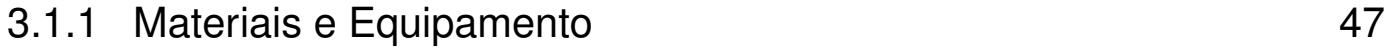

3.1.2 Procedimento Experimental 47

3.1.2.1 Experimental da Decomposição térmica 48

3.1.2.2 Procedimento Experimental da Decomposição redutora 48

3.2 Modelagem Matemática 49

3.3 Estimação de parâmetros e intervalos de confiança 55

3.3.1 Cálculo do Coeficiente de Determinação $\mathrm{R}^{2} \quad 57$

4 Resultados e Discussão $\quad 58$

4.1 Resultados Experimentais $\quad 58$

4.1.1 Decomposição térmica 58

4.1.2 Queima do Coque Breeze 64 
4.1.3 Decomposição Redutora 65

4.2 Resultados das simulações dos modelos 73

4.3 Resultados da Estimação Experimental 85

4.4 Resultado da estimação de parâmetros utilizando o enxame de partículas

90

4.4.1 Decomposição térmica 90

$\begin{array}{lll}4.4 .1 .1 & 1 \text { a Etapa } & 90\end{array}$

4.4.1.2 2 $2^{\mathrm{a}}$ Etapa 96

4.4.2 Decomposição na presença de agente redutor 101

4.4.2.1 $1^{\text {a }}$ Etapa 102

$\begin{array}{ll}4.4 .2 .22^{\text {a }} \text { Etapa } & 107\end{array}$

$\begin{array}{lll}4.5 & \text { Comentários Finais } & 110\end{array}$

5 Conclusões $\quad 111$

5.1 Trabalhos Futuros 112

6 Referências bibliográficas 113 


\section{Lista de figuras}

american american brazilian brazilian

Figura 2.1 Ciclo do Potássio no solo.

Figura 2.2 Relação tempo e temperatura para o processo Mannheim (Shultz et al. (2000)).

25

Figura 2.3 Fluxograma de processamento da Glauconita.

Figura 2.4 Fluxograma de processamento da Glauconita com destaque para a etapa de decomposição do precursor alúmen de potássio

Figura 2.5 Processo Bayer, versão resumida.

Figura 2.6 Gráfico $\Delta \mathrm{G}$ XT para a reação de decomposição do alúmen. Produzido por HSC Chemistry 6.0

Figura 2.7 Gráfico $\Delta \mathrm{G}^{\circ} \mathrm{x} T$ para a reação de decomposição dos sulfatos, de alumínio e de potássio. Produzido por HSC Chemistry 6.0

Figura 2.8 Gráfico da composição de equilíbrio para a reação de decomposição térmica. Produzido por HSC Chemistry 6.0

Figura 2.9 Gráfico da composição de equilíbrio para a reação de decomposição redutora. Produzido por HSC Chemistry 6.0

Figura 2.10 Reação de Boudouard

Figura 2.11 Curva cinética da decomposição do Alúmen.

35

Figura 2.12 Variação mássica do alúmen processado a $800{ }^{\circ} \mathrm{C}$.

Figura 2.13 Fluxograma de estimação experimental de parâmetros cinéticos por análise termogravimétrica usando o método de Osawa.

Figura 2.14 Fluxograma do método do Enxame de Partículas.

40

43

Figura 3.1 Modelo em uma etapa.

49

Figura 3.2 Modelo em duas etapas. $\quad 50$

Figura 3.3 Modelo em três etapas. 51

Figura 3.4 Modelo em quatro etapas. 52

Figura 3.5 Região de confiança dos parâmetros. 56

Figura 3.6 Resultado da simulação da função com o intervalo de confiança da mesma.

Figura 4.1 Resultado de TG para o alúmen de potássio, a 15 $\mathrm{K} / \mathrm{min}\left(15^{\circ} \mathrm{C} / \mathrm{min}\right)$ em atmosfera de ar sintético (Amostra T15Ar).

Figura 4.2 Resultado de TG para o alúmen de potássio, a 15 $\mathrm{K} / \mathrm{min}\left(15^{\circ} \mathrm{C} / \mathrm{min}\right)$ em atmosfera inerte (Amostra T15In).

Figura 4.3 Comparação das curvas de TG para o alúmen de potássio, a $15 \mathrm{~K} / \mathrm{min}\left(15^{\circ} \mathrm{C} / \mathrm{min}\right)$ em atmosfera inerte e atmosfera de ar sintético (Amostras T15In e T15Ar).

Figura 4.4 Resultado de DTG para o alúmen de potássio, a 15 $\mathrm{K} / \mathrm{min}\left(15{ }^{\circ} \mathrm{C} / \mathrm{min}\right)$ para ambas atmosferas, inerte e em ar sintético. 
Figura 4.5 Resultado de TG para o alúmen de potássio, a 10 $\mathrm{K} / \mathrm{min}\left(10^{\circ} \mathrm{C} / \mathrm{min}\right)$, em atmosfera inerte (Amostra T10In).

Figura 4.6 Resultado de TG para o alúmen de potássio, a 20 $\mathrm{K} / \mathrm{min}\left(20^{\circ} \mathrm{C} / \mathrm{min}\right)$, em atmosfera inerte (Amostra T20ln)

Figura 4.7 Curvas de TG para o alúmen de potássio em atmosfera inerte, para as taxas de aquecimento de 10,15 e 20 $\mathrm{K} / \mathrm{min}$ (Amostras T10In, T15In e T20In)

Figura 4.8 Resultado de TG para o coque breeze, a $15 \mathrm{~K} / \mathrm{min}(15$ ${ }^{\circ} \mathrm{C} / \mathrm{min}$ ), em atmosfera inerte

Figura 4.9 Resultado de TG para o coque breeze, a $15 \mathrm{~K} / \mathrm{min}(15$ ${ }^{\circ} \mathrm{C} / \mathrm{min}$ ), em atmosfera de ar sintético (C15Ar)

Figura 4.10 Resultado de TG para o alúmen de potássio com o coque breeze, a $15 \mathrm{~K} / \mathrm{min}\left(15{ }^{\circ} \mathrm{C} / \mathrm{min}\right)$, em atmosfera de ar sintético (R15Ar)

Figura 4.11 Resultado de TG para o alúmen de potássio com o coque breeze, a $15 \mathrm{~K} / \mathrm{min}\left(15^{\circ} \mathrm{C} / \mathrm{min}\right)$, em atmosfera inerte (R15ln)

Figura 4.12 Comparação das curvas de TG para o alúmen de potássio com o coque breeze, a $15 \mathrm{~K} / \mathrm{min}\left(15^{\circ} \mathrm{C} / \mathrm{min}\right)$, em atmosfera inerte e atmosfera de ar sintético (Amostras R15In e R15Ar).

Figura 4.13 Resultado de TG para o alúmen de potássio com o coque breeze, a $10 \mathrm{~K} / \mathrm{min}\left(10^{\circ} \mathrm{C} / \mathrm{min}\right)$, em atmosfera inerte(R10ln). 68

Figura 4.14 Resultado de TG para o alúmen de potássio com o coque breeze, a $20 \mathrm{~K} / \mathrm{min}\left(20^{\circ} \mathrm{C} / \mathrm{min}\right)$, em atmosfera inerte (R20ln).

Figura 4.15 Curvas de TG para o alúmen de potássio em presença de agente redutor em atmosfera inerte para as taxas de aquecimento de 10,15 e $20 \mathrm{~K} / \mathrm{min}$.

Figura 4.16 Resultado de TG para as decomposições do alúmen de potássio com e sem a presença de agente redutor, a $15 \mathrm{~K} / \mathrm{min}\left(15^{\circ} \mathrm{C} / \mathrm{min}\right)$, em atmosfera inerte (Amostras T15ln e R15In).

Figura 4.17 Decomposições do alúmen de potássio com e sem a presença de agente redutor pela temperatura (Amostras T15ln e R15In).

Figura 4.18 Resultado de DTG para as decomposições do alúmen de potássio com e sem a presença de agente redutor, a $15 \mathrm{~K} / \mathrm{min}\left(15^{\circ} \mathrm{C} / \mathrm{min}\right)$, em atmosfera inerte (Amostras T15ln e R15In).

Figura 4.19 Comparação dos dados experimentais com o Modelo 1 de uma etapa.

Figura 4.20 Evolução da quantidade de mols ao longo do tempo para o Modelo 1 de uma etapa.

Figura 4.21 Composição mássica ao longo do tempo para o Modelo 1 de uma etapa.

Figura 4.22 Comparação dos dados experimentais com o Modelo 2 de duas etapas. 
Figura 4.23 Evolução da quantidade de mols ao longo do tempo para o Modelo 2 de duas etapas.

Figura 4.24 Composição mássica ao longo do tempo para o Modelo 2 de duas etapas.

Figura 4.25 Comparação dos dados experimentais com o Modelo 3 de três etapas.

78

Figura 4.26 Evolução da quantidade de mols ao longo do tempo para o Modelo 3 de três etapas.

Figura 4.27 Composição mássica ao longo do tempo para o Modelo 3 de três etapas.

Figura 4.28 Comparação dos dados experimentais com o Modelo 4 de quatro etapas.

80

Figura 4.29 Evolução da quantidade de mols ao longo do tempo para o Modelo 4 de quatro etapas.

Figura 4.30 Composição mássica ao longo do tempo para o Modelo 4 de quatro etapas.

Figura 4.31 Mecanismo de ação do Modelo 5 de três etapas para a decomposição térmica na presença de agente redutor.

Figura 4.32 Comparação dos dados experimentais para a decomposição com agente redutor com o Modelo 5 de três etapas

Figura 4.33 Evolução da quantidade de mols ao longo do tempo para a decomposição com agente redutor com o Modelo 5 de três etapas.

Figura 4.34 Composição mássica ao longo do tempo para a decomposição com agente redutor com o Modelo 5 de três etapas.

Figura 4.35 Comparação dos dados experimentais da decomposição térmica com o Modelo 4 de quatro etapas a partir dos parâmetros estimados pelo método de Osawa com a taxa de aquecimento de $10 \mathrm{~K} / \mathrm{min}$.

Figura 4.36 Comparação dos dados experimentais da decomposição térmica com o Modelo 4 de quatro etapas a partir dos parâmetros estimados pelo método de Osawa com a taxa de aquecimento de $15 \mathrm{~K} / \mathrm{min}$.

Figura 4.37 Comparação dos dados experimentais da decomposição térmica com o Modelo 4 de quatro etapas a partir dos parâmetros estimados pelo método de Osawa com a taxa de aquecimento de $20 \mathrm{~K} / \mathrm{min}$.

Figura 4.38 Comparação dos dados experimentais da decomposição redutora com o Modelo 5 de três etapas a partir dos parâmetros estimados pelo método de Osawa com a taxa de aquecimento de $10 \mathrm{~K} / \mathrm{min}$.

Figura 4.39 Comparação dos dados experimentais da decomposição redutora com o Modelo 5 de três etapas a partir dos parâmetros estimados pelo método de Osawa com a taxa de aquecimento de $15 \mathrm{~K} / \mathrm{min}$. 
Figura 4.40 Comparação dos dados experimentais da decomposição redutora com o Modelo 5 de três etapas a partir dos parâmetros estimados pelo método de Osawa com a taxa de aquecimento de $20 \mathrm{~K} / \mathrm{min}$.

Figura 4.41 Comparação dados experimentais com o modelo, a partir dos parâmetros estimados, para a primeira reação de desidratação da primeira etapa da decomposição térmica.

Figura 4.42 Comparação dados experimentais com o modelo, a partir dos parâmetros estimados, para a segunda reação de desidratação da primeira etapa da decomposição térmica.

Figura 4.43 Taxa específica da primeira reação referente à primeira reação da primeira etapa da decomposição térmica.

Figura 4.44 Taxa específica da primeira reação referente à primeira reação da primeira etapa da decomposição térmica.

Figura 4.45 Região de confiança dos parâmetros $A_{1}$ e $B_{1}$ para a decomposição térmica.

Figura 4.46 Região de confiança dos parâmetros $A_{2}$ e $B_{2}$ para a decomposição térmica.

Figura 4.47 Comparação dos dados experimentais com o modelo, a partir dos parâmetros estimados, para a primeira reação da segunda etapa da decomposição térmica.

Figura 4.48 Comparação dos dados experimentais com o modelo, a partir dos parâmetros estimados, para a segunda reação da segunda etapa da decomposição térmica.

Figura 4.49 Taxa específica da primeira reação referente à segunda etapa da decomposição térmica.

Figura 4.50 Taxa específica da segunda reação referente à segunda etapa da decomposição térmica.

Figura 4.51 Região de confiança dos parâmetros $A_{3}$ e $B_{3}$ para a decomposição térmica.

Figura 4.52 Região de confiança dos parâmetros $\mathrm{A}_{4}$ e $\mathrm{B} 4$ para a decomposição térmica.

Figura 4.53 Comparação dos dados experimentais com o modelo, a partir dos parâmetros estimados, para a primeira reação da segunda etapa da decomposição redutora.

Figura 4.54 Comparação dos dados experimentais com o modelo, a partir dos parâmetros estimados, para a segunda reação da segunda etapa da decomposição redutora.

Figura 4.55 Taxa específica da primeira reação referente à primeira etapa da decomposição redutora.

Figura 4.56 Taxa específica da segunda reação referente à primeira etapa da decomposição redutora.

Figura 4.57 Região de confiança dos parâmetros $A_{1}$ e $B_{1}$ para a decomposição redutora.

Figura 4.58 Região de confiança dos parâmetros $A_{2}$ e $B_{2}$ para a decomposição redutora. 
Figura 4.59 Comparação dados experimentais com o modelo, a partir dos parâmetros estimados, para a segunda etapa da decomposição redutora.

Figura 4.60 Taxa específica da reação, referente à segunda etapa da decomposição redutora.

Figura 4.61 Região de confiança dos parâmetros $A_{3}$ e $B_{3}$ para a decomposição redutora. 


\section{Lista de tabelas}

american american brazilian brazilian

Tabela 2.1 Potenciais termodinâmicos de reações de dessulfurização do alúmen em atmosfera de $H_{2}$.

Tabela 3.1 Composição do Alúmen de potássio dodecahidratado sintético

Tabela 3.2 Massa pesada para os experimentos de decomposição térmica com alúmen de potássio dodecahidratado

Tabela 3.3 Massa pesada para os experimentos com coque breeze 48

Tabela 3.4 Massa pesada para os experimentos de decomposição redutora com alúmen de potássio dodecahidratado na presença do coque breeze como agente redutor

Tabela 4.1 Comparação entre as perdas de massa finais (\%) da decomposição térmica do alúmen de potássio para as três taxas de aquecimento

Tabela 4.2 Comparação entre as perdas de massa finais (\%) da decomposição redutora do alúmen de potássio para as três taxas de aquecimento

Tabela 4.3 Resultados da estimação de parâmetros pelo método de Osawa para a primeira etapa da desidratação da decomposição térmica

Tabela 4.4 Resultados da estimação de parâmetros pelo método de Osawa para a segunda etapa da desidratação da decomposição térmica

Tabela 4.5 Resultados da estimação de parâmetros pelo método de Osawa para a etapa da decomposição da decomposição térmica

Tabela 4.6 Resultados da estimação de parâmetros pelo método de Osawa para a primeira etapa da desidratação da decomposição redutora

Tabela 4.7 Resultados da estimação de parâmetros pelo método de Osawa para a segunda etapa da desidratação da decomposição redutora

Tabela 4.8 Resultados da estimação de parâmetros pelo método de Osawa para a etapa da decomposição da decomposição redutora

Tabela 4.9 Parâmetros estimados, correspondentes constantes cinéticas e suas respectivas reações para a Etapa 1 da decomposição térmica do alúmen de potássio

Tabela 4.10 Resumo dos resultados da estimação de parâmetros para a primeira etapa (desidratação) da decomposição térmica 91

Tabela 4.11 Parâmetros de Arrhenius para a primeira etapa da decomposição térmica 
Tabela 4.12 Parâmetros estimados, correspondentes constantes cinéticas e suas respectivas reações para a Etapa 2 da decomposição térmica do alúmen de potássio

Tabela 4.13 Resumo do resultado da estimação de parâmetros para a segunda etapa (decomposição) da decomposição térmica

Tabela 4.14 Parâmetros de Arrhenius para a segunda etapa da decomposição térmica

Tabela 4.15 Comparação dos resultados do modelo e dos dados experimentais

Tabela 4.16 Parâmetros estimados, correspondentes constantes cinéticas e suas respectivas reações para a Etapa 1 da decomposição redutora do alúmen de potássio

Tabela 4.17 Resumo dos resultados da estimação de parâmetros para a primeira etapa (desidratação) da decomposição redutora.

Tabela 4.18 parâmetros estimados para a primeira etapa da decomposição redutora

Tabela 4.19 2 Parâmetros estimados, correspondentes constantes cinéticas e suas respectivas reações para a Etapa 2 da decomposição redutora do alúmen de potássio

Tabela 4.20 Resumo dos resultados da estimação da segunda etapa (decomposição) da decomposição redutora

Tabela 4.21 Parâmetros de Arrhenius para a segunda etapa da decomposição redutora

Tabela 5.1 Parâmetros de Arrhenius para a decomposição térmica do alúmen de potássio

Tabela 5.2 Parâmetros de Arrhenius para a decomposição redutora do alúmen de potássio 
Behind every successful woman is a tribe of other successful women who have her back.

Anonymous 


\section{Introdução}

A agricultura é a atividade chave da produção mundial de alimentos. Produção essa anualmente cada vez mais exigida, dado o crescimento populacional exponencial experimentado desde a revolução industrial. Em consequência, agricultores precisam produzir mais, em menor área e de maneira mais sustentável, destacando-se a necessidade de fertilizantes que, segundo a definição de Camargo (2012)[1], oferecem resposta rápida no aumento de produtividade e que, além de contribuírem para reduzir o desmatamento e a erosão, evitam causar danos ao meio ambiente.

Quanto à nutrição mineral das plantas, são três os meios que contribuem com os elementos químicos para a composição das mesmas: ar (provedor de carbono, como $\mathrm{CO}_{2}$ ) água (traz hidrogênio e oxigênio) e solo (responsável por trazer os demais elementos minerais). Embora ar e a água sejam os meios mais importantes de fornecimento de elementos às plantas, o solo possui a facilidade de se tornar mais produtivo, artificialmente pela ação do homem, através de intervenção química (calagem e adubação), que é a maneira mais rápida, mais barata e mais eficiente de que se dispõe para aumentar a produção, conforme Faquin (2005)[2].

Dentre os macronutrientes necessários à planta, destacam-se o nitrogênio $(N)$, fósforo $(P)$, enxofre $(S)$ e o potássio $(K)$. No contexto nacional, sabe-se que a produção brasileira de fertilizantes não passa de $15 \%$ da necessidade, e portanto ainda depende fortemente da importação. Além disso, é importante que o país reduza a dependência de importações de fósforo de $49 \%$ para $12 \%$ e de nitrogênio de $78 \%$ para $33 \%$. Porém, a necessidade da importação de potássio se mantem alta, acima dos $80 \%$. Assim, a procura por produção de insumos fertilizantes desse tipo, se torna cada vez mais imperativa[3, 4].

Os principais minerais de potássio explorados atualmente são a silvinita e a carnalita $\left(\mathrm{KMgCl}_{3} \cdot 6 \mathrm{H}_{2} \mathrm{O}\right)$. A silvinita é composta por halita $(\mathrm{NaCl})$ e silvita $(\mathrm{KCl})$. Outros minerais menos explorados, mas também importantes são a langbeinita $\left(\mathrm{KMg}_{2}\left(\mathrm{SO}_{4}\right)_{3}\right)$, polihalita $\left(\mathrm{K}_{2} \mathrm{MgCa}_{2}\left(\mathrm{SO}_{4} \cdot 4 \mathrm{H}_{2} \mathrm{O}\right)\right.$ e kainita $\left(4 \mathrm{KCl}_{4} \mathrm{MgSO}_{4} \cdot 11 \mathrm{H}_{2} \mathrm{O}\right)$. No Brasil, existe apenas uma mina produtora de $\mathrm{KCl}$ (a partir de silvinita) em operação, a mina Taquari Vassouras, em Ser- 
gipe. Esta unidade produziu aproximadamente 716 mil toneladas de $\mathrm{KCl}$ em 2010, o que corresponde a apenas $10 \%$ das necessidades do país, como pode ser visto no trabalho de Silva, et al. (2012)[5].

Sabendo que os cloretos são responsáveis por $90 \%$ da quantidade de potássio oferecida pela indústria, o sulfato de potássio se mostra altamente vantajoso como a fonte de potássio na agricultura. O interesse em fertilizantes contendo ânions sulfato $\left(\mathrm{SO}_{4}\right)^{2-}$ vem ganhando força especialmente em áreas com culturas específicas que sofrem com estresse salino causado pela presença de íons de cloro, além da necessidade de alguns cultivos por enxofre[3].

Em paralelo a esse contexto, setores voltados para o processamento químico de materiais reconhecem a importância no que diz respeito ao desenvolvimento de propostas que buscam matérias primas alternativas capazes de prover fertilizantes mais baratos e mais eficientes, aos já consagrados processos de obtenção de fertilizantes. Essas rotas alternativas possibilitam a utilização de novos precursores e a concomitante obtenção de compostos químicos de interesse[6]. Essa procura por novas rotas químicas para obter compostos ricos em potássio tem sido investigada por algumas empresas que partem do mineral bruto, como a glauconita[7].

A glauconita é um mineral silicatado hidratado constituído principalmente por alumínio, potássio, magnésio, ferro, silício, oxigênio e hidrogênio. Em geral, pode-se dizer que a glauconita tem um teor de potássio variando de 6 a 14\% de $\mathrm{K}_{2} \mathrm{O}$, o que estimula a sua utilização em processos de obtenção de $\mathrm{K}_{2} \mathrm{SO}_{4}[5]$.

O processo alternativo para a ocorrência mineral de uma empresa do setor mineral brasileiro voltada para a produção de compostos químicos fertilizantes para a agricultura, e em particular o sulfato de potássio, a partir da glauconita, tem como etapa importante no fluxograma de processo, a reação de decomposição térmica do alúmen de potássio, um sal duplo de potássio e alumínio, precursor do sulfato de potássio[8].

Por outro lado, contrastante à essa etapa, existe a possibilidade de tratar a decomposição do alúmen de potássio como decomposição redutora, com a presença de um agente redutor, que poderia trazer como benefícios a diminuição da temperatura de reação, e a consequente diminuição do gasto de energia.

Diante do que foi apresentado, há fortes indícios de que a obtenção do sulfato de potássio a partir da decomposição térmica do precursor alúmen de potássio (na presença ou não de um catalisador) é uma rota promissora que pode ser atraente para a indústria, principalmente na área de fertilizan- 
tes. Contudo, apesar desse processo já ter sido investigado, não há muitos dados disponíveis da literatura e, até onde temos conhecimento, ainda faltam informações relevantes em relação à cinética de reação envolvida.

Desse modo, o desenvolvimento de um modelo matemático capaz de representar esse sistema reacional torna-se peça fundamental para maior obtenção de conhecimento em relação ao processo. Pois, com o modelo validado, diferentes condições experimentais podem ser simuladas e condições ótimas podem ser determinadas para que sejam executadas em uma planta piloto visando futura aplicação do processo em escala industrial.

No entanto, a validação do modelo matemático requer a comparação das respostas do mesmo com dados experimentais reais. Quando o modelo responder adequadamente aos dados reais disponíveis a diferentes condições experimentais, respeitados os erros dos experimentos e de predição, ele pode ser considerado um modelo confiável e, portanto, validado.

Tendo isso em vista, a utilização de análises termogravimétricas como uma ferramenta de caracterização cinética de processos químicos tem sido amplamente difundida[9, 10, 11, 12, 13, 14, 15, 16], principalmente pela vantagem de exigir menores quantidades de amostra e ser uma análise relativamente rápida. Assim, com o uso de análises feitas em TG, é possível estudar a cinética de degradação de compostos e, inclusive, usar os dados obtidos dessa análise para a estimação de parâmetros cinéticos desconhecidos.

Portanto, algumas perguntas sobre a obtenção do sulfato de potássio por TG surgem naturalmente, como:

- É realmente vantajoso realizar a decomposição térmica do alúmen de potássio na presença de um agente redutor?

- Quais mecanismos cinéticos explicam a decomposição térmica do alúmen de potássio com e sem agente redutor?

- Como as taxas reacionais são definidas?

- Quais os valores das constantes cinéticas das reações envolvidas?

Visando responder esses questionamentos, os principais objetivos da presente dissertação de mestrado podem ser listados como:

- Investigar a decomposição térmica do alúmen de potássio com e sem a presença de agente redutor por meio de experimentos de análise termogravimétrica (TG). 
- Investigar mecanismos cinéticos capazes de representar a decomposição térmica do alúmen de potássio com ou sem agente redutor por meio do desenvolvimento de seus respectivos modelos matemáticos e simulação dos mesmos.

- Estimar os parâmetros cinéticos dos modelos por meio do método de otimização enxame de partículas.

- Realizar testes estatísticos para avaliar os parâmetros estimados e obter os intervalos de confiança da predição dos modelos.

\section{1}

\section{Organização do trabalho}

A presente dissertação consiste de 6 capítulos e está organizada como segue:

- O capítulo 1 apresenta uma breve introdução e contextualização da temática de produção de sulfato de potássio;

- O capítulo 2 apresenta uma revisão bibliográfica abrangente desde as rotas de processamento até a influência termodinâmica e cinética no processo;

- O capítulo 3 apresenta a metodologia utilizada no presente trabalho, que inclui a metodologia experimental, a modelagem matemática e estimação de parâmetros (por métodos experimentais e através da otimização por enxame de partículas) para ambos os casos da decomposição térmica, com e sem agente redutor;

- O capítulo 4 apresenta os resultados e discussão. Envolve os resultados dos experimentos práticos, da simulação inicial do modelo, da estimação dos parâmetros, e da comparação na decomposição térmica com e sem agente redutor;

- O capítulo 5 apresenta as conclusões obtidas no trabalho e as propostas para futuros trabalhos.

- O capítulo 6 apresenta as referências bibliográficas usadas. 


\section{2 \\ Revisão Bibliográfica}

\section{1}

\section{Sulfato de potássio empregado em fertilizantes}

Desde o século III a.C. já se sabia, por conhecimento empírico, da necessidade do potássio no metabolismo das plantas. Há referências de sua utilização como fertilizante desde essa época, de cinzas resultantes da queima de árvores, material contendo uma concentração expressiva de potássio, e é conhecido hoje, que nenhum homem ou planta sobrevive sem um fornecimento adequado de potássio[17].

A nutrição mineral de plantas trata da aquisição e utilização pelas mesmas da grande maioria dos elementos químicos que entram em sua composição. Estes nutrientes são elementos como nitrogênio, fósforo, enxofre e potássio, e o reservatório básico destes elementos são as rochas, o oceano e a atmosfera[5].

Sendo o terceiro nutriente mais exigido pelas culturas, atrás apenas do nitrogênio e do fósforo, o potássio está disponível naturalmente em grandes quantidades no solo principalmente em espécies minerais. Entretanto, no Brasil, o potássio se torna escasso devido à elevada acidez dos solos tropicais (solos com baixo teor de nutrientes e baixo pH em virtude das suas condições climáticas)[5].

O potássio, que compõe de 1 a $4 \%$ da matéria seca das plantas, tem muitas funções conhecidas. Entre estas funções, pode-se citar a ativação de mais de 60 enzimas e, portanto, tem papel vital na síntese de proteínas e carboidratos. Melhora a transferência de água na planta e aumenta a sua tolerância à seca, salinidade e geada. Além disso, plantas bem supridas de potássio são menos afetadas por doenças. Podem perder a capacidade de absorver a água do solo, e consequentemente outros nutrientes ali presentes. O potássio influencia também no tamanho, cor e sabor da planta[18, 19].

A principal forma de potássio no solo é a mineral e é encontrada na rede cristalina de minerais primários, silicatos de potássio-alumínio como a mica e o feldspato, porém a liberação deste potássio para a solução do 
solo é muito lenta[5]. Desta forma os cátions de potássio adsorvidos na fase mineral, na matéria orgânica e dissolvidos na solução do solo são as principais fontes do nutriente para as plantas e microrganismos presentes no seu ciclo.

Considerando que a solução do solo é a única fonte contribuinte da nutrição das plantas e que ela sofre com o processo de lixiviação, é importante dirigir o fluxo de potássio dos depósitos para repor a capacidade da nutrição (Figura 2.1).

\section{Ciclo do Potássio}
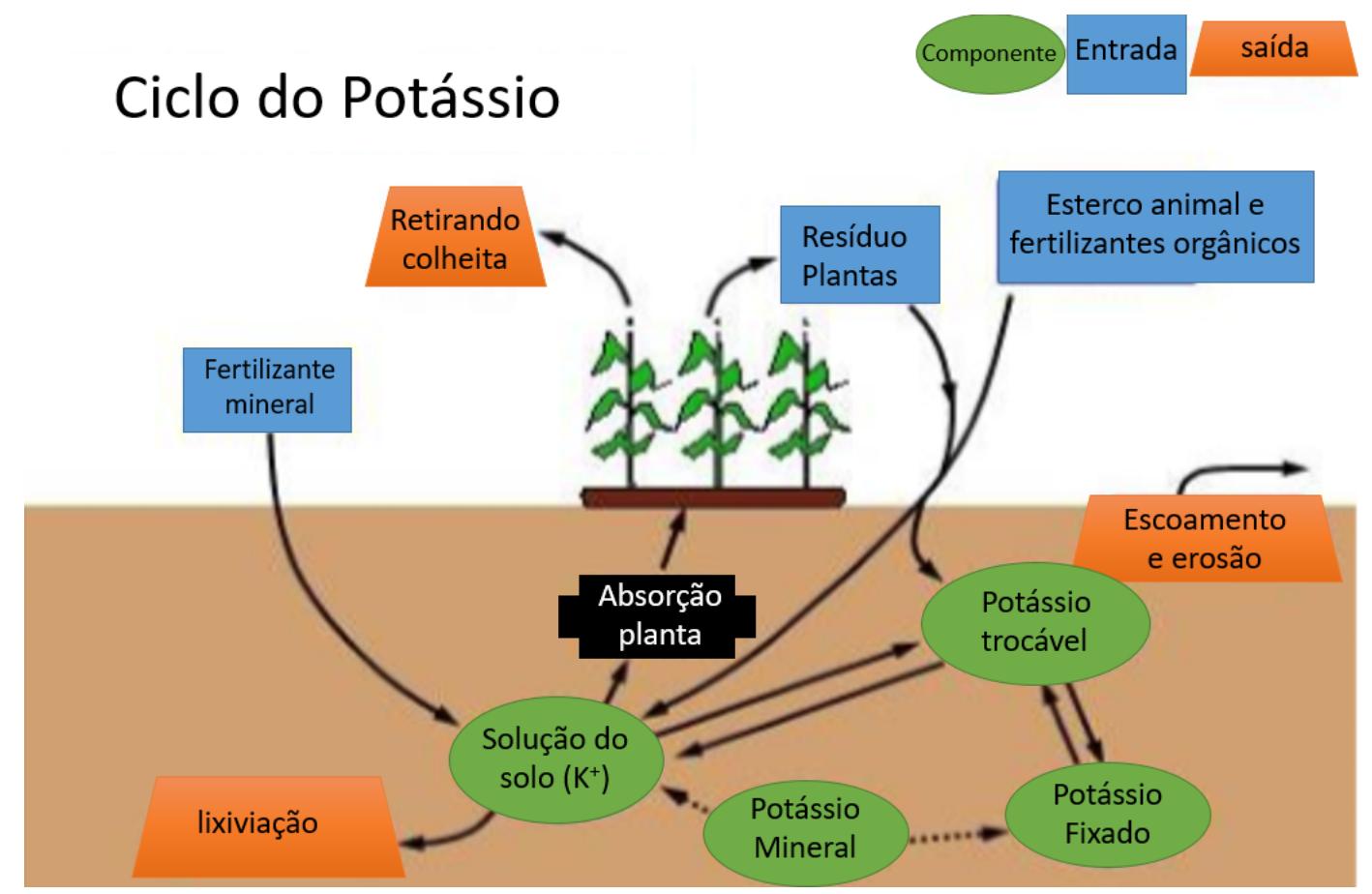

Figura 2.1: Ciclo do Potássio no solo.

A deficiência causada pela carência de potássio é visível pela ocorrência de coloração amarelo alaranjada e seca nas bordas das folhas e que, futuramente acarreta a morte da planta. Além disso, também leva a cachos pequenos, frutos pequenos e finos, maturação irregular e limitação de sabor da polpa[20].

Os solos agrícolas possuem comumente 300 a $50.000 \mathrm{~kg} / \mathrm{ha}$ (quilograma por hectare) de potássio a uma profundidade de $15 \mathrm{~cm}$, mas as culturas podem remover de 200 a $700 \mathrm{~kg} / \mathrm{ha}$ por colheita, por isso é tamanha a necessidade de fertilização[21]. O potássio (K) é considerado o nutriente mais importante para a produção de frutos de qualidade superior. A quantidade recomendada varia de 100 a $750 \mathrm{~kg}$ de $\mathrm{K}_{2} \mathrm{O} / \mathrm{ha}$, dependendo do teor no solo e da produtividade esperada. A primeira aplicação deve ser feita em cobertura, no terceiro ou quarto mês após o plantio. Caso o teor de $\mathrm{K}$ 
no solo seja inferior a $59 \mathrm{mg} / \mathrm{dm}^{3}$, a primeira aplicação deve ser feita no plantio juntamente à adubação fosfatada e orgânica. Pode ser aplicado sob as formas de cloreto de potássio $\left(60 \%\right.$ de $\left.\mathrm{K}_{2} \mathrm{O}\right)$, sulfato de potássio $(50 \%$ de $\left.\mathrm{K}_{2} \mathrm{O}\right)$ e nitrato de potássio $\left(48 \%\right.$ de $\left.\mathrm{K}_{2} \mathrm{O}\right)$. Solos com teores de $\mathrm{K}$ acima de $234 \mathrm{mg} / \mathrm{dm}^{3}$ dispensam a adubação potássica[22].

\section{2}

\section{Rotas de produção do Sulfato de potássio}

A escolha do método de produção e da localização de uma planta de sulfato de potássio depende do fornecimento abundante de matéria-prima e da capacidade de reuso ou tratamento de rejeitos e subprodutos. A maior parte das plantas de produção se localiza próximas aos depósitos de sal de onde, pelo menos parte da matéria prima pode ser extraída. Plantas industriais em que o cloreto de potássio reage com ácido sulfúrico, com a liberação de cloreto de hidrogênio, se localizam geralmente em regiões onde há demanda por ácido hidroclórico, ou operam em conjunto com processos que necessitem de cloreto de hidrogênio[23].

No Brasil, a utilização do concentrado mineral de glauconita pode ser visto como uma fonte potencial de matéria-prima. O "verdete" é uma rocha sedimentar rica em glauconita (entre outros minerais potássicos) com teores de $\mathrm{K}_{2} \mathrm{O}$ de 6 a $14 \%$. A experiência brasileira na utilização de minerais de glauconita está focada no "verdete" em Minas Gerais. Os estudos empregados para este "verdete" visam à obtenção de termofosfatos potássicos, que são aqueles resultantes do tratamento térmico de rochas potássicas, com ou sem adição de outros tipos de rocha. $O$ tratamento térmico tem como objetivo a decomposição das estruturas cristalinas dos minerais fonte de potássio para formação de compostos nos quais este nutriente esteja mais disponível aos vegetais[5].

Dentre as principais rotas de produção de sulfato de potássio estão o processo Mannheim, o método Hargreaves e também métodos que empregam $\mathrm{KCl}$ e outros sulfatos. No entanto, existem rotas alternativas que vêm sendo estudadas para futura aplicação industrial como a rota de processamento da glauconita. Esses processos estão descritos nas seções a seguir[23]:

- O Processo Mannheim (a partir de $\mathrm{KCl}$ e $\mathrm{H}_{2} \mathrm{SO}_{4}$ )

- Método Hargreaves

- Métodos com emprego de $\mathrm{KCl}$ e outros sulfatos

- Rota de processamento da glauconita 


\subsection{1}

\section{O Processo Mannheim (a partir de $\mathrm{KCl}$ e $\mathrm{H}_{2} \mathrm{SO}_{4}$ )}

O sulfato de potássio neste processo é produzido a partir de minerais simples ou misturas, ou a partir de salmouras. O processo acontece com a reação do cloreto de potássio com ácido sulfúrico e em dois estágios, como pode ser visualizado nas Equações 2-1 e 2-2. O processo ocorre em temperatura entre 600 e $700{ }^{\circ} \mathrm{C}$. O ácido sulfúrico é utilizado em excesso para minimizar o cloreto contido no produto final.

$$
\begin{aligned}
& \mathrm{KCl}+\mathrm{H}_{2} \mathrm{SO}_{4} \rightarrow \mathrm{KHSO}_{4}+\mathrm{HCl} \\
& \mathrm{KCl}+\mathrm{KHSO}_{4} \rightarrow \mathrm{K}_{2} \mathrm{SO}_{4}+\mathrm{HCl}
\end{aligned}
$$

O sulfato de potássio resultante normalmente contém $50-52 \%$ de $\mathrm{K}_{2}$ O e 1,5-2\% de cloreto. O gás cloreto de hidrogênio gerado concomitantemente é absorvido em água formando ácido hidroclórico[24].

O processo Mannheim é um processo vantajoso por um lado, por ser simples e de alto rendimento, além de conseguir reaproveitamento do subproduto, o $\mathrm{HCl}$, para a produção de diversos compostos, como o fosfato de cálcio, cloreto de vinila ou cloreto de cálcio. Por outro lado, o processo Mannheim é altamente dispendioso energeticamente e precisa lidar com a corrosão severa dos equipamentos[24].

Outro ponto negativo deste processo, segundo Simon (1961)[25], é que os sulfatos produzidos pelo processo Mannheim estão sujeitos à efeitos indesejáveis, além da presença do cloreto de potássio alcalino, e também de bissulfato de potássio, que age como agente aglutinante a umidades relativas acima de $50 \%$.

No trabalho de Dave e Ghosh (2006)[26], é reportado que o Processo Mannheim é bem estabelecido e conhecido para a produção de sulfato de potássio a partir do cloreto de potássio. Enquanto o trabalho de Königsberger e Eriksson (1999)[27] descreve a produção concomitante de cloreto de hidrogênio acompanhando o sulfato de potássio.

Porém, de acordo com Pennel (1937)[28], o sulfato de potássio produzido apresenta ainda um teor remanescente de cloreto de potássio, que atinge até de 2 a $5 \%$ em massa. Uma série de processos pode ser feita de forma a diminuir essa percentagem, porém é citado não ser possível obter uma quantidade menor a $1 \%$ em massa.

Shultz et al. (2000)[29] verificaram experimentalmente a relação entre o tempo de reação e a temperatura no processo Mannheim, conforme apresentado na Figura 2.2. Vê-se que o tempo de reação diminui com o aumento de temperatura, porém na prática o processo é operado entre 600$700{ }^{\circ} \mathrm{C}$, de forma a minimizar o resíduo de $\mathrm{KCl}$. 


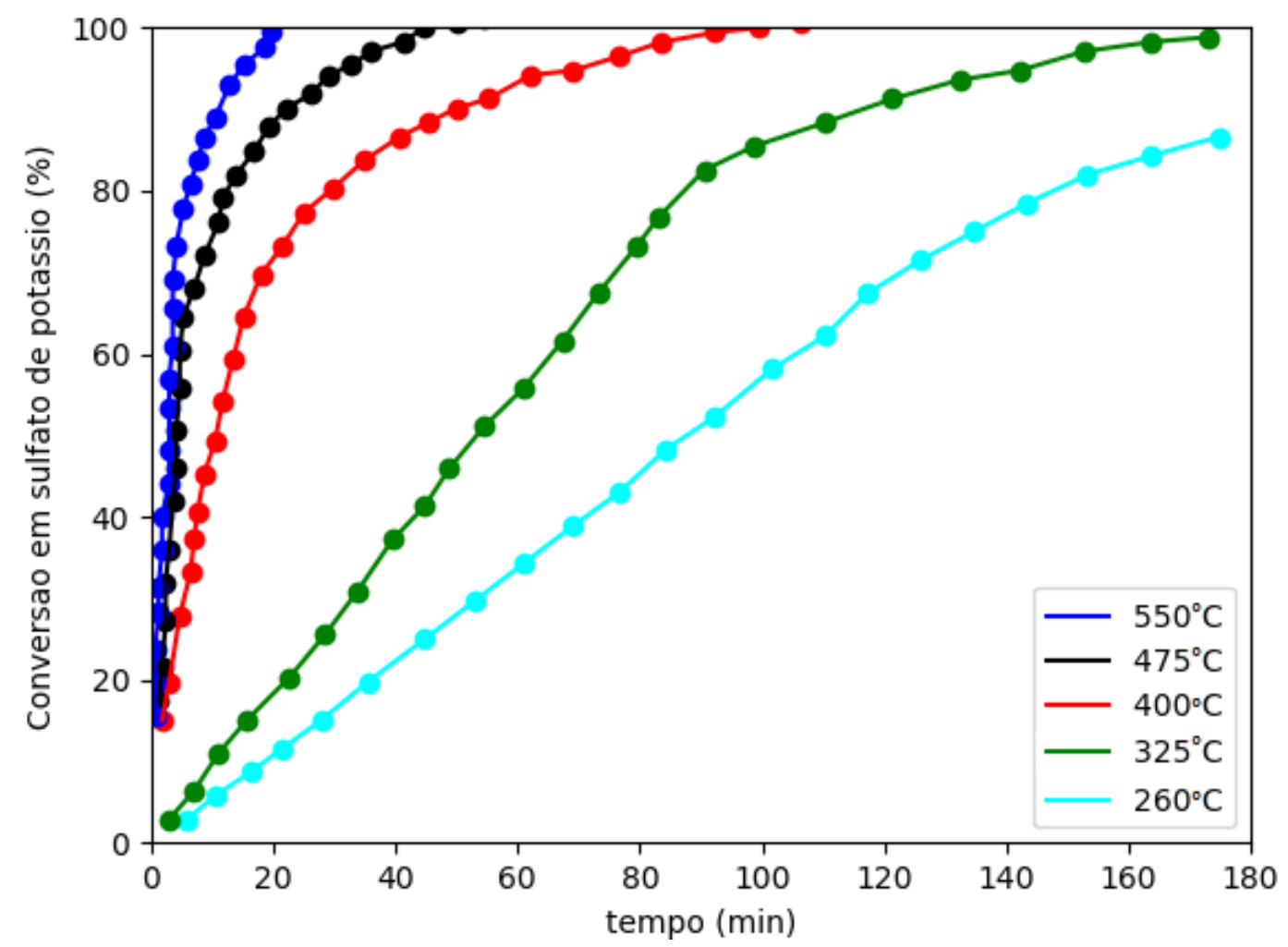

Figura 2.2: Relação tempo e temperatura para o processo Mannheim (Shultz et al. (2000)).

\subsection{2}

\section{Método Hargreaves}

O processo Hargreaves, mais utilizado nos Estados Unidos, se caracteriza pelo uso de uma corrente de óxido de enxofre (proveniente da combustão do enxofre), ar em excesso e vapor de água que aquece o cloreto de potássio em briquetes colocados no reator[25]. Ou seja, de forma similar ao método de Mannheim, também é utilizado para produzir sulfato de sódio a partir do cloreto de sódio e do ácido sulfúrico[24].

$$
2 \mathrm{KCl}+\mathrm{H}_{2} \mathrm{O}+\mathrm{O}_{2}+\mathrm{SO}_{2} \rightarrow \mathrm{K}_{2} \mathrm{SO}_{4}+2 \mathrm{HCl}
$$

Ainda de acordo com Simon (1961)[25], de forma semelhante ao processo Mannheim, o sulfato de potássio produzido pelo método Hargreaves está sujeito à aglomeração em condições de alta umidade, trazendo um problema de manipulação e armazenamento. Além disso, o autor reportou que essa tendência à aglomeração vem do cloreto de potássio não convertido. Outro problema reportado é a coloração expressiva resultante de óxido de ferro entranhando no produto final, em que é vista uma coloração de rosa à vermelha, onde espera-se um produto branco.

De acordo com Lippman et al. (1940)[30], uso extensivo de mão de obra e equipamento são necessários nesse processo para a fabricação dos briquetes de $\mathrm{KCl}$, e para sua colocação e recarga intermitente na câmara de 
aquecimento. Por isso, perdas de energia são expressivas, que vêm do resfriamento das câmaras e da remoção intermitente do sulfato quente. Dessa forma, plantas de Processo Hargreaves devem operar continuamente.

\subsection{3}

\section{Método com emprego de $\mathrm{KCl}$ e outros sulfatos}

Aproximadamente metade da produção mundial de sulfato de potássio $\left(\mathrm{K}_{2} \mathrm{SO}_{4}\right)$ é obtida pela reação do cloreto de potássio $(\mathrm{KCl})$ com o sulfato de magnésio $\left(\mathrm{MgSO}_{4}\right)$ cuja reação ocorre pelo mineral de schoenita $\left(\mathrm{K}_{2} \mathrm{SO}_{4} \cdot \mathrm{MgSO}_{4} \cdot 6 \mathrm{H}_{2} \mathrm{O}\right)$ ou pelo mineral de langbeinita $\left(\mathrm{K}_{2} \mathrm{SO}_{4} \cdot \mathrm{MgSO}_{4}\right)$. $\mathrm{Na}$ Alemanha, a kieserita $\left(\mathrm{MgSO}_{4} \cdot \mathrm{H}_{2} \mathrm{O}\right)$ é convertida em schoenita $\left(\mathrm{K}_{2} \mathrm{SO}_{4} \cdot \mathrm{MgSO}_{4} \cdot 6 \mathrm{H}_{2} \mathrm{O}\right)$ pela reação da kieserita com o cloreto de potássio (KCl), segundo Equações 2-4 e 2-5[24].

$$
\begin{gathered}
2\left(\mathrm{MgSO}_{4} \cdot \mathrm{H}_{2} \mathrm{O}\right)+4 \mathrm{H}_{2} \mathrm{O}+2 \mathrm{KCl} \rightarrow \mathrm{K}_{2} \mathrm{SO}_{4} \cdot \mathrm{MgSO}_{4} \cdot 6 \mathrm{H}_{2} \mathrm{O}+\mathrm{MgCl}_{2} \\
\left(\mathrm{~K}_{2} \mathrm{SO}_{4} \cdot \mathrm{MgSO}_{4} \cdot 6 \mathrm{H}_{2} \mathrm{O}\right)+2 \mathrm{KCl} \rightarrow 2 \mathrm{~K}_{2} \mathrm{SO}_{4}+\mathrm{MgCl}_{2}+6 \mathrm{H}_{2} \mathrm{O}
\end{gathered}
$$

Contudo, estes métodos com emprego de $\mathrm{KCl}$ não garantem uma conversão que satisfaça os requisitos de ausência de $\mathrm{Cl}$ no produto final[23].

Nos Estados Unidos, segundo Scharf (1990)[31] e Senderowitz et al. (1996)[32], o sulfato de potássio tem sido produzido através de reações de troca iônica, a partir de $\mathrm{KCl}$ e sais de sódio ou magnésio. Porém, quando referente à produção do sulfato de potássio, o método mais usado a partir da troca iônica é com o sal $\mathrm{CaSO}_{4}$ e $\mathrm{KCI}[32]$ e não permite produção de sulfato de potássio isento de cloro.

\subsection{4}

\section{Rota de processamento da Glauconita}

De maneira mais específica, para a produção de sulfato de potássio, vê-se como alternativa às rotas mais convencionais, a rota química via processamento da glauconita conforme explorado por empreendimentos de uma empresa brasileira do setor de exploração mineral conforme mostrado na Figura 2-3. Este processo já foi implementando em uma planta piloto e futuramente poderá ser aplicado em escala industrial[8]. 


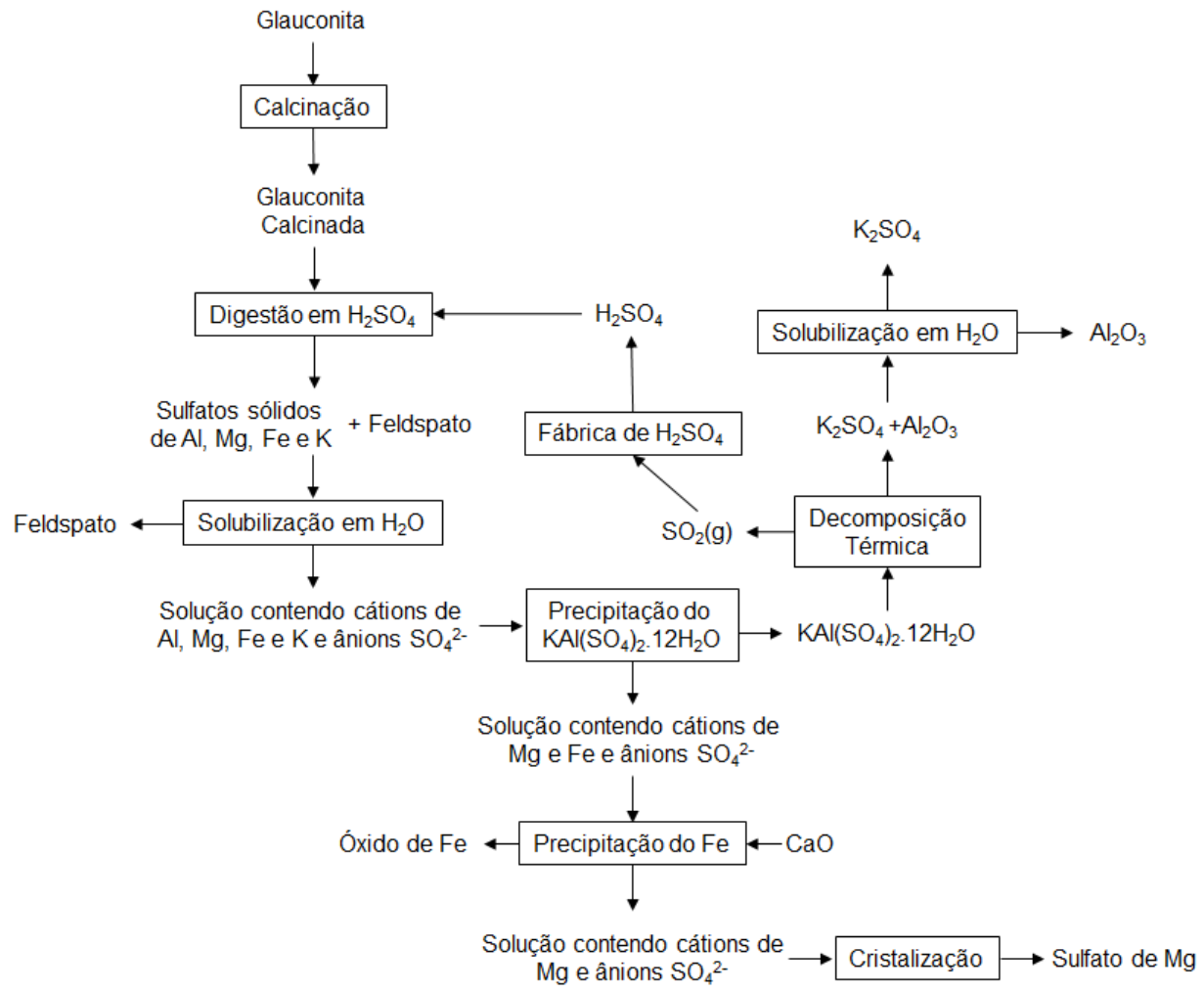

Figura 2.3: Fluxograma de processamento da Glauconita.

Vê-se pelo fluxograma da Figura 2-3 que, após uma etapa de calcinação inicial, a glauconita (descrita como um mineral silicatado) passa por um processo de digestão em ácido sulfúrico. Dessa digestão, ou lixiviação, (realizada com reuso de ácido de etapas subsequentes) é formada uma mistura de sulfatos (entre eles, os sulfatos de alumínio, magnésio, ferro e potássio) e feldspato.

O feldspato formado, após solubilização em água, é separado e vendido. Sua utilidade se dá devido a presença de compostos alcalinos insolúveis em água, tornando-os os fundentes mais empregados nas formulações de produtos cerâmicos[8].

Já na etapa da digestão nota-se um comportamento seletivo com relação à sílica $\left(\mathrm{SiO}_{2}\right)$, visto que este cristal é completamente insolúvel em água, possibilitando uma separação via filtração e consecutivas lavagens.

Sequencialmente, o licor composto de sulfatos sólidos resultante desse processo de digestão possui uma composição química que, após processos sucessivos de cristalização, e por meio de resfriamento após evaporações controladas, é capaz de viabilizar a formação de um sal duplo composto de sulfato de alumínio e potássio, o alúmen de potássio $\left(\mathrm{KAl}\left(\mathrm{SO}_{4}\right)_{2}\right)$. Nesta etapa, observa-se a separação do ferro e magnésio ainda presentes na mistura.

Com a adição de óxido de cálcio, separa-se seletivamente o óxido de ferro, que posteriormente é usado para pigmentos, adsorventes, abrasivos e indústria de vidro, por exemplo. Enquanto a solução de magnésio, após 
cristalização, forma o sulfato de magnésio, que pode ser aplicado em cosméticos, na produção de papel, materiais a prova de fogo, cerâmicas, etc[8].

Segundo Majumder et al. (1995)[33] e Yadav et al. (2000)[34] minerais de glauconita cuja composição de $\mathrm{K}_{2} \mathrm{O}$ varia entre 4 e $8 \%$ tem sido usados mundialmente como fonte de fertilizantes potássicos. Majumder et al. (1995) reportou dissolução de $90 \%$ do potássio presente na glauconita através de ustulação via cloreto de cálcio a temperaturas entre 750 e 900 ${ }^{\circ} \mathrm{C}$ seguido de lixiviação. Enquanto, Yadav et al. (2000) e Yadav e Sharma (1992)[35], de forma semelhante, também reportaram a extração de $96 \%$ do potássio a partir da glauconita e lixiviação com ácido hidroclórico.

De acordo com Castro e Tourn (2003)[36], na Argentina, diversos estudos tem sido implementados sobre a produção de fertilizantes de sulfato de potássio a partir da glauconita.

Paralelamente ao cenário relatado, o alúmen de potássio descrito anteriormente como produto intermediário desse processo é precursor para a obtenção e separação seletiva do $\mathrm{K}_{2} \mathrm{SO}_{4}$, objetivo do processo, e o $\mathrm{Al}_{2}$ $\mathrm{O}_{3}$ via decomposição térmica e subsequente solubilização do sulfato. Esta etapa de decomposição, que é o foco deste trabalho, pode ser vista em destaque na Figura 2-4.

Além do mais, o subproduto óxido de alumínio, ou alumina, tem grande valor agregado, e oferece ainda a possibilidade de reciclar parte do ácido.

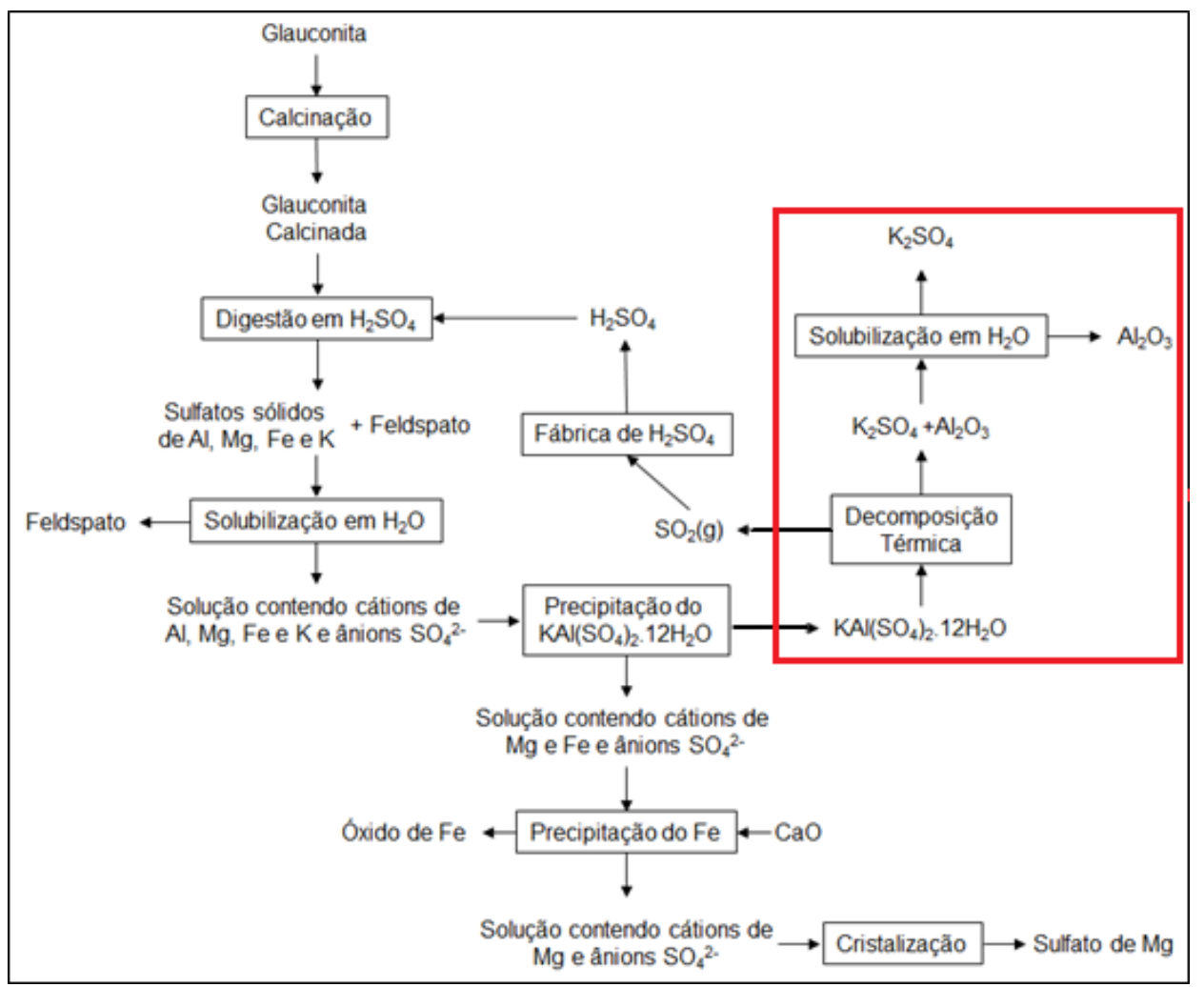

Figura 2.4: Fluxograma de processamento da Glauconita com destaque para a etapa de decomposição do precursor alúmen de potássio 


\section{3 \\ Processo Bayer e obtenção da alumina}

A alumina, ou óxido de alumínio, é o composto de maior valor agregado na produção de alumínio. A produção mundial de quase $100 \mathrm{mi}-$ Ihões de toneladas é feita principalmente com bauxita empregando o processo Bayer[37]. Outras aplicações industriais incluem abrasivos, materiais refratários, aditivos em plásticos e uso como suportes em catalisadores industriais[38].

Apesar do processo Bayer ser amplamente difundido e aplicado mundialmente (Figura 2-5), ele tem um ponto bastante negativo que é a formação de um resíduo sólido conhecido como "lama vermelha".

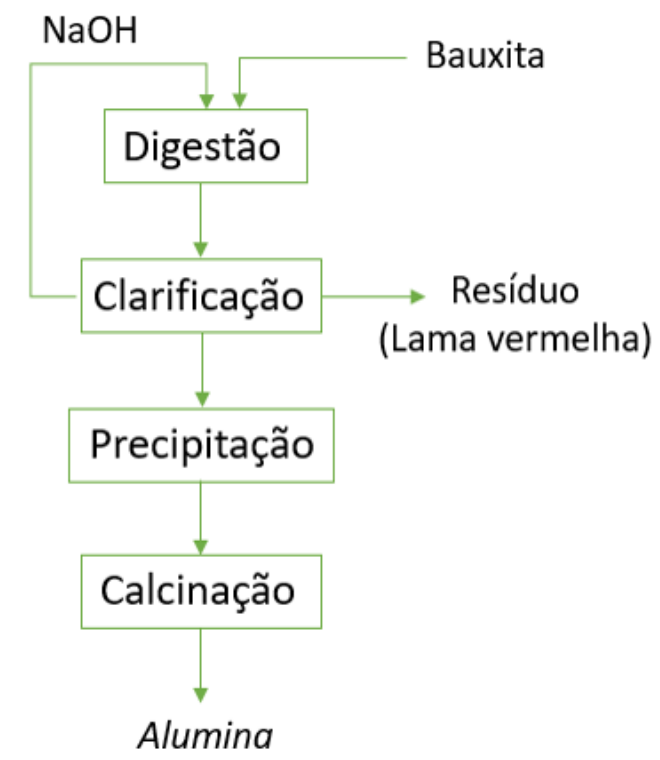

Figura 2.5: Processo Bayer, versão resumida.

O processo Bayer, de forma resumida, ocorre da seguinte forma: em um estágio inicial, após a moagem da bauxita, é feita a digestão do material com uma solução de hidróxido de sódio $(\mathrm{NaOH})$. Em seguida, a clarificação trata da separação entre as fases sólida (resíduo insolúvel) e líquida (licor). Em seguida, ocorre a etapa de precipitação, quando se dá o resfriamento do licor. A alumina cristalizada segue para a calcinação e o licor residual contendo $\mathrm{NaOH}$ e uma pequena quantidade de alumina é recirculada para a etapa de digestão (Silva Filho et al. (2007)[39]).

O resíduo insolúvel separado na clarificação se trata da lama vermeIha. É composto de diversas substâncias, entre elas carbonatos e aluminatos de cálcio e dióxido de titânio. A quantidade de lama vermelha gerada anualmente é enorme, na ordem de milhões de toneladas, e representa um sério problema ambiental atualmente.

Pela presença do hidróxido de sódio, a lama vermelha tem propriedades alcalinas e metais pesados em sua constituição[40, 41]. Essa composição fez a lama vermelha ser classificada como resíduo tóxico para o meio 
ambiente. Porém, estudos apontam a lama vermelha como um resíduo não inerte[42, 43, 44].

Existem ainda estudos que provam a viabilidade da utilização deste resíduo para materiais de construção[40, 45, 46, 47, 48] como telhas, tijolos e cimento, por exemplo. Há ainda a vertente que mostra melhora nas propriedades destes materiais, especialmente no aumento de resistência. Porém, apesar de já existir tecnologia de neutralização da lama vermelha, não existem políticas de reuso em larga escala, levando-a a ser armazenada ocupando grandes áreas[49, 50].

Portanto, a alumina produzida pelo processo a partir da glauconita representa um grande avanço ambiental quando comparado à lama vermelha produzida pela digestão química da bauxita.

\section{4}

\section{Termodinâmica de reações químicas envolvendo sulfatos}

Com relação ao alúmen de potássio, isto é, o sal duplo de alumínio e potássio, estuda-se a termodinâmica da decomposição, de forma a gerar preferencialmente os compostos desejados. A reação de decomposição do alúmen de potássio é vista na Equação 2-6.

$$
2 \mathrm{KAl}\left(\mathrm{SO}_{4}\right)_{2} .12 \mathrm{H}_{2} \mathrm{O} \rightarrow \mathrm{K}_{2} \mathrm{SO}_{4}+\mathrm{Al}_{2} \mathrm{O}_{3}+3 \mathrm{SO}_{3}(g)+24 \mathrm{H}_{2} \mathrm{O}(g)
$$

Contudo, de acordo com os trabalhos de Galwey et al.(1987, 2000)[51, 52], Psiak et al (1981)[53] e também por conta da experiência do nosso grupo de pesquisa na decomposição térmica do alúmen[54], sabe-se que a reação acima é na verdade a reação global do processo tendo em vista que o mesmo ocorre em diversas etapas.

A primeira etapa do processo é mostrada na Equação 2-7, e inclui a desidratação do alúmen, ou seja, a perda das 12 moléculas de água.

$-1^{\text {a }}$ etapa

$$
\mathrm{KAl}\left(\mathrm{SO}_{4}\right)_{2} .12 \mathrm{H}_{2} \mathrm{O} \rightarrow \mathrm{KAl}\left(\mathrm{SO}_{4}\right)_{2}+12 \mathrm{H}_{2} \mathrm{O}(\mathrm{g})
$$

Em seguida, a segunda etapa, apresentada na Equação 2-8, consiste na decomposição do alúmen em dois sulfatos distintos: sulfatos de alumínio e de potássio.

$$
\text { - 2 } 2^{\text {a }} \text { etapa } \quad 2 \mathrm{KAl}\left(\mathrm{SO}_{4}\right)_{2} \rightarrow \mathrm{K}_{2} \mathrm{SO}_{4}+\mathrm{Al}_{2}\left(\mathrm{SO}_{4}\right)_{3}
$$

Porém, a forma sulfatada do alumínio não se mantém estável. Dessa forma, ainda há uma terceira etapa (Equação 2-9) que trata da decomposição deste.

$$
\text { - 3a etapa }
$$

$$
\mathrm{Al}_{2}\left(\mathrm{SO}_{4}\right)_{3} \rightarrow \mathrm{Al}_{2} \mathrm{O}_{3}+3 \mathrm{SO}_{3}(\mathrm{~g})
$$


As Figuras 2-6 e 2-7 mostram a relação da variação da energia livre de Gibbs padrão $\left(\Delta \mathrm{G}^{\circ}\right)$ com a temperatura, para os casos da decomposição térmica do alúmen e dos sulfatos subsequentes. Pela análise da Figura 2-6, é possível perceber que o momento de maior espontaneidade da decomposição do alúmen, ou seja, a partir do ponto em que o $\Delta \mathrm{G}^{\circ}$ se torna negativo, ocorre em torno dos $840{ }^{\circ} \mathrm{C}$. O que quer dizer que, para a decomposição térmica se dar exclusivamente com a força motriz do aumento de temperatura, o sistema reacional necessita estar acima desta temperatura.

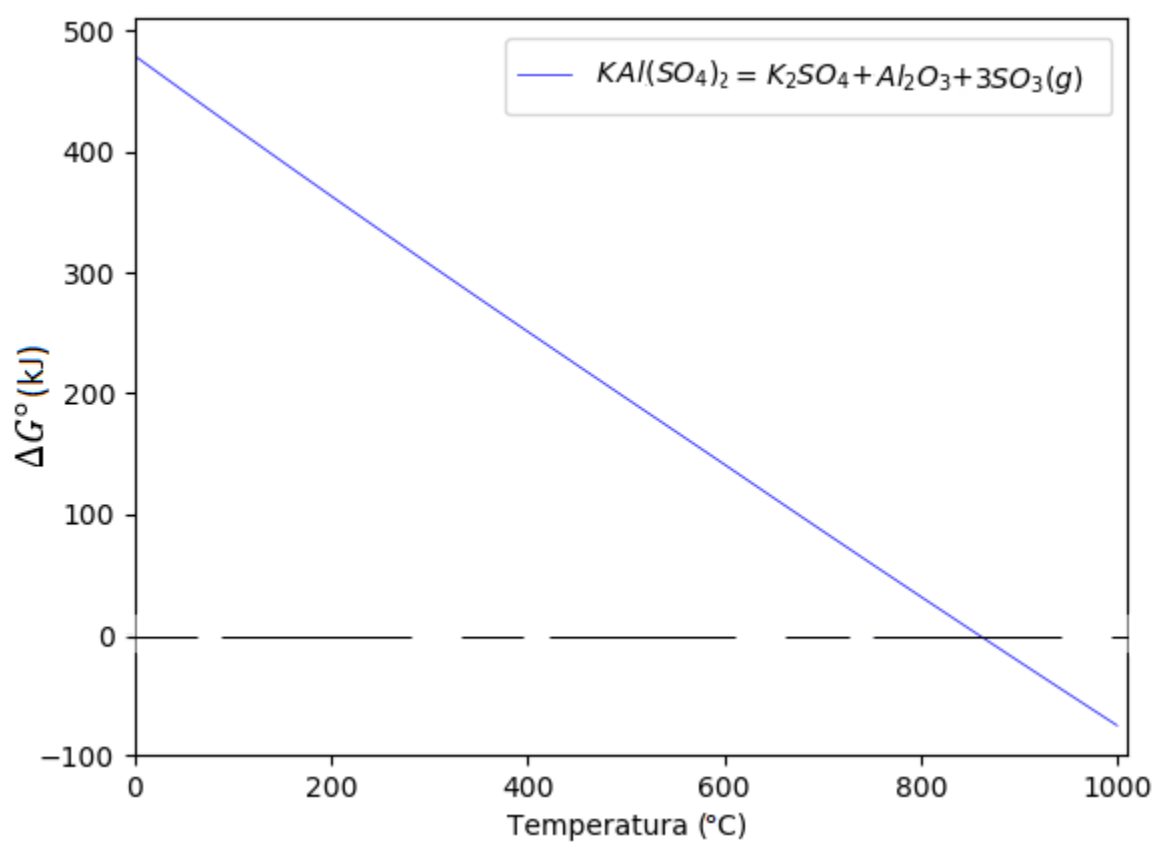

Figura 2.6: Gráfico $\Delta \mathrm{G}{ }^{9} \times \mathrm{T}$ para a reação de decomposição do alúmen. Produzido por HSC Chemistry 6.0

Em relação ao sulfato de alumínio, percebe-se na Figura 2-7 que em temperaturas acima de $840{ }^{\circ} \mathrm{C}$ aproximadamente, região onde a reação anterior se processa, o sulfato de alumínio não apresenta seletividade em relação ao óxido de alumínio, subproduto desejado. Em outras palavras, sua estabilidade é maior após a decomposição em óxido, respondendo ao objetivo do processo. Por outro lado, o sulfato de potássio não tem espontaneidade de se decompor em óxido de potássio, dado os valores positivos de $\Delta \mathrm{G}^{\circ}$ em relação à reação de decomposição do $\mathrm{K}_{2} \mathrm{SO}_{4}$, sendo benéfico ao processo, já que o mesmo visa a obtenção do sulfato de potássio. 


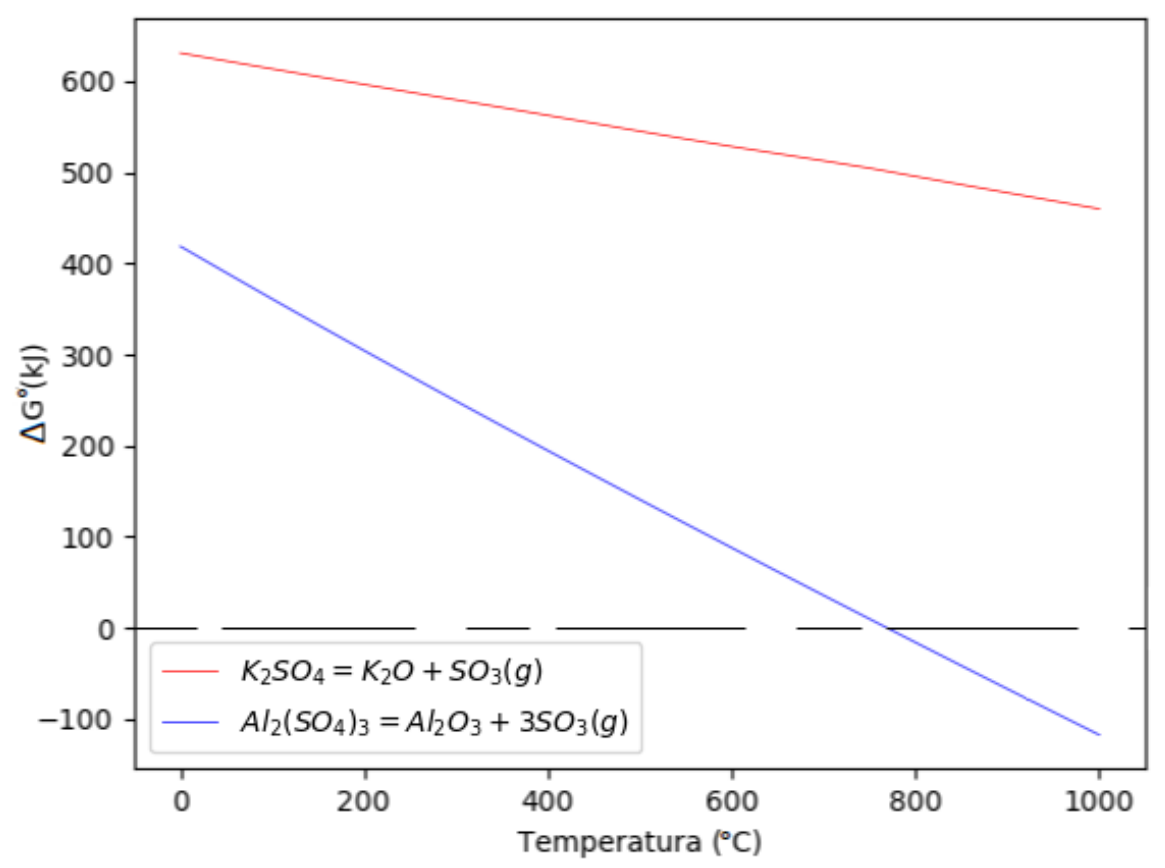

Figura 2.7: Gráfico $\Delta \mathrm{G}^{\circ} \mathrm{x} T$ para a reação de decomposição dos sulfatos, de alumínio e de potássio. Produzido por HSC Chemistry 6.0

\subsection{1}

Termodinâmica da decomposição térmica na presença de agente redutor

A decomposição térmica na presença de agente redutor oriundo de carbono é o processo de transformação de uma substância mineral, com o emprego do gás CO. Esse gás tem origem na substância portadora do elemento carbono, comumente presente como coque ou como carvão vegetal[55].

Além disso, pode-se ver que Pacewska et. al (1991)[56] investigaram a decomposição do alúmen de potássio em atmosfera de gás hidrogênio e atmosfera inerte. Os autores estudaram a viabilidade termodinâmica de diversas reações factíveis de ocorrer nesse sistema, e elas estão apresentadas na Tabela 2-1. Entre as reações investigadas, a atmosfera redutora de $\mathrm{H}_{2}$ em baixas temperaturas exige, concomitantemente, uma atmosfera de $\mathrm{SO}_{2}$ para o deslocamento do equilíbrio químico (de forma a aumentar a força motriz do sistema e com a atmosfera de $\mathrm{SO}_{2}$ imposta, facilitar a formação do sulfato). 
Tabela 2.1: Potenciais termodinâmicos de reações de dessulfurização do alúmen em atmosfera de $\mathrm{H}_{2}$.

\begin{tabular}{|c|c|c|c|c|c|}
\hline & \multirow{2}{*}{ Reação } & \multicolumn{4}{|c|}{$\Delta G^{\circ}(\mathrm{kcal} / \mathrm{mol})$} \\
\hline & & $298 \mathrm{~K}$ & $600 \mathrm{~K}$ & $800 \mathrm{~K}$ & $1000 \mathrm{~K}$ \\
\hline 1 & $\mathrm{KAl}\left(\mathrm{SO}_{4}\right)_{2} \rightarrow 0.5 \mathrm{~K}_{2} \mathrm{SO}_{4}+0.5 \mathrm{Al}_{2} \mathrm{O}_{3}+1.5 \mathrm{SO}_{2}(\mathrm{~g})+0.75 \mathrm{O}_{2}(\mathrm{~g})$ & 80,54 & 49,64 & 29,70 & 9,96 \\
\hline 2 & $\mathrm{KAl}\left(\mathrm{SO}_{4}\right)_{2} \rightarrow 0.5 \mathrm{~K}_{2} \mathrm{SO}_{4}+0.5 \mathrm{Al}_{2}\left(\mathrm{SO}_{4}\right)_{3}$ & 7,22 & 6,91 & 6,60 & 6,00 \\
\hline 3 & $\mathrm{KAl}\left(\mathrm{SO}_{4}\right)_{2}+2 \mathrm{H}_{2} \rightarrow 0.5 \mathrm{~K}_{2} \mathrm{O}+0.5 \mathrm{Al}_{2} \mathrm{O}_{3}+2 \mathrm{SO}_{2}(g)+2 \mathrm{H}_{2} \mathrm{O}(g)$ & 54,30 & 20,05 & 1,56 & $-22,34$ \\
\hline 4 & $\mathrm{KAl}\left(\mathrm{SO}_{4}\right)_{2}+1.5 \mathrm{H}_{2}(\mathrm{~g}) \rightarrow 0.5 \mathrm{~K}_{2} \mathrm{SO}_{4}+0.5 \mathrm{Al}_{2} \mathrm{O}_{3}+1.5 \mathrm{SO}_{2}(\mathrm{~g})+1.5 \mathrm{H}_{2} \mathrm{O}(\mathrm{g})$ & $-1,43$ & $-27,11$ & $-43,28$ & $-59,11$ \\
\hline 5 & $\mathrm{KAl}\left(\mathrm{SO}_{4}\right)_{2}+3.5 \mathrm{H}_{2}(\mathrm{~g}) \rightarrow 0.5 \mathrm{~K}_{2} \mathrm{~S}+0.5 \mathrm{Al}_{2} \mathrm{O}_{3}+1.5 \mathrm{SO}_{2}(\mathrm{~g})+3.5 \mathrm{H}_{2} \mathrm{O}(\mathrm{g})$ & $-2,93$ & $-33,70$ & $-52,84$ & $-70,20$ \\
\hline
\end{tabular}

Na Tabela 2-1, vê-se a possibilidade da utilização da atmosfera de $\mathrm{H}_{2}$ como agente redutor tendo em vista que valores negativos das variações da energia livre padrão de Gibbs foram obtidos para a reação 3 conduzida a $1000 \mathrm{~K}$ e para as reações 4 e 5 em toda faixa de temperatura investigada pelos autores. A decomposição do alúmen de potássio na presença de carbono ou vapor de água é comprovadamente diferente da decomposição em hidrogênio. Cálculos comprovam que a etapa de retirada do $\mathrm{SO}_{3}$ do alúmen (ou seja, a decomposição) quando em atmosfera de hidrogênio redutor, deve ocorrer em temperaturas mais baixas e de forma mais completa, possibilitando obter maiores conversões, quando comparada à decomposição térmica[57].

Por um lado, a dessulfurização do alúmen de potássio em atmosfera de $\mathrm{H}_{2}$ menores temperaturas operacionais, tornando a manipulação do processo mais fácil. Porém, por outro lado, a atmosfera de hidrogênio exige a compra de cilindros de $\mathrm{H}_{2}$ puros, para análise, aumentando consideravelmente o custo do processo. A utilização de um agente redutor sólido, como o coque, vem de encontro à essas dificuldades. A utilização de um agente redutor gasoso gera a necessidade de manipulação de diversas variáveis como fluxo e pressão, enquanto a utilização do agente sólido necessita apenas de boa superfície de contato com o reagente.

Uma alternativa ao uso do gás hidrogênio é o emprego do coque breeze, cuja origem vem dos materiais finos do coque das coqueterias siderúrgicas. O coque breeze é um resíduo siderúrgico, e, portanto, reutilizá-lo é uma solução econômica e ambientalmente correta.

Em siderúrgicas, para um melhor desempenho do alto forno, o coque utilizado geralmente apresenta teor de matéria volátil inferior a $2 \%$, teores de cinza de no máximo $11,5 \%$ e, por consequência, teores de carbono fixo acima de $85 \%[58]$.

O coque breeze apresenta, no entanto, em torno de $20 \%$ de matéria volátil, e $10 \%$ de teor de cinzas, e, portanto, em torno de $70 \%$ de teor de carbono fixo (como será visto no item 3.1). Porém, dada a sua disponibilidade industrial, ele se torna uma possibilidade razoável.

Nas Figuras 2-8 e 2-9 abaixo, tem-se o gráfico da distribuição de equilíbrio das decomposições térmica e redutora, de forma a perceber a vantagem do uso do coque breeze. Os gráficos foram produzidos com dados extraídos do software HSC Chemistry 6.0[59], utilizando a ferramenta "Composições de equilíbrio". 


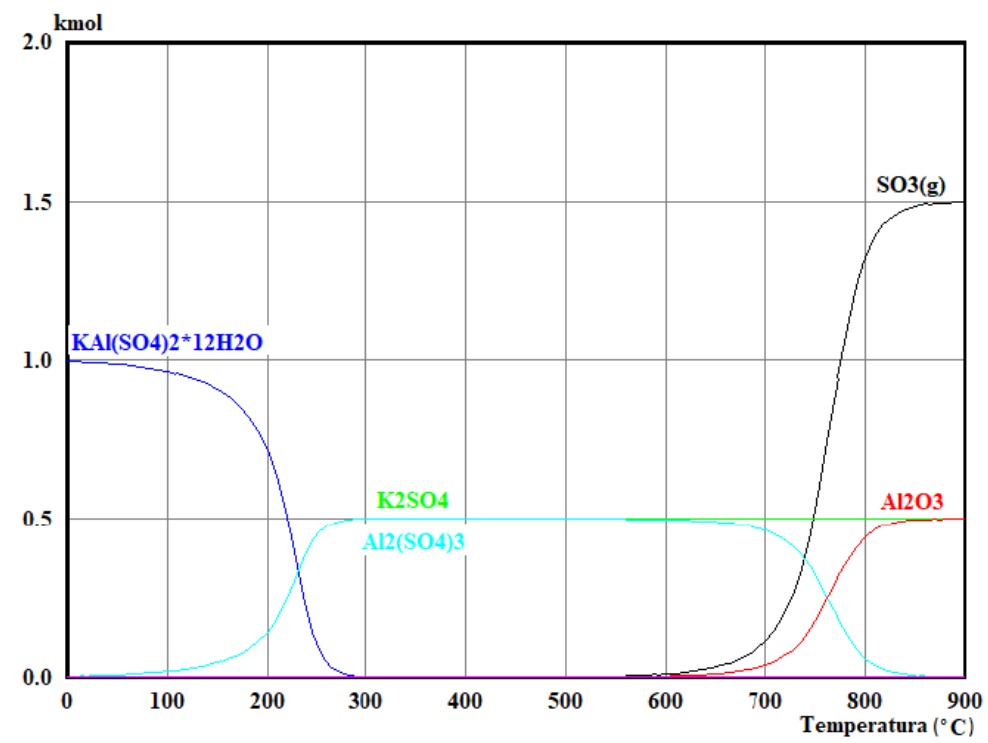

Figura 2.8: Gráfico da composição de equilíbrio para a reação de decomposição térmica. Produzido por HSC Chemistry 6.0

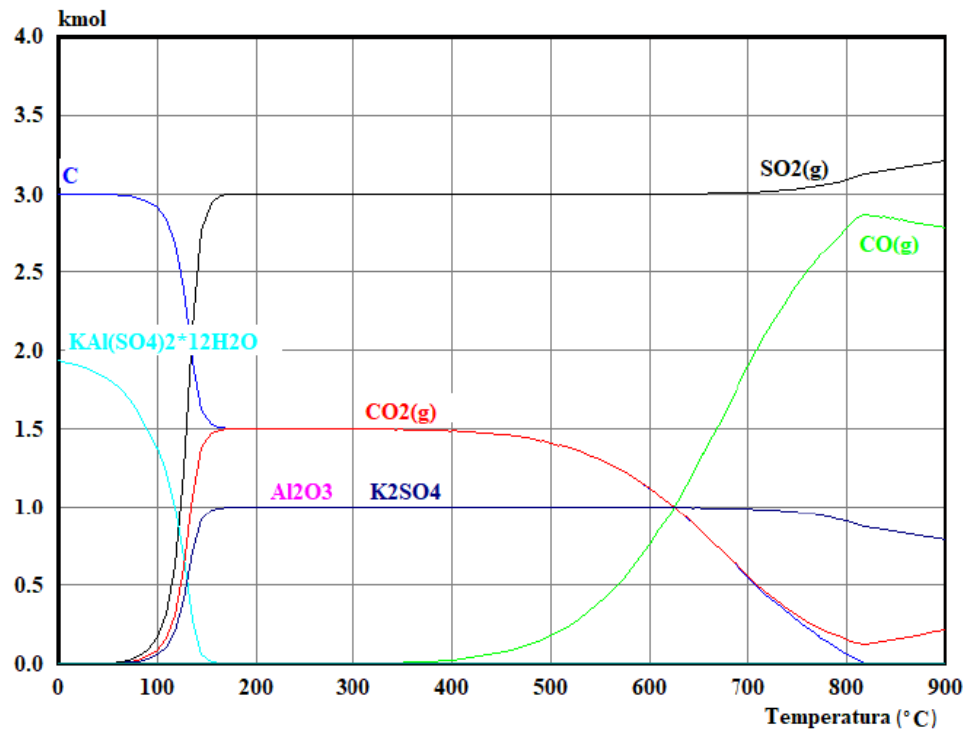

Figura 2.9: Gráfico da composição de equilíbrio para a reação de decomposição redutora. Produzido por HSC Chemistry 6.0

Pode-se observar na Figura 2-8 que os dois sulfatos (alumínio e potássio) começam a ser formados juntos, a partir da decomposição do alúmen. Enquanto o sulfato de potássio se mantém estável, o sulfato de alumínio, a partir de $650{ }^{\circ} \mathrm{C}$, começa a se decompor em óxido de alumínio e gás $\mathrm{SO}_{3}$. $\mathrm{O} \mathrm{SO}_{3}$ se mantém então em equilíbrio com os compostos finais, sulfato de potássio e óxido de alumínio, que são gerados em composições estequiométricas.

Já na Figura 2-9, é possível observar que, com a adição do coque breeze (no gráfico, está representado na forma de carbono puro), e com a 
decomposição do alúmen, os dois compostos finais já se formam concomitantemente, ou seja, já é possível uma conversão direta em menores temperaturas (aproximadamente $120^{\circ} \mathrm{C}$ ). Além disso, a formação de $\mathrm{CO} / \mathrm{CO}_{2}$ se dá de maneira inversa. Inicialmente com a formação do $\mathrm{CO}_{2}$ gasoso, e em torno de $650{ }^{\circ} \mathrm{C}$ (ou $923 \mathrm{~K}$ ) com o consumo desse, há a geração do CO gasoso.

Na Figura 2-10 está apresentado o gráfico que mostra a relação entre as quantidades de $\mathrm{CO}$ e $\mathrm{CO}_{2}$ a partir da Reação de Boudouard[60]. Na redução carbotérmica, a composição da atmosfera oscila entre os valores determinados seja pelo equilíbrio do sub-sistema 'redução pelo CO' ou pelo subsistema da 'reação de Boudouard'[60]. Dessa forma, a formação de $\mathrm{CO}$ se dará seletivamente à do $\mathrm{CO}_{2}$ a partir dessa temperatura de equilíbrio, em torno de $950 \mathrm{~K}$. Comportamento similar ocorre com a reação de decomposição térmica do alúmen de potássio na presença de coque breeze.

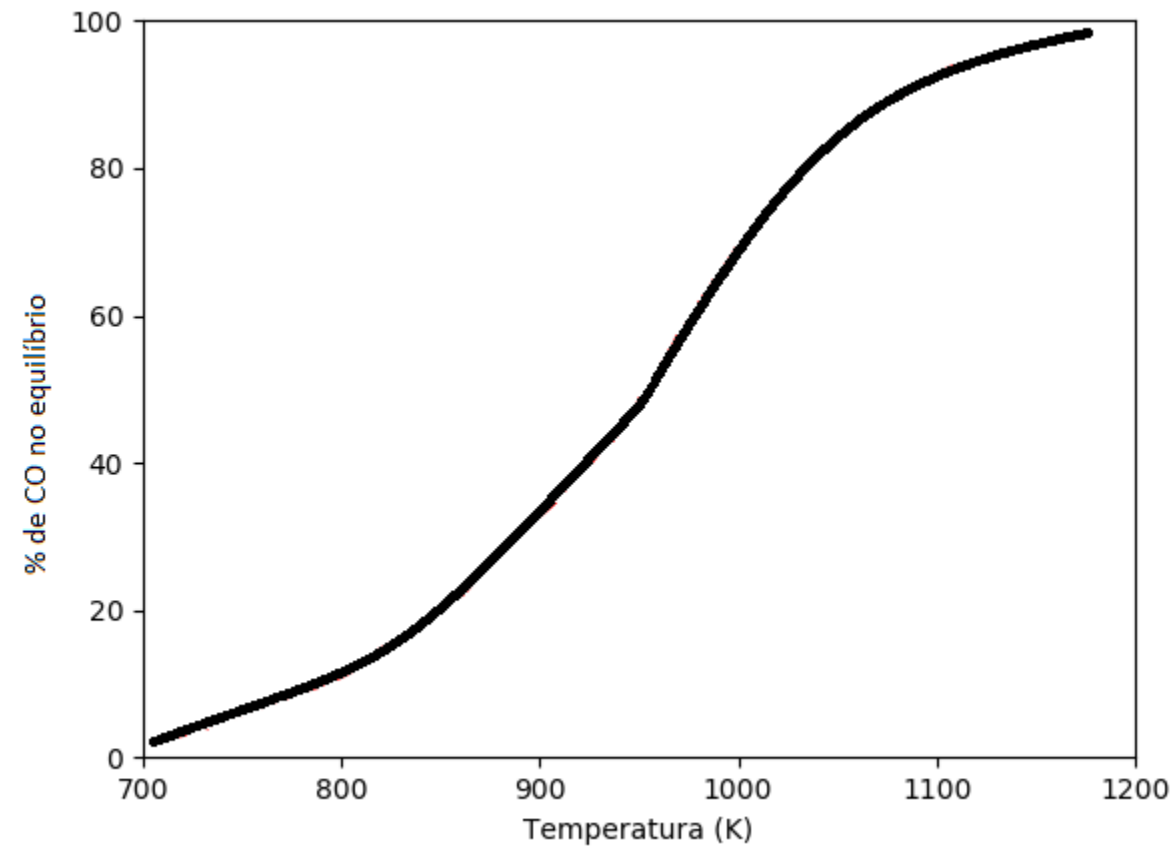

Figura 2.10: Reação de Boudouard

Um exemplo clássico da utilização do coque como agente redutor é no alto forno para a fabricação de ferro gusa. $O$ alto forno é um equipamento que realiza o processo de redução do ferro, e obtém este a partir dos óxidos nos quais é encontrado (hematita, magnetita, wustita). Esta separação funciona através de uma reação de redução, em que o agente redutor (o coque breeze, ou fino de coque metalúrgico) apresenta maior atração pelo oxigênio do que o metal a ser reduzido[58].

Dessa forma, em uma regra geral, metais que formam óxidos estáveis podem ser redutores de óxidos menos estáveis. Simplificando, tem-se no diagrama de Ellingham[61], as retas de formação de óxidos, em variação da energia livre padrão de Gibbs $\left(\Delta G^{\circ}\right)$ com a temperatura. Entende-se 
que aqueles com menores valores de $\Delta \mathrm{G}^{\circ}$ possuem maior espontaneidade em uma reação, de maneira que aqueles óxidos cujas retas se localizam na base do gráfico tem mais seletividade para reduzir aqueles com valores superiores de $\Delta \mathrm{G}^{\circ}$, na parte superior do gráfico[61, 62]. Para o leitor que deseja consultar o diagrama de Ellingham, favor consultar a referência de de Dannat et al. 1948[61].

\section{5}

\section{Cinética da decomposição térmica do alúmen de potássio}

A primeira etapa de decomposição do alúmen envolve a remoção das doze moléculas de água, reação conhecida como desidratação. Já a segunda envolve a formação dos sulfatos de potássio e alumínio, sendo este último posteriormente convertido em óxido de alumínio consistindo de uma terceira etapa[8, 54].

Pysiak e Glinka, 1981[53] investigaram a cinética do processo de decomposição térmica do alúmen de potássio, e a Figura 2-11 mostra um dos resultados reportados pelos autores, em extensão da reação (calculada em relação à perda de massa do reagente alúmen de potássio) pelo tempo em minutos. Segundo Pisiak e Glinka, a etapa de desidratação ocorre preferencialmente nos primeiros 20 minutos de reação.

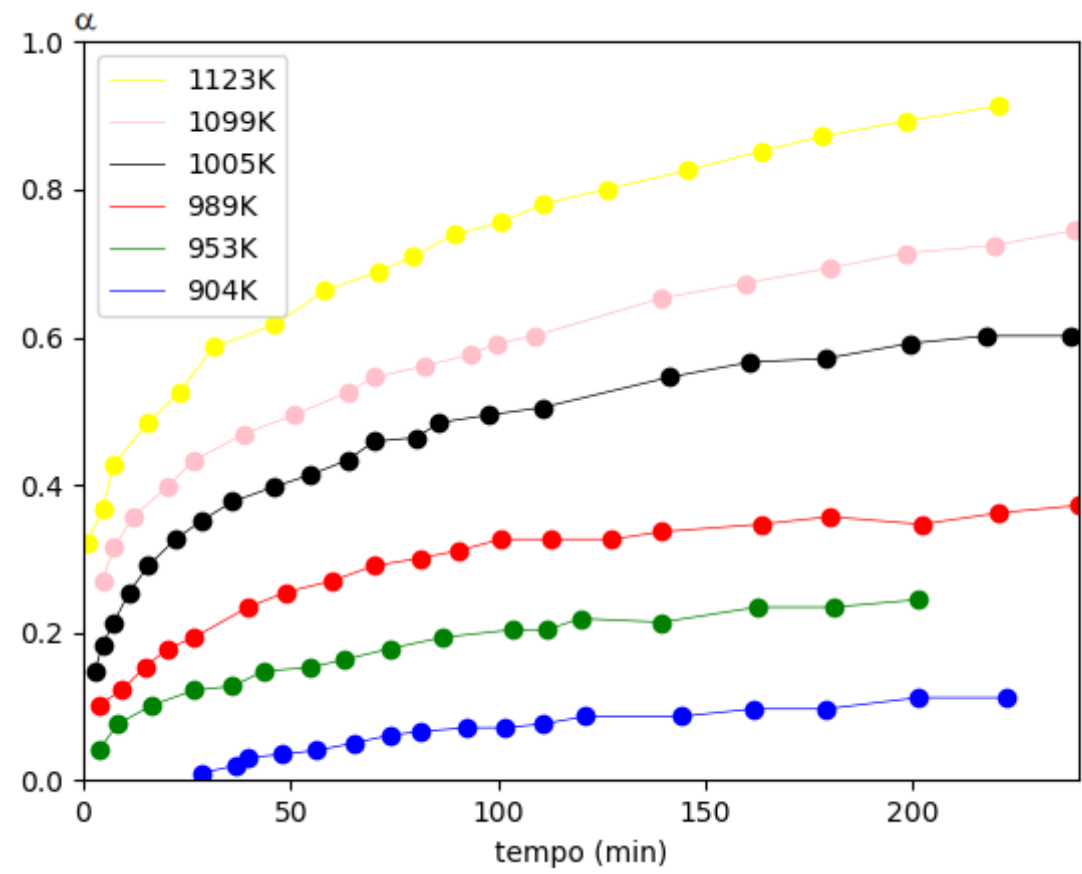

Figura 2.11: Curva cinética da decomposição do Alúmen.

Na Figura 2-11, também é visível a ação da temperatura, dado que quanto maiores são as temperaturas empregadas no processo, maiores também são os valores da extensão da reação. Além disso, os autores demonstraram que a desidratação não necessariamente ocorre em uma etapa única, perdendo as 12 moléculas de água. Além disso, foi observado pelos autores que a desidratação difere de uma decomposição por não 
afetar a estrutura inicial do alúmen de potássio e pelos diferentes valores dos parâmetros cinéticos, que se alteram com a mudança de temperatura, o que provavelmente indica que seguem a lei de Arrhenius.

Já no trabalho de Apte et. al (1988)[63], os autores reportaram que a taxa de reação é controlada pela cinética da reação e pela taxa de difusão do produto gasoso $\left(\mathrm{H}_{2} \mathrm{O}\right)$ pela camada dos sulfatos sólidos formada na superfície dos grãos do alúmen de potássio. De forma que a etapa lenta do processo, e a controladora do tempo de reação, é a decomposição do alúmen.

De acordo com os estudos realizados por Fragoso (2014) sobre a decomposição térmica do alúmen de potássio em atmosfera com fluxo contínuo de $\mathrm{SO}_{2}$, é possível identificar que a maior variação mássica durante todo o processo ocorre nos primeiros 20 minutos, apontada como a perda dos 12 moles de água (por mol de alúmen) em comparação ao restante do processo. Em um segundo momento, as amostras apresentaram valores de perda de massa que indicam possivelmente a decomposição do alúmen, e subsequentemente o consumo do sulfato de alumínio e formação do óxido de alumínio e $\mathrm{SO}_{3}$ (motivo da perda de massa, pois $\mathrm{SO}_{3}$ é produto gasoso). A partir de 30 minutos, observa-se uma estabilização da variação mássica, indicando uma provável obtenção de produtos reacionais de acordo com a seletividade desejada. A Figura 2-12 ilustra esse processo.

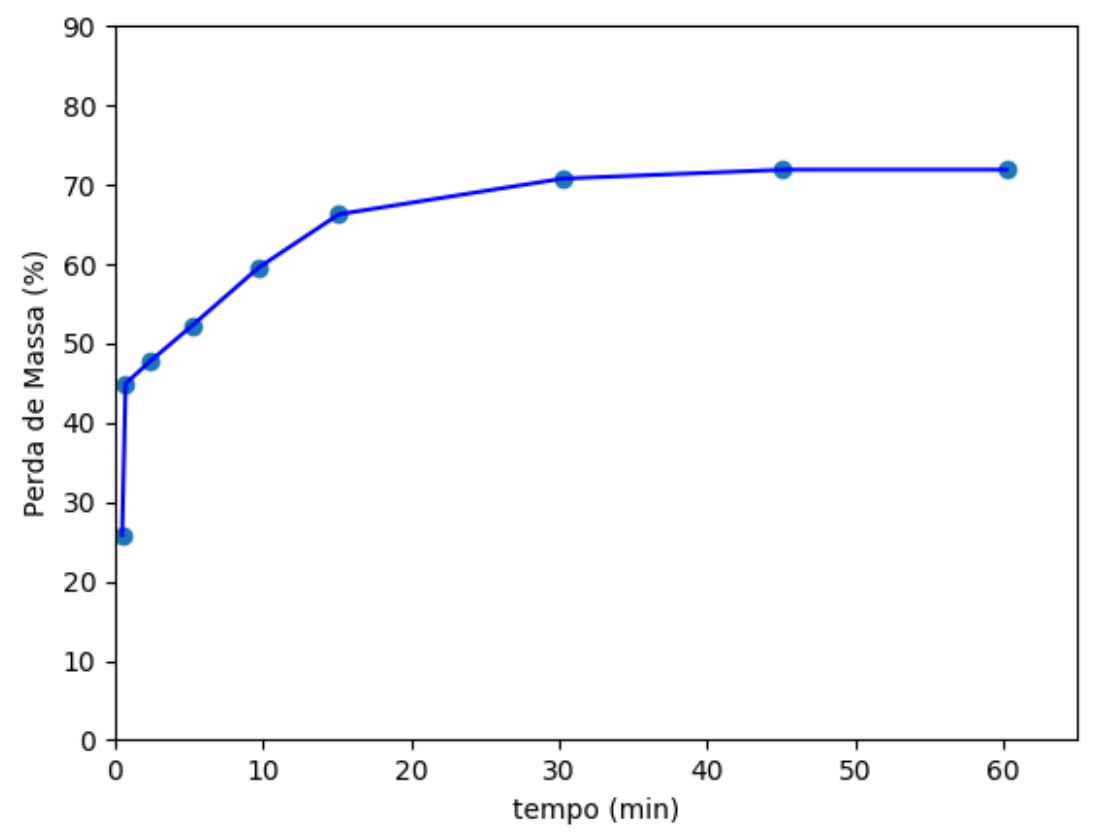

Figura 2.12: Variação mássica do alúmen processado a $800{ }^{\circ} \mathrm{C}$. 


\section{6 \\ Termogravimetria, calorimetria exploratória diferencial e análise tér- mica diferencial}

Uma análise térmica consiste em uma análise dependente da adição de calor e engloba diversas técnicas de medição, cujos objetivos vão desde a obtenção de uma propriedade do material (calor específico ou porosidade) a até mesmo a obtenção do perfil cinético de uma reação ou sistema através da medição da perda de massa ao longo do processo[64].

O perfil de uma análise térmica expressa resultados em fração decomposta de sólido ou conversão da transformação (já que não se calcula a concentração para cinética de sólidos). A análise pode ser feita em condições isotérmicas ou não-isotérmicas, ou seja, em função do tempo ou da temperatura[65].

Portanto, os seguintes conceitos devem ser definidos[64]:

Termogravimetria (TG): nessa análise, mede-se a massa da amostra em função da temperatura, enquanto há um controle do aquecimento. Os gráficos são apresentados em termos de $\Delta \mathrm{m} \times \mathrm{T}$ ou $\Delta \mathrm{m} \times \mathrm{t}$.

Termogravimetria derivada (DTG): Derivada primeira da TG, expressa em função da temperatura ou do tempo.

Análise térmica diferencial (DTA): mede a diferença de temperatura $(\Delta T)$ entre a amostra e o material de referência, quando há um controle do aquecimento. Curva em $\Delta \mathrm{T} \times \mathrm{T}$ ou $\Delta \mathrm{T} \times \mathrm{t}$.

Calorimetria Exploratória Diferencial (DSC): mede a diferença da energia fornecida à amostra e o material de referência, em função da temperatura, quando há um controle do aquecimento. Gráfico dado por fluxo de calor $(\mathrm{J} / \mathrm{s}) \times \mathrm{T}$ ou $\mathrm{t}$.

Tem-se que a diferença principal entre os dois últimos, é que a análise de DTA é adequada para a determinação de temperaturas características, enquanto que o DSC, adicionalmente, permite a determinação de valores calóricos como calor de fusão ou calor de cristalização, por exemplo.

\subsection{1}

\section{TG e DTG}

Uma maneira muito conhecida de determinar parâmetros cinéticos (como os de Arrhenius) de uma decomposição térmica é através da investigação por análises térmicas.

A termogravimetria (TG) é uma técnica que mede a massa de uma substância em função da temperatura enquanto a substância recebe uma quantidade controlada de calor, através da taxa de aquecimento. Essa análise é uma ferramenta importante na identificação de mecanismos envolvidos em um processo, dado que auxilia na assimilação de diferentes reações, e, por conseguinte, na modelagem matemática[64]. A curva TG tem o perfil $\Delta$ massa $x$ Temperatura. Enquanto isso, a termogravimetria derivada (DTG) trata da primeira derivada da curva TG, em função do tempo ou da temperatura.

A análise TG sob condição não isotérmica apresenta uma vantagem importante em relação à análise feita em condição isotérmica, já que 
até que o equipamento chegue na temperatura de análise, uma parte da amostra pode reagir durante o aquecimento, o que pode ocasionar interpretações erradas sobre os resultados[64].

Nagai et. al (2010)[66] utiliza a termogravimetria (TG) para demonstrar a desidratação em duas etapas do sulfato de alumínio, baseando a conclusão no balanço de massa e estequiometria.

Já no trabalho de Ghasri-Khouzani et. al (2009)[67], a decomposição do sulfato de alumínio foi estudada com análises termogravimétricas. Segundo os autores, a conversão completa do sulfato de alumínio em óxido de alumínio e gás $\mathrm{SO}_{3}$ se dá na temperatura de $1000{ }^{\circ} \mathrm{C}$. Além disso, foi demonstrado que a curva DTG da decomposição térmica do sulfato de alumínio exibe um pico de perda de massa, que corresponde à estequiometria, aproximadamente $70 \%$ (em massa), ou seja, conversão total em óxido de alumínio.

\subsection{2}

\section{Métodos de estimação experimental de energia de ativação}

Existem diversas formas de extrair parâmetros cinéticos de dados experimentais. Andrade et. al(2006)[68] apresentam o uso da curva de DSC para a determinação da energia de ativação por regressão linear, para casos de ordem de reação elementar. A partir da análise de TG, é possível também aplicar o método integral[69], baseado na taxa de conversão $(\alpha)$, e extraindo o valor da velocidade de reação $\mathrm{k}$ a partir do gráfico $\ln (1-\alpha)$ versus t.

Outro método de estimação experimental a partir do gráfico de TG é o método de Osawa[70]. Este método é aplicável para qualquer forma de reação cuja dependência com a temperatura possa ser ajustável por um único conjunto de parâmetros de Arrhenius, e assim utilizando as temperaturas máximas de uma TG (onde entende-se ocorrer uma reação) de pelo menos três taxas de aquecimento diferentes.

O método é aplicável ao pico da curva derivativa, o DTG, considerando que no pico a fração de decomposição independe da razão de aquecimento. Dessa forma, entende-se que cada reação do modelo deverá ter sua estimação independente. O processo da estimação experimental dos parâmetros de Arrhenius, baseado no método de Osawa é demonstrado na Figura 2-13.

O processo parte da análise da curva de DTG e da distinção dos picos, as temperaturas em que a perda de massa se torna máxima. Essa temperatura, distinta para cada reação, será utilizada para traçar a curva $\log \beta$ vs. $1 / T_{m}$, em que $\beta$ corresponde à taxa de aquecimento.

Com a curva traçada, que deverá ser uma reta de perfil decrescente, o coeficiente angular da reta será usado para calcular a energia de ativação, enquanto esta será usada para o cálculo do fator pré-exponencial.

MacCallum (1969)[71] aponta que o método de Osawa falha para pontos obtidos em baixas conversões (abaixo de $30 \%$ ) dada a não linearidade dos dados. A razão para isto, segundo o autor, é a dificuldade em extrair a temperatura de pico precisa para esses pontos. Enquanto Alvarez (2004)[72] explica que, apesar do método de Osawa ser o que apre- 
senta maior aplicabilidade a todos os pontos da curva TG, o método não faz nenhuma suposição sobre a ordem da reação. Apesar disso, Yi-Che (2005)[73] conclui que o método de Osawa se ajusta bem em análises cinéticas dinâmicas.

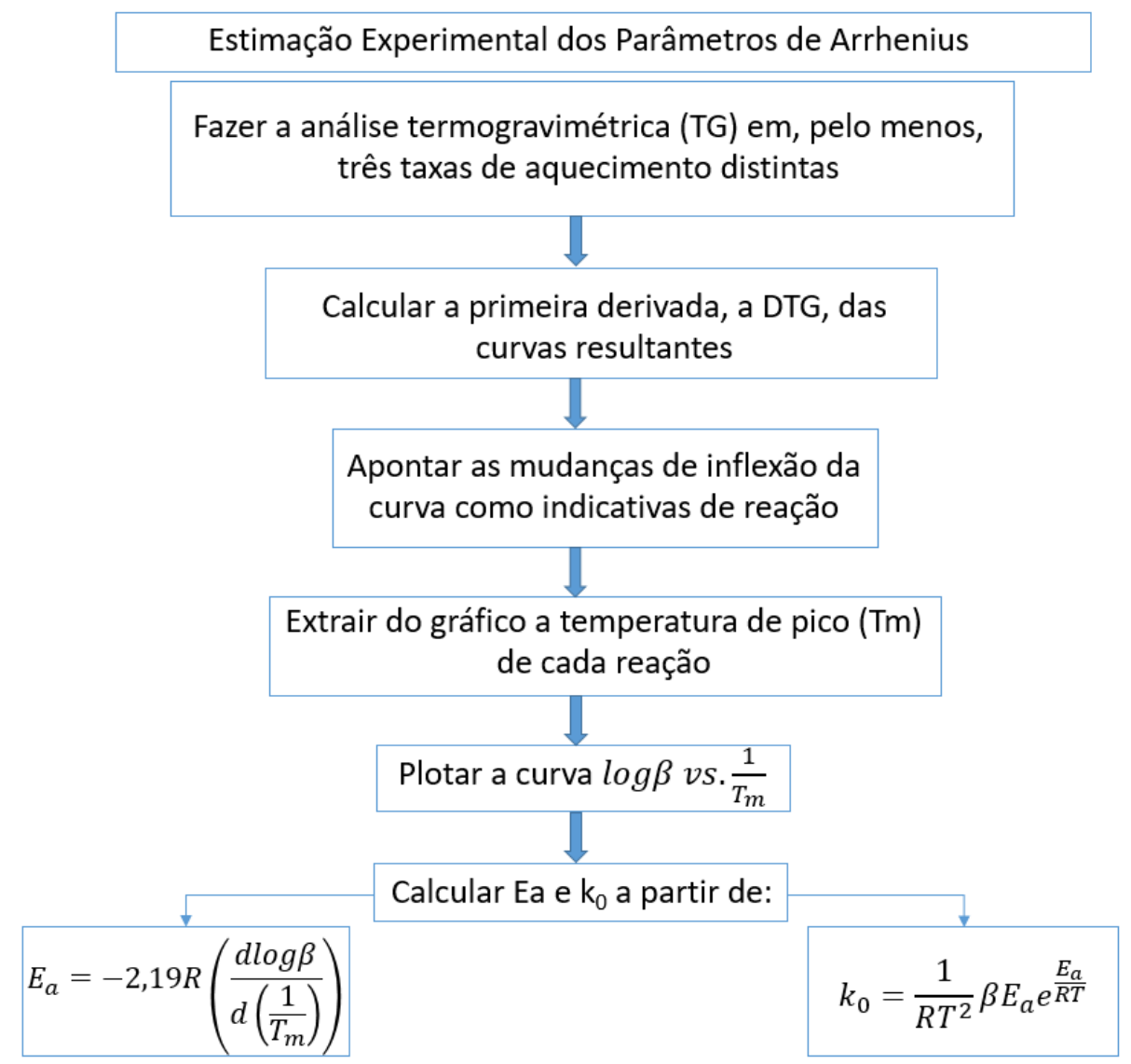

Figura 2.13: Fluxograma de estimação experimental de parâmetros cinéticos por análise termogravimétrica usando o método de Osawa.

Neste cenário, Toniolo et al. (2008)[74] discute que os dados dinâmicos de TG que são analisados com ajuda de métodos simplistas, tendem a ser deformados após a sua manipulação (como por exemplo o uso de logaritmo dos dados experimentais), e por isso, distorcem o significado da análise estatística. Segundo os autores, tais métodos não se mostram necessários considerando a disponibilidade de ferramentas de resolução computacional de equações de métodos numéricos de alta performance.

\section{7}

\section{Estimação de parâmetros}

No processo de construção de um modelo, dois passos são básicos e fundamentais. Primeiramente a definição da estrutura do modelo, isto é, a relação entre as variáveis, que pode se dar de maneira linear, logarítmica, por exemplo. Em seguida, é necessário impor uma capacidade preditiva e quantitativa ao modelo, e às variáveis consequentemente. Para isso, é necessário estimar os parâmetros do modelo[75]. 
Por exemplo, para o caso de um modelo que siga a estrutura linear, que tem como forma geral $y=\alpha x+\beta, \alpha$ e $\beta$ tornam-se os parâmetros de correlação entre o modelo e os dados experimentais.

Dessa forma, a solução para a definição desses parâmetros, é o procedimento de estimação de parâmetros. Esse procedimento utiliza uma função objetivo, que é o objetivo principal, o que deseja ser atingido, como por exemplo a maximização dos lucros de um processo ou a minimização entre a diferença da resposta do modelo e os dados experimentais medidos.

Segundo Schwaab e Pinto (2007)[75], o problema de estimação de parâmetros pode ser dividido em três partes:

- a definição da função objetivo;

- a minimização da função objetivo (encontrar o ponto ótimo);

- a interpretação estatística dos parâmetros estimados e da qualidade do modelo.

Um exemplo de função objetivo muito usada é a função dos mínimos quadrados (Equação 2-10).

$$
F_{o b j}=\sum_{i=1}^{N E}\left(y_{i}^{\text {experimental }}-y_{i}^{\text {modelo }}\right)^{2}
$$

Na qual, NE é o número de experimentos, $y_{i}^{\text {experimental }}$ é o resultado

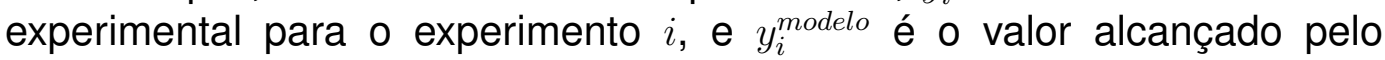
modelo para este mesmo ponto. A finalidade da minimização da função objetivo é alcançar a menor diferença possível entre o modelo e os dados experimentais.

Após a minimização da função objetivo e a obtenção dos parâmetros do modelo, a última etapa da estimação de parâmetros envolve a análise estatística da qualidade dos resultados, de forma a validá-los. Esta análise tem o objetivo de avaliar se o modelo é adequado e a qualidade dos parâmetros estimados[76].

\subsection{1}

\section{Método de otimização Enxame de Partículas}

No procedimento de estimação de parâmetros são empregados métodos de minimização que podem ser determinísticos, estocásticos ou híbridos.

Métodos determinísticos têm um experimento associado a cada resultado experimental, enquanto os estocásticos têm associado para cada condição experimental um conjunto de possíveis resultados, que se diferem pela probabilidade de ocorrer[77].

Para modelos não-lineares, os métodos estocásticos ou híbridos (mais de um método de otimização sendo ao menos um estocástico e um determinístico) geralmente são mais empregados. Porém, pode-se dizer, que os métodos estocásticos estão quase sempre presentes na estimação de parâmetros de modelos não lineares. Isso se deve devido à complexidade de modelos na engenharia química, em que métodos determinísticos estão 
sujeitos a calcular um ponto ótimo que não é mínimo global, mas um mínimo local. Eles dependem do chute inicial fornecido[75]. Enquanto isso, os métodos estocásticos, ou heurísticos, que são caracterizados pela realização de muitas avaliações da função objetivo em toda a região de busca, apresentam significante vantagem frente aos modelos determinísticos.

O método estocástico tem a vantagem de determinar a região de confiança sem custos adicionais de computação, já que os mesmos pontos avaliados durante a minimização são usados para descrever a região de confiança. Assim, a principal desvantagem dos métodos heurísticos, sua exigência computacional, acaba se tornando uma importante vantagem, permitindo uma avaliação estatística rigorosa dos parâmetros estimados.

Outra vantagem do método estocástico[77, 78] é o processo de busca global pelo ponto ótimo. Estabelecendo primeiramente uma região de busca, os métodos não exigem uma estimativa inicial de parâmetro nem uma diferenciação da função objetivo ou do modelo. No entanto, faixas de valores válidos dos parâmetros devem ser fornecidas.

Comparativamente, um método híbrido é aquele que começa a busca com um método heurístico (obtém uma boa estimativa inicial) e posteriormente termina com um método determinístico.

Dentre os métodos estocásticos mais utilizados, tem-se os métodos de Monte Carlo, Algoritmo Genético, e Enxame de Partículas. Segundo Schwaab (2005), o método do Enxame de Partículas obtém os melhores resultados nas minimizações das funções teste, devido à sua robustez.

Sua concepção faz uma analogia com o comportamento de agrupamento de animais (pássaros, peixes, etc.), em que as partículas do enxame trocam informações entre si para encontrar o ótimo global da função objetivo.

Este método é marcado pela busca global inicial, que progride à uma busca local, ao longo do processo iterativo com a convergência das partículas. Com a busca global, possíveis pontos mínimos são localizados, para, em seguida com a busca em nível local, procurar-se uma maior precisão do valor obtido. Dessa forma, além de crescer a probabilidade de achar o ponto mínimo global, o método garante a maior precisão deste.

A maneira como as iterações se modificam no método é conduzida pela soma de três termos[77], relativo à inércia (ou como a partícula tem se movido), relativo à atração da partícula ao melhor ponto encontrado por ela mesma até o momento, e relativo à atração da partícula ao melhor ponto encontrado pelo conjunto como um todo. O fluxograma da Figura 2-14 apresenta o método de forma mais clara.

Dessa forma, dentro da região de busca pré-estabelecida, são sorteados pontos (tamanho do enxame) e avaliados de acordo com o valor da função objetivo nestes pontos. Dentre estes pontos, o ponto ótimo (ou seja, com menor valor de função objetivo) é comparado com o ótimo estabelecido anteriormente $\left(F_{\text {otm }}\right)$, e atualizado como novo ótimo geral, se o valor da função objetivo no ponto atual for menor que o ótimo anterior.

Assim, o método se processa até atingir o critério de parada, ou seja, até atingir o número máximo de iterações (resultado incompleto) ou até dizer-se que o resultado convergiu ao resultado ótimo (resultado final) de 
acordo com algum critério de convergência definido pelo programador ou usuário, atualizando os novos ótimos a cada iteração.

No trabalho de Toniolo et al. (2008)[74], o enxame de partículas foi aplicado para estimação de parâmetros a partir de dados de análises termogravimétricas da combustão catalítica de fuligem de diesel. Segundo os autores, foi possível, através do uso destes métodos, a estimação de parâmetros cinéticos estatisticamente significativos para um modelo de balanço fenomenológico.

Porém, no que diz respeito à decomposição térmica do alúmen de potássio, até onde se tem conhecimento, métodos estocásticos para estimar parâmetros cinéticos não tinham sido empregados até o presente trabalho.

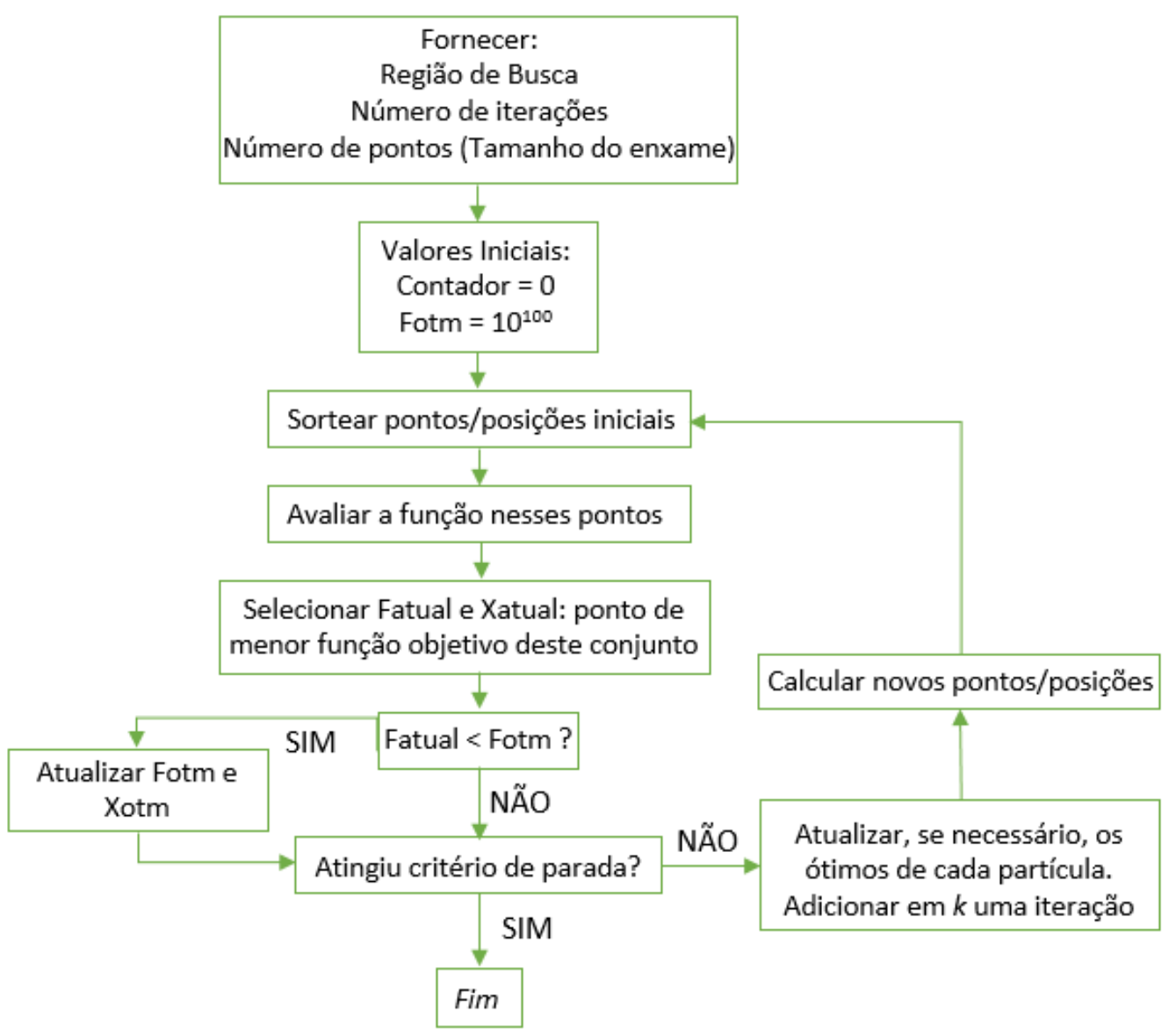

Figura 2.14: Fluxograma do método do Enxame de Partículas.

\subsection{2 \\ Interpretação estatística dos parâmetros estimados e da qualidade de predição do modelo}

Um erro comum é achar que o processo da estimação de parâmetros acaba após a minimização da função objetivo e da obtenção dos parâmetros. Na verdade, após esses passos, ainda é necessário realizar a análise da qualidade dos parâmetros, através de ferramentas estatísticas, de forma a garantir a relevância dos parâmetros e a qualidade do modelo[75]. 
Dessa maneira, de forma a medir a qualidade dos parâmetros estimados, calculam-se as matrizes de covariância e de correlação entre eles. Primeiramente, define-se o que é covariância e correlação, e suas diferenças.

Define-se como covariância entre duas variáveis $\left(s^{2}\right)$ :

$$
\operatorname{Covar}(x, y)=\sum p\left(x_{i}, y_{i}\right)\left(x_{i}-\mu_{x}\right)\left(y_{i}-\mu_{y}\right)
$$

Em que: $p$ é a frequência relativa (ou probabilidade de ocorrer o par $\left.\left(x_{i}, y_{i}\right)\right)$ e $\mu_{i}$ é a média para os valores da variável indicada.

De forma que, para eventos independentes, tem-se a covariância entre as variáveis igual a zero. Por isso, a covariância é usada como uma medida de independência entre os resultados obtidos a partir de diferentes experimentos.

Assim, a matriz de covariâncias é aquela que, simétrica, sumariza as covariâncias entre todas as variáveis.

Já o fator de correlação é a forma normalizada da covariância, já que esta tem dimensão das variáveis $x$ e y simultaneamente. A configuração normalizada se faz necessária porque a magnitude das variáveis pode mudar de problema para problema, sendo conveniente adotar a forma normalizada. Assim, o fator de correlação se dá por:

$$
\rho_{x y}=\frac{\sigma_{x y}^{2}}{\sigma_{x} \sigma_{y}}
$$

Quando as variáveis $x$ e $y$ são independentes, $\sigma_{x y}^{2}=0$ e $\rho_{x y}=0$. Quando $y=\alpha x+\beta$, então $\mu_{y}=\alpha \mu_{x}, \mu_{y}=\alpha \mu_{x}+\beta, \sigma_{y}^{2}=\alpha^{2} \sigma_{x}^{2}, \sigma_{x y}^{2}=\alpha \sigma_{x}^{2}$ e $\rho_{x y}= \pm 1$. .

Portanto, a matriz de correlação é igual a matriz de covariância das variáveis padronizadas. A matriz de correlação é simétrica porque a correlação entre $x_{i}$ e $y_{i}$ é igual à correlação entre $y_{i}$ e $x_{i}$. A correlação tem valor igual a 1 se uma das variáveis é uma função linear crescente da outra. $E$, portanto, -1 se a função é decrescente. Os valores entre -1 e 1 demonstram o grau de dependência linear entre as duas variáveis. A correlação é maior entre as variáveis, quanto mais próximo esse valor for dos extremos -1 e $1[62,63]$.

Assim, assumindo que os desvios entre os dados experimentais e preditos sigam uma distribuição normal, a região de confiança dos parâmetros toma a forma de um hiper-elipsóide. Com o ponto de estimação dos parâmetros localizado no centro deste elipsoide[79].

Para o caso de modelos não lineares, em que soluções analíticas não são possíveis, procedimentos iterativos são feitos para ambas as avaliações, de minimização da função objetivo e para a avaliação da região de confiança dos parâmetros, de forma a definir a incerteza dos parâmetros obtidos, e assim avaliá-los propriamente. A aproximação do elipsóide para a região de confiança é amplamente usada dada a sua simplicidade, onde as estimativas para os parâmetros seguem a distribuição normal, de forma que os únicos dados necessários são da estimativa ponto a ponto e da matriz de covariância[80, 81]. 
A equação da região de confiança com grau de confiança 1- $\alpha$ (em que $\alpha$ representa o nível de confiança; neste trabalho sempre de $95 \%$ ) foi primeiramente proposta por Beale(1960)[82]. A equação é uma aproximação a partir da distribuição $\chi$-quadrado, que segue a distribuição de Fisher, com $n-p$ graus de liberdade, em que $n$ refere-se ao número total de dados experimentais e $p$ se refere ao número de parâmetros.

$$
S(\theta) \leq S(\hat{\theta})\left(1+\frac{p}{n-p} F_{p, n-p}^{1-\alpha}\right)
$$

Em que, $S(\theta)$ e $S(\hat{\theta})$, provenientes da expansão da série de Taylor, denotam, respectivamente a função objetivo (ou seja, o intervalo de confiança) e o ponto de mínimo; dessa forma garantindo que a função da região de confiança englobe o ponto de mínimo e as iterações de estimativa dos parâmetros. Finalmente, a região de confiança é determinada pelas combinações de parâmetros que satisfaçam a Equação 2-13 ao longo do processo de busca ótima. A região de confiança paramétrica mostra todos os conjuntos de parâmetros viáveis capazes de fornecer uma resposta do modelo aceitável, fazendo-o capaz de representar de modo adequado os dados experimentais disponíveis.

A incerteza dos valores dos parâmetros nos intervalos de confiança é descrita por:

$$
\theta_{j}^{e s t}-\epsilon_{\theta j}<\theta_{j}^{r e a l}<\theta_{j}^{e s t}+\epsilon_{\theta j}
$$

Em que, $\theta_{j}^{e s t}$ corresponde ao valor estimado do parâmetros, $\theta_{j}^{\text {real }}$ se refere ao valor verdadeiro e desconhecido, e $\epsilon_{\theta j}$ representa o erro do parâmetro.

O intervalo de confiança dos parâmetros pode ser determinado por meio da consideração de que a distribuição paramétrica segue a distribuição $t$ - Student, como feito por Toniolo et al. (2008) e Brandão et al. (2016 e 2018)[83, 84].

\section{8}

\section{Comentários finais}

Muitas rotas são conhecidas e bem estabelecidas mundialmente para a produção de sulfato de potássio. Entre elas, a rota cujo produto intermediário é o alúmen de potássio. Apesar do alúmen de potássio ter sido amplamente estudado, sua decomposição com o objetivo de formação de sulfato de potássio não havia sido ainda o foco de trabalhos publicados na literatura até onde se tem conhecimento.

Apesar de existirem muitos estudos que envolvam o estudo cinético da decomposição do alúmen de potássio, muitas questões permanecem em aberto a respeito da cinética envolvida e dos valores dos parâmetros reacionais. Além do mais, a estimação dos parâmetros das reações envolvidas na decomposição do alúmen de potássio através de um método de otimização estocástico, usando dados de análises termogravimétricas é uma inovação na área, tendo em vista que a maioria dos trabalhos encon- 
trados utilizaram métodos simplificados, baseados na forma logarítmica da equação de Arrhenius para a taxa específica de reação. 


\section{3 \\ Metodologia}

\section{1}

\section{Parte Experimental}

\subsection{1}

\section{Materiais e Equipamento}

Os seguintes produtos químicos foram utilizados nas análises termogravimétricas:

- Alúmen de potássio dodecahidratado sintético (Sulfato de Potássio e Alumínio $\left(12 \mathrm{H}_{2} \mathrm{O}\right)$, P.A.), ISOFAR, de composição:

Tabela 3.1: Composição do Alúmen de potássio dodecahidratado sintético

\begin{tabular}{|c|c|}
\hline Dosagem & $98 \%$ \\
\hline Insolúveis & $0,005 \%$ \\
\hline Cloreto $(\mathrm{Cl})$ & $5 \mathrm{ppm}$ \\
\hline Metais pesados (como $\mathrm{Pb})$ & $0,001 \%$ \\
\hline Ferro $(\mathrm{Fe})$ & $0,001 \%$ \\
\hline Sódio $(\mathrm{Na})$ & $0,02 \%$ \\
\hline Amônio $(\mathrm{NH} 4)$ & $0,005 \%$ \\
\hline
\end{tabular}

- Nitrogênio (grau de pureza de 99,999 \%, Linde AG)

- $\operatorname{Ar}$ sintético $\left(20 \%\right.$ de $\mathrm{O}_{2}$ em $\mathrm{N}_{2}$, AGA S/A)

- Coque breeze (finos de coque obtidos junto a uma empresa siderúrgica situada no estado do Rio de Janeiro)

Todas as análises termogravimétricas foram conduzidas em um equipamento Netzsch, modelo STA 449 F3 Jupiter ${ }^{\circledR}$.

\subsection{2}

\section{Procedimento Experimental}

As amostras foram nomeadas de acordo com:

- O tipo de decomposição (térmica - $T$, redutora - $R$ ou do coque - C),

- a taxa de aquecimento $(10,15$ ou $20 \mathrm{~K} / \mathrm{min})$,

- a atmosfera na qual o material foi submetido (inerte - In ou ar sintético - Ar). 


\subsubsection{1}

\section{Experimental da Decomposição térmica}

Amostras de $30 \mathrm{mg}$ de Alúmen de potássio dodecahidratado sintético $\left(\mathrm{KAl}\left(\mathrm{SO}_{4}\right)_{2} .12 \mathrm{H}_{2} \mathrm{O}\right)$ foram pesadas e submetidas à análise termogravimétrica em ambas atmosfera pura de nitrogênio inerte e atmosfera de ar sintético, em uma taxa de aquecimento de $15 \mathrm{~K} / \mathrm{min}$, iniciando em temperatura ambiente $\left(25^{\circ} \mathrm{C}\right)$, até atingir $1000^{\circ} \mathrm{C}$, e em seguida permanecendo em isoterma por $1 \mathrm{~h}$.

Posteriormente, outras duas análises de alúmen de potássio foram realizadas, seguindo a mesma metodologia descrita, em atmosfera pura de nitrogênio inerte, com taxas de aquecimento de $10 \mathrm{~K} / \mathrm{min}$ e $20 \mathrm{~K} / \mathrm{min}$. A Tabela 3-2 apresenta as massas pesadas em todas as condições experimentais de decomposição térmica do alúmen de potássio investigadas nesse trabalho.

Tabela 3.2: Massa pesada para os experimentos de decomposição térmica com alúmen de potássio dodecahidratado

\begin{tabular}{|c|c|}
\hline \multicolumn{2}{|c|}{ Alúmen $(\mathrm{mg})$} \\
\hline T10ln & 30,2 \\
\hline T15ln & 30,6 \\
\hline T15Ar & 32,1 \\
\hline T20ln & 30,6 \\
\hline
\end{tabular}

\subsubsection{2}

\section{Procedimento Experimental da Decomposição redutora}

Inicialmente, como preparação para a decomposição redutora, foram feitas as análises de TG a $15 \mathrm{~K} / \mathrm{min}$ em atmosfera de nitrogênio inerte e ar sintético para o coque breeze sozinho (Tabela 3-3).

Tabela 3.3: Massa pesada para os experimentos com coque breeze

\begin{tabular}{|c|c|}
\hline \multicolumn{2}{|c|}{ Coque (mg) } \\
\hline C15ln & 34,4 \\
\hline C15Ar & 30,7 \\
\hline
\end{tabular}

Sob atmosfera inerte, com a ação da temperatura, tem-se o processo de dissipação dos voláteis, entre eles principalmente a água. E, na presença de ar sintético, ou atmosfera oxidante, ocorre a queima do carbono fixo, restando apenas a massa das cinzas.

Dessa forma, fez-se o cálculo da estequiometria para a quantidade de carbono fixo presente no coque breeze, que se dá subtraindo a percentagem de voláteis e cinzas da quantidade inicial de coque breeze, para que a decomposição se mantenha estequiométrica.

Portanto, após esse procedimento, amostras de $30 \mathrm{mg}$ da mistura estequiométrica de alúmen de potássio sintético e coque breeze foram pesadas e submetidas à análise termogravimétrica em atmosfera pura 
de nitrogênio inerte nas três taxas de aquecimento: 10, 15, $20 \mathrm{~K} / \mathrm{min}$, e atmosfera de ar sintético para $15 \mathrm{~K} / \mathrm{min}$ (Tabela 3-4).

Tabela 3.4: Massa pesada para os experimentos de decomposição redutora com alúmen de potássio dodecahidratado na presença do coque breeze como agente redutor

\begin{tabular}{|c|c|}
\hline \multicolumn{2}{|c|}{ Alúmen+Coque $(\mathrm{mg})$} \\
\hline R10In & 30,9 \\
\hline R15In & 31,4 \\
\hline R15Ar & 30,6 \\
\hline R20In & 30,4 \\
\hline
\end{tabular}

\section{2}

\section{Modelagem Matemática}

Os modelos propostos foram desenvolvidos a partir do balanço molar para o sistema de decomposição térmica. Foram testados 4 tipos de modelos, e o melhor deles foi aplicado para simular a decomposição redutora. Os modelos estão descritos em quantidade de mol por tempo em minutos.

- Modelo 1 de decomposição térmica: Reação em uma etapa

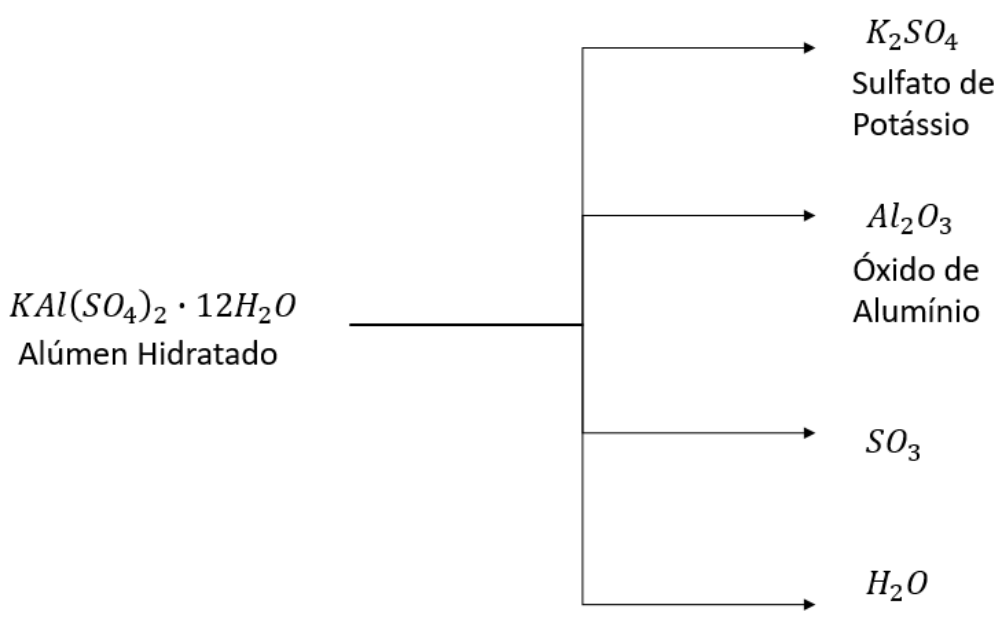

Figura 3.1: Modelo em uma etapa.

$$
\mathrm{KAl}\left(\mathrm{SO}_{4}\right)_{2} .12 \mathrm{H}_{2} \mathrm{O} \stackrel{\mathrm{k}}{\rightarrow} 0.5 \mathrm{~K}_{2} \mathrm{SO}_{4}+0.5 \mathrm{Al}_{2} \mathrm{O}_{3}+1.5 \mathrm{SO}_{3}+12 \mathrm{H}_{2} \mathrm{O}
$$

Balanço Molar do modelo 1 (BM1):

$$
\frac{d(\text { AlúmenHidratado })}{d t}=-k * \text { AlúmenHidratado }
$$




$$
\begin{gathered}
\frac{d\left(\mathrm{~K}_{2} \mathrm{SO}_{4}\right)}{d t}=\frac{d\left(\mathrm{Al}_{2} \mathrm{O}_{3}\right)}{d t}=0.5 k * \text { AlúmenHidratado } \\
\frac{d\left(\mathrm{SO}_{3}\right)}{d t}=1.5 k * \text { AlúmenHidratado } \\
\frac{d\left(\mathrm{H}_{2} \mathrm{O}\right)}{d t}=12 k * \text { AlúmenHidratado }
\end{gathered}
$$

\section{- Modelo 2 de decomposição térmica: Reação em duas etapas}

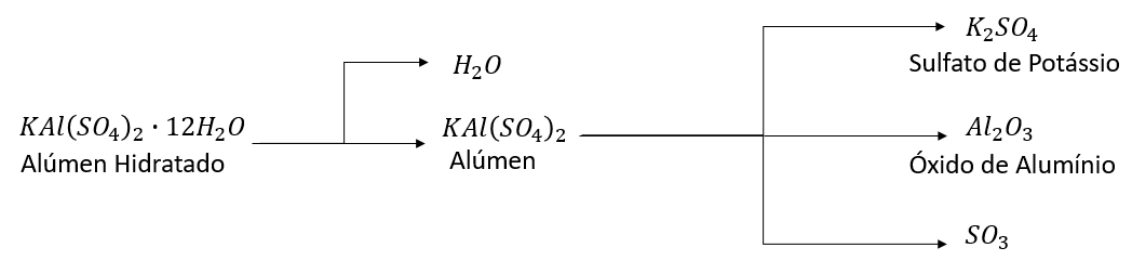

Figura 3.2: Modelo em duas etapas.

Balanço Molar do Modelo 2 (BM2):

$$
\begin{gathered}
\frac{d(\text { AlúmenHidratado })}{d t}=-k 1 * \text { AlúmenHidratado } \\
\frac{d\left(\mathrm{H}_{2} \mathrm{O}\right)}{d t}=12 k 1 * \text { AlúmenHidratado } \\
\frac{d(\text { Alúmen })}{d t}=k 1 * \text { AlúmenHidratado }-k 2 * \text { Alúmen } \\
\frac{d\left(\mathrm{~K}_{2} S \mathrm{O}_{4}\right)}{d t}=\frac{d\left(\mathrm{Al}_{2} \mathrm{O}_{3}\right)}{d t}=0.5 k 2 * \text { Alúmen } \\
\frac{d\left(\mathrm{SO}_{3}\right)}{d t}=1.5 k 2 * \text { Alúmen }
\end{gathered}
$$




\section{- Modelo 3 de decomposição térmica: Reação em três etapas}

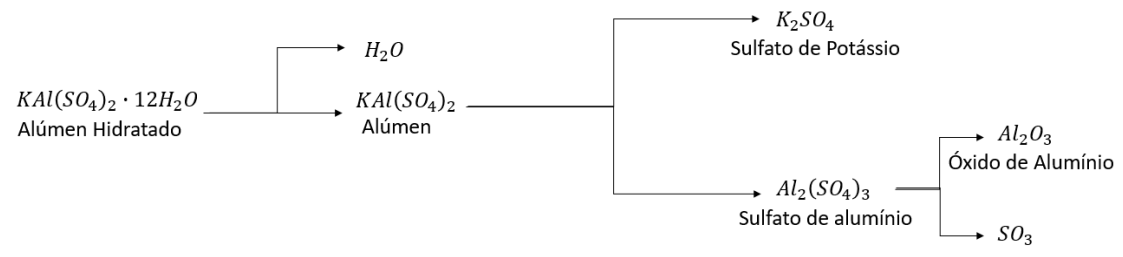

Figura 3.3: Modelo em três etapas.

$$
\begin{gathered}
\mathrm{KAl}\left(\mathrm{SO}_{4}\right)_{2} .12 \mathrm{H}_{2} \mathrm{O} \stackrel{\mathrm{k} 1}{\rightarrow} \mathrm{KAl}\left(\mathrm{SO}_{4}\right)_{2}+12 \mathrm{H}_{2} \mathrm{O} \\
\mathrm{KAl}\left(\mathrm{SO}_{4}\right)_{2} \stackrel{\mathrm{k} 2}{\longrightarrow} 0.5 \mathrm{~K}_{2} \mathrm{SO}_{4}+0.5 \mathrm{Al}_{2}\left(\mathrm{SO}_{4}\right)_{3} \\
\mathrm{Al}_{2}\left(\mathrm{SO}_{4}\right)_{3} \stackrel{\mathrm{k} 3}{\longrightarrow} \mathrm{Al}_{2} \mathrm{O}_{3}+3 \mathrm{SO}_{3}
\end{gathered}
$$

Balanço Molar do Modelo 3 (BM3):

O balanço molar BM3 é igual ao BM2 para os reagentes (Equações 3-8 e 3-10) e para a água (Equação 3-9).

$$
\begin{gathered}
\frac{d\left(K_{2} S O_{4}\right)}{d t}=0.5 k 2 * \text { Alúmen } \\
\frac{d\left(A l_{2}\left(S O_{4}\right)_{3}\right)}{d t}=0.5 k 2 * \text { Alúmen }-k 3 * A l_{2}\left(S O_{4}\right)_{3} \\
\frac{d\left(A l_{2} O_{3}\right)}{d t}=k 3 * A l_{2}\left(S O_{4}\right)_{3} \\
\frac{d\left(S O_{3}\right)}{d t}=3 k 3 * A l_{2}\left(S O_{4}\right)_{3}
\end{gathered}
$$




\section{- Modelo 4 de decomposição térmica: Reação em quatro etapas}

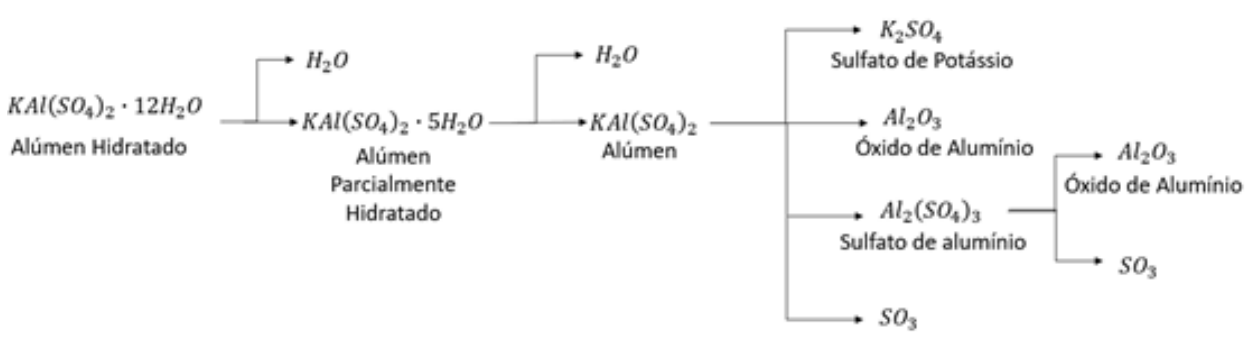

Figura 3.4: Modelo em quatro etapas.

$$
\begin{gathered}
\mathrm{KAl}\left(\mathrm{SO}_{4}\right)_{2} .12 \mathrm{H}_{2} \mathrm{O} \stackrel{\mathrm{k} 1}{\longrightarrow} \mathrm{KAl}\left(\mathrm{SO}_{4}\right)_{2} .5 \mathrm{H}_{2} \mathrm{O}+7 \mathrm{H}_{2} \mathrm{O} \\
\mathrm{KAl}\left(\mathrm{SO}_{4}\right)_{2} .5 \mathrm{H}_{2} \mathrm{O} \stackrel{\mathrm{k} 2}{\longrightarrow} \mathrm{KAl}\left(\mathrm{SO}_{4}\right)_{2}+5 \mathrm{H}_{2} \mathrm{O}
\end{gathered}
$$

$$
\mathrm{KAl}\left(\mathrm{SO}_{4}\right)_{2} \stackrel{\mathrm{k} 3}{\longrightarrow} 0.5 \mathrm{~K}_{2} \mathrm{SO}_{4}+0.25 \mathrm{Al}_{2}\left(\mathrm{SO}_{4}\right)_{3}+0.25 \mathrm{Al}_{2} \mathrm{O}_{3}+0.75 \mathrm{SO}_{2}+0.75 \mathrm{O}_{2}
$$

$$
\mathrm{Al}_{2}\left(\mathrm{SO}_{4}\right)_{3} \stackrel{\mathrm{k} 4}{\rightarrow} \mathrm{Al}_{2} \mathrm{O}_{3}+3 \mathrm{SO}_{2}+1.5 \mathrm{O}_{2}
$$

Balanço Molar do Modelo 4 (BM4):

A equação do balanço molar do reagente hidratado se mantém igual à Equação 3-8.

$\frac{d(\text { AlúmenParcial.Hid. })}{d t}=k 1 *$ AlúmenHidratado-k2*AlúmenParcial.Hid .

$$
\frac{d(\text { Alúmen })}{d t}=k 2 * \text { AlúmenParcial.Hid. }-k 3 * \text { Alúmen }
$$

$$
\frac{d\left(\mathrm{H}_{2} \mathrm{O}\right)}{d t}=7 k 1 * \text { AlúmenHidratado }+5 k 2 * \text { AlúmenParcial.Hid. }
$$

$$
\frac{d\left(K_{2} S O_{4}\right)}{d t}=0.5 k 3 * \text { Alúmen }
$$




$$
\begin{gathered}
\frac{d\left(\mathrm{Al}_{2}\left(\mathrm{SO}_{4}\right)_{3}\right)}{d t}=0.25 k 3 * \text { Alúmen }-k 4 * \mathrm{Al}_{2}\left(\mathrm{SO}_{4}\right)_{3} \\
\frac{d\left(\mathrm{Al}_{2} \mathrm{O}_{3}\right)}{d t}=0.25 k 3 * \text { Alúmen }+k 4 * A l_{2}\left(\mathrm{SO}_{4}\right)_{3} \\
\frac{d\left(\mathrm{SO}_{2}\right)}{d t}=0.75 k 3 * \text { Alúmen }+3 k 4 * \mathrm{Al}_{2}\left(\mathrm{SO}_{4}\right)_{3} \\
\frac{d\left(\mathrm{O}_{2}\right)}{d t}=0.75 k 3 * \text { Alúmen }+1.5 k 4 * \mathrm{Al}_{2}\left(\mathrm{SO}_{4}\right)_{3}
\end{gathered}
$$

O balanço molar do Modelo 4 foi descrito baseado na saída de gases $\mathrm{SO}_{2}$ e $\mathrm{O}_{2}$, diferentemente dos outros modelos, de forma a manter as reações elementares e em proporções estequiométricas. Considerando o equilíbrio descrito na Equação 3-32, que tem uma relação proporcional à temperatura, e levando-se em conta que o TG mede a perda de massa, ou seja, a saída dos gases em quaisquer das formas descritas, optou-se por manter os três primeiros balanços molares baseados na saída de $\mathrm{SO}_{3}$ enquanto o último trata de $\mathrm{SO}_{2}$ e $\mathrm{O}_{2}$.

$$
\mathrm{SO}_{2}+\frac{1}{2} \mathrm{O}_{2}=\mathrm{SO}_{3}
$$

Em todos os modelos, as constantes de taxa de reação são descritas pela equação de Arrhenius (Equação 3-33)

$$
k_{i}=k_{0 i} e^{\frac{-E_{a i}}{R T}}
$$

Na qual, $i=1$ a $4 ; k=$ constante de taxa específica; $k_{0}=$ constante pré-exponencial; $E_{a}=$ Energia de ativação; $R=$ constante dos gases; $T=$ Temperatura.

Porém, devido à estrutura matemática da equação de Arrhenius, que envolve uma exponencial do inverso da temperatura, a correlação entre os parâmetros $k_{0}$ e $E_{a}$ geralmente é muito alta e, por isso, em muitos casos é extremamente difícil uma estimação precisa dos seus valores, especialmente através de minimização da função objetivo que minimiza a diferença entre o dado medido e o calculado[85]. A alta correlação entre os parâmetros pode ser reduzida pela reparametrização da Equação de Arrhenius (Agarwal e Brisk, 1985)[86]. Uma possível forma da equação reparametrizada está apresentada na Equação 3-34.

$$
k=e^{A+B\left(\frac{T-T_{r e f}}{T}\right)}
$$

Na qual $T_{r e f}$ é uma temperatura de reação de referência e os parâmetros da equação reparametrizada ( $A$ e $B$ ) se relacionam aos da equação tradicional de Arrhenius por: 


$$
\begin{gathered}
A=\ln k_{\text {Tref }}=\ln k_{0}-\frac{E_{a}}{R T_{\text {ref }}} \\
B=\frac{E_{a}}{R T_{\text {ref }}}
\end{gathered}
$$

Dessas equações, nota-se que $k_{\text {Tref }}$ é a taxa específica de reação avaliada na temperatura de referência. Além de diminuir a correlação entre os parâmetros, a equação reparametrizada permite a diminuição do esforço computacional requerido para a minimização da função objetivo (Espie e Macchietto, 1988)[87].

Dessa forma, são:

- 8 parâmetros desconhecidos (dois para cada constante cinética) no Modelo 4,

- 6 parâmetros no Modelo 3,

- 4 parâmetros no Modelo 2, e

- 2 parâmetros no Modelo 1.

Cada modelo foi implementado e diferentes combinações entre os valores dos seus parâmetros foram testadas exaustivamente de modo que o respectivo modelo conseguisse ajustar melhor os dados experimentais. A simulação de cada modelo foi executada através da resolução das equações de balanço molar apresentadas anteriormente.

As EDOs das equações dos balanços molares foram integradas pelo integrador 'Isoda' (Livermore Solver para Equações diferenciais ordinárias) através do método numérico implícito BDF (backward differentiation formula) na linguagem de programação Python 3.

Com a resolução dos balanços molares de cada componente, a quantidade de moles e a composição de cada componente eram conhecidas a cada instante de tempo. A perda de massa foi então calculada conforme a Equação 3-37:

$$
P M=\frac{m_{\mathrm{KAl}\left(\mathrm{SO}_{4}\right)_{2} .12 \mathrm{H}_{2} \mathrm{O}}^{t}+m_{\mathrm{KAl}\left(\mathrm{SO}_{4}\right)_{2} .5 \mathrm{H}_{2} \mathrm{O}}+m_{\mathrm{KAl}_{\left(\mathrm{SO}_{4}\right)_{2}}}+m_{\mathrm{Al}_{2} \mathrm{O}_{3}}+m_{\mathrm{Al}_{2}\left(\mathrm{SO}_{4}\right)_{3}}+m_{K_{2} \mathrm{SO}_{4}}}{m_{\mathrm{KAl}\left(\mathrm{SO}_{4}\right)_{2} .12 \mathrm{H}_{2} \mathrm{O}}} 100
$$

\section{Em que:}

- $m_{\mathrm{KAl}\left(\mathrm{SO}_{4}\right)_{2} \cdot 12 \mathrm{H}_{2} \mathrm{O}}^{\mathrm{O}}$ é a massa do alúmen de potássio dodecahidratado (reagente) no tempo t de reação,

- $m_{\mathrm{KAl}\left(\mathrm{SO}_{4}\right)_{2} .5 \mathrm{H}_{2} \mathrm{O}}$ é a massa do alúmen de potássio parcialmente hidratado (produto intermediário),

- $m_{K A l\left(S O_{4}\right)_{2}}$ é a massa do alúmen de potássio anidro (produto intermediário),

- $m_{\mathrm{Al}_{2}\left(\mathrm{SO}_{4}\right)_{3}}$ é a massa do sulfato de alumínio (produto intermediário),

- $m_{\mathrm{Al}_{2} \mathrm{O}_{3}}$ é a massa do óxido de alumínio (co-produto), 
- $m_{K_{2} S O_{4}}$ é a massa do sulfato de alumínio (produto principal),

- $m_{\mathrm{KAl}\left(\mathrm{SO}_{4}\right)_{2} .12 \mathrm{H}_{2} \mathrm{O}}$ é a massa do alúmen de potássio dodecahidratado (reagente), no momento inicial $\mathrm{t}=0$.

No cálculo da perda de massa só não entraram os componentes gasosos formados. A cada intervalo de tempo foi contabilizada a massa total de todos os componentes sólidos presentes e comparada à massa inicial de alúmen de potássio dodecahidratado, de forma que a perda de massa represente a formação dos produtos gasosos (vapor de água e $\mathrm{SO}_{3}$ ).

\section{3}

\section{Estimação de parâmetros e intervalos de confiança}

Um notebook Windows 10 modelo Inspiron 3442, processador Intel ${ }^{\circledR}$ Core $^{T M}$ i5-4210U e memória de 8192MB RAM foi utilizado no presente trabalho. Em todas as estimações, foram empregadas 200 partículas e 250 iterações utilizando uma tolerância numérica de $1 * 10^{-8}$ para a função objetivo de mínimos quadrados. Além disso, foi considerado um intervalo de confiança de $95 \%$.

A estimação de parâmetros foi feita com o emprego do método de otimização enxame de partículas, mostrado no fluxograma da Figura (2.15) no capítulo de Revisão Bibliográfica. Para cada iteração do método do enxame de partículas, o modelo é simulado $x$ vezes onde $x$ corresponde ao número de partículas definido, e, para cada uma dessas simulações, a função objetivo é calculada. Esse processo é repetido até se chegar ao ponto ótimo ou se esgotar o número máximo de iterações fornecido.

A função objetivo utilizada, de mínimos quadrados, supõe a hipótese de que os dados experimentais são perfeitos, ou seja, dada a precisão do equipamento de TG, diz-se que os dados possuem variância igual a 1, dado que não foram feitas réplicas.

Juntamente ao cálculo da função objetivo, cada conjunto de parâmetros que resultou em um valor de função objetivo finito é salvo. Após o término da estimação, as combinações de parâmetros guardadas são acessadas e àquelas que respeitarem a Equação (2.13) são salvas em outro arquivo pois fazem parte da região de confiança paramétrica.

Como dito anteriormente, os parâmetros que pertencem à região de confiança paramétrica constituem todos os valores de parâmetros possíveis que o modelo pode assumir de modo a continuar sendo classificado com um modelo adequado à representação dos dados experimentais.

Então, definida a região de confiança dos parâmetros, o próximo passo é determinar os intervalos mínimo e máximo de cada parâmetro estimado. Para isso, o exemplo a seguir explica mais detalhadamente o procedimento aplicado no presente trabalho.

Supondo dois parâmetros $\mathrm{k}_{1}$ e $\mathrm{k}_{2}$, a região de confiança paramétrica assume a forma ilustrada na Figura 3-5. 


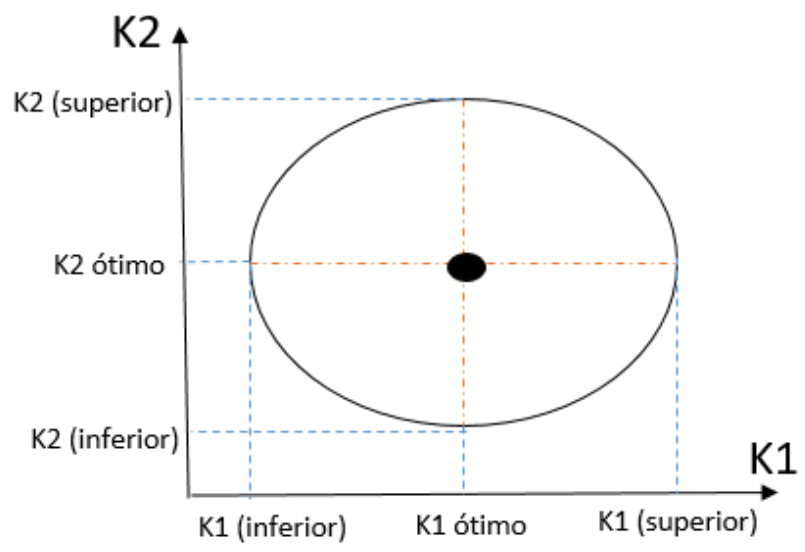

Figura 3.5: Região de confiança dos parâmetros.

A avaliação da confiabilidade dos parâmetros estimados é feita pela delimitação de uma região em torno do ponto de mínimo da função objetivo (ponto central da Figura 3-5), a essa região damos o nome de região de confiança dos parâmetros ou região de confiança paramétrica[76].

A elipse que apresenta inclinação denota correlação entre os parâmetros avaliados. A correlação implica dificuldade de análise dos resultados. Como a elipse da Figura 3-5 não está inclinada, pode-se assumir que os valores que um dos parâmetros pode assumir são independentes dos valores do outro parâmetro. As matrizes de covariância e correlação dos parâmetros estimados foram determinadas aplicando as Equações (2.11) e (2.12), respectivamente, apresentadas no capítulo anterior.

Determinada a região de confiança e os limites inferior e superior de cada parâmetro estimado, fica faltando determinar o intervalo de predição do modelo.

Assim, é feita uma simulação para cada conjunto de parâmetros estimados pertencente à região de confiança (Figura 3-6). Esta simulação (em que os valores são função de $x, k_{1}$ e $k_{2}$ ) gera limites superiores $e$ inferiores de valores da função para que ela esteja ainda dentro do limite aceito pelo método. A função, nesse caso, é o próprio modelo.

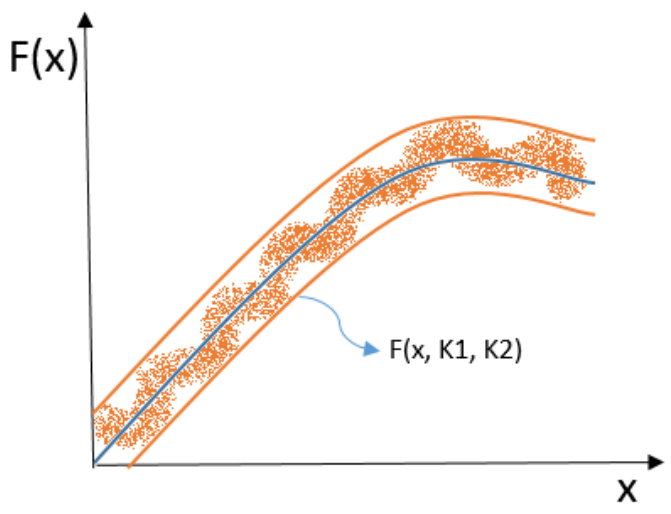

Figura 3.6: Resultado da simulação da função com o intervalo de confiança da mesma. 


\subsection{1}

\section{Cálculo do Coeficiente de Determinação $\mathbf{R}^{2}$}

Para o cálculo do coeficiente de determinação $R^{2}$, foram utilizadas as Equações 3-38 e 3-39.

$$
\begin{gathered}
\text { Desvio Experimental }=\sum_{i=1}^{N}\left(y_{i}-\bar{y}_{\text {exp }}\right)^{2} \\
\text { Desvio do Modelo }=\sum_{i=1}^{N}\left(\hat{y}_{i}-\bar{y}_{\text {modelo }}\right)^{2}
\end{gathered}
$$

Em que, $y_{i}$ é o valor observado, $\bar{y}_{\text {exp }}$ é a média dos valores observados, $\hat{y}_{i}$ é o valor estimado (previsão) e $\bar{y}_{\text {modelo }}$ é a média dos valores estimados.

Assim, o valor de $\mathrm{R}^{2}$ pode ser calculado através da Equação 4-40. $\mathrm{O}$ $R^{2}$ varia entre 0 e 1 indicando, em percentagem, o quanto o modelo consegue explicar os valores observados. Quanto maior o $\mathrm{R}^{2}$, mais explicativo é o modelo e melhor ele se ajusta à amostra.

$$
R^{2}=\frac{\text { Desvio do Modelo }}{\text { Desvio Experimental }}
$$




\section{4 \\ Resultados e Discussão}

O presente capítulo está organizado da seguinte forma: são apresentados inicialmente os resultados experimentais das decomposições na presença ou não de agente redutor, em diferentes taxas de aquecimento, e da análise do agente redutor, medidos pelo equipamento de análise termogravimétrica (TG) com diferentes atmosferas. Em seguida, são introduzidos os resultados das simulações dos modelos. Nessa seção do capítulo, são apresentadas as simulações sem a execução da estimação de parâmetros, ou seja, apenas as simulações com os parâmetros cinéticos selecionados por tentativa e erro para parâmetros que melhor ajustassem as respostas do modelo aos dados experimentais disponíveis. Posteriormente, a seção da estimação dos parâmetros usando o método de Osawa, como descrito na seção 2.6.2, é apresentada e discutida. Por fim, o capítulo de resultados é finalizado com os resultados da estimação de parâmetros para o melhor modelo, aquele que teve o melhor ajuste aos dados experimentais na seção das simulações.

\section{1}

\section{Resultados Experimentais}

A seguir, são expostos os resultados das curvas de TG e DTG para as análises feitas.

\subsection{1 \\ Decomposição térmica}

Inicialmente foi feito o teste para a decomposição térmica do alúmen de potássio dodecahidratado, na taxa de aquecimento de $15 \mathrm{~K} / \mathrm{min}$, porém para diferentes atmosferas de reação: inerte (T15ln) e ar sintético (T15Ar). 


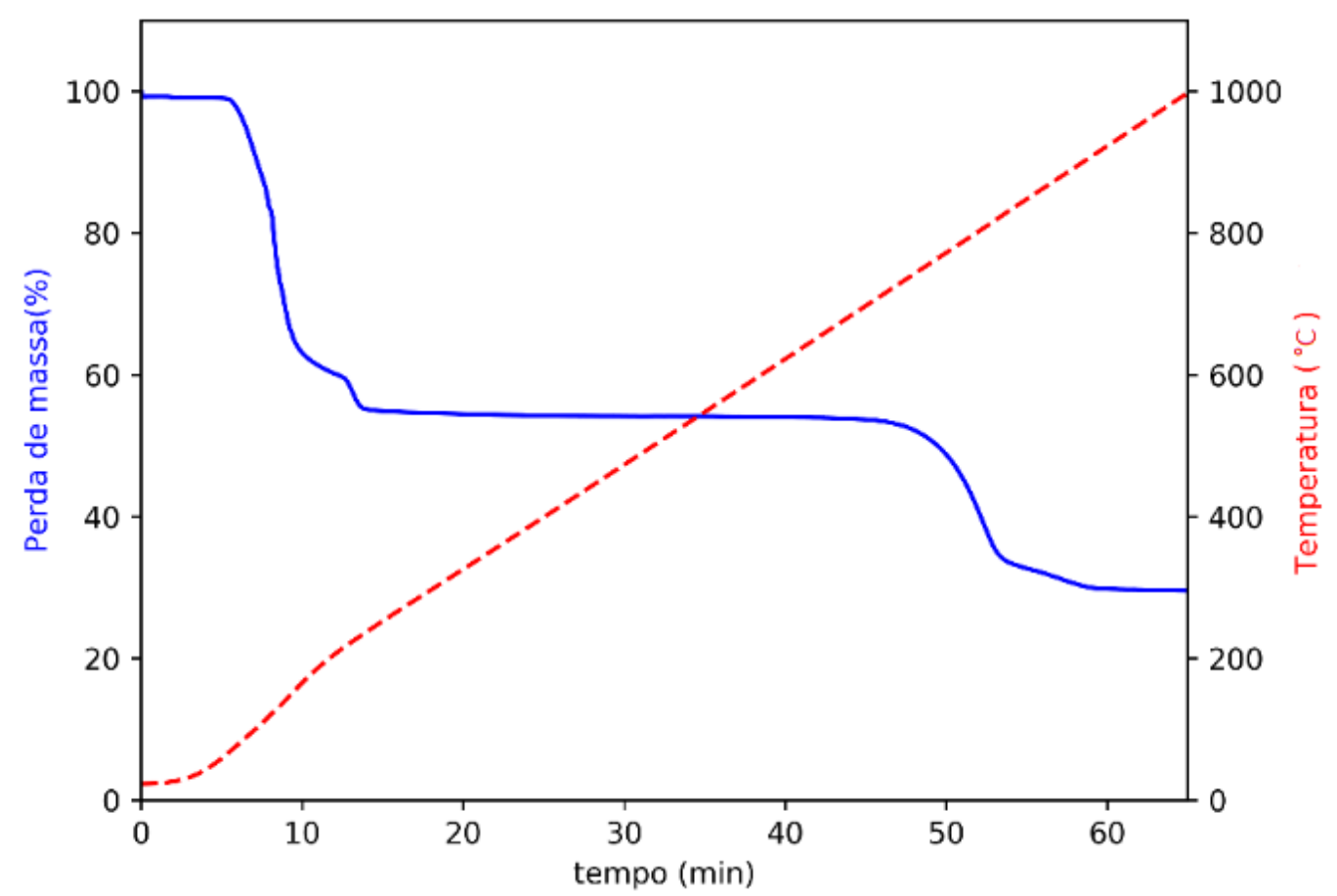

Figura 4.1: Resultado de TG para o alúmen de potássio, a $15 \mathrm{~K} / \mathrm{min}$ (15 ${ }^{\circ} \mathrm{C} / \mathrm{min}$ ) em atmosfera de ar sintético (Amostra T15Ar).

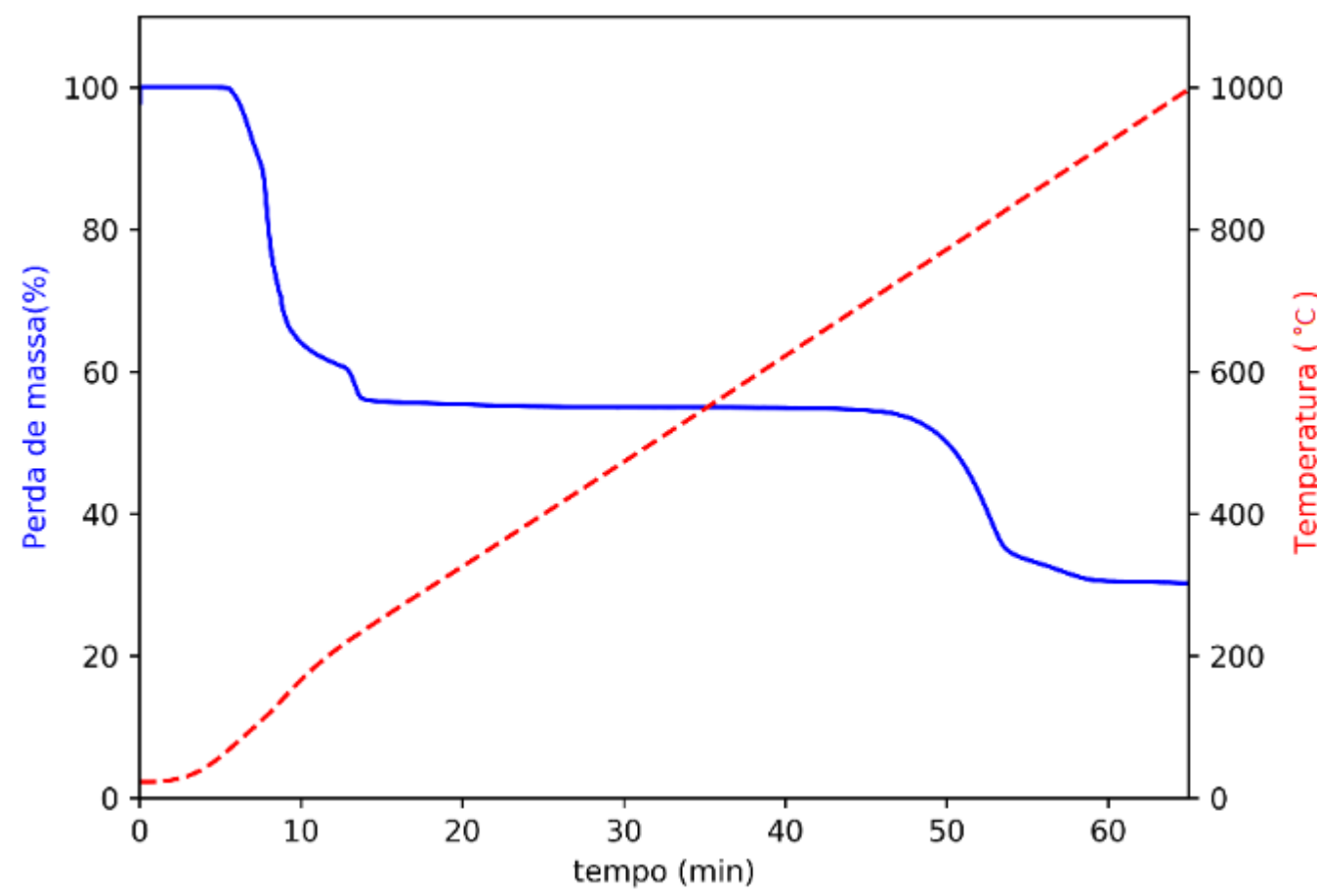

Figura 4.2: Resultado de TG para o alúmen de potássio, a $15 \mathrm{~K} / \mathrm{min}$ (15 ${ }^{\circ} \mathrm{C} / \mathrm{min}$ ) em atmosfera inerte (Amostra T15In).

É fácil notar, pela visualização dos gráficos das Figuras 4-1 e 4-2, que não há diferença real entre a análise em cada uma das duas atmosferas 
de reação escolhidas, confirmado pela Figura 4-3. O que se traduz no fato de que o $\mathrm{O}_{2}$ não interfere no comportamento da decomposição, ou seja, a decomposição do alúmen de potássio não é uma reação oxidativa.

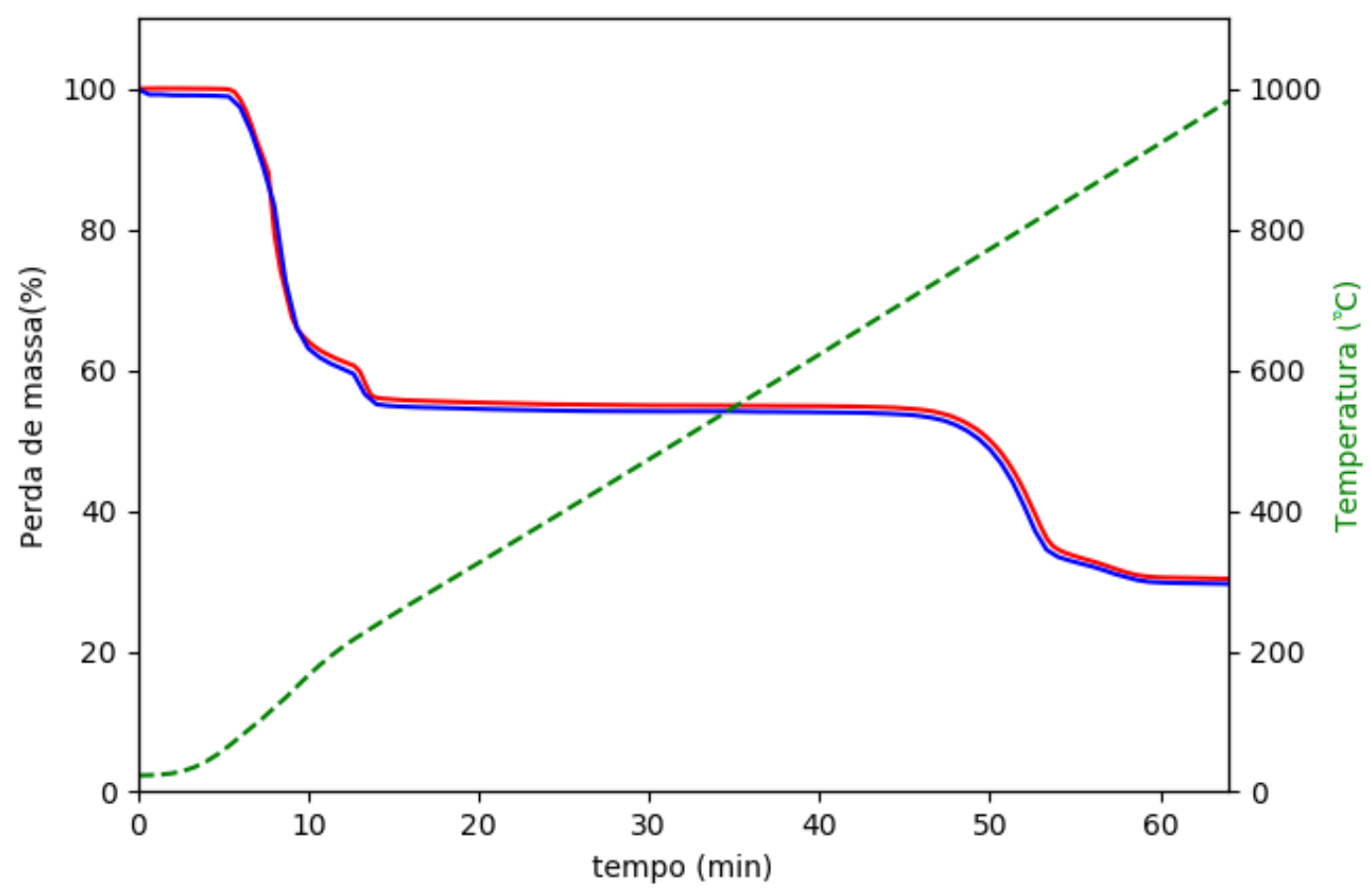

Figura 4.3: Comparação das curvas de TG para o alúmen de potássio, a 15 $\mathrm{K} / \mathrm{min}\left(15^{\circ} \mathrm{C} / \mathrm{min}\right.$ ) em atmosfera inerte e atmosfera de ar sintético (Amostras T15In e T15Ar).

Este resultado é importante, quando considerada a conjuntura industrial, em que o resultado do processo se mostra igual tanto para o gás inerte quanto para o ar (este não exige custos adicionais). Assim, o processo passa a ser economicamente mais viável quando realizado na presença de em ar atmosférico, sem comprometer a sua qualidade.

Além disso, percebe-se a existência de duas regiões separadas de perda de massa nas Figuras 4-1. 4-2 e 4-3. A primeira região está localizada na faixa de tempo entre 0 e 20 minutos, correspondendo à etapa de desidratação, enquanto que a segunda região aparece entre 45 e 60 minutos de análise, correspondendo à decomposição do alúmen de potássio.

Na primeira região, já é possível notar mais de uma mudança de inflexão na curva (que pode denotar a ocorrência de mais de uma reação química), o que corrobora com a proposta de desidratação em múltiplas etapas,como sugerido por Pysiak e Glinka (1981).

Os gráficos das Figuras 4-1 e 4-2 deixam claro que a partir de 850 ${ }^{\circ} \mathrm{C}$, com o alcance da temperatura de decomposição do sulfato de alumínio, os produtos formados são óxido de alumínio e sulfato de potássio, como desejado. Esses resultados são corroborados pelo trabalho de Souza et. al (2018) que, através uma análise de DRX para a reação a $15 \mathrm{~K} / \mathrm{min}$, obteve 
como frações mássicas do produto final da decomposição térmica 31,46 \% de $\mathrm{Al}_{2} \mathrm{O}_{3}$ e $68,54 \%$ de $\mathrm{K}_{2} \mathrm{SO}_{4}$.

Além disso, essas múltiplas etapas estão mais facilmente perceptíveis no gráfico da Figura 4-4, que corresponde à curva de DTG das análises da decomposição térmica do alúmen de potássio a $15 \mathrm{~K} / \mathrm{min}$ tanto em atmosfera inerte (em vermelho) como em atmosfera de ar sintético (curva azul).

Na primeira região, até em torno de $250{ }^{\circ} \mathrm{C}$, é possível identificar dois picos bem definidos de perda de massa, indicando que a reação de desidratação ocorre em pelo menos duas etapas. Os ruídos dessa primeira região do gráfico podem indicar também a perda da água adsorvida como umidade, antes da água estrutural, motivo pelo qual o primeiro pico apresenta uma perda de massa substancialmente maior que o segundo pico.

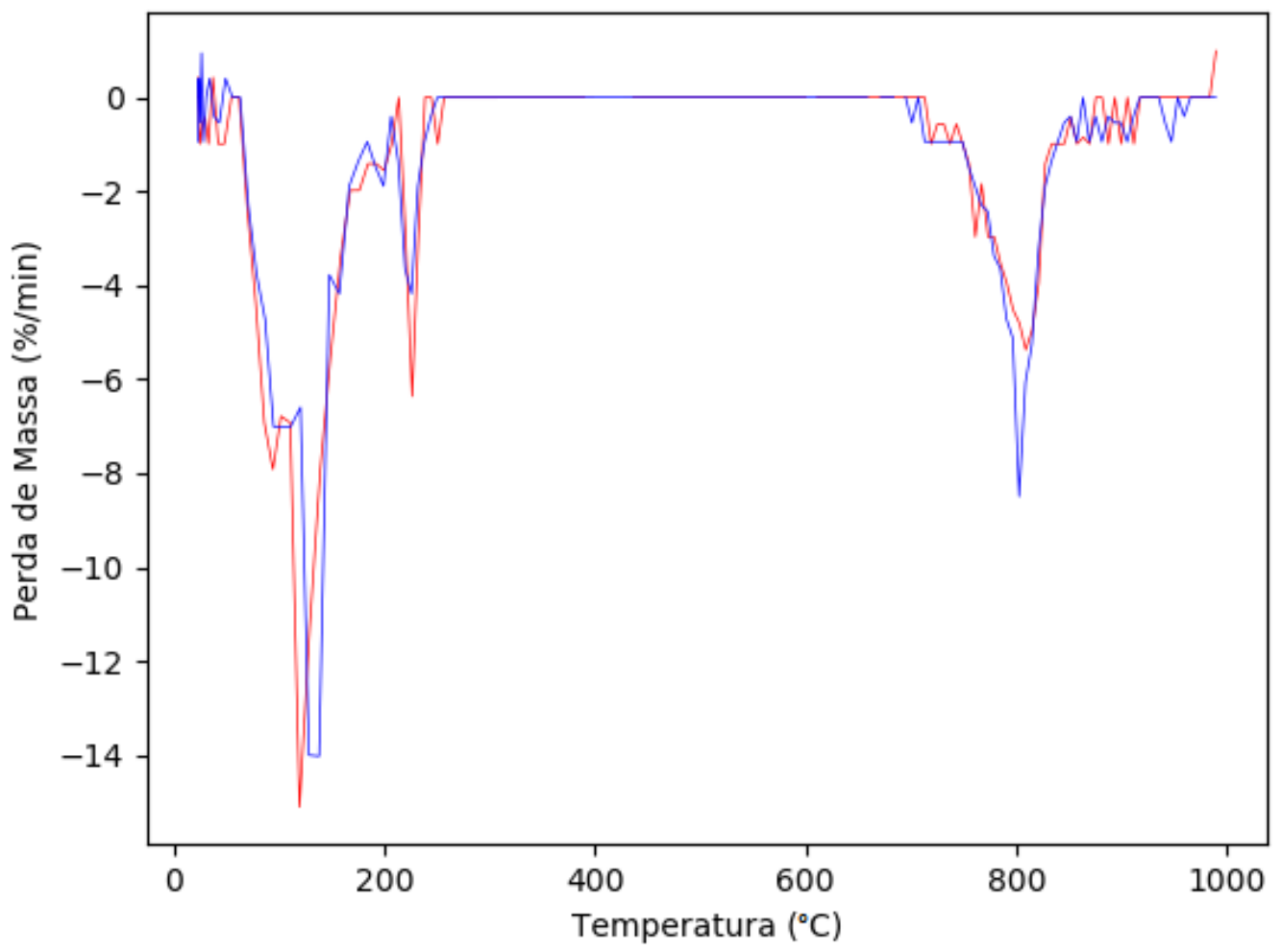

Figura 4.4: Resultado de DTG para o alúmen de potássio, a $15 \mathrm{~K} / \min$ (15 ${ }^{\circ} \mathrm{C} / \mathrm{min}$ ) para ambas atmosferas, inerte e em ar sintético.

Já na segunda região, localizada entre $700{ }^{\circ} \mathrm{C}$ a $850{ }^{\circ} \mathrm{C}$ aproximadamente, o único pico existente pode indicar que a decomposição ocorre em uma única etapa ou, então, pode indicar que as duas etapas de decomposição (para o caso do Modelo 4) ocorrem concomitantemente, o que é corroborado pela temperatura de decomposição do sulfato de alumínio (Figuras 2-7 e 2-8) em torno de $800{ }^{\circ} \mathrm{C}$.

Posteriormente, o resultado da análise TG do alúmen de potássio a $15 \mathrm{~K} / \mathrm{min}\left(15^{\circ} \mathrm{C} / \mathrm{min}\right.$ ) em atmosfera inerte foi comparado com os resultados para análises feitas em atmosfera inerte, para a decomposição térmica do 
alúmen de potássio com em diferentes taxas de aquecimento: 10 e $20 \mathrm{~K} / \mathrm{min}$ (Amostras T10ln e T20ln).

As Figuras 4-5 e 4-6 ilustram essas análises respectivamente.

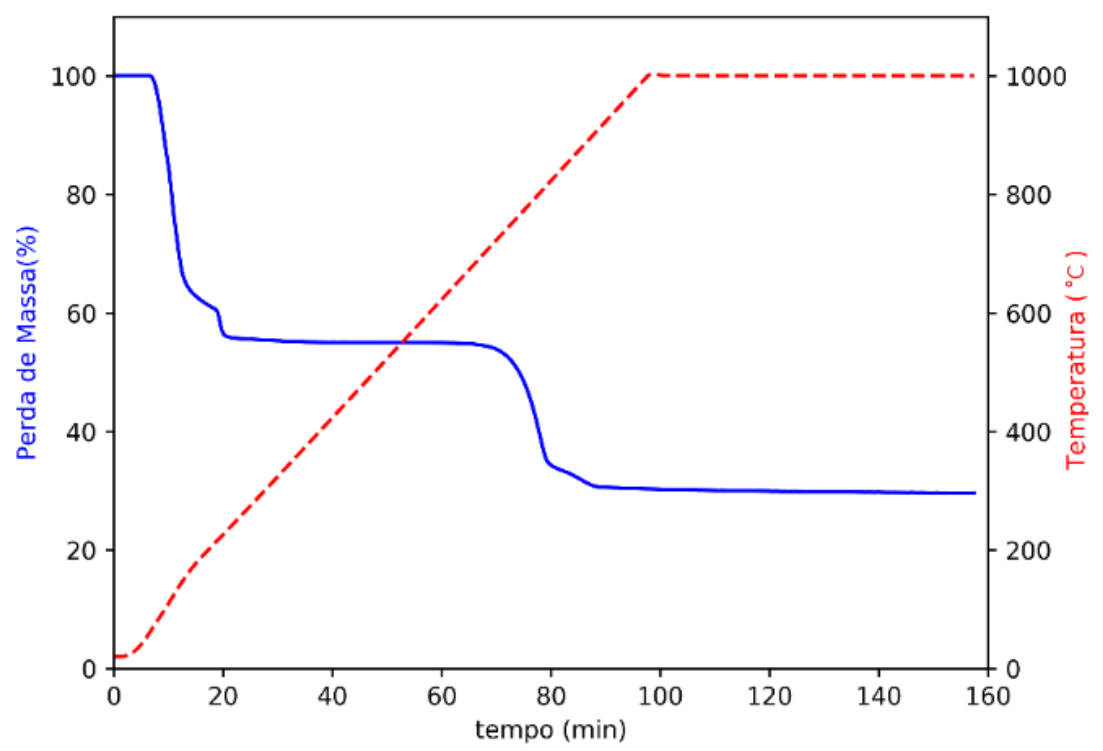

Figura 4.5: Resultado de TG para o alúmen de potássio, a $10 \mathrm{~K} / \mathrm{min}$ (10

${ }^{\circ} \mathrm{C} / \mathrm{min}$ ), em atmosfera inerte (Amostra T10In).

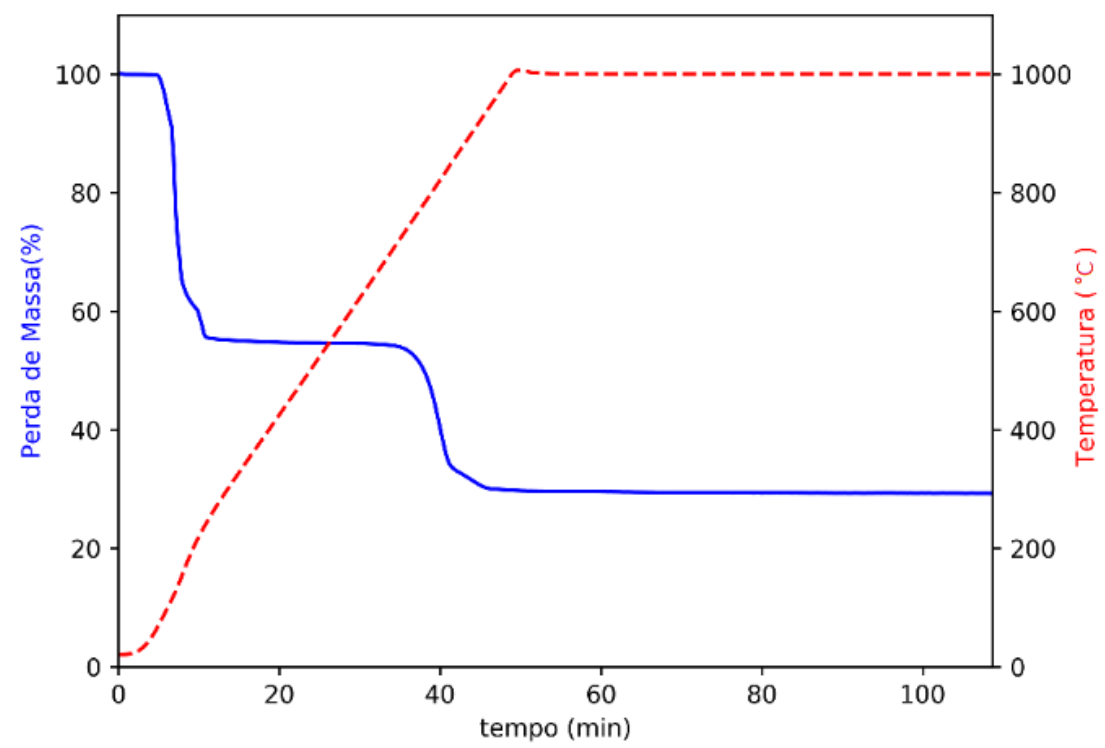

Figura 4.6: Resultado de TG para o alúmen de potássio, a $20 \mathrm{~K} / \min (20$ ${ }^{\circ} \mathrm{C} / \mathrm{min}$ ), em atmosfera inerte (Amostra T20In)

Comparando as duas curvas, já se percebe em uma primeira interpretação que a reação a $20 \mathrm{~K} / \mathrm{min}$ se processa em menor tempo. Apesar das reações ocorrerem na mesma temperatura, com a taxa de aquecimento maior (o dobro no caso), elas acontecem em menor tempo, como é possível perceber com maior clareza na Figura 4-7. 


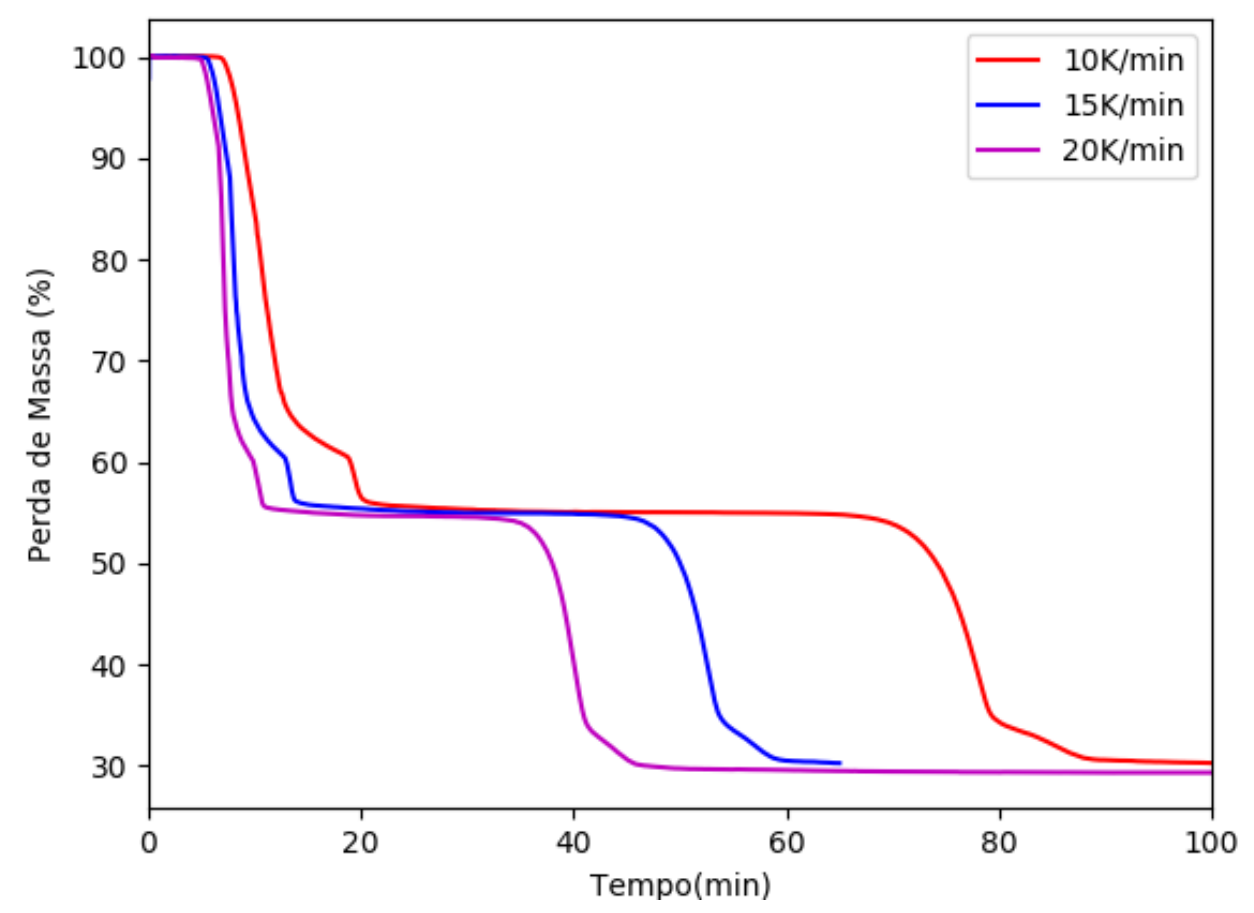

Figura 4.7: Curvas de TG para o alúmen de potássio em atmosfera inerte, para as taxas de aquecimento de 10, 15 e $20 \mathrm{~K} / \mathrm{min}$ (Amostras T10ln, T15ln e T20ln)

Percebe-se que, além do tempo de reação diminuir, as curvas para menores taxas de aquecimento se mostram mais definidas. Na curva com aquecimento de $10 \mathrm{~K} / \mathrm{min}$, a etapa de desidratação intermediária, em torno de 20 minutos, aparece mais abruptamente nos resultados de perda de massa, enquanto que, para aquecimentos em taxas maiores, esta curva se torna mais sutil. Esse cenário ocorre pelo maior tempo gasto por grau acrescido de temperatura quando se tem a taxa de aquecimento de 10 $\mathrm{K} / \mathrm{min}$, tornando a perda de massa mais sensível durante a análise. Ao contrário do aquecimento a $20 \mathrm{~K} / \mathrm{min}$, em que, com menor tempo de análise, a curva apresenta apenas um escopo geral.

Além disso, tem-se que, como as curvas estabilizam em $1000{ }^{\circ} \mathrm{C}$, pode-se dizer que elas atingem um equilíbrio, e, portanto, podem gerar o mesmo produto. $\mathrm{O}$ que pode ser confirmado pela termodinâmica, demostrada pelo gráfico da Figura 2-8.

Na Tabela 4-1, é possível ver a comparação entre as perdas de massa finais consequentes da decomposição térmica do alúmen de potássio, para as três taxas de aquecimento, de 10, 15 e $20 \mathrm{~K} / \mathrm{min}$. 
Tabela 4.1: Comparação entre as perdas de massa finais (\%) da decomposição térmica do alúmen de potássio para as três taxas de aquecimento

\begin{tabular}{cc|}
\hline Taxa de Aquecimento $(\mathrm{K} / \mathrm{min})$ & Perda de massa final $(\%)$ \\
\hline 10 & 30,324 \\
\hline 15 & 30,262 \\
\hline 20 & 29,304 \\
\hline
\end{tabular}

A Tabela 4-1 indica que as massas finais das três taxas de aquecimento não variam muito entre si, e são independente do tempo de reação.

\subsection{2}

\section{Queima do Coque Breeze}

Para o coque breeze, com o objetivo de acrescentar o carbono fixo na reação em quantidade estequiométrica, foram feitas análises de TG sem a presença do alúmen de potássio (Tabela 3.3). Com o resultado dessas análises, pôde-se calcular a quantidade de voláteis e cinzas presentes no coque breeze.

Inicialmente, para o TG da amostra C15In em atmosfera inerte, que corresponde ao aquecimento do coque breeze, diz-se que a perda de massa está relacionada apenas com a saída de voláteis, principalmente água, adsorvida em forma de umidade. Pela Figura 4-8, é possível observar que o valor de perda de massa no processo se traduz em 19,71\% de voláteis.

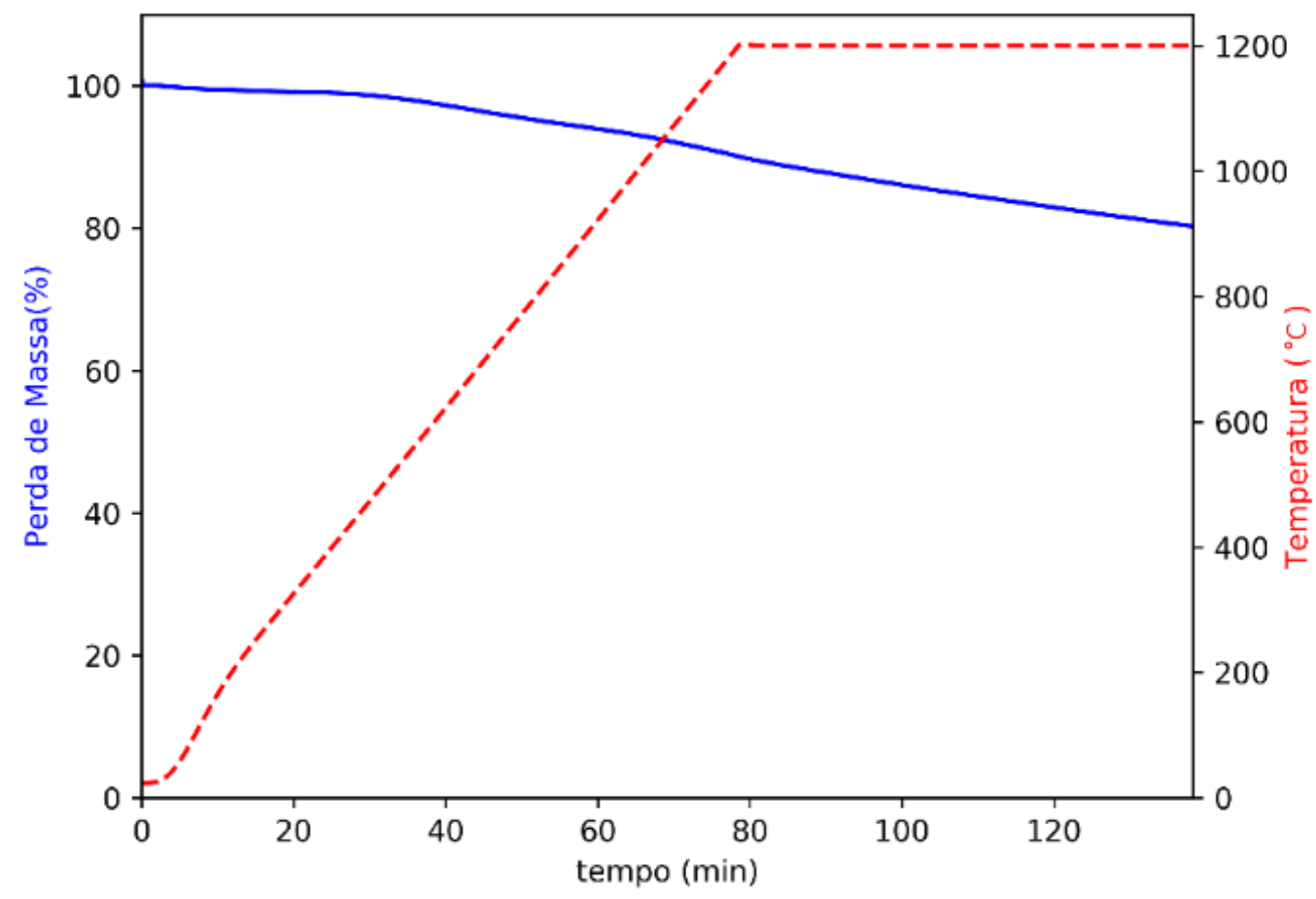

Figura 4.8: Resultado de TG para o coque breeze, a $15 \mathrm{~K} / \mathrm{min}\left(15^{\circ} \mathrm{C} / \mathrm{min}\right)$, em atmosfera inerte 
O TG em atmosfera de ar sintético (referente à amostra C15Ar) está apresentado na Figura 4-9.

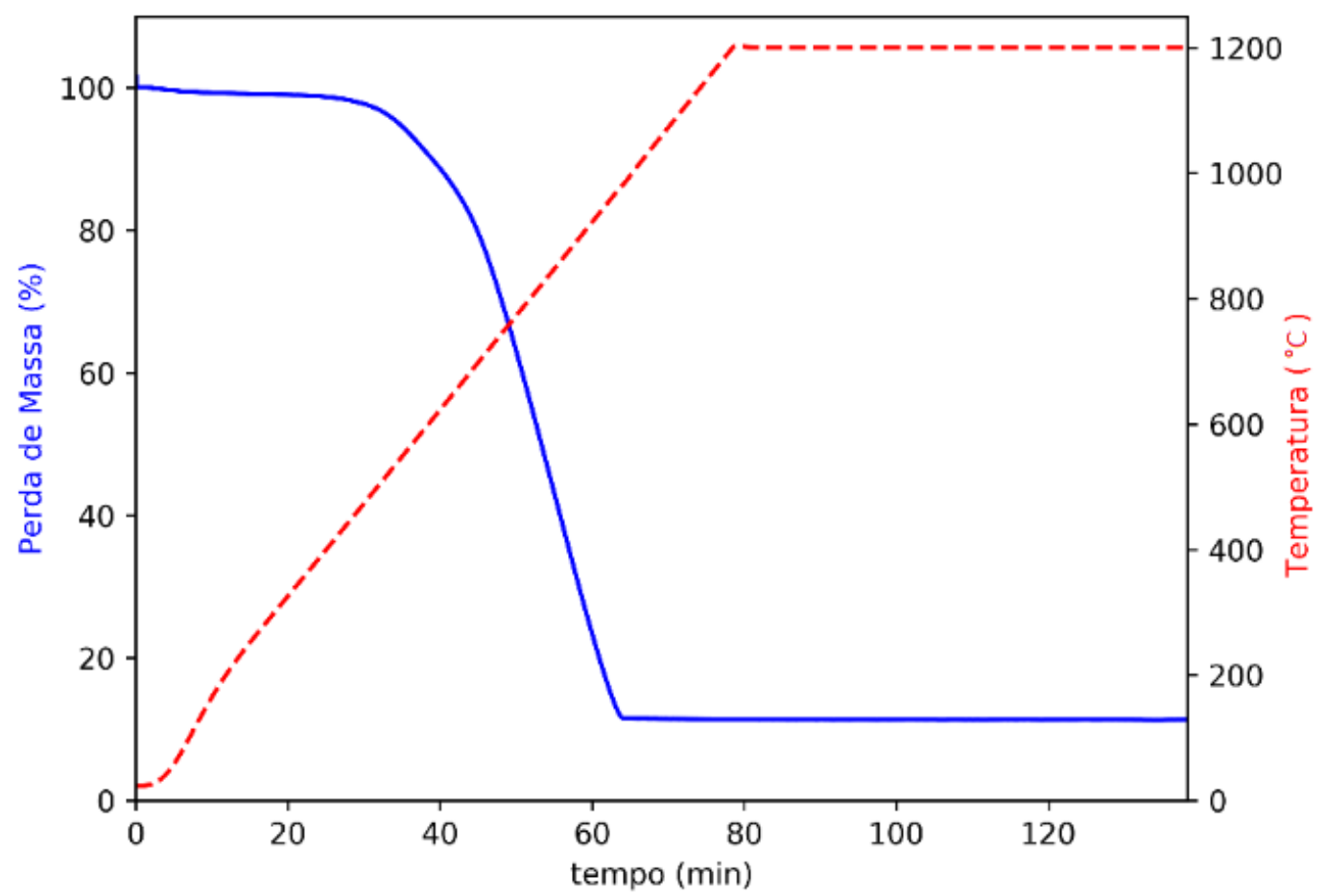

Figura 4.9: Resultado de TG para o coque breeze, a $15 \mathrm{~K} / \mathrm{min}\left(15^{\circ} \mathrm{C} / \mathrm{min}\right)$, em atmosfera de ar sintético (C15Ar)

Pela análise da Figura 4-9, pode-se dizer que a presença de gás $\mathrm{O}_{2}$ leva à queima do carbono, resultando em uma perda de massa de aproximadamente $88,69 \%$. Os $11,31 \%$ de massa restantes do processo possivelmente consiste de cinzas apenas.

Logo, a quantidade de carbono fixo a ser empregada nos testes de decomposição redutora do alúmen de potássio pode ser expressa pela seguinte relação:

$$
\% \text { Carbonofixo }=\text { Coque breeze }-\% \text { cinzas }-\% \text { voláteis }
$$

\subsection{3}

\section{Decomposição Redutora}

Com relação aos testes de decomposição redutora, inicialmente também foi feita a comparação das atmosferas de reação (R15Ar e R15In). E, como pode-se observar nas Figuras 4-10 e 4-11, conclui-se que a atmosfera também não interfere no processo de decomposição redutora do alúmen de potássio na presença do coque breeze. 


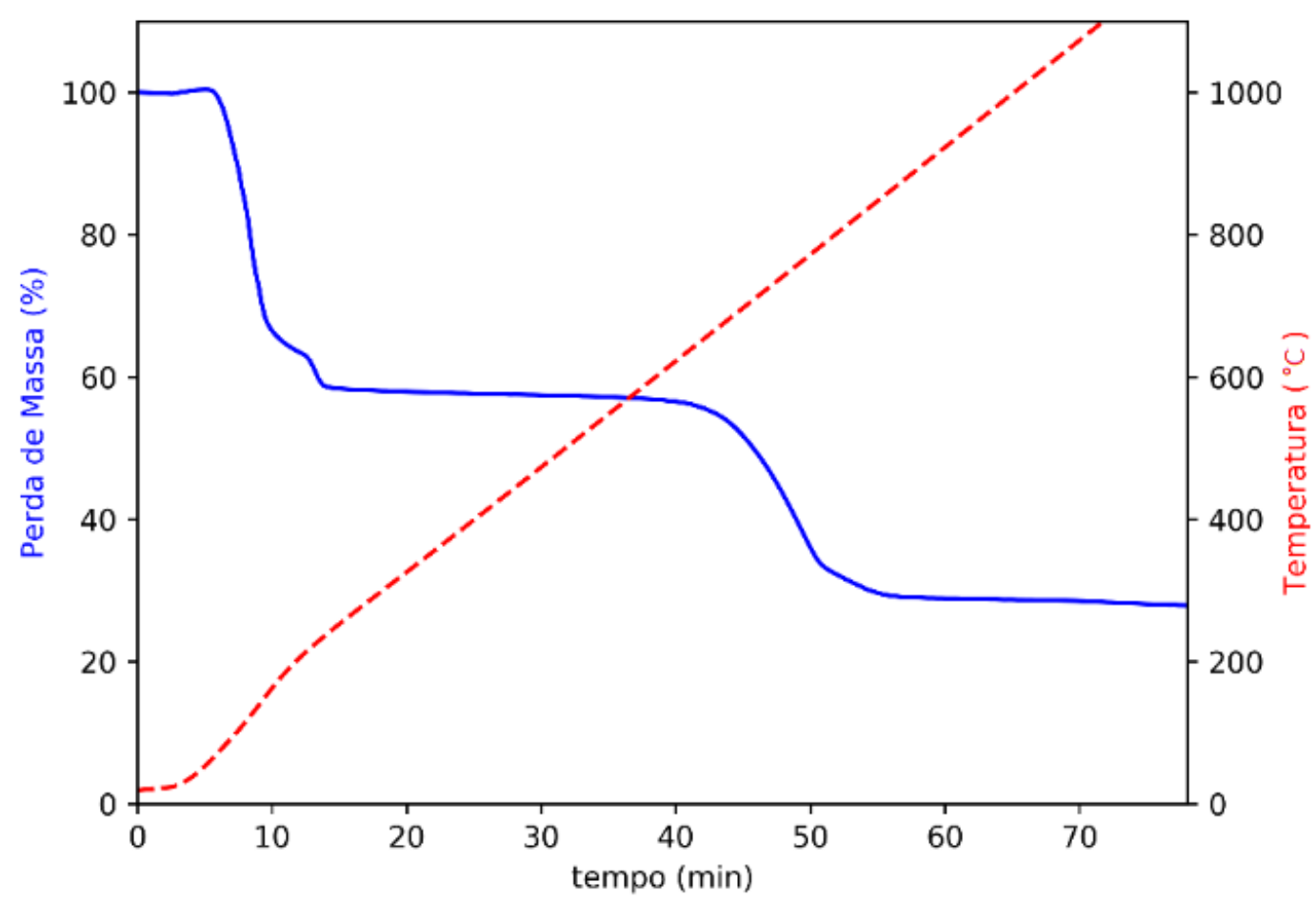

Figura 4.10: Resultado de TG para o alúmen de potássio com o coque Ũ breeze, a $15 \mathrm{~K} / \mathrm{min}\left(15^{\circ} \mathrm{C} / \mathrm{min}\right)$, em atmosfera de ar sintético (R15Ar)

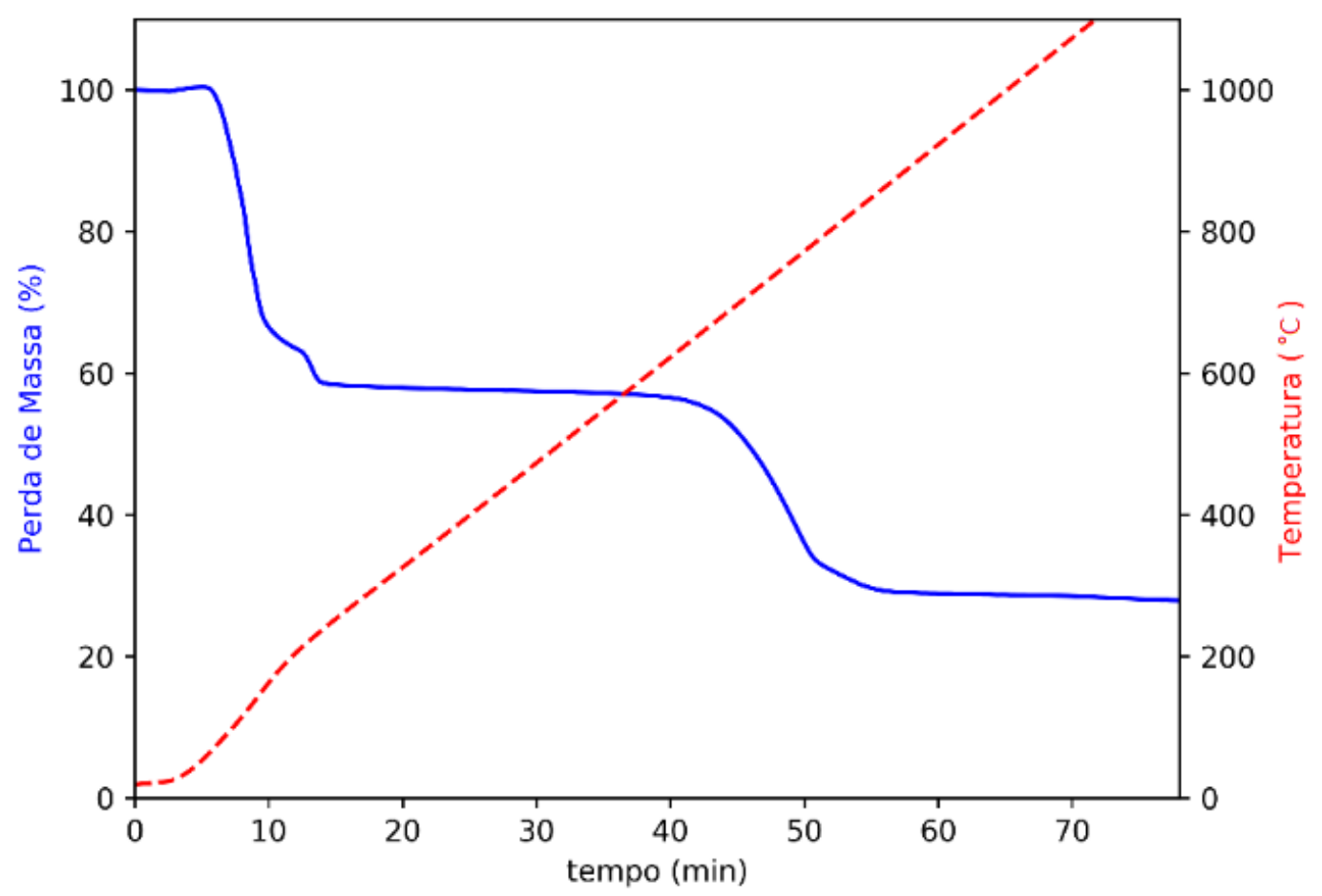

Figura 4.11: Resultado de TG para o alúmen de potássio com o coque breeze, a $15 \mathrm{~K} / \mathrm{min}\left(15^{\circ} \mathrm{C} / \mathrm{min}\right)$, em atmosfera inerte (R15In) 
Uma possível explicação do porquê das análises nas duas atmosferas terem resultados semelhantes (Figura 4-12), apesar da clara interação existente entre o carbono e o oxigênio, como observado na Figura 4-9, pode estar relacionada com uma possível interação do coque breeze inicial com o alúmen, de forma que este último iniba a queima do coque quando eles estão em mistura, de forma que a queima independente do coque não influencia na decomposição redutora.

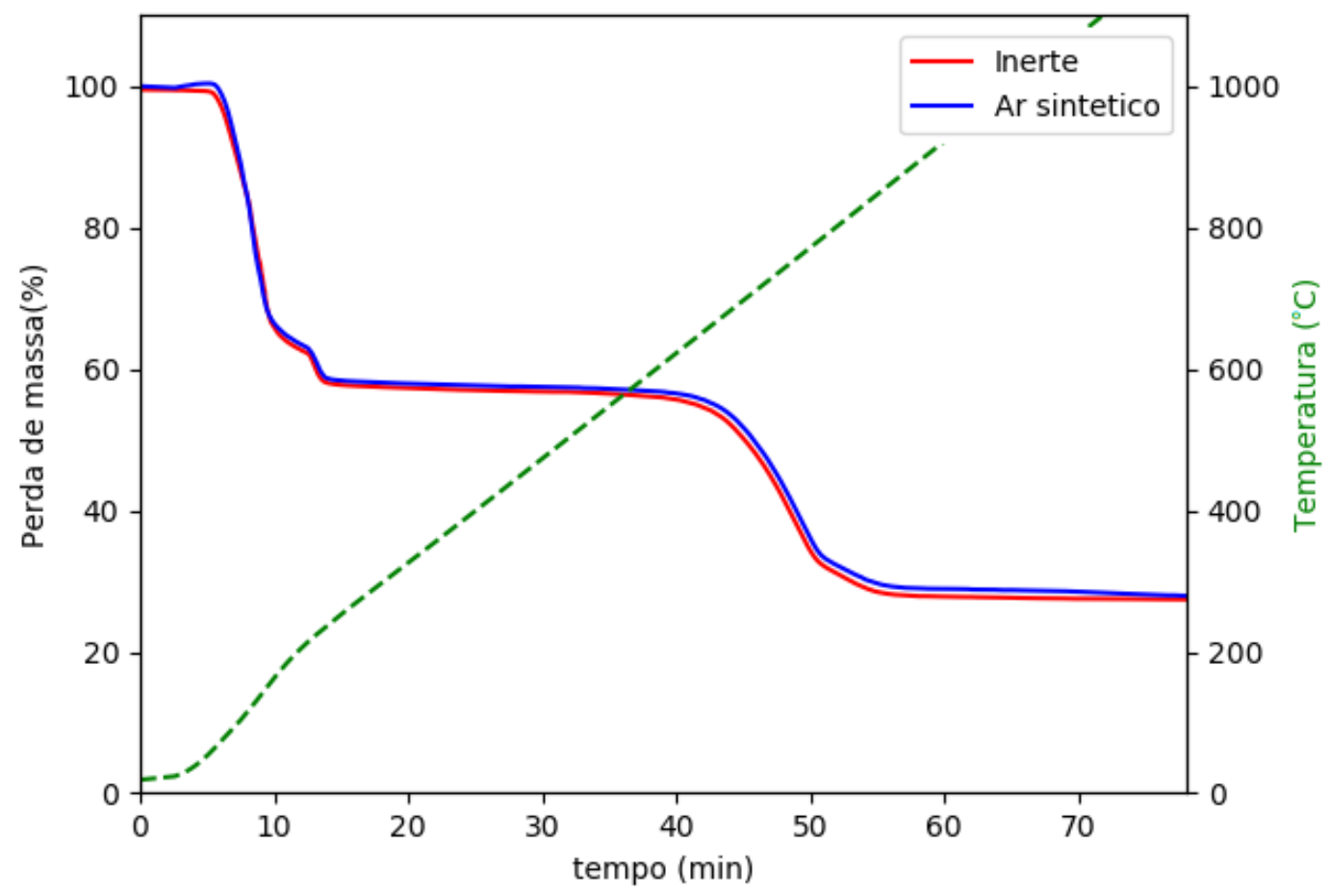

Figura 4.12: Comparação das curvas de TG para o alúmen de potássio com o coque breeze, a $15 \mathrm{~K} / \mathrm{min}\left(15^{\circ} \mathrm{C} / \mathrm{min}\right)$, em atmosfera inerte e atmosfera de ar sintético (Amostras R15In e R15Ar).

Subsequentemente foram feitas as análises em atmosfera inerte para a decomposição térmica do alúmen de potássio na presença de agente redutor para as demais taxas de aquecimento: $10 \mathrm{~K} / \mathrm{min}$ e $20 \mathrm{~K} / \mathrm{min}$ (R10ln e R20In).

Para a taxa de aquecimento de $10 \mathrm{~K} / \mathrm{min}$, apresentada na Figura 4-13, pode-se notar novamente, de forma semelhante à Figura 4-5, que as reações levam mais tempo para transcorrer quando comparadas às reações com maiores taxas de aquecimento, de forma que as curvas e inflexões se tornam mais visíveis a $10 \mathrm{~K} / \mathrm{min}$. Particularmente no que diz respeito à região da decomposição, localizada entre 50 e 100 min, nota-se uma curva adicional, que não apareceu em outros resultados de decomposição redutora. Essa curva adicional pode ser resultado da velocidade mais reduzida de aquecimento e, consequentemente de reação, que pode ter ocasionado a separação da etapa de decomposição do alúmen de potássio (Equação 2-8) e da etapa de decomposição sulfato 
de alumínio (Equação 2-9), formado pela decomposição do alúmen de potássio, em duas curvas distintas.

Para a análise de $20 \mathrm{~K} / \mathrm{min}$ apresentada na Figura 4-14, pela rapidez com que se passa o processo, as curvas ficam mais sutis. Nesta taxa de aquecimento, somente uma curva de decaimento de massa na região da decomposição do alúmen de potássio pode ser vista, sendo esse comportamento mais próximo do obtido com a taxa de aquecimento de $15 \mathrm{~K} / \mathrm{min}$. Além disso, a análise de $20 \mathrm{~K} / \mathrm{min}$ alcançou uma perda de massa ao final mais próxima daperda de massa alcançada com a análise térmica processada a $15 \mathrm{~K} / \mathrm{min}$.

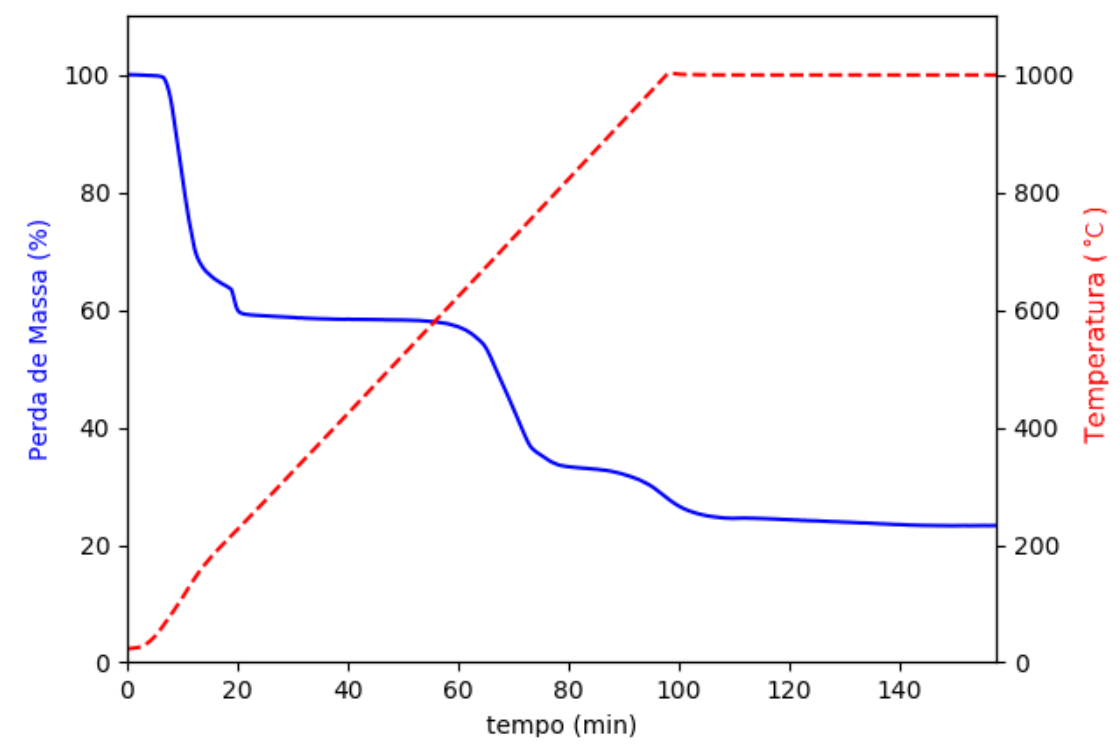

Figura 4.13: Resultado de TG para o alúmen de potássio com o coque breeze, a $10 \mathrm{~K} / \mathrm{min}\left(10^{\circ} \mathrm{C} / \mathrm{min}\right)$, em atmosfera inerte(R10ln). 


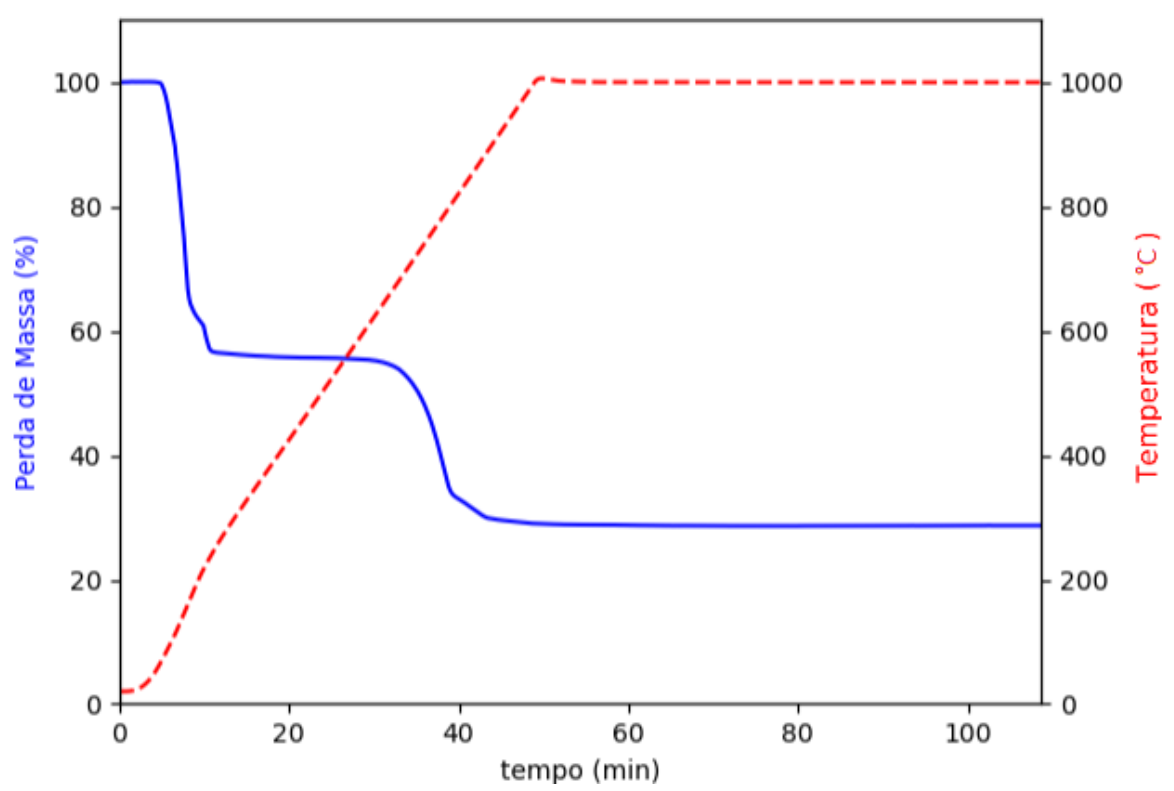

Figura 4.14: Resultado de TG para o alúmen de potássio com o coque breeze, a $20 \mathrm{~K} / \mathrm{min}\left(20^{\circ} \mathrm{C} / \mathrm{min}\right)$, em atmosfera inerte (R20ln).

Desse modo, a Figura 4-15 apresenta a comparação para a decomposição térmica na presença de agente redutor para as três taxas de aquecimento empregadas no presente trabalho. Semelhante à Figura 4-7, nota-se que as curvas são mais bem definidas quanto menor for a taxa de aquecimento aplicada.

Além disso, observando a Figura 4-15, nota-se com maior clareza uma perda de massa ligeiramente maior na decomposição do alúmen de potássio conduzida com a taxa de $10 \mathrm{~K} / \mathrm{min}$. Uma explicação que pode ser dada, inclusive ligada à curva adicional que se apresenta na etapa de decomposição do alúmen de potássio para esta taxa de aquecimento, é que pode se tratar de uma reação em que há formação de gás, e consequentemente maior perda de massa. A Tabela 4-2 demonstra essa diferença de massa final. 


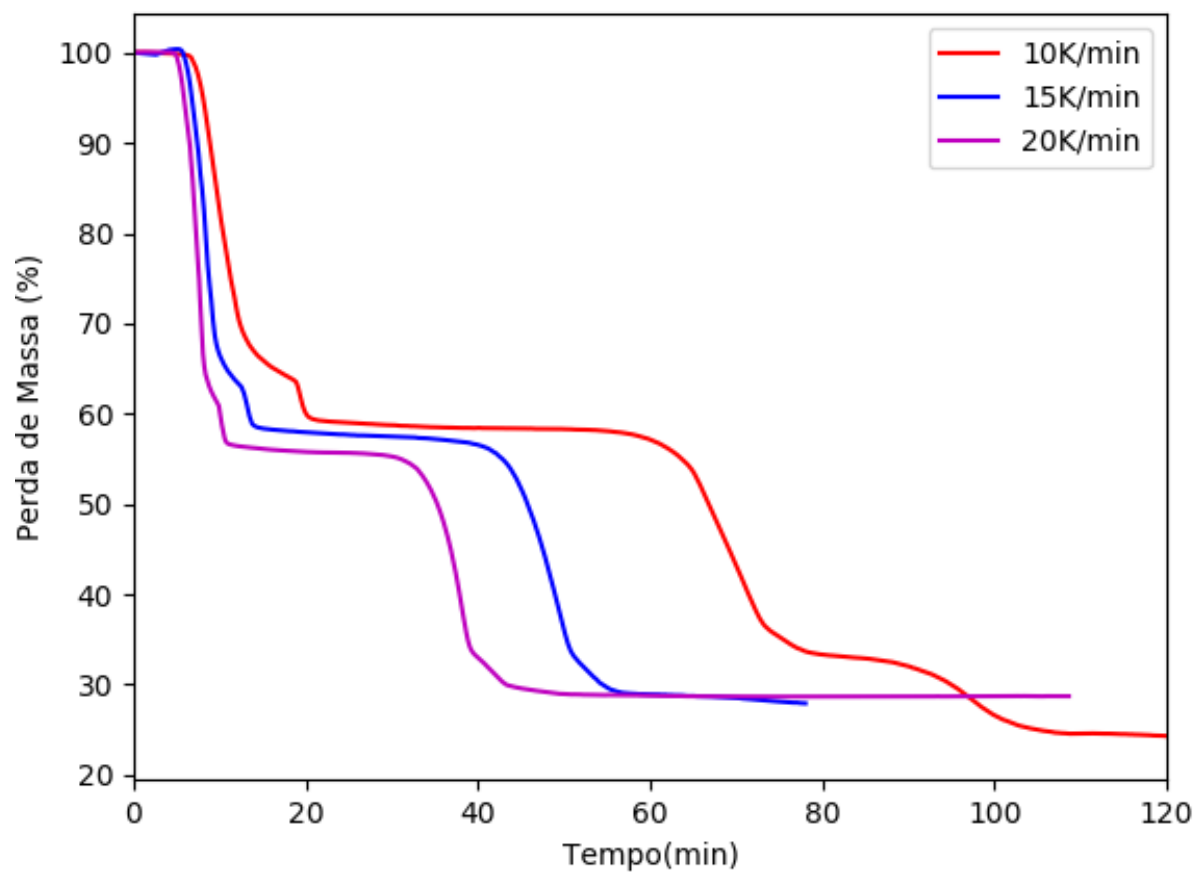

Figura 4.15: Curvas de TG para o alúmen de potássio em presença de agente redutor em atmosfera inerte para as taxas de aquecimento de 10, 15 e $20 \mathrm{~K} / \mathrm{min}$.

Tabela 4.2: Comparação entre as perdas de massa finais (\%) da decomposição redutora do alúmen de potássio para as três taxas de aquecimento

\begin{tabular}{c|c|}
\hline Taxa de Aquecimento $(\mathrm{K} / \mathrm{min})$ & massa final $(\%)$ \\
\hline 10 & 23,301 \\
\hline 15 & 27,909 \\
\hline 20 & 28,697 \\
\hline
\end{tabular}

Pela Tabela 4-2, vê-se a diferença entre as perdas de massa finais, que para a taxa de $10 \mathrm{~K} / \mathrm{min}$ chega a $5 \%$. Contudo, testes de caracterização de DR-X do material final devem ser conduzidos a fim de caracterizar a composição do mesmo e compreender melhor como esse composto foi formado e, possivelmente, que gases foram liberados nessa ou nessas reações.

Para a comparação entre a decomposição térmica e redutora, o gráfico da Figura 4-16 foi gerado. 


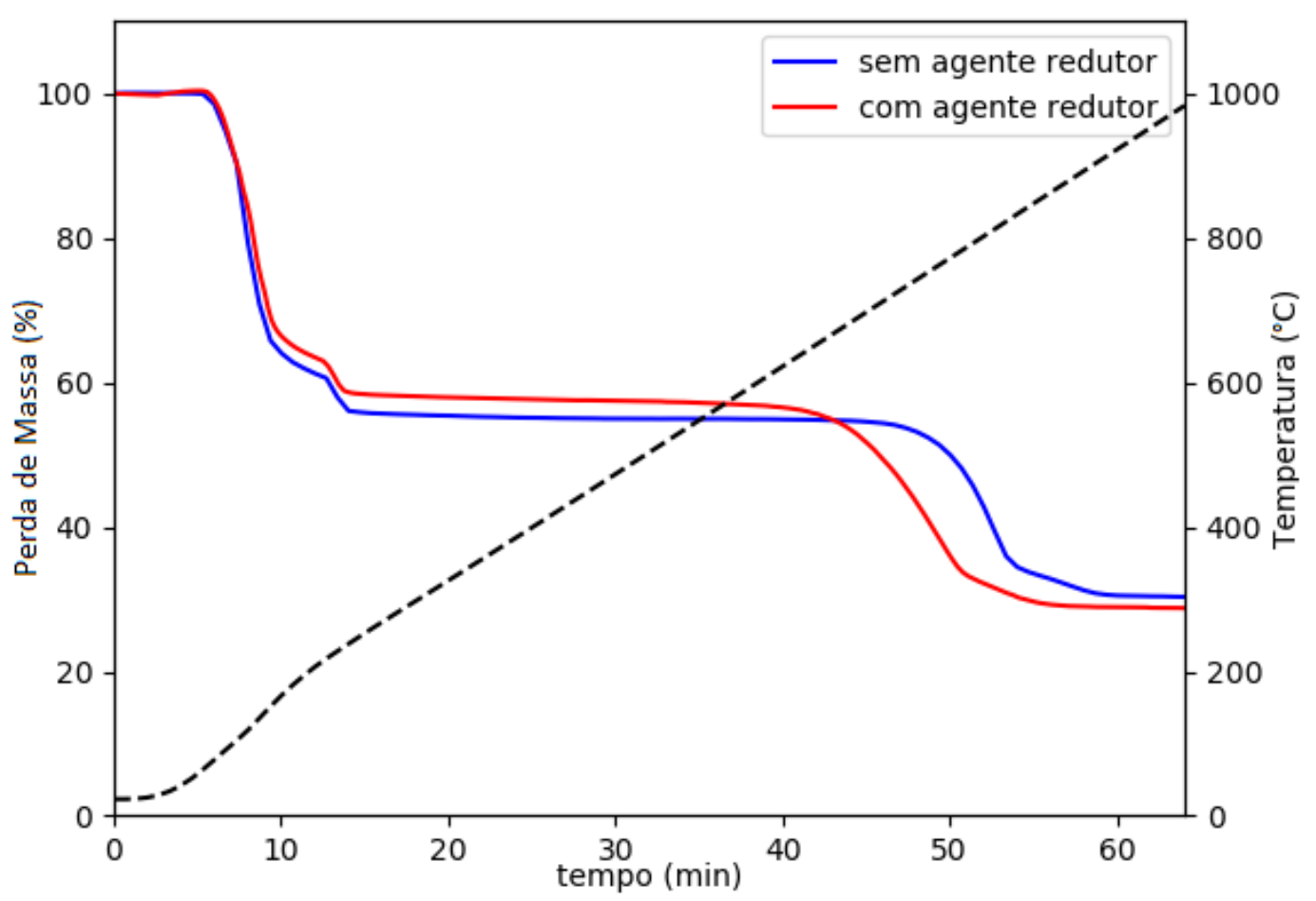

Figura 4.16: Resultado de TG para as decomposições do alúmen de potássio com e sem a presença de agente redutor, a $15 \mathrm{~K} / \mathrm{min}\left(15^{\circ} \mathrm{C} / \mathrm{min}\right)$, em atmosfera inerte (Amostras T15ln e R15ln).

Para mais fácil visualização e interpretação, o gráfico das decomposições do alúmen de potássio com e sem a presença de agente redutor (amostras T15In e R15In) é disposto em perda de massa (\%) por temperatura $\left({ }^{\circ} \mathrm{C}\right)$ na Figura 4-17. É possível observar com maior clareza que a presença do agente redutor diminui de fato a temperatura de reação da decomposição do alúmen de potássio. Analisando o gráfico das amostras C15In e C15Ar (Figuras 4-8 e 4-9, respectivamente), percebe-se que o coque consistentemente começa a queimar (ou perder massa) em torno de $40 \mathrm{~min}$. Este dado se assemelha ao visto pelo gráfico da Figura 4-16 e, com relação à temperatura na Figura 4-17, em que aos 40 min e $700{ }^{\circ} \mathrm{C}$ respectivamente (aproximadamente), as curvas representam o começo da decomposição na presença do agente redutor. 


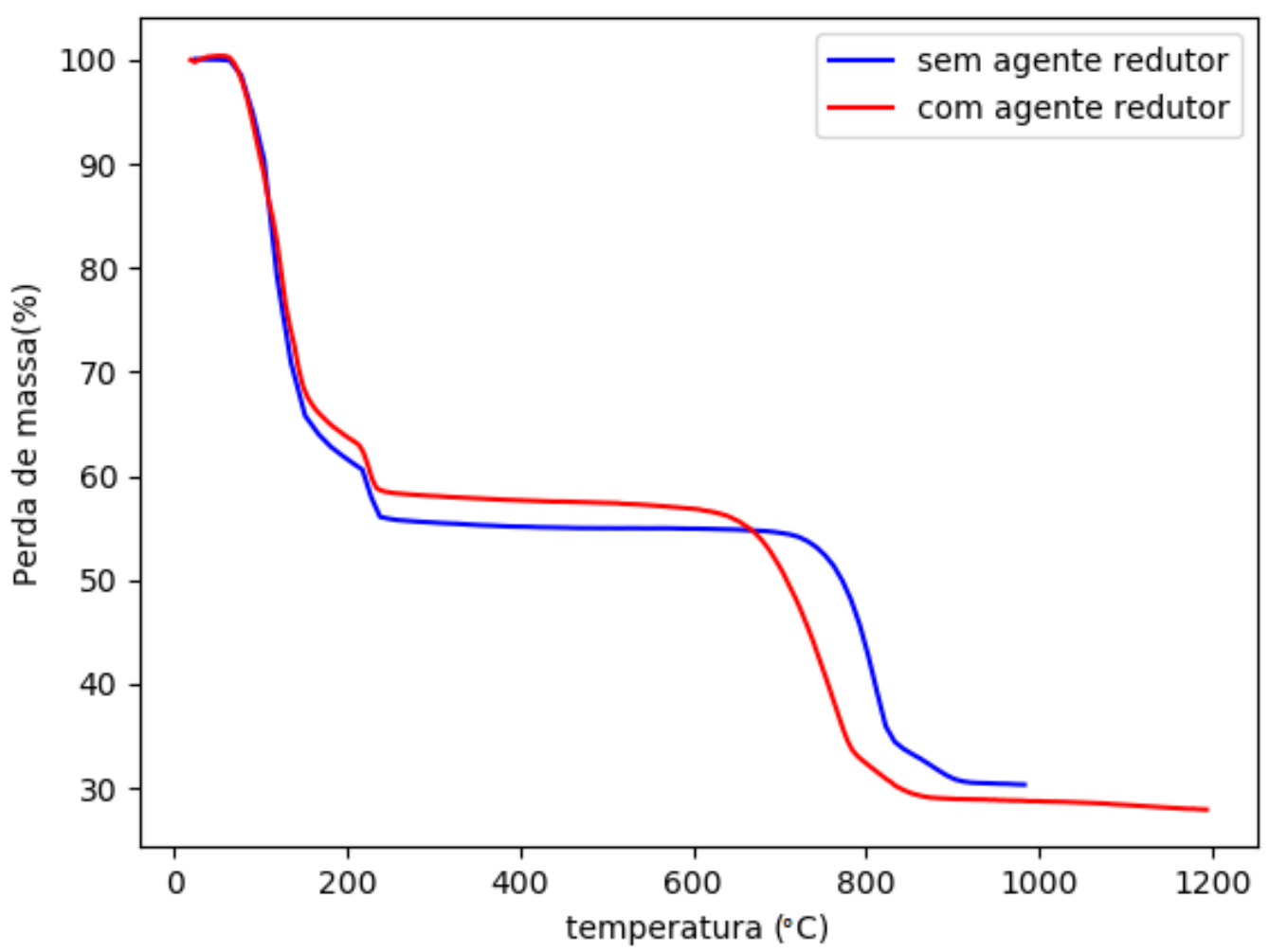

Figura 4.17: Decomposições do alúmen de potássio com e sem a presença de agente redutor pela temperatura (Amostras T15In e R15In).

Essa informação é ainda mais acentuada no gráfico do DTG, Figura 4-18, em que os picos de perda de massa para as decomposições com e sem o agente redutor aparecem deslocados; com a reação com agente redutor sendo efetuada em menores temperaturas.

Pode-se observar também, pela análise das Figuras 4-16 e 4-18 que a região de desidratação não é alterada com a presença do agente redutor, as diferenças de perda de massa computadas podem ser devidas à umidade inicial da amostra, porém para ambos os sistemas (com e sem agente redutor) a etapa de desidratação ocorre nas mesmas temperaturas. Além disso, pela observação da Figura 4-18, nota-se com nitidez a existência de dois picos na região de desidratação para ambas as análises, corroborando mais uma vez que a desidratação não ocorre em uma única etapa, mas em possivelmente duas como foi relatado anteriormente para a decomposição térmica do alúmen. 


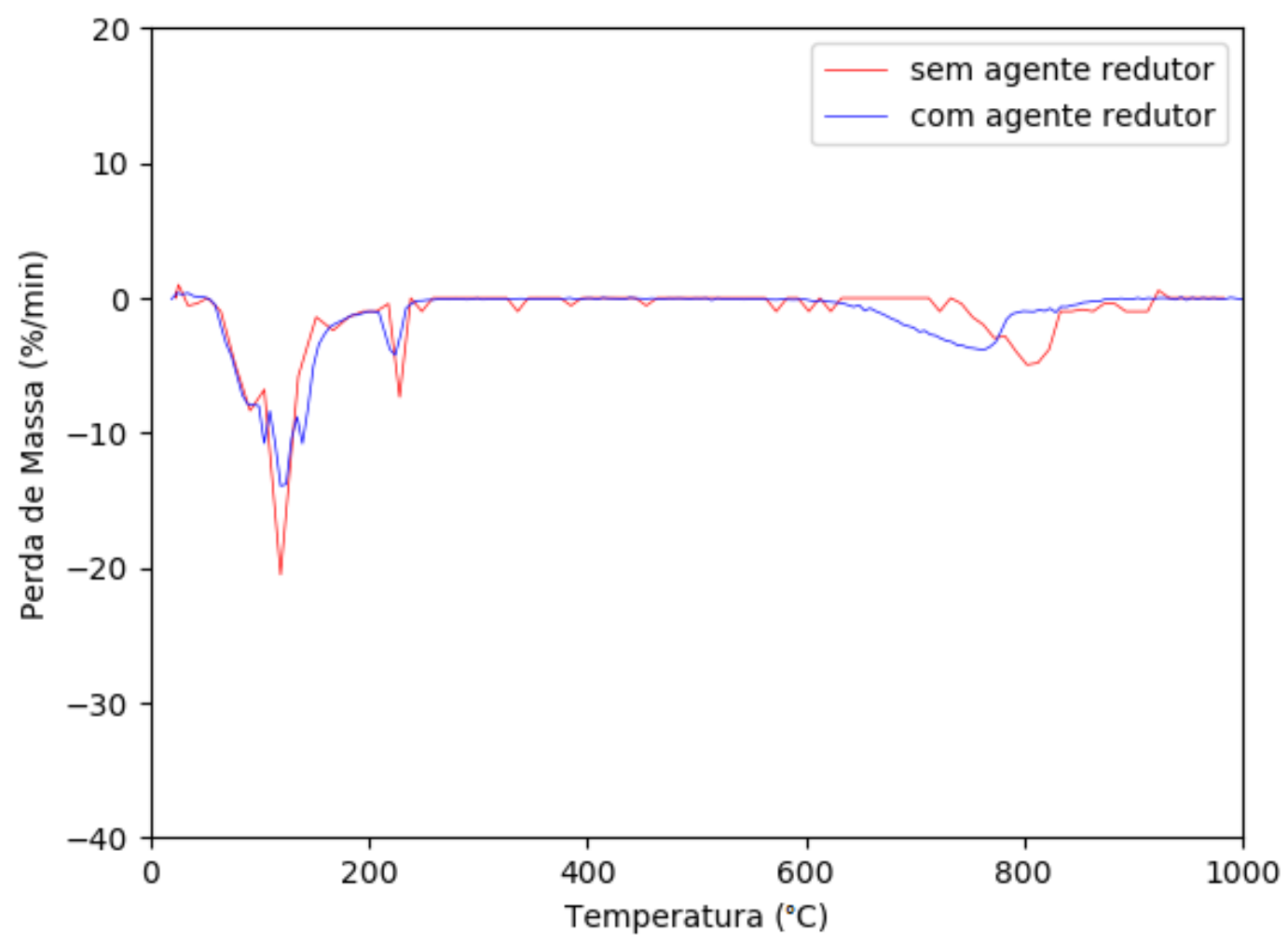

Figura 4.18: Resultado de DTG para as decomposições do alúmen de potássio com e sem a presença de agente redutor, a $15 \mathrm{~K} / \mathrm{min}\left(15^{\circ} \mathrm{C} / \mathrm{min}\right)$, em atmosfera inerte (Amostras T15In e R15In).

\section{2}

\section{Resultados das simulações dos modelos}

Os Modelos 1 a 4 foram implementados utilizando os balanços molares demonstrados no capítulo de Metodologia desta dissertação. Cada modelo foi simulado diversas vezes de modo obter as predições mais próximas possíveis dos dados experimentais de TG. Os valores dos parâmetros cinéticos foram variados por meio de tentativa e erro até que os valores mais adequados para cada modelo pudessem ser selecionados. Todos os modelos de decomposição térmica foram implementados considerando que as etapas são descritas por reações de primeira ordem.

Primeiramente, foi implementado o Modelo 1 de reação em uma etapa. Como pode ser visto no gráfico da Figura 4-19, o modelo em uma única etapa falha em predizer as duas regiões de perda de massa presentes na curva TG, apesar de alcançar um resultado final de perda de massa semelhante aos dados experimentais. Esse resultado já era esperado tendo em vista que o Modelo 1 é bem simplificado e não teria como representar mais de uma curva de perda de massa, pois só possui uma única reação. 


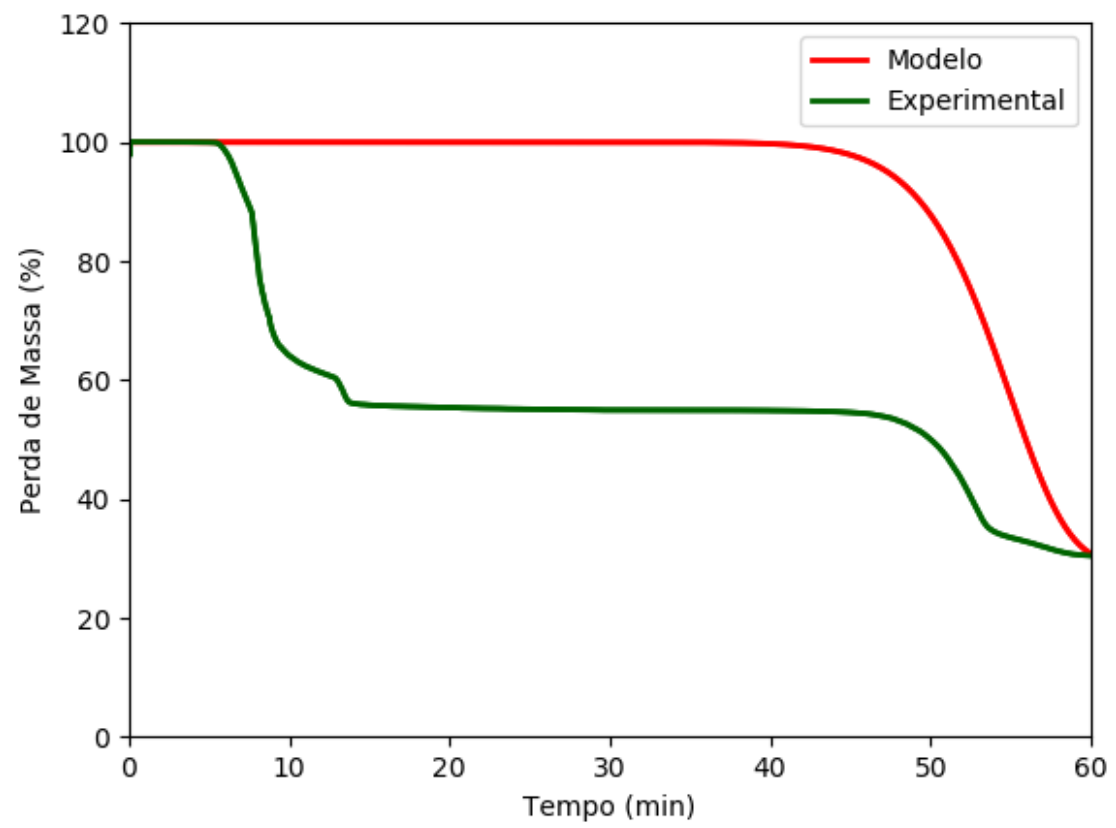

Figura 4.19: Comparação dos dados experimentais com o Modelo 1 de uma etapa.

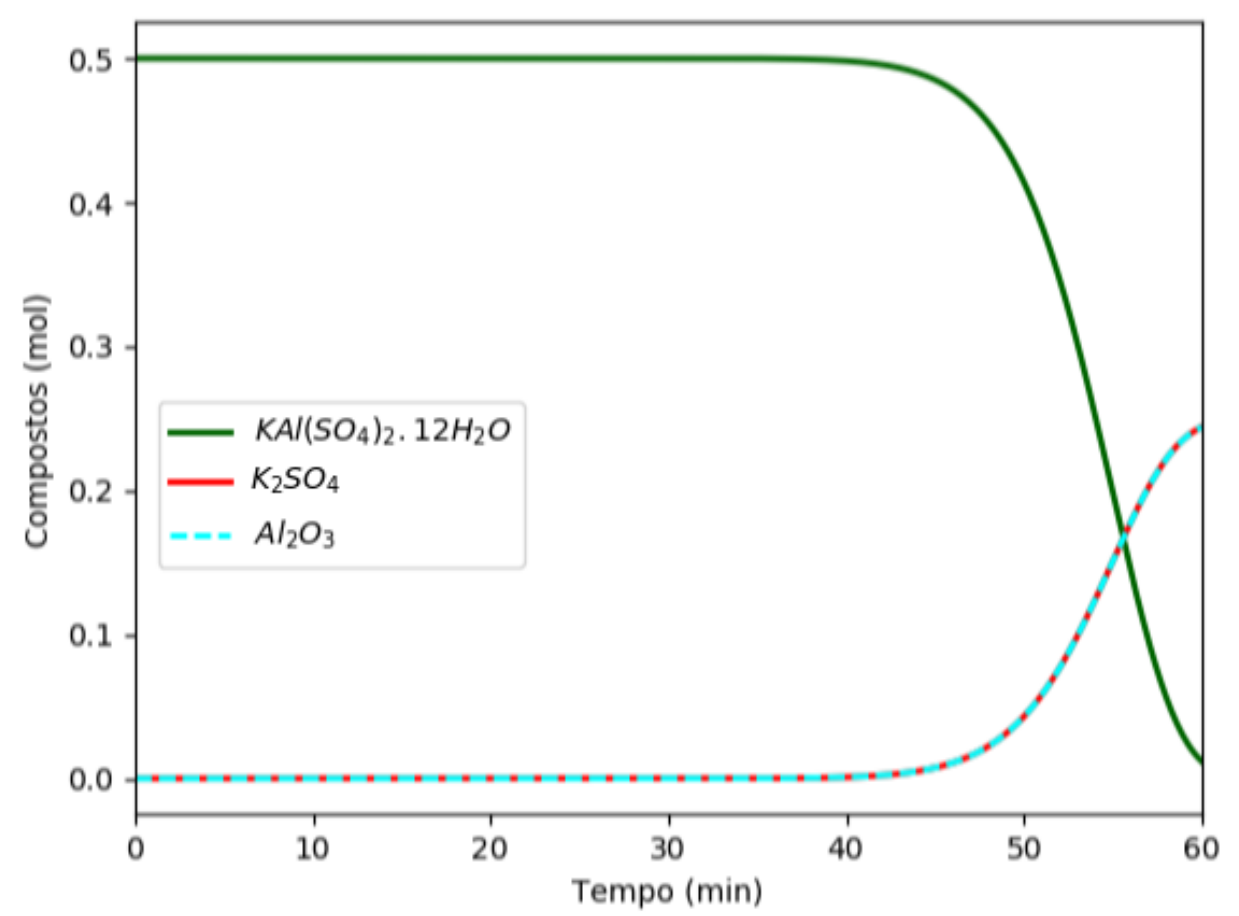

Figura 4.20: Evolução da quantidade de mols ao longo do tempo para o Modelo 1 de uma etapa. 
O gráfico da Figura 4-20 apresenta evolução da quantidade em mols ao longo do tempo para o Modelo 1. Pode-se perceber que o modelo descreve o consumo dos reagentes e a geração dos produtos e, observa-se na figura, que a reação de decomposição do alúmen de potássio leva em torno de 48 minutos para ser iniciada, o que é confirmado pela Figura 4-19. A vantagem do uso do modelo fica clara no gráfico da Figura 4-20 pois, com o uso do modelo, é possível conhecer o número de moles de todas as espécies presentes no meio reacional ao longo de toda a reação.

Pela observação do gráfico da Figura 4-21, nota-se que os valores finais de composição mássica dos produtos sulfato de potássio e óxido de alumínio se assemelham aos encontrados na literatura para essa reação (Souza et. al, 2018), em que o modelo encontrou 58,21\% para o sulfato de potássio e 34,06 \% para o óxido de alumínio enquanto que Souza et al. (2018) reportaram composições de 63,04 \% e 36,96 \% respectivamente. Este resultado indica que o modelo explica adequadamente 0 balanço molar geral do processo (resumidamente as entradas e saídas) enquanto não é capaz de explicar as etapas intermediárias do processo.

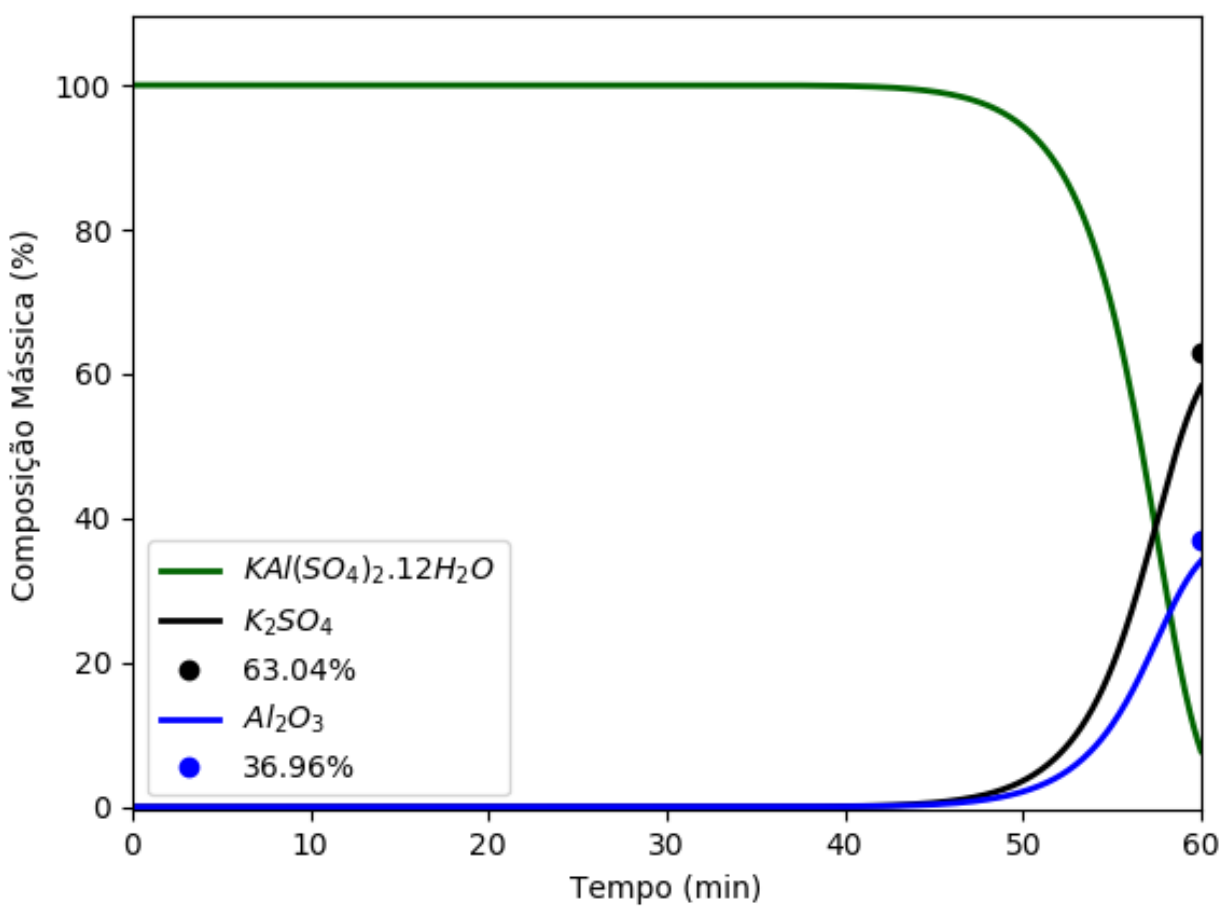

Figura 4.21: Composição mássica ao longo do tempo para o Modelo 1 de uma etapa.

A Figura 4-22 apresenta a simulação do Modelo 2 comparado aos dados experimentais de perda de massa da decomposição do alúmen de potássio. Com o uso do Modelo 2, já é possível visualizar a presença de duas curvas de decaimento de massa e que, em comparação ao desempenho do Modelo 1, o Modelo 2 se aproxima mais dos dados experimentais de TG da amostra T15In. 


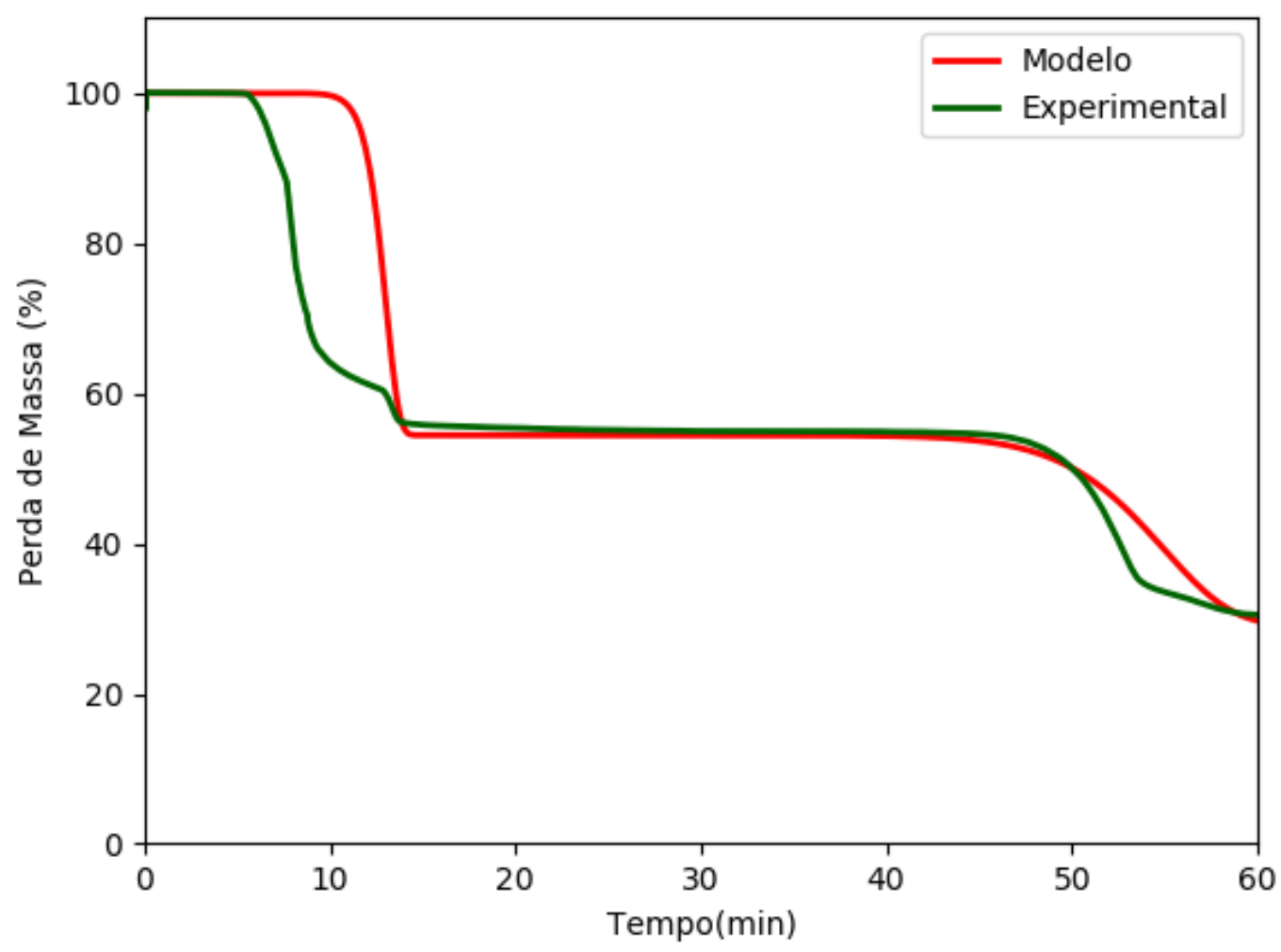

Figura 4.22: Comparação dos dados experimentais com o Modelo 2 de duas etapas.

Analisando a Figura 4-22, para a primeira região, referente à etapa de desidratação, o Modelo 2 parece atingir a perda de massa final, porém, ele não conseguiu predizer corretamente as etapas intermediárias de desidratação, corroborando novamente com a teoria de que a desidratação ocorre em mais de uma etapa. Se a desidratação ocorresse somente em uma etapa, o Modelo 2 deveria ser capaz de representar corretamente a perda das doze moléculas de água presentes no alúmen de potássio dodecahidratado. Com relação à segunda região, referente à decomposição térmica do alúmen de potássio, apesar do Modelo 2 atingir o resultado final bem próximo ao alcançado experimentalmente, de forma semelhante ao Modelo 1, o Modelo 2 ainda falha em predizer os dados experimentais no que diz respeito ao percurso da decomposição térmica do alúmen de potássio anidro.

No que tange ao gráfico da evolução da quantidade de mols ao longo do tempo para o Modelo 2, apresentada na Figura 4-23, observase que o Modelo 2 traz um entendimento maior do processo, quando comparado ao Modelo 1, tendo em vista que o Modelo 1 resultou em uma composição dos compostos constante na maior parte do tempo de análise da TG, variando essa composição somente a partir dos 48 min. Já com o emprego do Modelo 2, é possível visualizar a existência da reação de desidratação, correspondente à perda das doze moléculas de água do alúmen de potássio dodecahidratado e formação, em contrapartida, do alúmen anidro. 


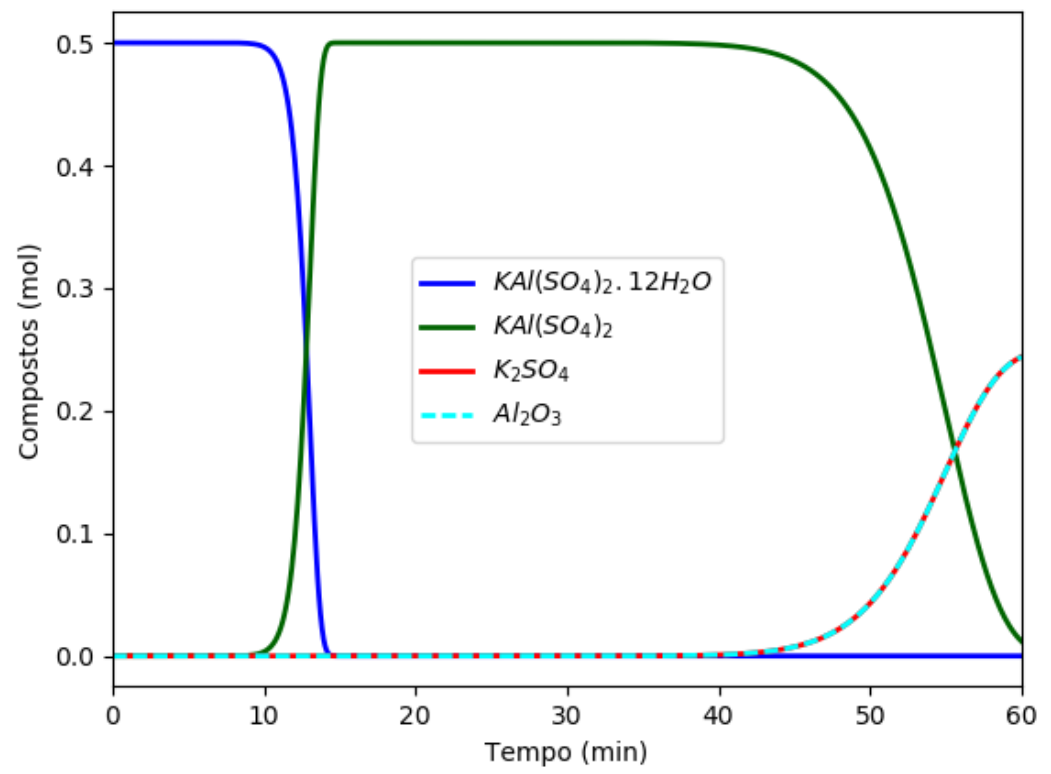

Figura 4.23: Evolução da quantidade de mols ao longo do tempo para o Modelo 2 de duas etapas.

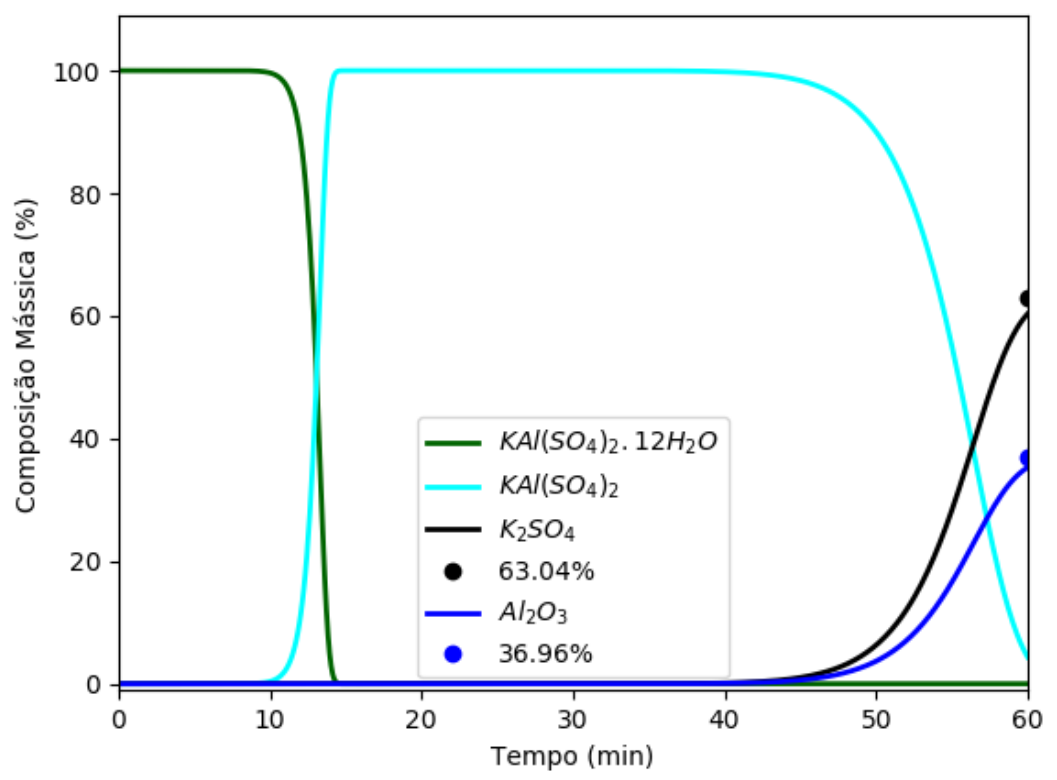

Figura 4.24: Composição mássica ao longo do tempo para o Modelo 2 de duas etapas.

Na Figura 4-24, que apresenta as composições mássicas, observa-se que os valores finais alcançados continuam bem próximos aos reportados na literatura. Onde as análises experimentais alcançaram $63,04 \%$ para 0 
sulfato de potássio, o modelo chegou à $60,34 \%$, enquanto que, para o óxido de alumínio, o resultado experimental foi $36,96 \%$ e o modelo $35,30 \%$.

Seguindo para o Modelo 3 , referente ao mecanismo cinético de três etapas reacionais, nota-se que, além do modelo conseguir predizer melhor a segunda região da curva $\mathrm{TG}$, onde ocorre a decomposição do alúmen de potássio, os resultados ainda se encontram mais próximos aos experimentais quando comparados aos resultados reportados anteriormente com o uso dos Modelos 1 e 2, como pode ser visualizado na Figura 4-25.

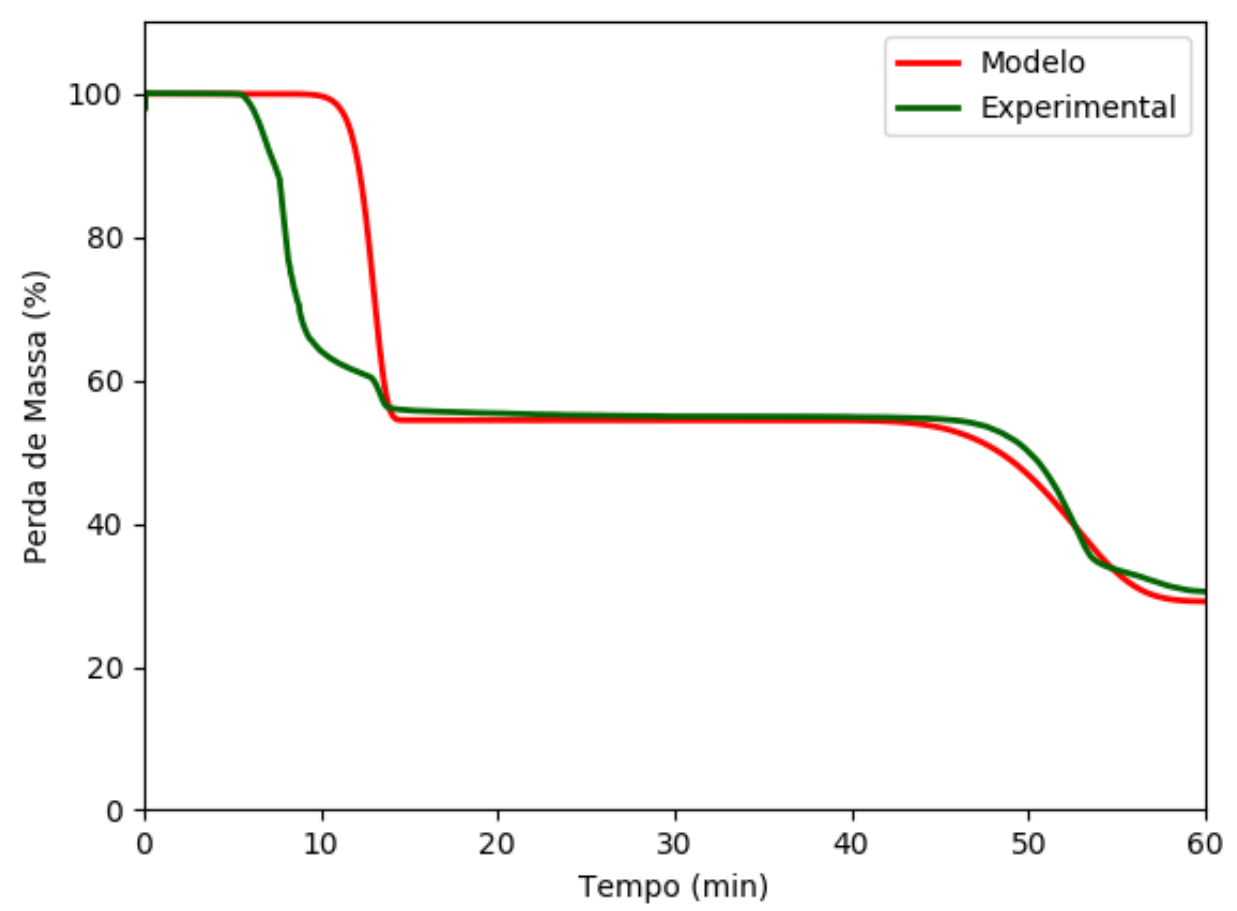

Figura 4.25: Comparação dos dados experimentais com o Modelo 3 de três etapas.

O Modelo 3 indica que a modelagem está seguindo na direção certa, já sendo capaz de predizer a decomposição do alúmen de potássio em apenas duas etapas. Portanto, o próximo passo é consertar a região de desidratação, conseguindo simular a etapa intermediária de desidratação.

A Figura 4-26 apresenta o gráfico da evolução da quantidade de mols ao longo do tempo de análise. Observando esse gráfico, é possível perceber a formação do composto intermediário, o sulfato de alumínio, e o seu consumo, de modo a formar o óxido de alumínio. Desta vez, com o uso do Modelo 3, o gráfico das composições mássicas, apresentado na Figura 4-27, aponta que o resultado do modelo (que alcançou resultados de composições de $63,06 \%$ para o sulfato de potássio e 36,87 \% para o óxido de alumínio) está idêntico aos dados experimentais reportados por Souza et al. (2018), indicando que o Modelo 3 é o que melhor simula até então o processo de decomposição térmica do alúmen de potássio. 


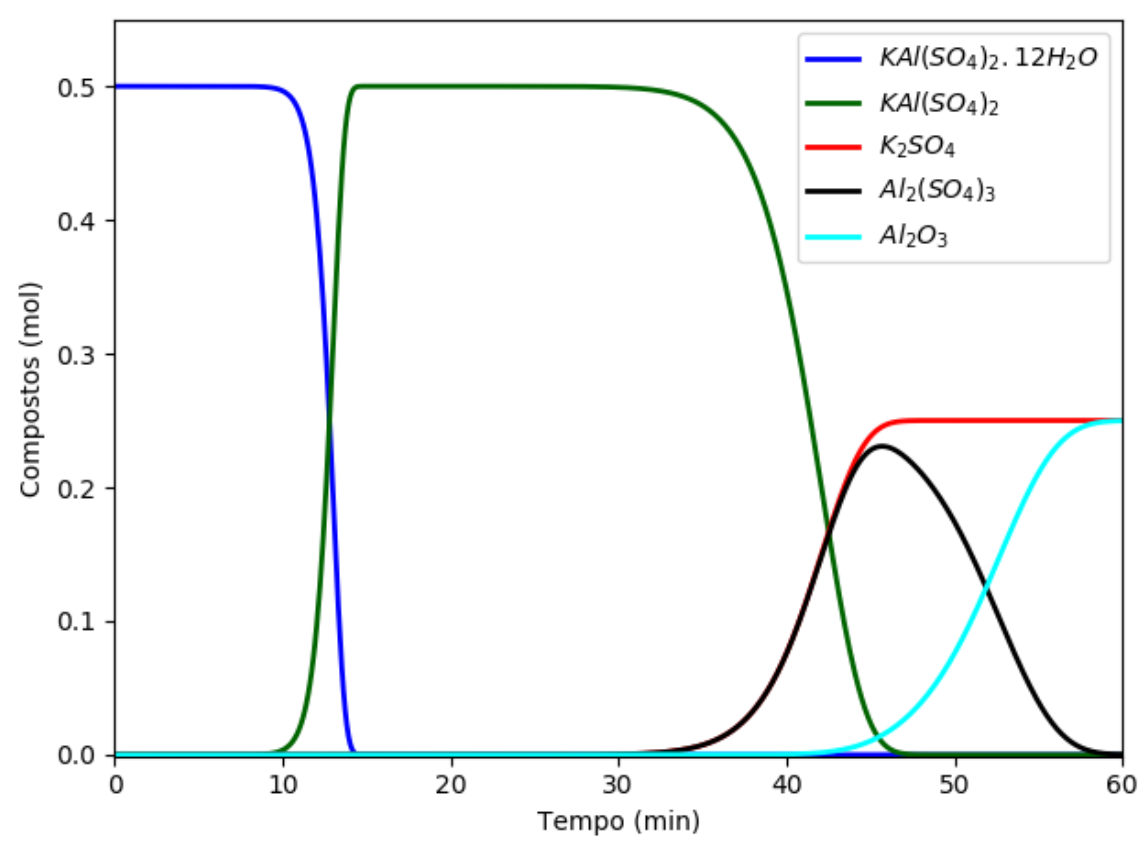

Figura 4.26: Evolução da quantidade de mols ao longo do tempo para o Modelo 3 de três etapas.

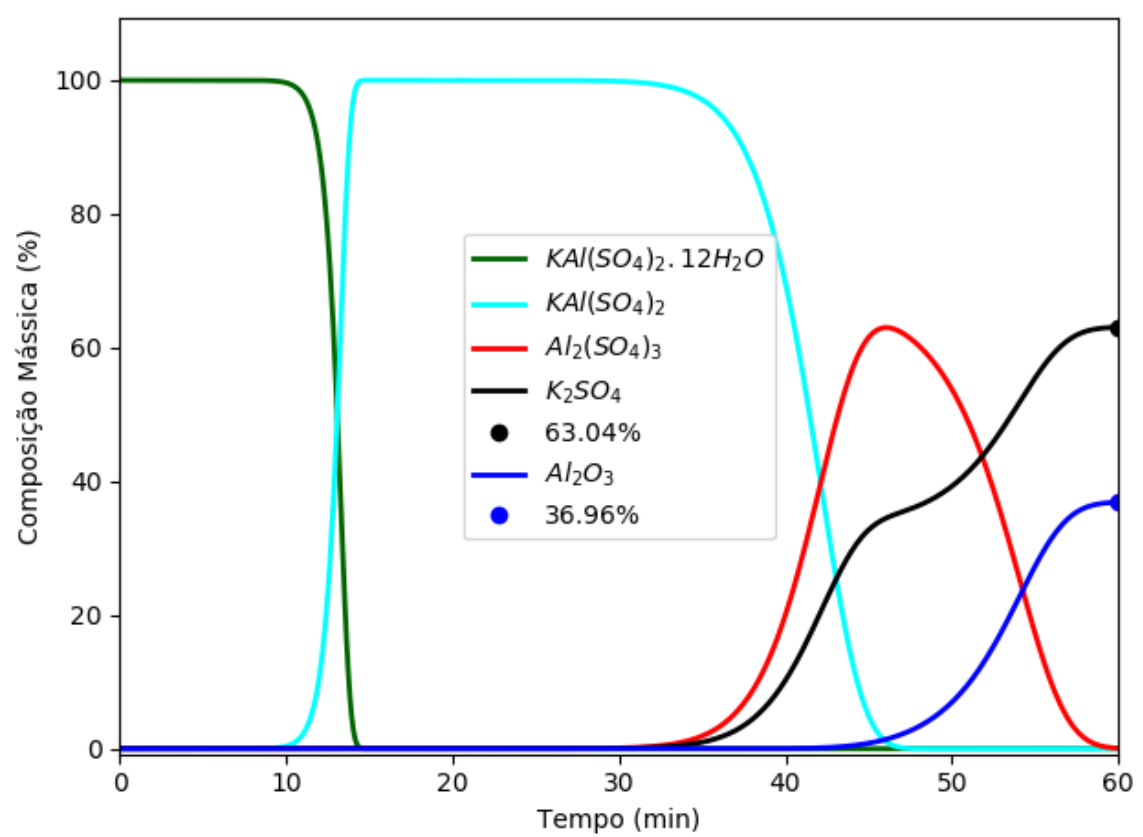

Figura 4.27: Composição mássica ao longo do tempo para o Modelo 3 de três etapas.

Finalmente, a Figura 4-28 apresenta as curvas de perda de massa ao longo do tempo de análise dos resultados preditos pelo Modelo $4 \mathrm{e}$ os resultados de TG da amostra T15In. Relembrando que o Modelo 4 
consiste de um mecanismo de 4 reações, como mostrado na seção 3.2 do capítulo de Metodologia. Nota-se na Figura 4-28 que o Modelo 4 consegue predizer muito fielmente as duas regiões da curva de TG, tanto a região de desidratação quanto a região da decomposição do alúmen de potássio. A perda de massa final não alcança os resultados experimentais tão bem quanto o Modelo 3, mas ainda pode ser considerada bem próxima, dado que o modelo alcançou composições mássicas de $58,13 \%$ para o sulfato de potássio e de 32,46\% para o óxido de alumínio. Além disso, até o presente momento, os parâmetros do Modelo 4 ainda não foram estimados e, após o processo de otimização, possivelmente ele tenderá a se aproximar mais dos dados de composição mássica ao final do processo reportados na literatura. Existe uma curva adicional na região de desidratação, como visto na seção 4.1, que pode indicar uma terceira etapa de desidratação, mas, apesar disso, o Modelo 4 consegue descrever bem os dados experimentais. Essa curva adicional é bem singela e, no presente trabalho, foi desconsiderada.

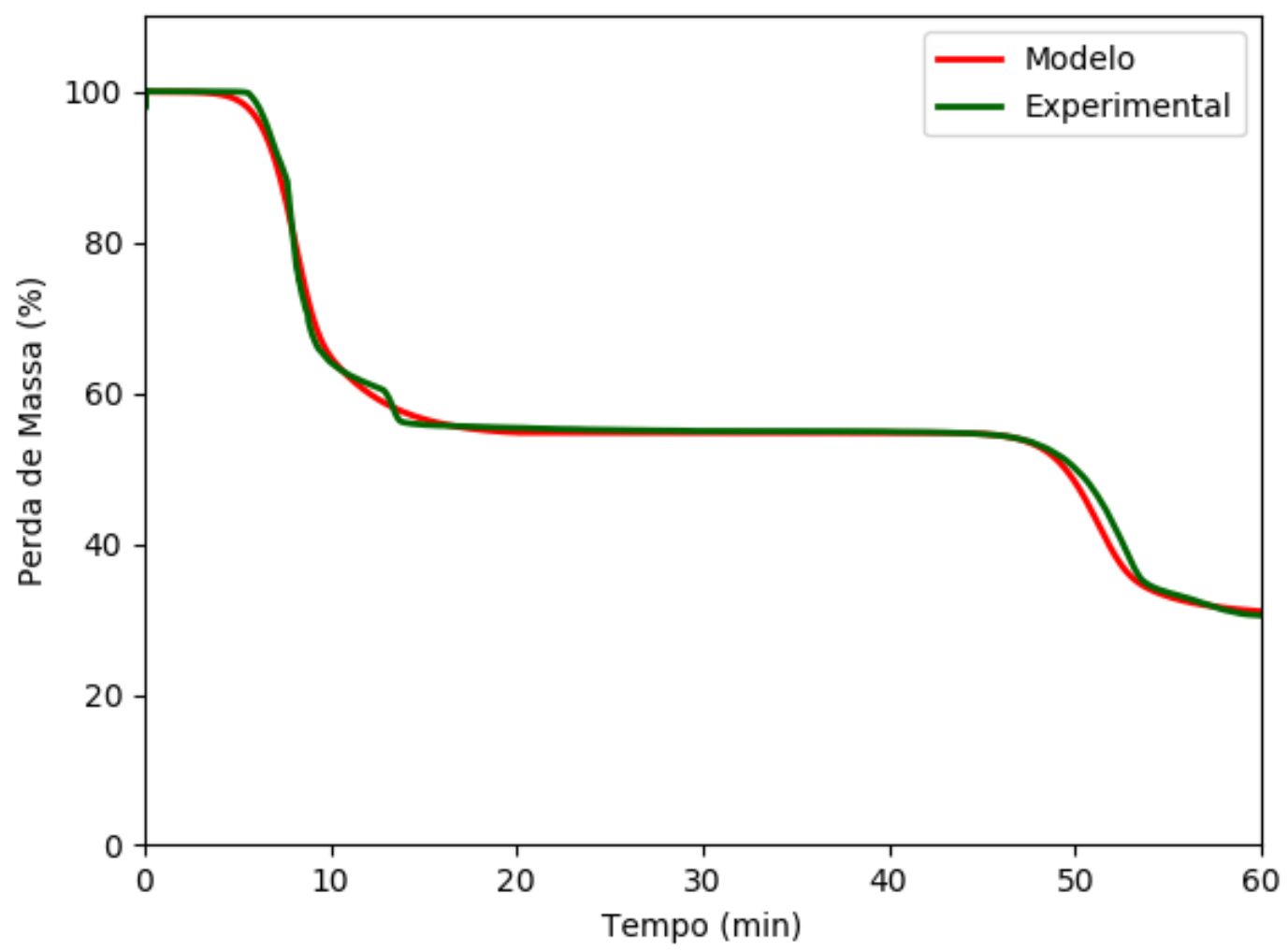

Figura 4.28: Comparação dos dados experimentais com o Modelo 4 de quatro etapas.

É possível observar nas Figuras 4-29 e 4-30 que o Modelo 4 foi capaz de predizer todo o processo de decomposição térmica do alúmen de potássio, incluindo todas as suas etapas intermediárias, chegando próximo ao resultado final de composição mássica medido experimentalmente por Souza et al.(2018). 


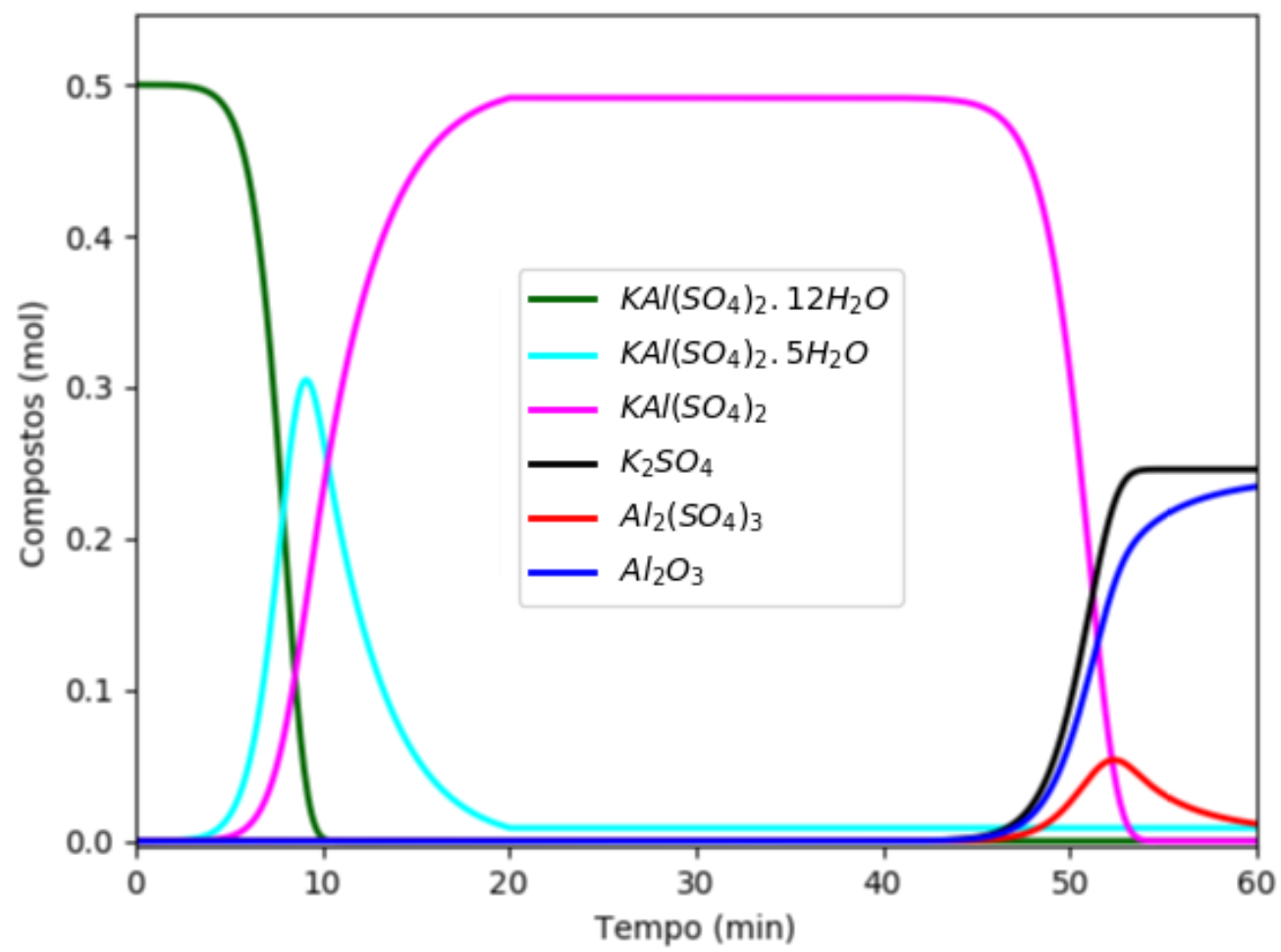

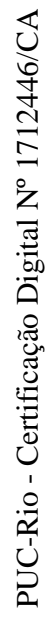

Figura 4.29: Evolução da quantidade de mols ao longo do tempo para o Modelo 4 de quatro etapas.

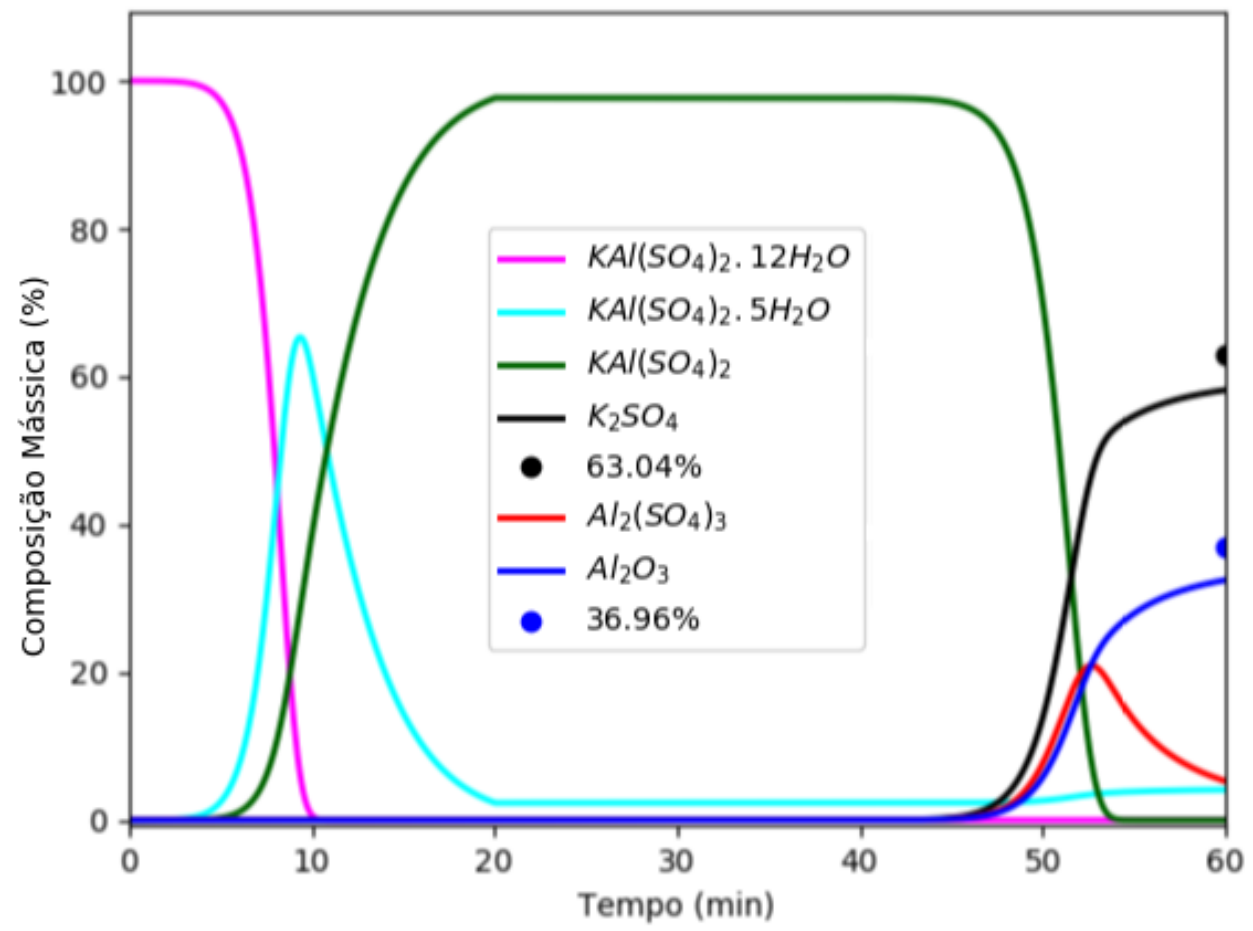

Figura 4.30: Composição mássica ao longo do tempo para o Modelo 4 de quatro etapas. 
Como pode-se perceber pelos modelos acima representados, o modelo que melhor se adaptou aos resultados e, ao mesmo tempo, que melhor conseguiu descrever a reação, foi o Modelo 4.

Porém, como visto antes da seção 2.4.1, o sulfato de alumínio intermediário não se forma na presença de agente redutor. Neste caso, ocorre a formação direta do óxido de alumínio. Portanto, foi criado o Modelo 5, para simular a decomposição térmica do alúmen de potássio na presença de agente redutor. Esse novo modelo é baseado na desidratação em duas etapas, como feito no Modelo 4, porém com a decomposição em apenas uma etapa. A Figura 31 e as Equações 4-2 a 4-4 apresentam o mecanismo de reação empregado para esse processo.

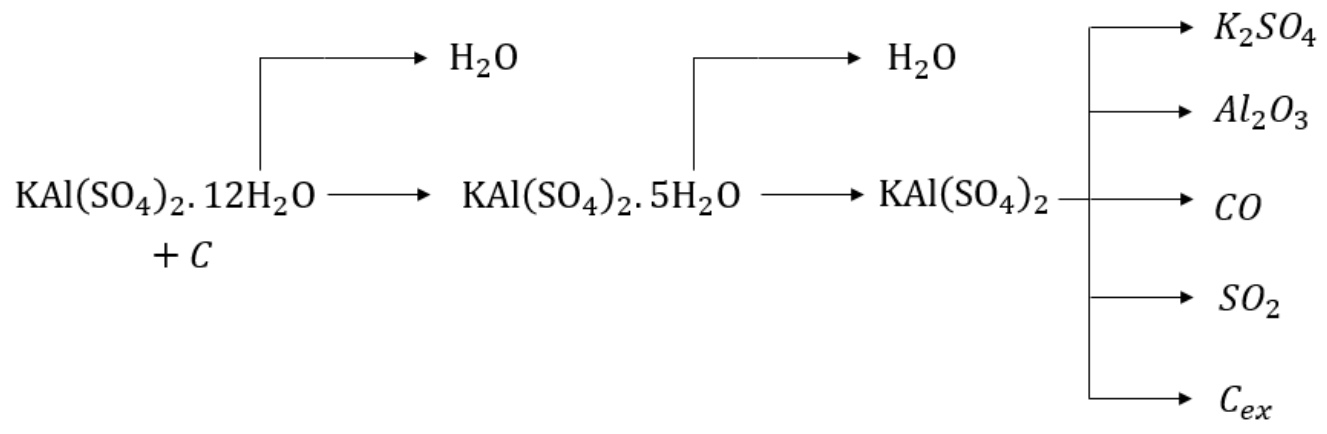

Figura 4.31: Mecanismo de ação do Modelo 5 de três etapas para a decomposição térmica na presença de agente redutor.

$$
\begin{gathered}
\mathrm{KAl}\left(\mathrm{SO}_{4}\right)_{2} .12 \mathrm{H}_{2} \mathrm{O} \stackrel{\mathrm{k} 1}{\longrightarrow} \mathrm{KAl}\left(\mathrm{SO}_{4}\right)_{2} .5 \mathrm{H}_{2} \mathrm{O}+7 \mathrm{H}_{2} \mathrm{O} \\
\mathrm{KAl}\left(\mathrm{SO}_{4}\right)_{2} .5 \mathrm{H}_{2} \mathrm{O} \stackrel{\mathrm{k} 2}{\longrightarrow} \mathrm{KAl}\left(\mathrm{SO}_{4}\right)_{2}+5 \mathrm{H}_{2} \mathrm{O} \\
\mathrm{KAl}\left(\mathrm{SO}_{4}\right)_{2}+1.5 \mathrm{C} \stackrel{\mathrm{k} 3}{\longrightarrow} 0.5 \mathrm{~K}_{2} \mathrm{SO}_{4}+0.5 \mathrm{Al}_{2} \mathrm{O}_{3}+2 \mathrm{SO}_{2}+0.5 \mathrm{CO}+\mathrm{C}_{\text {sólido }}
\end{gathered}
$$

Os balanços molares referentes ao Modelo 5 estão apresentados nas Equações 4-5 a 4-10. O modelo selecionado para a decomposição na presença de agente redutor trata a taxa da reação de decomposição do alúmen de potássio como elementar e, portanto, segue a estequiometria dos reagentes como ordem de reação, enquanto as demais taxas de reações permanecem com ordem 1.

A reação do reagente hidratado se mantém igual à Equação 3.8, enquanto que as reações do reagente parcialmente hidratado e da água se mantém iguais às Equações 3.24 e 3.26, respectivamente.

$$
\frac{d(\text { Alúmen })}{d t}=k 2 * \text { AlúmenParcial.Hid. }-k 3 * \text { Alúmen } * C^{1,5}
$$




$$
\begin{gathered}
\frac{d\left(K_{2} S O_{4}\right)}{d t}=0,5 k 3 * \text { Alúmen } * C^{1,5} \\
\frac{d\left(A_{2} O_{3}\right)}{d t}=0,5 k 3 * \text { Alúmen } * C^{1,5} \\
\frac{d\left(S O_{2}\right)}{d t}=2 k 3 * \text { Alúmen } * C^{1,5} \\
\frac{d(C)}{d t}=-k 3 * \text { Alúmen } * C^{1,5} \\
\frac{d(C O)}{d t}=0,5 k 3 * \text { Alúmen } * C^{1,5}
\end{gathered}
$$

Na Figura 4-32 está apresentado o resultado da simulação deste modelo para a decomposição do alúmen de potássio na presença de agente redutor.

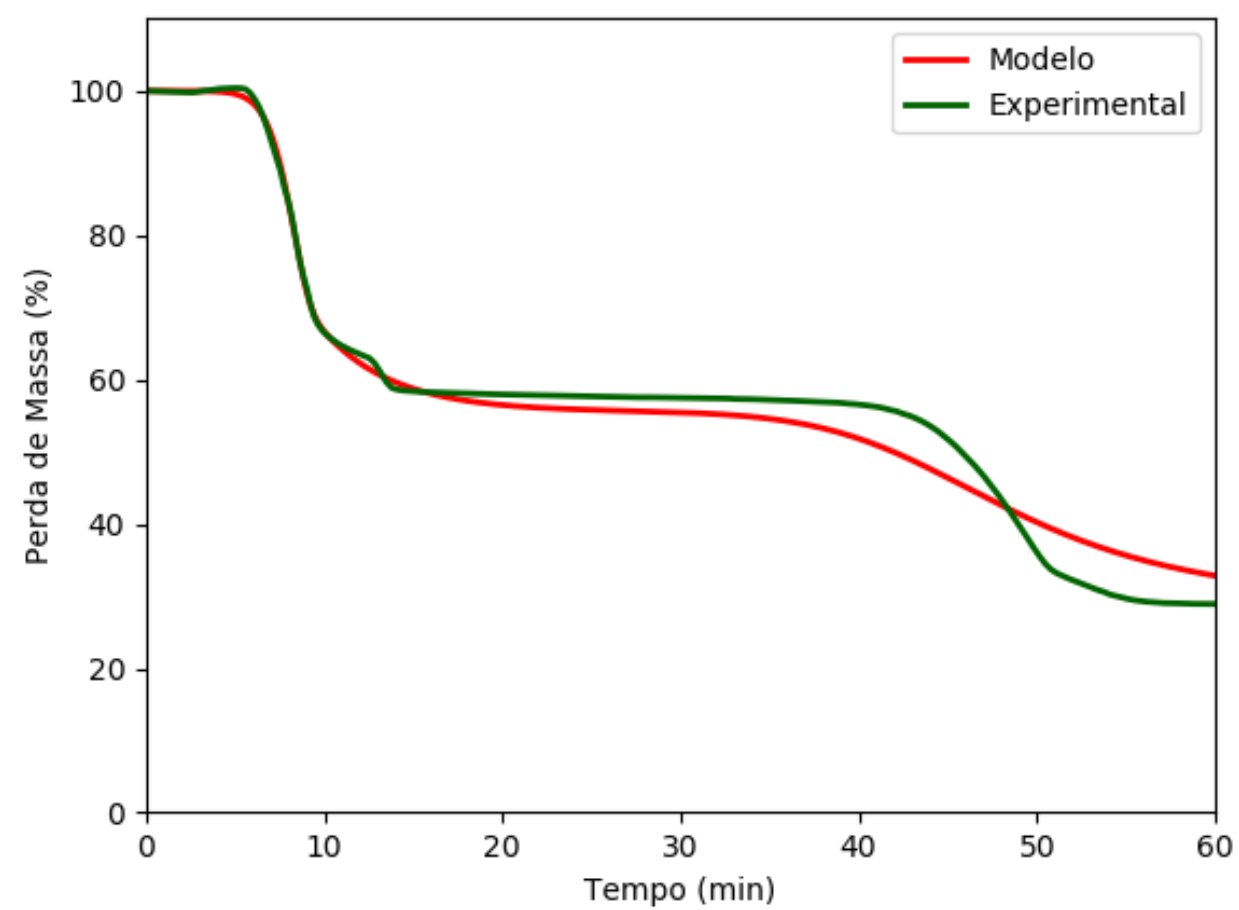

Figura 4.32: Comparação dos dados experimentais para a decomposição com agente redutor com o Modelo 5 de três etapas.

O Modelo 5 conseguiu predizer qualitativamente o comportamento dos dados experimentais de perda de massa. A partir dos gráficos de evolução da quantidade de mols ao longo do tempo e composição mássica em percentagem, Figuras 4-33 e 4-34 respectivamente, é possível visualizar que o percurso da reação foi bem representado. 


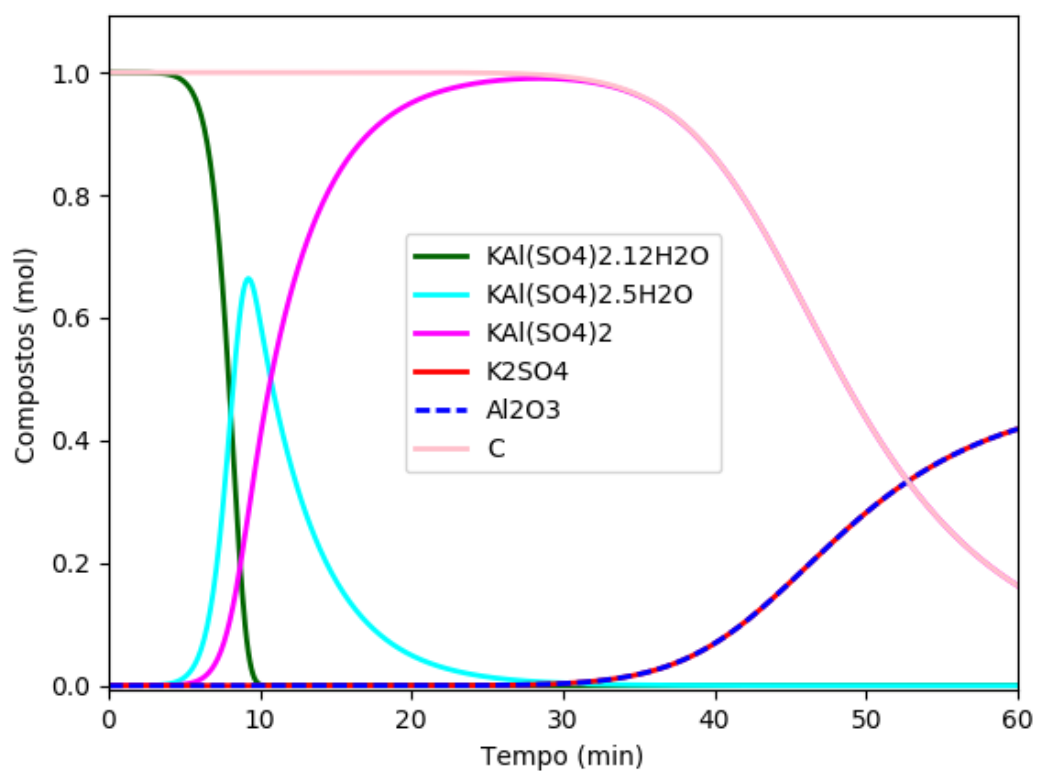

Figura 4.33: Evolução da quantidade de mols ao longo do tempo para a decomposição com agente redutor com o Modelo 5 de três etapas.

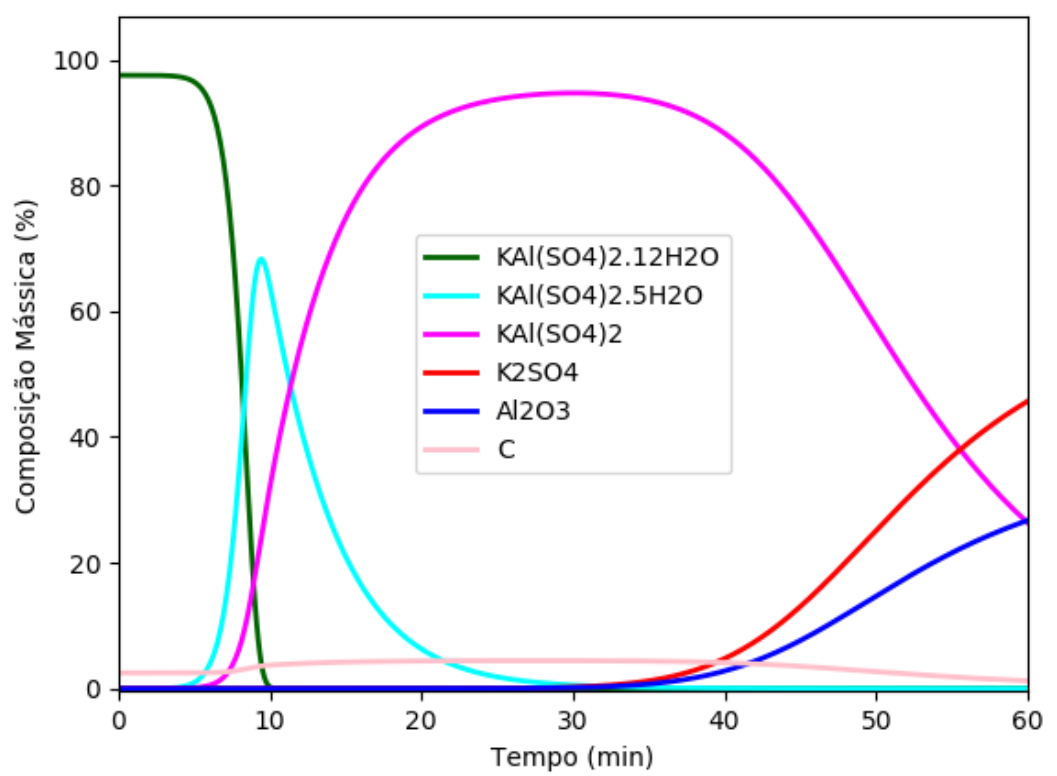

Figura 4.34: Composição mássica ao longo do tempo para a decomposição com agente redutor com o Modelo 5 de três etapas. 


\section{3 \\ Resultados da Estimação Experimental}

Inicialmente, o Método de Osawa (apresentado na seção 2.6.2) foi selecionado para executar a estimação experimental dos parâmetros de Arrhenius para cada uma das reações envolvidas. As duas etapas da reação de desidratação, (que na curva TG aparecem em relação ao tempo até $250^{\circ} \mathrm{C}$ aproximadamente), e a reação de decomposição.

$\mathrm{Na}$ região de decomposição, em que concluiu-se haver duas reações separadas, a decomposição do alúmen de potássio e a decomposição do sulfato de alumínio, optou-se por estimar os parâmetros considerando uma etapa única, tendo em vista que o método exige a visualização das temperaturas de pico da curva DTG. Portanto, a dificuldade está no fato de que as duas etapas da decomposição se misturam em uma na curva de TG e, consequentemente, a curva de DTG tem um único pico.

De acordo com Osawa (1970), o método é aplicado ao pico da curva DTG, considerando que no pico a fração de decomposição independe da taxa de aquecimento. De forma que, para estimar parâmetros cinéticos, a energia de ativação medida é independente da temperatura e da escala de tempo experimental, e depende somente da quantidade estrutural de amostra. Ou seja, para todas as taxas de aquecimentos a mesma energia de ativação é estimada, mas o fator pré-exponencial é alterado com a taxa de aquecimento.

As Tabelas 4-3 a 4-5 trazem os resultados para as três etapas da decomposição térmica: as duas etapas de desidratação e a decomposição.

Tabela 4.3: Resultados da estimação de parâmetros pelo método de Osawa para a primeira etapa da desidratação da decomposição térmica

Etapa 1 de desidratação

\begin{tabular}{|c|c|c|c|c|c|c|c|}
\hline Amostra & $\beta\left({ }^{\circ} \mathrm{C} / \mathrm{min}\right)$ & $\log \beta$ & $\operatorname{Tm}\left({ }^{\circ} \mathrm{C}\right)$ & $1 / \operatorname{Tm}\left({ }^{\circ} \mathrm{C}^{-1}\right)$ & Coeficiente Angular & $\mathrm{E}_{a}(\mathrm{~J} / \mathrm{mol})$ & $\mathrm{k}_{0}\left(\mathrm{~min}^{-1}\right)$ \\
\hline T10In & 10 & 1 & 121,99 & 0,0082 & \multirow{3}{*}{$-7266,6$} & \multirow{3}{*}{132307,8} & 31,16 \\
\hline T15ln & 15 & 1,18 & 126,82 & 0.0079 & & & 39,93 \\
\hline T20In & 20 & 1.3 & 128,05 & 0,0078 & & & 51,23 \\
\hline
\end{tabular}

Tabela 4.4: Resultados da estimação de parâmetros pelo método de Osawa para a segunda etapa da desidratação da decomposição térmica

Etapa 2 de desidratação

\begin{tabular}{|c|c|c|c|c|c|c|c|}
\hline Amostra & $\beta\left({ }^{\circ} \mathrm{C} / \mathrm{min}\right)$ & $\log \beta$ & $\operatorname{Tm}\left({ }^{\circ} \mathrm{C}\right)$ & $1 / \operatorname{Tm}\left({ }^{\circ} \mathrm{C}^{-1}\right)$ & Coeficiente Angular & $\mathrm{E}_{a}(\mathrm{~J} / \mathrm{mol})$ & $\mathrm{k}_{0}\left(\min ^{-1}\right)$ \\
\hline T10In & 10 & 1 & 220,97 & 0,0045 & \multirow{3}{*}{$-5606,3$} & \multirow{3}{*}{102077,6} & 4,515 \\
\hline T15ln & 15 & 1,18 & 228,33 & 0,0044 & & & 6,213 \\
\hline T20In & 20 & 1,3 & 231,34 & 0,0043 & & & 8,007 \\
\hline
\end{tabular}

Tabela 4.5: Resultados da estimação de parâmetros pelo método de Osawa para a etapa da decomposição da decomposição térmica

Etapa da decomposição
\begin{tabular}{|c|c|c|c|c|c|c|c|}
\hline Amostra & $\beta\left({ }^{\circ} \mathrm{C} / \mathrm{min}\right)$ & $\log \beta$ & $\operatorname{Tm}\left({ }^{\circ} \mathrm{C}\right)$ & $1 / \mathrm{Tm}\left({ }^{\circ} \mathrm{C}^{-1}\right)$ & Coeficiente Angular & $\mathrm{E}_{a}(\mathrm{~J} / \mathrm{mol})$ & $\mathrm{k}_{0}\left(\mathrm{~min}^{-1}\right)$ \\
\hline T10ln & 10 & 1 & 803,03 & 0,00124 & & & \multirow{2}{*}{-30509} \\
\cline { 1 - 5 } T15ln & 15 & 1,18 & 811,79 & 0,00123 & 555497,5 & 1,683 \\
\hline T20ln & 20 & 1,3 & 816,32 & 0,00122 & & & 2,217 \\
\hline
\end{tabular}


A partir dos resultados apresentados nas Tabelas 4-3 a 4-5, fez-se a simulação do Modelo 4 com os parâmetros cinéticos estimados, para cada taxa de aquecimento, e os resultados do modelo foram comparados ao conjunto dos dados experimentais. Esses resultados estão apresentados nas (Figuras 4-35 a 4-37).

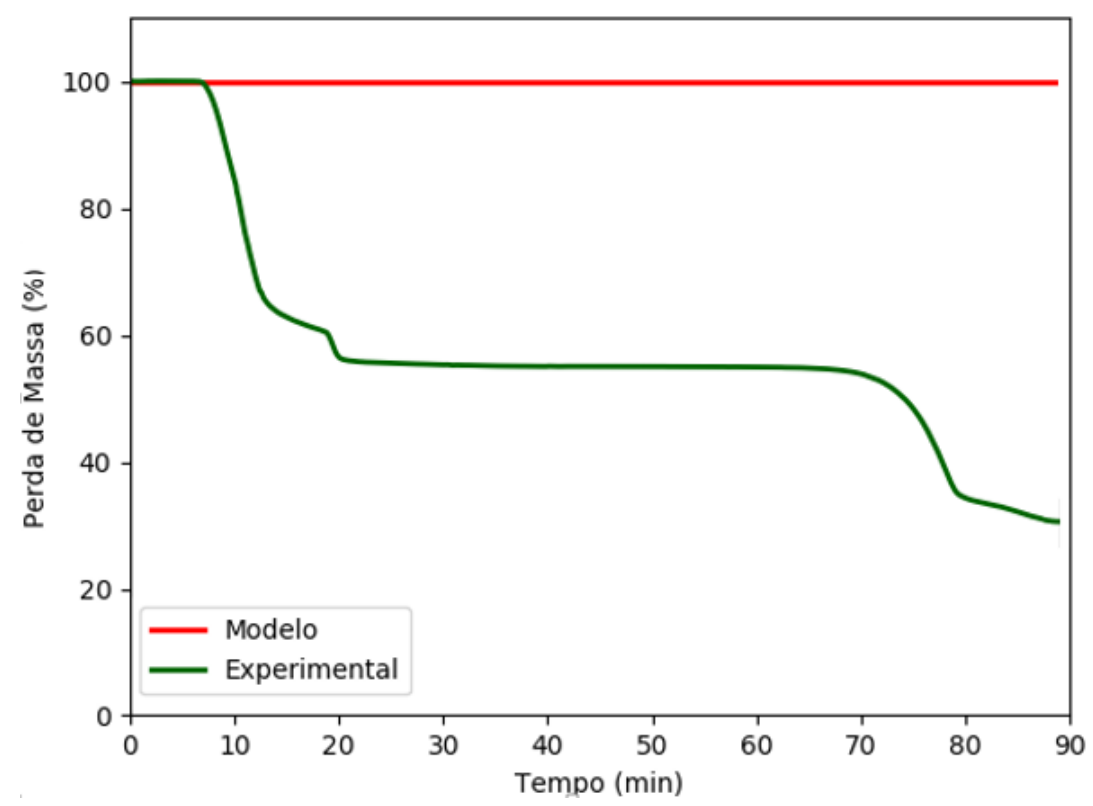

Figura 4.35: Comparação dos dados experimentais da decomposição térmica com o Modelo 4 de quatro etapas a partir dos parâmetros estimados pelo método de Osawa com a taxa de aquecimento de $10 \mathrm{~K} / \mathrm{min}$.

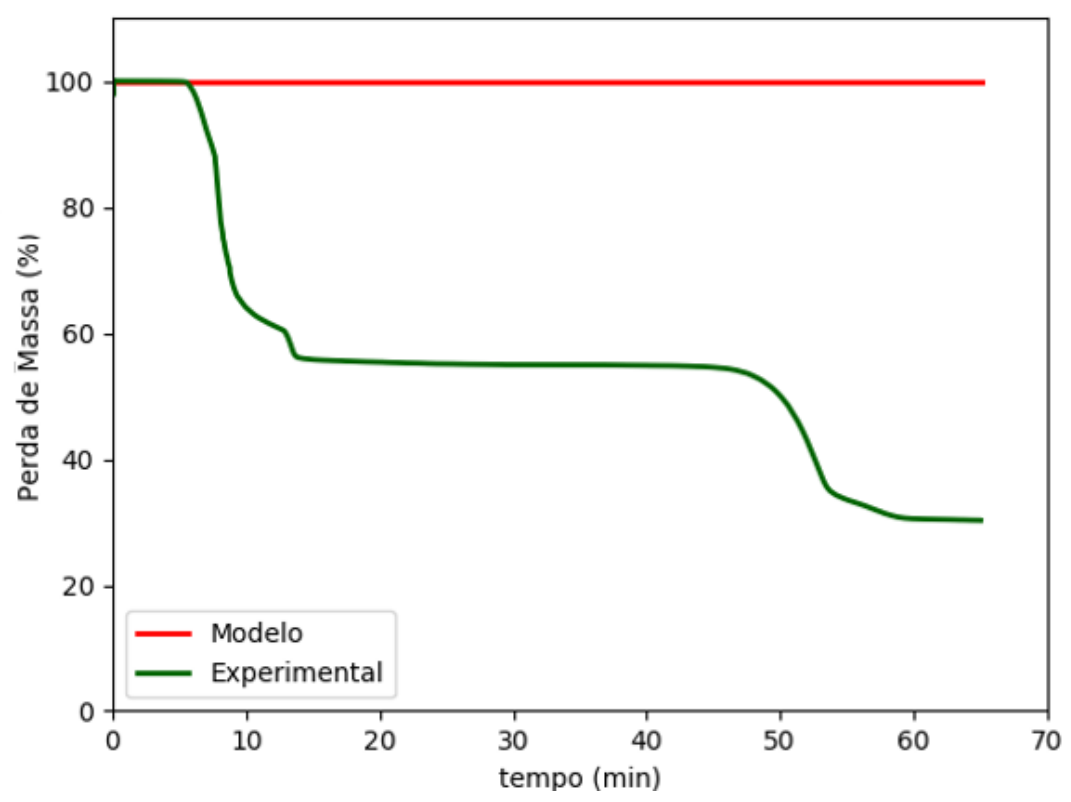

Figura 4.36: Comparação dos dados experimentais da decomposição térmica com o Modelo 4 de quatro etapas a partir dos parâmetros estimados pelo método de Osawa com a taxa de aquecimento de $15 \mathrm{~K} / \mathrm{min}$. 


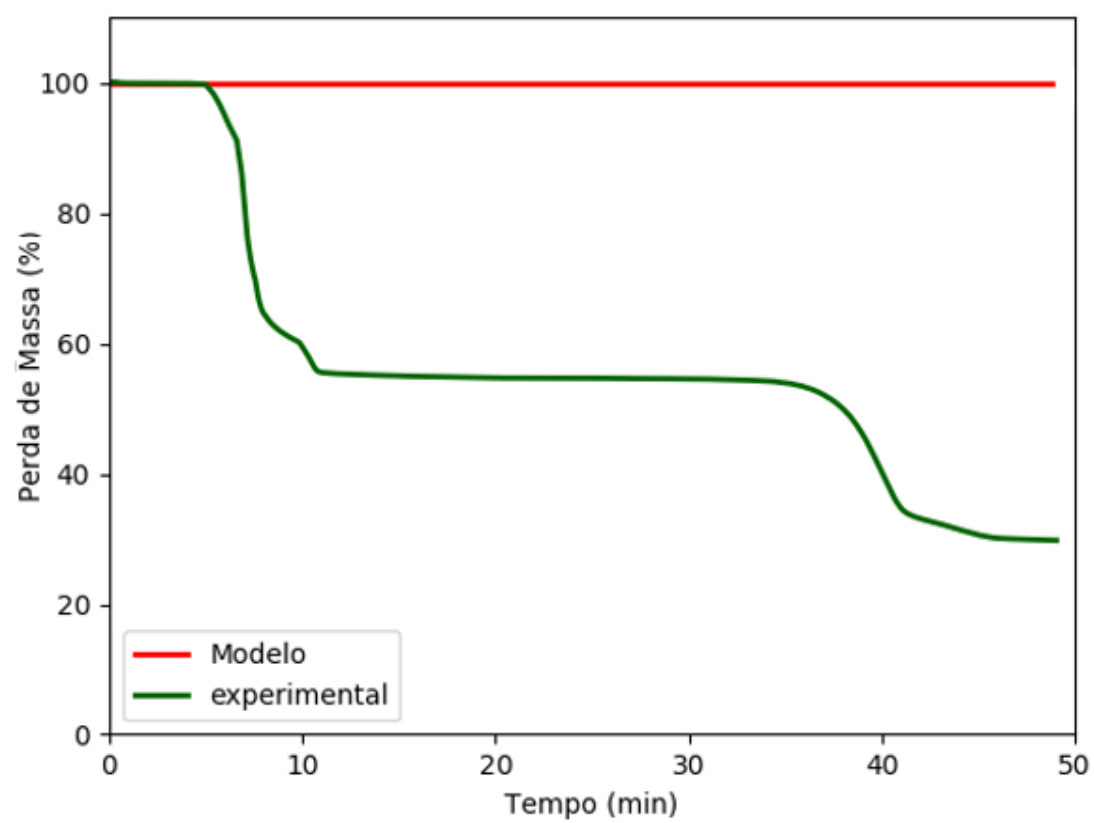

Figura 4.37: Comparação dos dados experimentais da decomposição térmica com o Modelo 4 de quatro etapas a partir dos parâmetros estimados pelo método de Osawa com a taxa de aquecimento de $20 \mathrm{~K} / \mathrm{min}$.

Para todas as taxas de aquecimento, é possível perceber que o modelo com os parâmetros estimados pelo método de Osawa não se ajustou aos dados experimentais. Os parâmetros se encontraram maiores que a sensibilidade do modelo, de forma que o modelo não conseguiu responder adequadamente aos dados experimentais. Visivelmente, os parâmetros estimados não representam os valores reais dos mesmos, o que comprometeu a predição do modelo.

Subsequentemente, as Tabelas 4-6 a 4-8 apresentam os resultados para a decomposição com agente redutor.

Tabela 4.6: Resultados da estimação de parâmetros pelo método de Osawa para a primeira etapa da desidratação da decomposição redutora

Etapa 1 da desidratação

\begin{tabular}{|c|c|c|c|c|c|c|c|}
\hline Amostra & $\beta\left({ }^{\circ} \mathrm{C} / \mathrm{min}\right)$ & $\log \beta$ & $\operatorname{Tm}\left({ }^{\circ} \mathrm{C}\right)$ & $1 / \operatorname{Tm}\left({ }^{\circ} \mathrm{C}^{-1}\right)$ & Coeficiente Angular & $\mathrm{E}_{a}(\mathrm{~J} / \mathrm{mol})$ & $\mathrm{k}_{0}\left(\mathrm{~min}^{-1}\right)$ \\
\hline T10In & 10 & 1 & 106,82 & 0,009 & \multirow{3}{*}{$-121,65$} & \multirow{3}{*}{2214,9} & 0,239 \\
\hline T15ln & 15 & 1,18 & 123,93 & 0,008 & & & 0,265 \\
\hline T20In & 20 & 1,3 & 145,30 & 0,007 & & & 0,256 \\
\hline
\end{tabular}

Tabela 4.7: Resultados da estimação de parâmetros pelo método de Osawa para a segunda etapa da desidratação da decomposição redutora

Etapa 2 da desidratação

\begin{tabular}{|c|c|c|c|c|c|c|c|}
\hline \multirow{2}{*}{\multicolumn{8}{|c|}{\begin{tabular}{|l|l|l|l|l}
$\operatorname{Tm}\left({ }^{\circ} \mathrm{C}\right)$ & $1 / \operatorname{Tm}\left({ }^{\circ} \mathrm{C}^{-1}\right)$ & Coeficiente Anqular & $\mathrm{F}_{(\mathrm{J}}(\mathrm{J} / \mathrm{mol})$ & $\mathrm{k}_{8}\left(\mathrm{~min}^{-1}\right)$
\end{tabular}}} \\
\hline & $\beta\left({ }^{\circ} \mathrm{C} / \mathrm{min}\right)$ & $\log \beta$ & $\operatorname{Tm}\left({ }^{\circ} \mathrm{C}\right)$ & $1 / \operatorname{Tm}\left({ }^{\circ} \mathrm{C}^{-1}\right)$ & Coeficiente Angular & $\mathrm{E}_{a}(\mathrm{~J} / \mathrm{mol})$ & $\mathrm{k}_{0}\left(\min ^{-1}\right)$ \\
\hline T10ln & 10 & 1 & 219,65 & 0,0046 & \multirow{3}{*}{$-1254,4$} & \multirow{3}{*}{22839.7} & 0,621 \\
\hline T15In & 15 & 1,18 & 223,93 & 0,0045 & & & 0,868 \\
\hline T20In & 20 & 1,3 & 228,44 & 0,0044 & & & 0,111 \\
\hline
\end{tabular}


Tabela 4.8: Resultados da estimação de parâmetros pelo método de Osawa para a etapa da decomposição da decomposição redutora

\begin{tabular}{|c|c|c|c|c|c|c|c|}
\hline \multicolumn{8}{|c|}{ Decomposição } \\
\hline Amostra & $\beta\left({ }^{\circ} \mathrm{C} / \mathrm{min}\right)$ & $\log \beta$ & $\operatorname{Tm}\left({ }^{\circ} \mathrm{C}\right)$ & $1 / \operatorname{Tm}\left({ }^{\circ} \mathrm{C}^{-1}\right)$ & Coeficiente Angular & $\mathrm{E}_{a}(\mathrm{~J} / \mathrm{mol})$ & $\mathrm{k}_{0}\left(\min ^{-1}\right)$ \\
\hline T10In & 10 & 1 & 727,93 & 0,0014 & \multirow{3}{*}{$-2889,4$} & \multirow{3}{*}{52609,2} & $1.21 \mathrm{E}-01$ \\
\hline T15ln & 15 & 1,18 & 763,93 & 0,0013 & & & 0,164 \\
\hline T20In & 20 & 1,3 & 787,24 & 0,0012 & & & 0,206 \\
\hline
\end{tabular}

Novamente, a partir dos resultados acima apresentados, o Modelo 5 foi simulado usando os novos parâmetros estimados, e sua resposta foi comparada com os dados experimentais, para a decomposição na presença do agente redutor, para cada uma das taxas de aquecimento (Figuras 4-38 a 4-40).

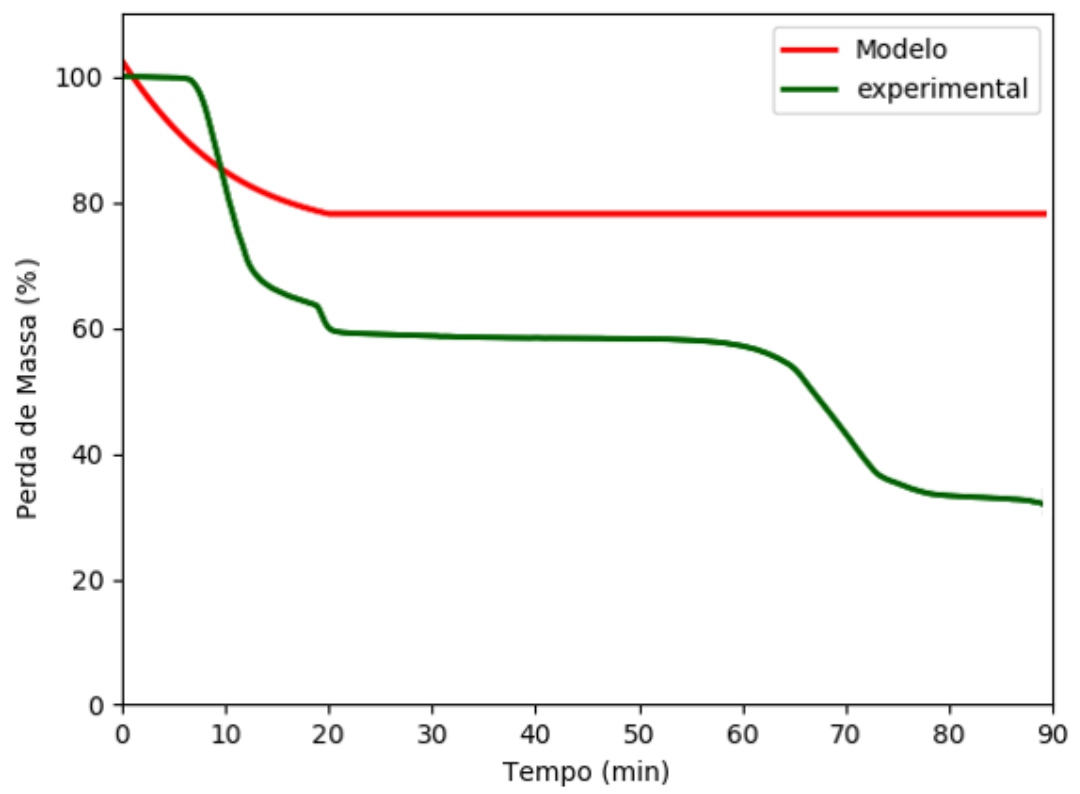

Figura 4.38: Comparação dos dados experimentais da decomposição redutora com o Modelo 5 de três etapas a partir dos parâmetros estimados pelo método de Osawa com a taxa de aquecimento de $10 \mathrm{~K} / \mathrm{min}$.

Para todas as taxas de aquecimento, observa-se que os parâmetros já estão na faixa de sensibilidade do modelo, isto é, o modelo já consegue traçar a curva a partir dos parâmetros estimados. Porém, observa-se que esses parâmetros estimados pelo método de Osawa não conseguiram ajustar o modelo à curva experimental, ou seja, não seguem o mesmo comportamento dos dados experimentais. Dessa forma, os parâmetros estimados pelo método de Osawa são qualificados como sendo assim incapazes de gerar respostas do modelo próximas às curvas experimentais das reações. 


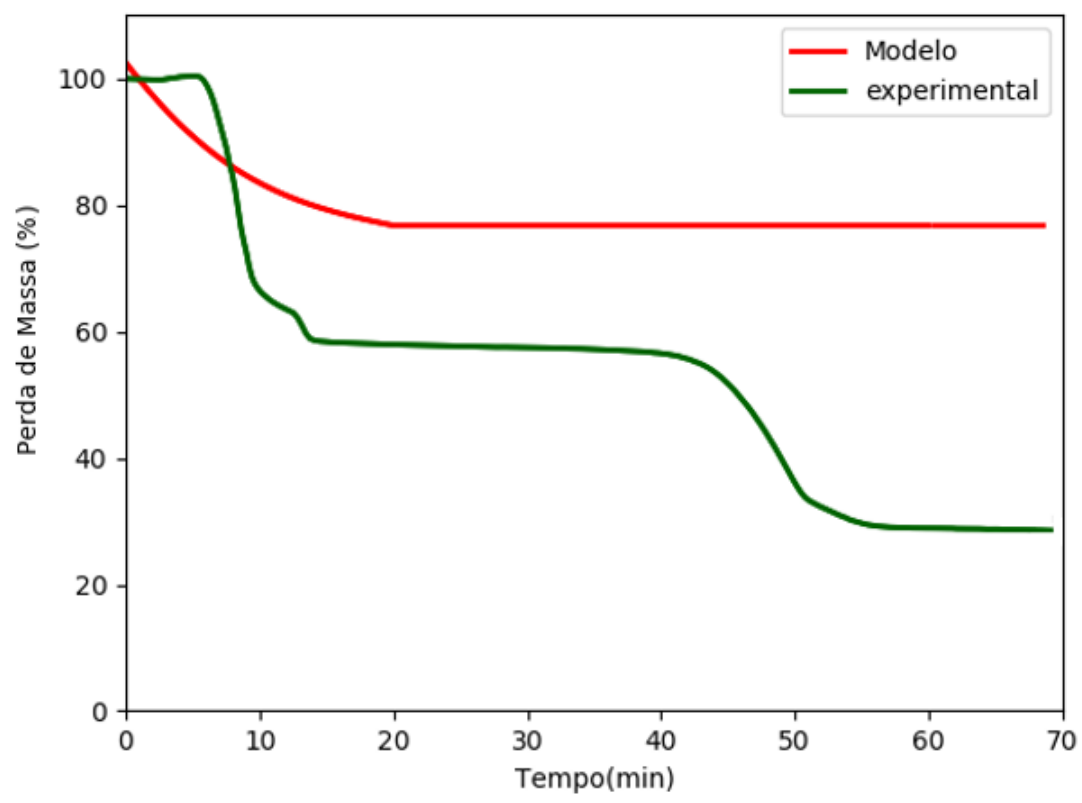

Figura 4.39: Comparação dos dados experimentais da decomposição redutora com o Modelo 5 de três etapas a partir dos parâmetros estimados pelo método de Osawa com a taxa de aquecimento de $15 \mathrm{~K} / \mathrm{min}$.

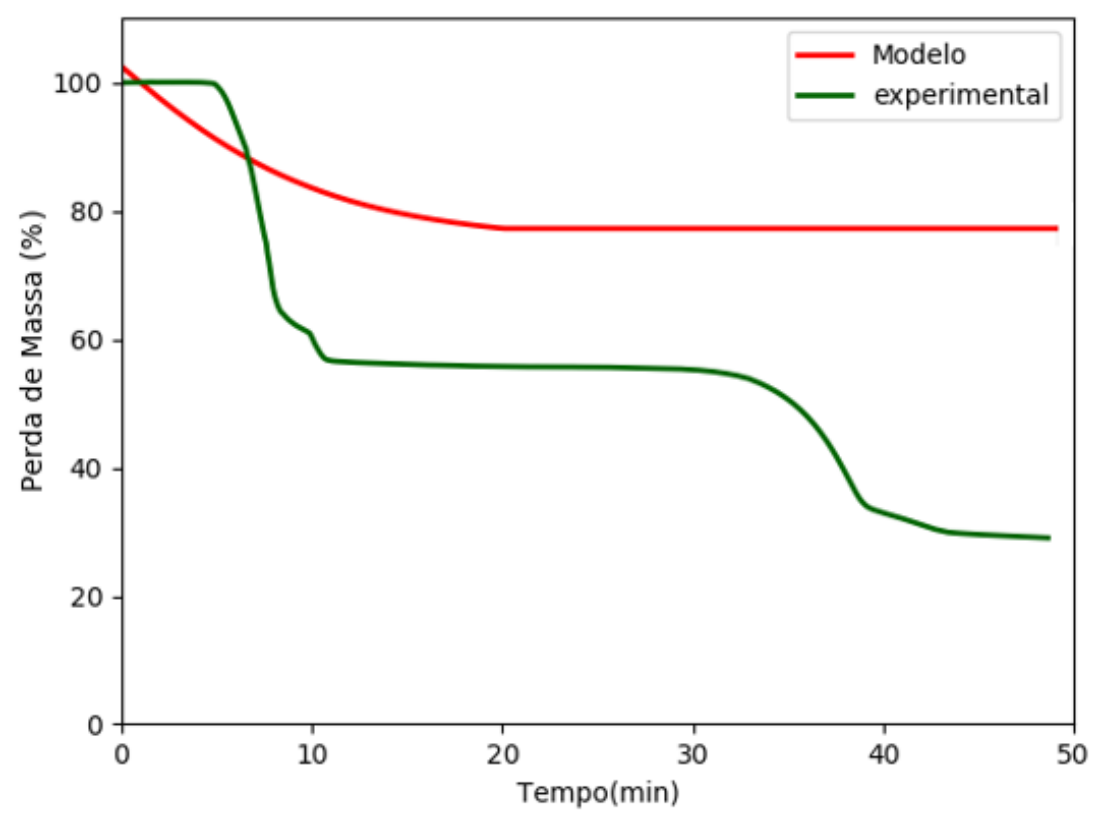

Figura 4.40: Comparação dos dados experimentais da decomposição redutora com o Modelo 5 de três etapas a partir dos parâmetros estimados pelo método de Osawa com a taxa de aquecimento de $20 \mathrm{~K} / \mathrm{min}$.

Desses resultados, conclui-se que o método de Osawa para estimação dos parâmetros de Arrhenius, para o caso da decomposição térmica do alúmen de potássio, mostrou ser de baixa confiabilidade. Uma possível forma de resolver esse problema é realizando-se mais análises de TG, com 
variadas taxas de aquecimento, de modo que a reta $\ln \beta$ vs. $1 / T_{m}$ do método de Osawa possua mais pontos.

Além disso, devido ao fato do método ser baseado em alguns poucos pontos de toda a análise de TG, a sua simplificação pode ser uma causa da distorção da interpretação dos dados experimentais. Consequentemente, uma forma de utilizar toda a extensão de dados da análise térmica é pela integração numérica dos balanços de massa. Como pode ser visto na próxima seção.

\section{4}

\section{Resultado da estimação de parâmetros utilizando o enxame de partí- culas}

Nesta seção, são apresentados os resultados da estimação dos parâmetros do Modelo 4 para a decomposição térmica do alúmen de potássio, com taxa de aquecimento de $15 \mathrm{~K} / \mathrm{min}$, referente à condição experimental T15In, utilizando o método de otimização enxame de partículas. O processo de decomposição do alúmen de potássio foi dividido em duas etapas. A primeira refere-se à desidratação (até aproximadamente 20 minutos de análise) enquanto que a segunda etapa é referente à decomposição do alúmen anidro. Cada etapa teve os seus respectivos parâmetros estimados separadamente. Posteriormente, o mesmo procedimento foi empregado para o processo de decomposição térmica do alúmen de potássio na presença de agente redutor utilizando o Modelo 5 , condição experimental referente à amostra R15In.

\subsection{1 \\ Decomposição térmica}

\subsubsection{1}

1. Etapa

Como comentado na Seção 3.2, as constantes cinéticas foram representadas por meio de uma equação reparametrizada de Arrhenius (Equação 3.34) a fim de diminuir a correlação entre os parâmetros estimados. A Tabela 4-9 apresenta quais parâmetros foram estimados, as equações das constantes cinéticas em função desses parâmetros e quais reações essas constantes fazem parte.

Tabela 4.9: Parâmetros estimados, correspondentes constantes cinéticas e suas respectivas reações para a Etapa 1 da decomposição térmica do alúmen de potássio

\begin{tabular}{ccc}
\hline Parâmetros estimados $^{a}$ & Constantes cinéticas & Reação \\
\hline $\mathrm{A}_{1}$ & $k_{1}=e^{A_{1}+10^{B_{1}}\left(\left(T-T_{\text {ref } 1) / T)}\right.\right.}$ & Equação (3.20) \\
\hline $\mathrm{B}_{1}$ & $k_{2}=e^{A_{2}+10^{B_{2}\left(\left(T-T_{r e f 2}\right) / T\right)}}$ & Equação (3.21) \\
\hline $\mathrm{A}_{2}$ & \\
\hline $\mathrm{B}_{2}$ & &
\end{tabular}


Os parâmetros $\mathrm{B}_{1}$ e $\mathrm{B}_{2}{ }^{a}$ da Equação 3.34 foram estimados na sua forma logarítmica. Com essa estratégia, valores negativos desses parâmetros não foram considerados durante a estimação.

Os valores $T_{r e f 1}$ e $T_{r e f 2}$ são 388,15 e $493,15 \mathrm{~K}$ respectivamente. Eles foram determinados a partir das curvas de perda de massa da análise TG e correspondem à temperatura média da região onde pode-se dizer que ocorre as respectivas reações.

Os resultados da estimação para a primeira etapa da decomposição térmica se encontram na Tabela 4-10. Como estratégia de otimização, optou-se por fazer a estimação de cada uma das reações separadamente, uma vez que elas são independentes, e usando o resultado da estimação da primeira reação como parâmetros fixos na estimação da segunda reação (e assim por diante.)

Tabela 4.10: Resumo dos resultados da estimação de parâmetros para a primeira etapa (desidratação) da decomposição térmica

\begin{tabular}{|cc|c|cc|c|}
\hline Valores Estimados & $\mathrm{F}_{o b j}$ & \multicolumn{2}{|c|}{ Intervalo de confiança } & $\mathrm{R}^{2}$ \\
\cline { 1 - 4 } & & & Limite Inferior & Limite Superior & \\
\hline $\mathrm{A}_{1}$ & $-1,058587$ & 236,52 & $-1,059446$ & 1,531837 & 0,989 \\
$\mathrm{~B}_{1}$ & 1,527837 & & $-1,066857$ & 1,526361 & \\
$10^{B_{1}}$ & 33,71607413 & & & & \\
$\mathrm{~A}_{2}$ & $-1,146301$ & & $-1,120086$ & $-1,145712$ & \\
$\mathrm{~B}_{2}$ & 0,01680616 & 987,31 & 0,08492807 & 0,01669066 & 0,981 \\
$10^{B_{2}}$ & 1,039456119 & & & & \\
\hline
\end{tabular}

Simulando o modelo com os parâmetros estimados, em comparação com os dados experimentais até 20 minutos de reação tem-se as Figuras 441 e 4-42, em que DE representa os dados experimentais, PM a predição do modelo e ICM o intervalo de confiança do mesmo. Na Figura 4-42, observase ainda que há uma curva nos dados experimentais que o modelo não se ajusta, essa curva adicional é bem singela e, no presente trabalho, foi desconsiderada, como dito anteriormente. Apesar disso, o modelo prevê bem tanto o comportamento, quando a perda de massa decorrente da desidratação, perceptível também na observação dos valores de $\mathrm{R}^{2}$, ambos acima de 0,98 . 


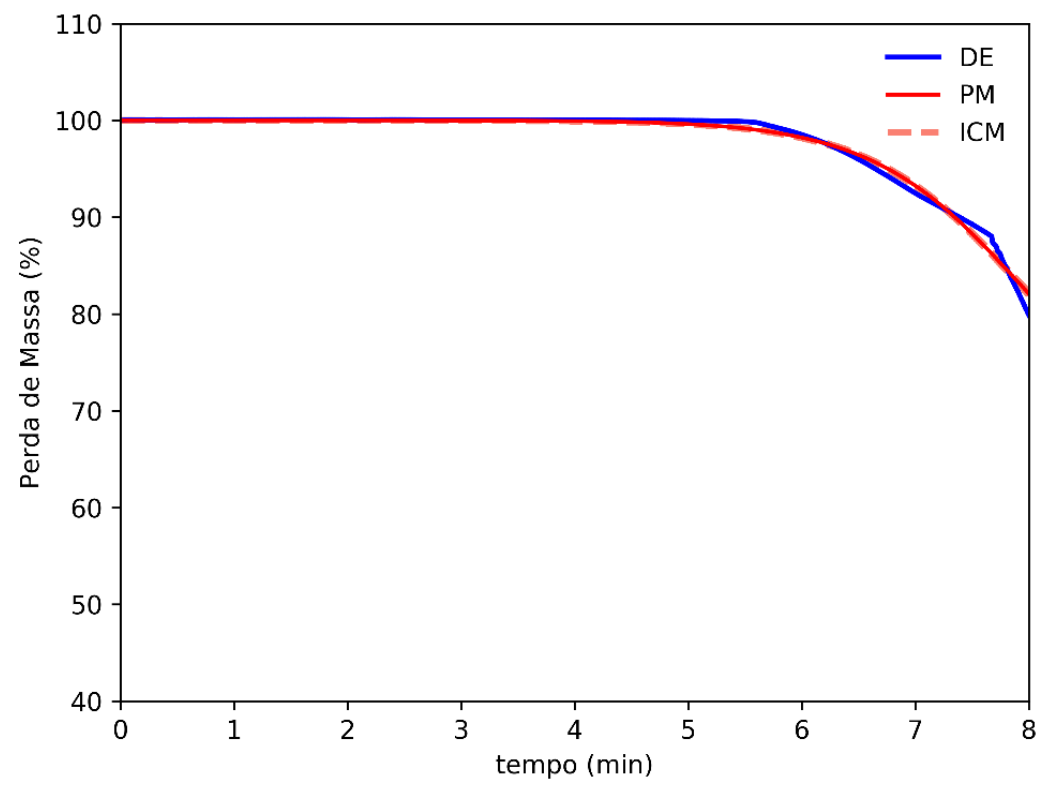

Figura 4.41: Comparação dados experimentais com o modelo, a partir dos parâmetros estimados, para a primeira reação de desidratação da primeira etapa da decomposição térmica.

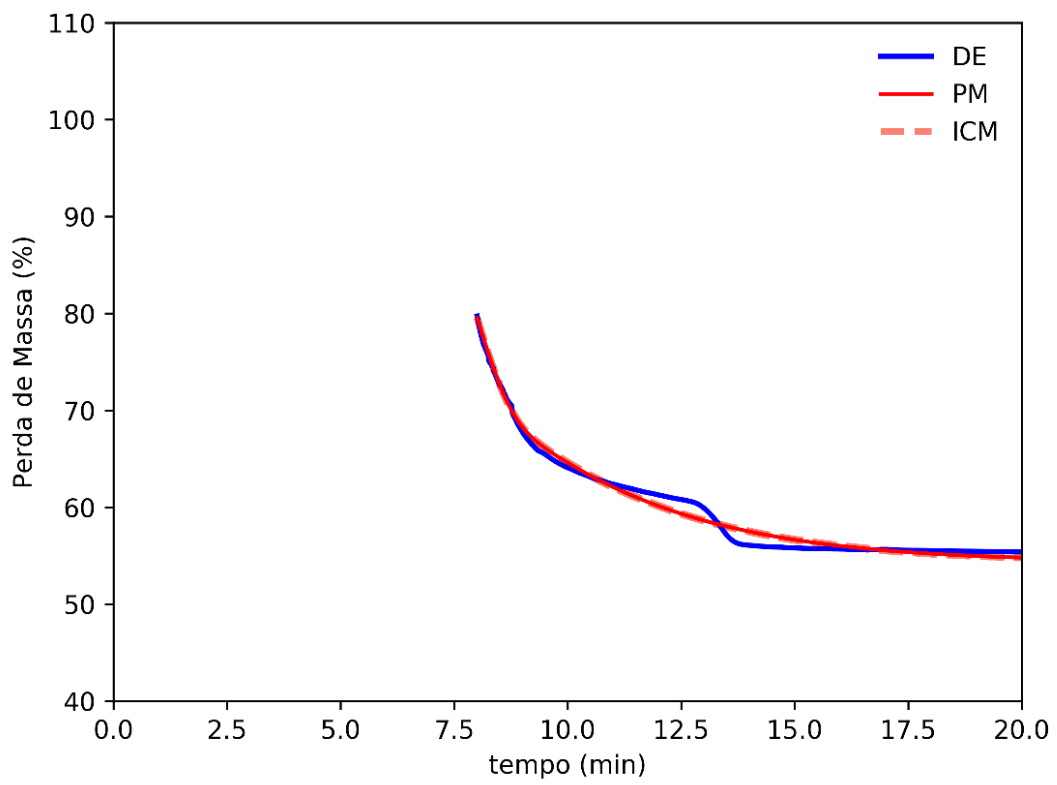

Figura 4.42: Comparação dados experimentais com o modelo, a partir dos parâmetros estimados, para a segunda reação de desidratação da primeira etapa da decomposição térmica. 
Com relação às taxas de velocidade da reação, $\mathrm{k}_{1}$ e $\mathrm{k}_{2}$, que são funções dos parâmetros de Arrhenius e da temperatura $\left(f\left(k_{0}, E_{a}, T\right)\right)$, é possível observar o comportamento destes ao longo do tempo reacional pelas Figuras 4-43 e 4-44. Nota-se nos gráficos a variação do seu perfil e a dependência da temperatura pois, conforme a reação prossegue, há um aumento contínuo da temperatura.

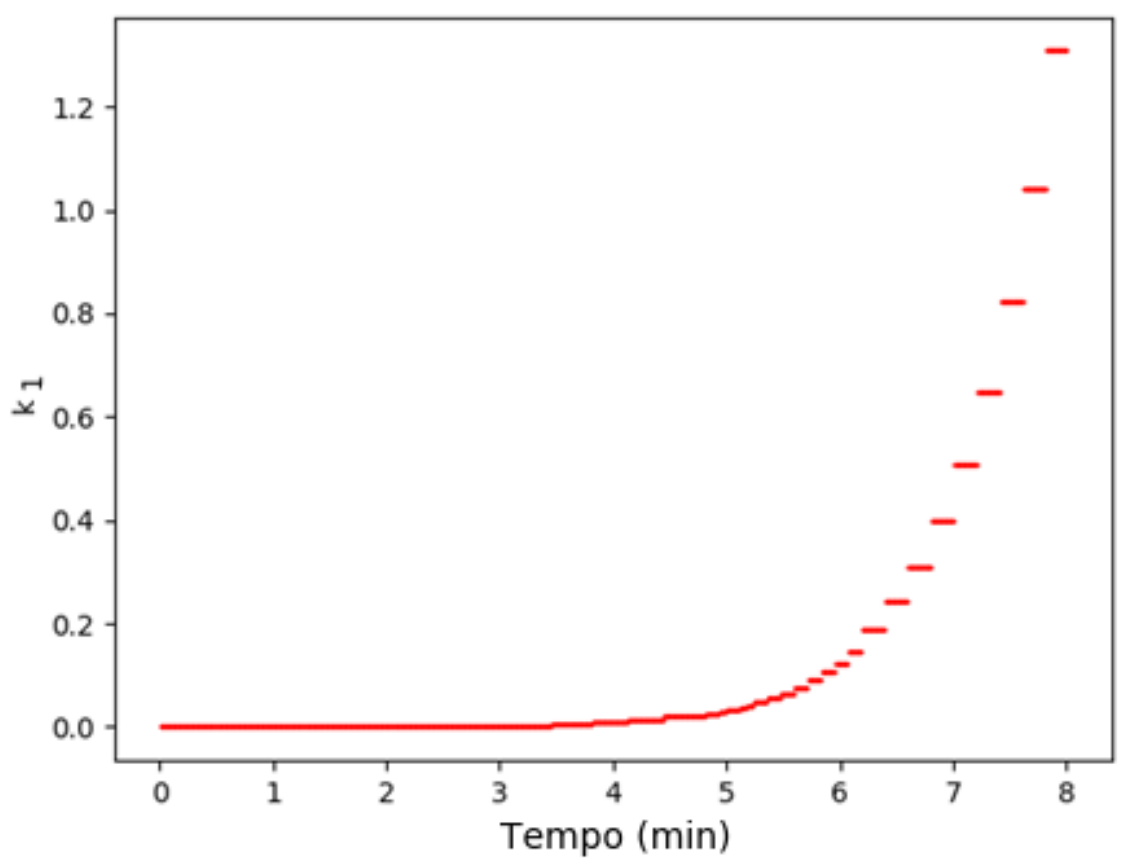

Figura 4.43: Taxa específica da primeira reação referente à primeira reação da primeira etapa da decomposição térmica. 


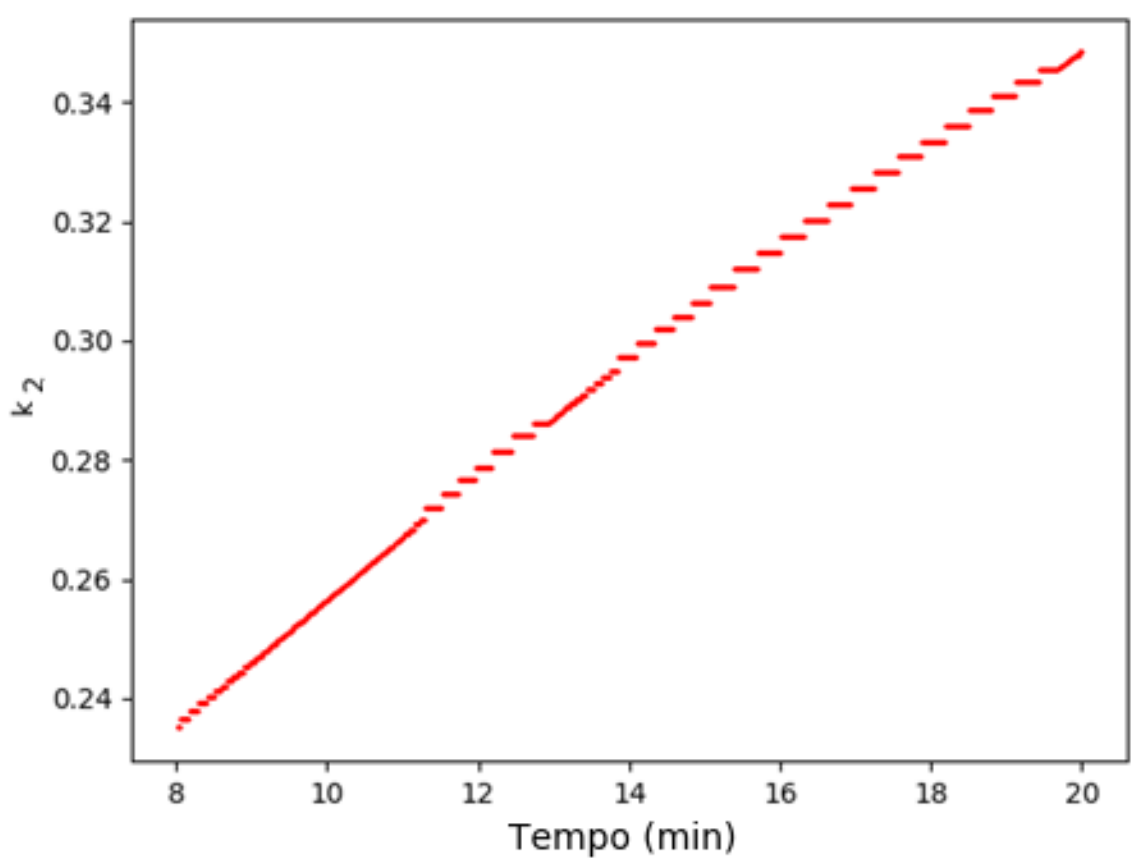

Figura 4.44: Taxa específica da primeira reação referente à primeira reação da primeira etapa da decomposição térmica.

A matriz de covariância dos parâmetros estimados e a sua matriz de correlação estão apresentadas nas Equações 4-11 e 4-12 respectivamente, para os parâmetros $A_{1}$ e $B_{1}$, e 4-13 e 4-14 para os parâmetros $A_{2}$ e $B_{2}$.

$$
\begin{aligned}
& V_{1}=\left[\begin{array}{ll}
1,305 * 10^{-05} & 1,539 * 10^{-06} \\
1,539 * 10^{-06} & 7,416 * 10^{-06}
\end{array}\right] \\
& A_{1} \quad B_{1} \\
& V_{\text {correlação }}=A_{1} \quad 1,000 \quad 0,156 \\
& B_{1} \quad 0,156 \quad 1,000 \\
& V_{2}=\left[\begin{array}{ll}
3,042 * 10^{-05} & 6,003 * 10^{-05} \\
6,003 * 10^{-05} & 2,656 * 10^{-04}
\end{array}\right] \\
& A_{2} \quad B_{2} \\
& V_{\text {correlação }}=A_{2} \quad 1,000 \quad 0,667 \\
& B_{2} \quad 0,667 \quad 1,000
\end{aligned}
$$

A matriz de correlação dos parâmetros $A_{1}$ e $B_{1}$ mostra que os parâmetros estimados não são dependentes entre si, dado que a correlação entre eles é menor que 0,2. Esse resultado indica que os parâmetros separadamente são significativos.

Por outro lado, para os parâmetros $A_{2}$ e $B_{2}$, tem-se a correlação na ordem de 0,66 , indicando que os parâmetros podem ser alterados um com os outros, dificultado a estimação em separado.

Em seguida, as Figuras 4-45 e 4-46 apresentam as regiões de confiança dos parâmetros $A_{1}$ e $B_{1}$, e $A_{2}$ e $B_{2}$ respectivamente, e posicionados 
no centro das mesmas estão os valores ótimos fornecidos pelo enxame. O desenho em formato de cruz afunilando para o ponto ótimo central na primeira figura indica como foi o caminho de convergência do método de otimização enxame de partículas.

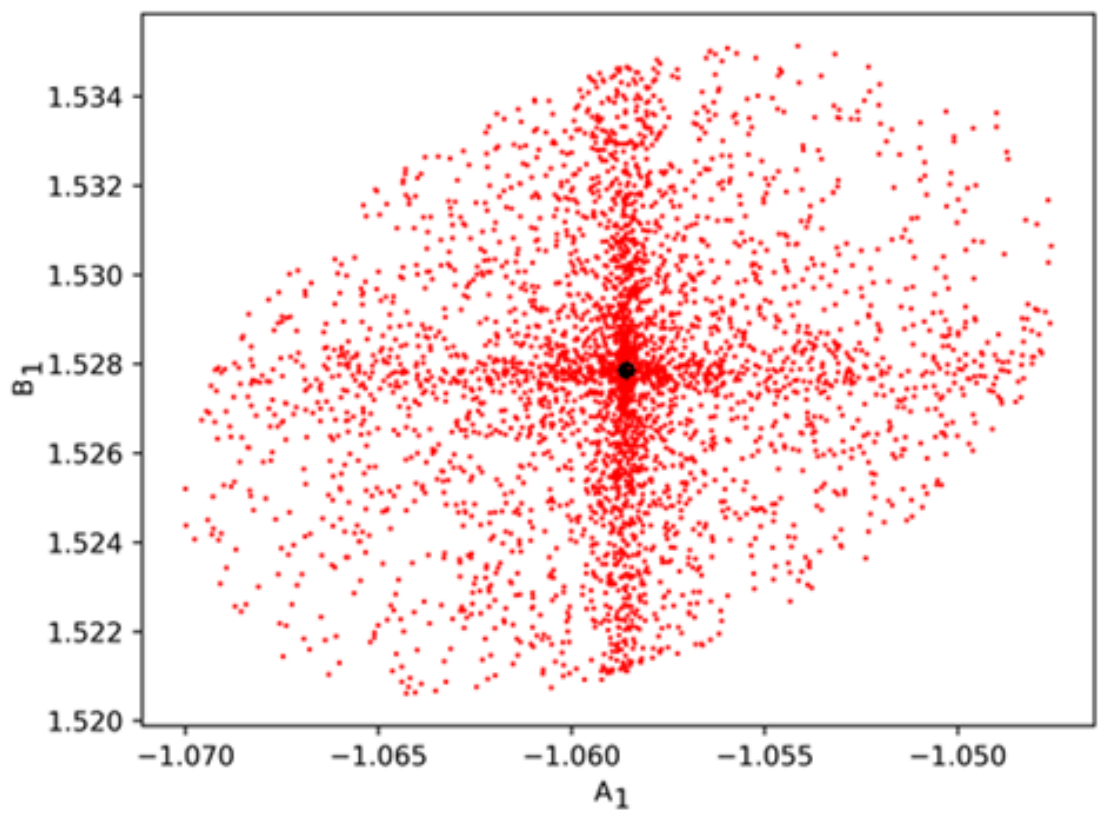

Figura 4.45: Região de confiança dos parâmetros $A_{1}$ e $B_{1}$ para a decomposição térmica.

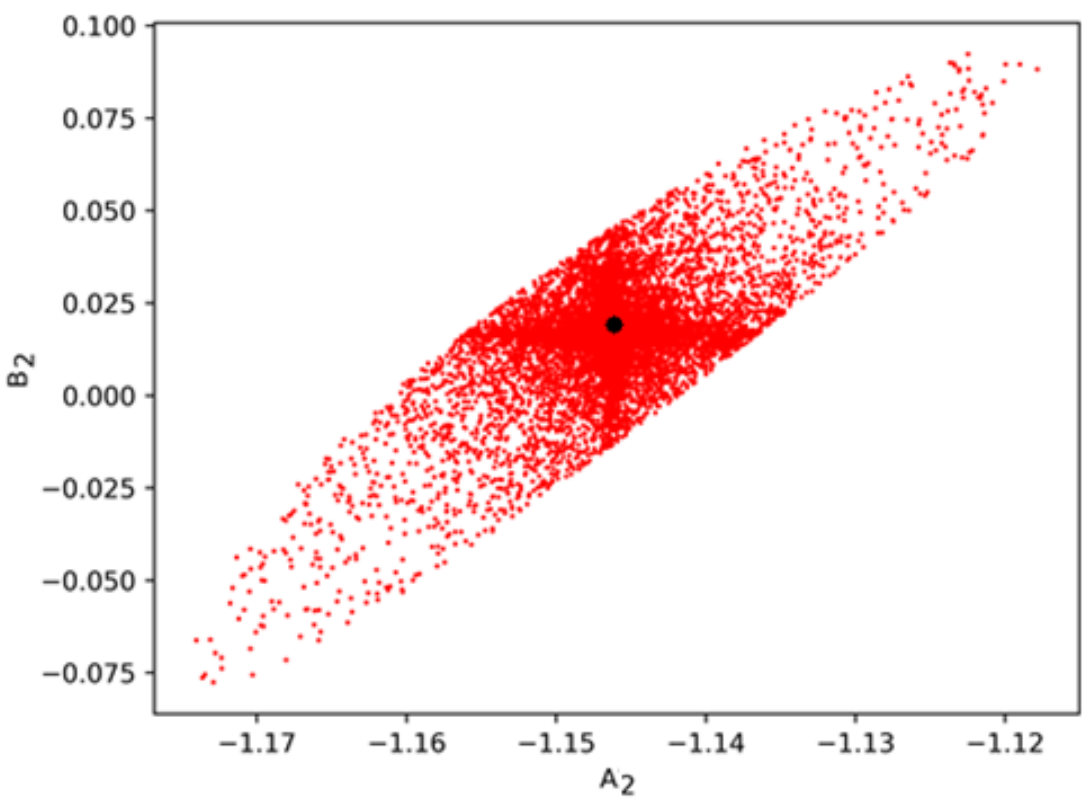

Figura 4.46: Região de confiança dos parâmetros $A_{2}$ e $B_{2}$ para a decomposição térmica. 
Por fim, os parâmetros de Arrhenius, fator pré-exponencial e energia de ativação, foram recuperados (usando as Equações 3.35 e 3.36) utilizando os 4 parâmetros estimados. Esses resultados encontram-se na Tabela 4-11.

Tabela 4.11: Parâmetros de Arrhenius para a primeira etapa da decomposição térmica

$$
\begin{array}{llll}
\mathrm{k}_{01}\left(\mathrm{~min}^{-1}\right) & \mathrm{Ea}_{1}(\mathrm{~J} / \mathrm{mol}) & \mathrm{k}_{02}\left(\mathrm{~min}^{-1}\right) & \mathrm{Ea}_{2}(\mathrm{~J} / \mathrm{mol}) \\
1,524 * 10^{+14} & 108804,4 & 0,899 & 4261,8
\end{array}
$$

\subsubsection{2}

\section{2a Etapa}

A Tabela 4-12 apresenta quais parâmetros foram estimados para a $2^{\text {a }}$ etapa da decomposição térmica do alúmen de potássio, as equações das constantes cinéticas em função desses parâmetros e quais reações essas constantes fazem parte. Novamente, como estratégia de otimização, as reações tiveram suas estimações feitas separadamente.

Tabela 4.12: Parâmetros estimados, correspondentes constantes cinéticas e suas respectivas reações para a Etapa 2 da decomposição térmica do alúmen de potássio

\begin{tabular}{ccc}
\hline Parâmetros estimados $^{a}$ & Constantes cinéticas & Reação \\
\hline $\mathrm{A}_{3}$ & $k_{3}=e^{A_{3}+10^{B_{3}}\left(\left(T-T_{\text {ref }}\right) / T\right)}$ & Equação (3.22) \\
\hline $\mathrm{B}_{3}$ & $k_{4}=e^{A_{4}+10^{B_{4}}\left(\left(T-T_{\text {ref }}\right) / T\right)}$ & Equação (3.23) \\
\hline $\mathrm{A}_{4}$ &
\end{tabular}

Os parâmetros $\mathrm{B}_{3}$ e $\mathrm{B}_{4}$ originários da Equação 3.34 foram estimados na sua forma logarítmica.

Os valores $T_{\text {ref } 3}$ e $T_{\text {ref } 4}$ são ambos $1122,15 \mathrm{~K}$. Como a temperatura de referência deve ser a temperatura média da região onde ocorre a reação e, como foi dito anteriormente, as duas reações de decomposição aparecem sobrepostas na análise TG, optou-se por utilizar a mesma temperatura de referência para ambas as estimações.

O resumo dos resultados da estimação para a segunda etapa da decomposição térmica se encontra na Tabela 4-13. 
Tabela 4.13: Resumo do resultado da estimação de parâmetros para a segunda etapa (decomposição) da decomposição térmica

\begin{tabular}{|c|c|c|c|c|c|}
\hline \multicolumn{2}{|c|}{ Valores Estimados } & $\mathrm{F}_{o b j}$ & \multicolumn{2}{|c|}{ Intervalo de confiança } & \multirow[t]{2}{*}{$\mathrm{R}^{2}$} \\
\hline & & & Limite Inferior & Limite Superior & \\
\hline $\mathrm{A}_{3}$ & 0,659153 & \multirow{3}{*}{1237,71} & 0,574574 & 0,7626067 & \multirow{3}{*}{0,989} \\
\hline $\mathrm{B}_{3}$ & 1,650566 & & 1,64091 & 1,66115 & \\
\hline $10^{B_{3}}$ & 44,72661 & & & & \\
\hline $\mathrm{A}_{4}$ & $-1,47381$ & \multirow{3}{*}{1210,87} & $-1,48422$ & $-1,476026$ & \multirow{3}{*}{0,963} \\
\hline $\mathrm{B}_{4}$ & 0,24244 & & 0,2284857 & 0,2959523 & \\
\hline $10^{B_{4}}$ & 1,747592 & & & & \\
\hline
\end{tabular}

Simulando o modelo com os parâmetros estimados, em comparação com os dados experimentais de 20 minutos ao final da análise, tem-se as Figuras 4-47 e 4-48, em que DE representa os dados experimentais, PM a predição do modelo e ICM o intervalo de confiança do mesmo. Para ambas as figuras, nos pontos inicial e final das reações, observa-se ainda que há uma pequena diferença entre o resultado do modelo e dos dados experimentais. Porém, como essa diferença é menor que $3 \%$, o modelo ainda descreve bem tanto o comportamento, quando a perda de massa decorrente da decomposição.

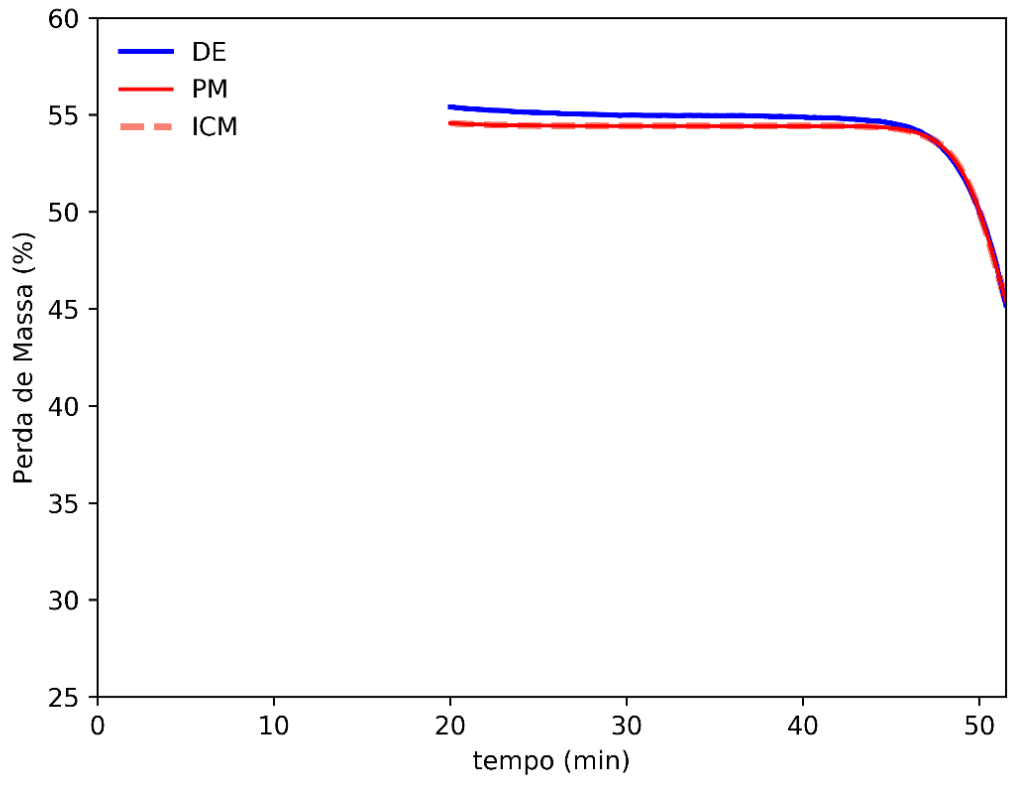

Figura 4.47: Comparação dos dados experimentais com o modelo, a partir dos parâmetros estimados, para a primeira reação da segunda etapa da decomposição térmica. 


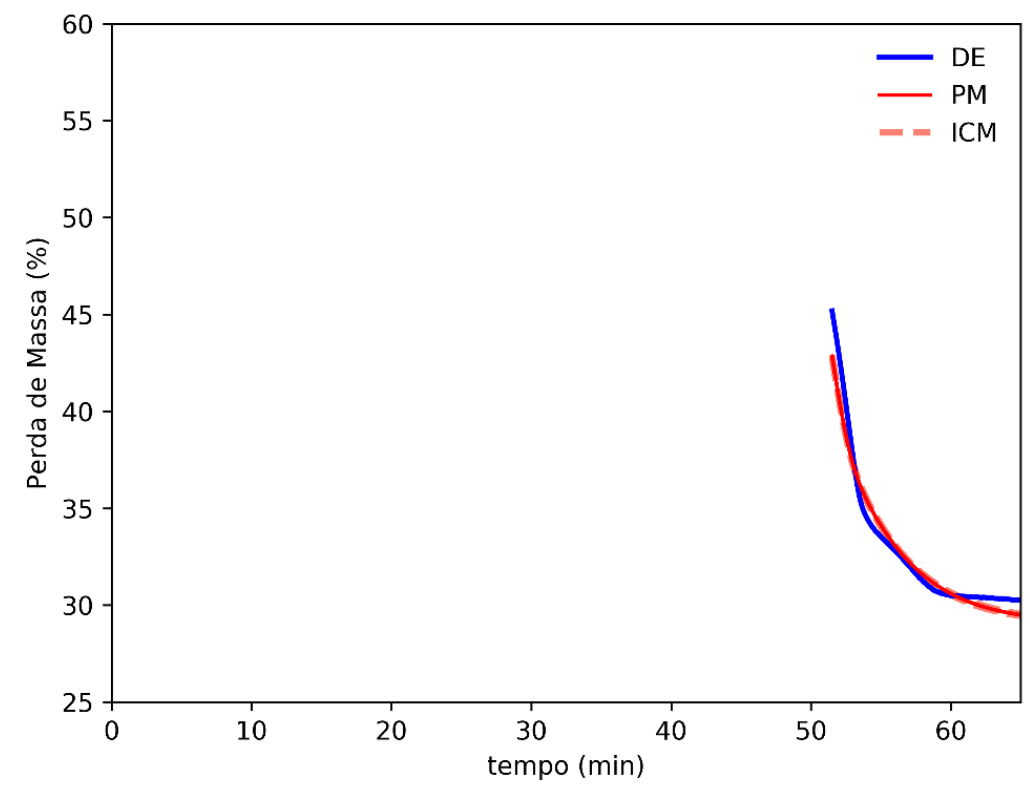

Figura 4.48: Comparação dos dados experimentais com o modelo, a partir dos parâmetros estimados, para a segunda reação da segunda etapa da decomposição térmica.

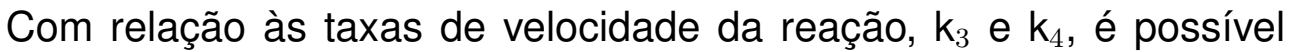
observar o comportamento destas ao longo do tempo reacional pelas Figuras 4-49 e 4-50. Nota-se nos gráficos a variação do seu perfil e a dependência da temperatura pois, conforme a reação prossegue, há um aumento contínuo da temperatura, como visto anteriormente. 


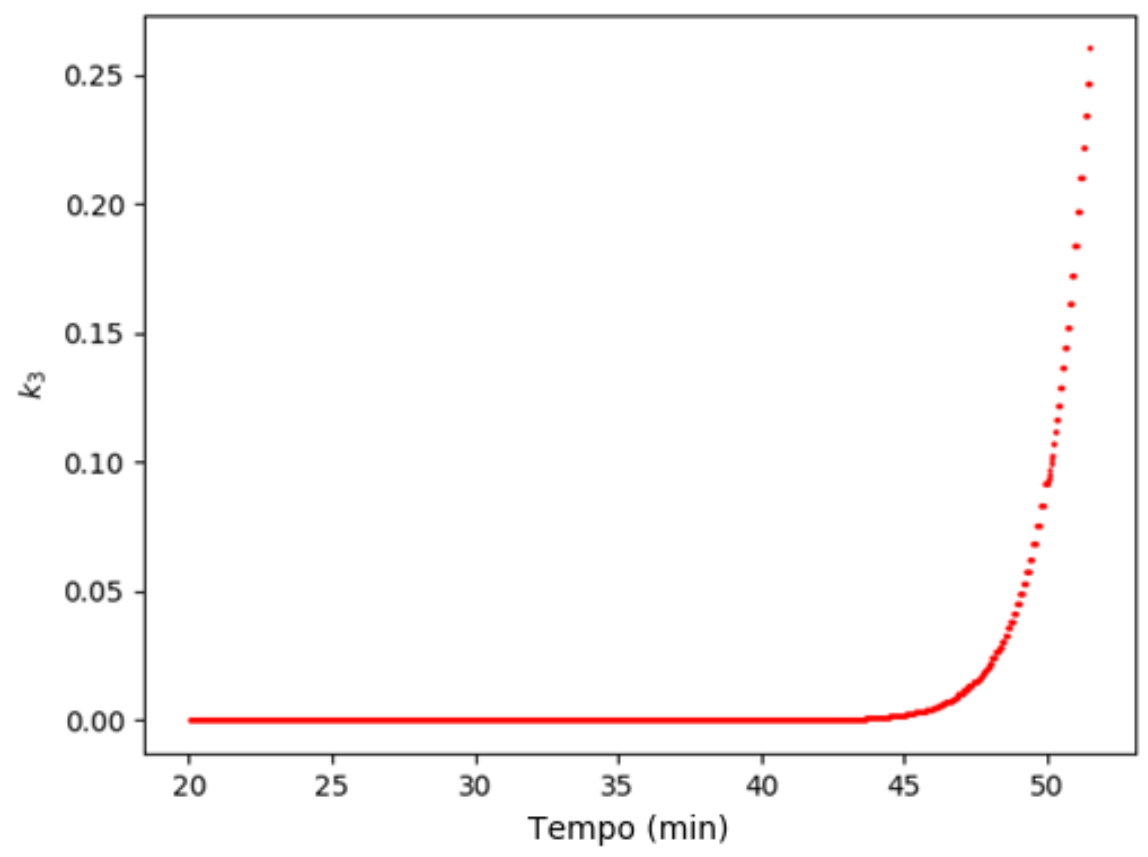

Figura 4.49: Taxa específica da primeira reação referente à segunda etapa da decomposição térmica.

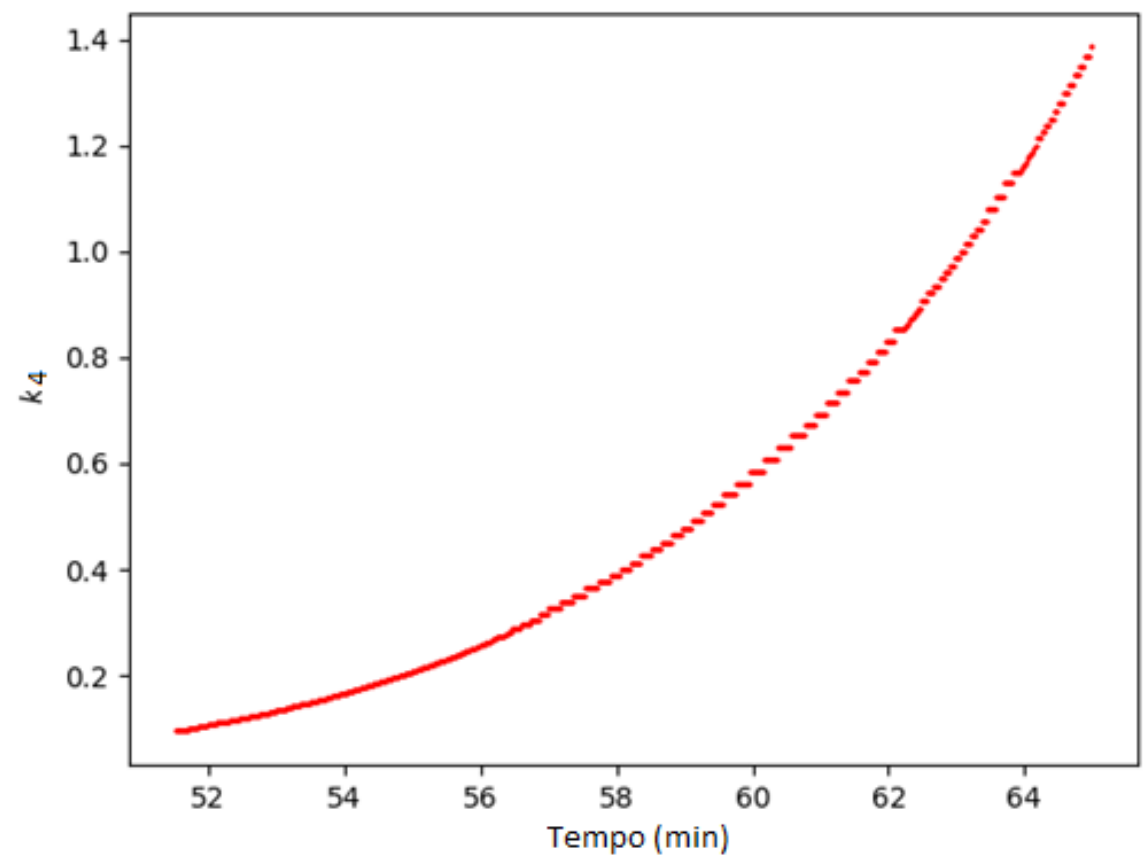

Figura 4.50: Taxa específica da segunda reação referente à segunda etapa da decomposição térmica.

A matriz de covariância dos parâmetros estimados e a sua matriz de correlação estão apresentadas nas Equações 4-17 e 4-18 respectivamente, para os parâmetros $A_{3}$ e $B_{3}$, e 4-19 e 4-20 para os parâmetros $A_{4}$ e $B_{4}$. 


$$
\begin{aligned}
& V_{3}=\left[\begin{array}{ll}
7,076 * 10^{-04} & 7,326 * 10^{-05} \\
7,326 * 10^{-05} & 8,657 * 10^{-06}
\end{array}\right] \\
& A_{3} \quad B_{3} \\
& V_{\text {correlação }}=A_{3} \quad 1,000 \quad 0,936 \\
& B_{3} \quad 0,936 \quad 1,000 \\
& V_{4}=\left[\begin{array}{ll}
5,709 * 10^{-05} & 2,918 * 10^{-04} \\
2,918 * 10^{-04} & 5,132 * 10^{-03}
\end{array}\right] \\
& A_{4} \quad B_{4} \\
& V_{\text {correlação }}=A_{4} \quad 1,000 \quad 0,545 \\
& B_{4} \quad 0,545 \quad 1,000
\end{aligned}
$$

A matriz de correlação dos parâmetros $A_{3}$ e $B_{3}$ mostra que os parâmetros estimados são muito dependentes entre si, dado que a correlação entre eles é maior que 0,9. Esse resultado indica que os parâmetros separadamente não podem ser medidos, visto que são muito interligados. Caso similar para os parâmetros $\mathrm{A}_{4}$ e $\mathrm{B}_{4}$, que tem a correlação na ordem de 0,5 , indicando que os parâmetros têm também uma dependência.

Em seguida, as Figuras 4-51 e 4-52 apresentam as regiões de confiança dos parâmetros $A_{3}$ e $B_{3}$, e $A_{4}$ e $B_{4}$ respectivamente, e posicionados no centro das mesmas estão os valores ótimos fornecidos pelo enxame. O desenho em formato alongado evidencia a grande correlação entre os parâmetros, enquanto que para os parâmetros $A_{4}$ e $B_{4}$, vê-se a nuvem em forma mais dispersa.

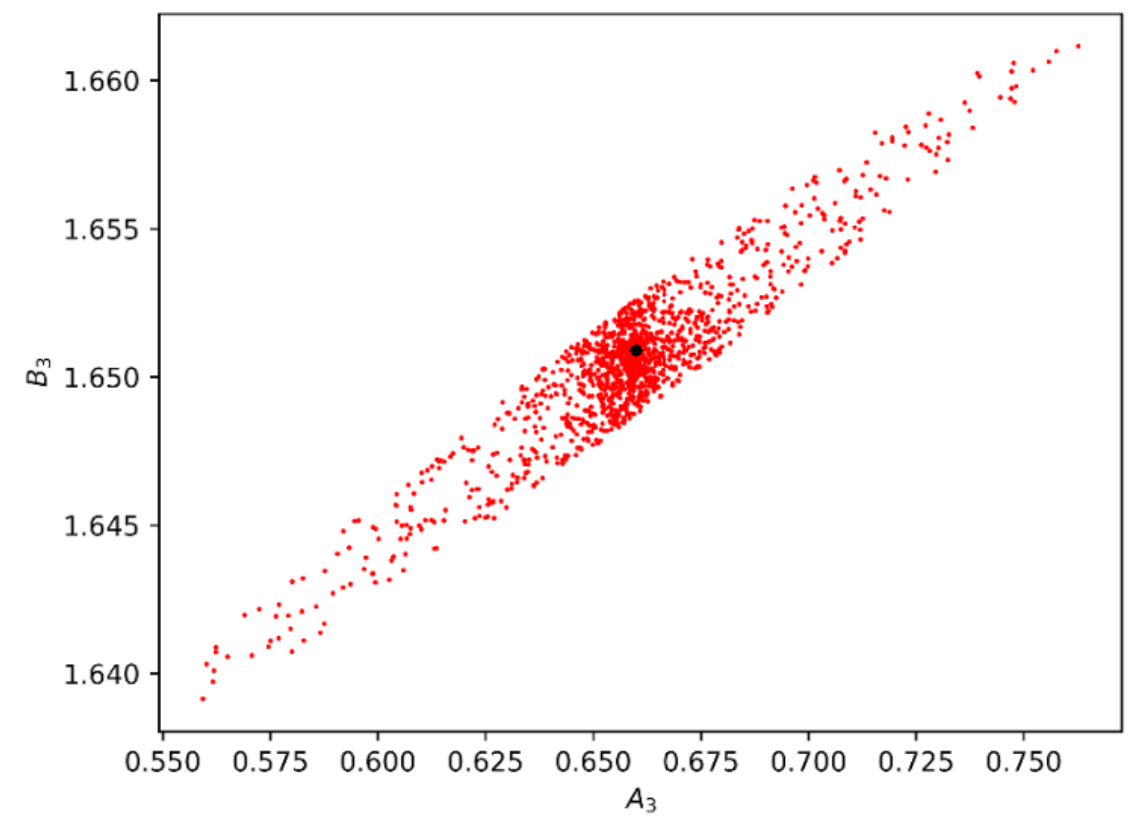

Figura 4.51: Região de confiança dos parâmetros $A_{3}$ e $B_{3}$ para a decomposição térmica. 


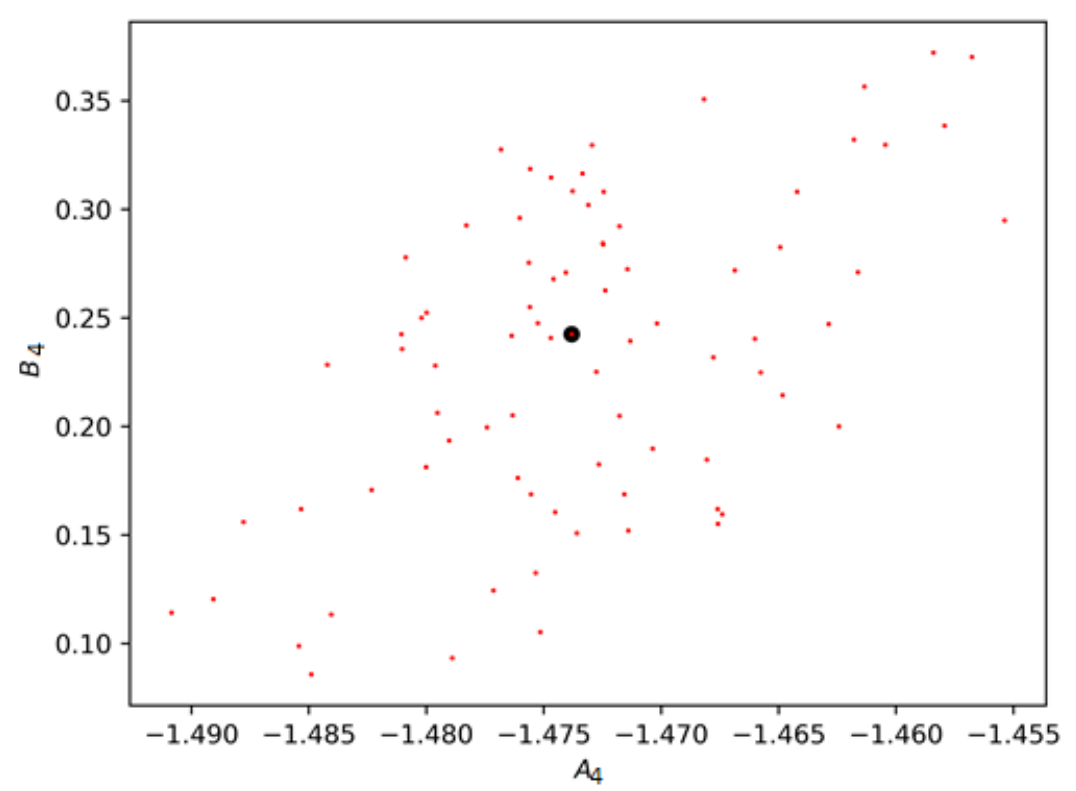

Figura 4.52: Região de confiança dos parâmetros $\mathrm{A}_{4}$ e $\mathrm{B} 4$ para a decomposição térmica.

Por fim, os parâmetros de Arrhenius, fator pré-exponencial e energia de ativação, foram recuperados (usando as Equações 3.35 e 3.36) utilizando os 4 parâmetros estimados. Esses resultados encontram-se na Tabela 4-14.

Tabela 4.14: Parâmetros de Arrhenius para a segunda etapa da decomposição térmica

$$
\begin{array}{llll}
\mathrm{k}_{03}\left(\mathrm{~min}^{-1}\right) & \mathrm{Ea}_{3}(\mathrm{~J} / \mathrm{mol}) & \mathrm{k}_{04}\left(\mathrm{~min}^{-1}\right) & \mathrm{Ea}_{4}(\mathrm{~J} / \mathrm{mol}) \\
5,13792 * 10^{+19} & 417279,4 & 1,315 & 16304,25
\end{array}
$$

Assim, a Tabela 4-15 mostra os resultados finais do modelo, dos dados experimentais e o erro entre eles para as composições mássicas de $\mathrm{Al} 2 \mathrm{O} 3$ e K2SO4.

Tabela 4.15: Comparação dos resultados do modelo e dos dados experimentais

\begin{tabular}{|c|c|c|c|}
\hline & Resultado Experimental & Resultado do Modelo & Erro (\%) \\
\hline $\mathrm{Al}_{2} \mathrm{O}_{3}$ & 0,3696 & 0,3587 & 2,94 \\
\hline $\mathrm{K}_{2} \mathrm{SO}_{4}$ & 0,6304 & 0,6226 & 1,12 \\
\hline
\end{tabular}

\subsection{2}




\subsubsection{1}

\section{1․ Etapa}

Como comentado na Seção 3.2, as constantes cinéticas foram representadas por meio de uma equação reparametrizada de Arrhenius (Equação 3.34) a fim de diminuir a correlação entre os parâmetros estimados. A Tabela 4-16 apresenta quais parâmetros foram estimados, as equações das constantes cinéticas em função desses parâmetros e quais reações essas constantes fazem parte.

Tabela 4.16: Parâmetros estimados, correspondentes constantes cinéticas e suas respectivas reações para a Etapa 1 da decomposição redutora do alúmen de potássio

\begin{tabular}{ccc}
\hline Parâmetros estimados & Constantes cinéticas & Reação \\
\hline $\mathrm{A}_{1}$ & $k_{1}=e^{A_{1}+10^{B_{1}}\left(\left(T-T_{r e f 1}\right) / T\right)}$ & Equação (4.2) \\
\hline $\mathrm{B}_{1}$ & $k_{2}=e^{A_{2}+10^{B_{2}\left(\left(T-T_{r e f 2}\right) / T\right)}}$ & Equação (3.21) \\
\hline $\mathrm{A}_{2}$ & \\
\hline $\mathrm{B}_{2}$ &
\end{tabular}

Os parâmetros $B_{1}$ e $B_{2}$ foram estimados na sua forma logarítmica. Com essa estratégia, valores negativos desses parâmetros não foram considerados durante a estimação.

Os valores $T_{r e f 1}$ e $T_{\text {ref } 2}$ são 388,15 e 493,15 $\mathrm{K}$ respectivamente. Eles foram determinados a partir das curvas de perda de massa da análise TG e correspondem à temperatura média da região onde pode-se dizer que ocorre as respectivas reações.

Os resultados da estimação para a primeira etapa da decomposição redutora se encontram na Tabela 4-17. De maneira semelhante à decomposição térmica, optou-se por fazer a estimação de cada uma das reações separadamente, uma vez que elas são independentes, e usando o resultado da estimação da primeira reação como parâmetros fixos na estimação da segunda reação (e assim por diante.)

Tabela 4.17: Resumo dos resultados da estimação de parâmetros para a primeira etapa (desidratação) da decomposição redutora.

\begin{tabular}{|ccc|cc|c|}
\hline Valores Estimados & $\mathrm{F}_{o b j}$ & \multicolumn{3}{|c|}{ Intervalo de confiança } & $\mathrm{R}^{2}$ \\
\cline { 6 - 6 } & & & Limite Inferior & Limite Superior & \\
\hline $\mathrm{A}_{1}$ & $-1,17227$ & \multirow{2}{*}{8,01} & $-1,17532$ & $-1,11734$ & \multirow{2}{*}{0,991} \\
$\mathrm{~B}_{1}$ & 1,512332 & & 1,508722 & 1,523226 & \\
$10^{B_{1}}$ & 32,53359 & & & & \\
$\mathrm{~A}_{2}$ & $-1,68463$ & & $-1,67077$ & $-1,47128$ & 0,970 \\
$\mathrm{~B}_{2}$ & 0,271006 & 43,53 & -5 & 0,268586 & \\
$10^{B_{2}}$ & 1,866407 & & & & \\
\hline
\end{tabular}

Simulando o modelo com os parâmetros estimados, em comparação com os dados experimentais até 20 minutos de reação tem-se as Figuras 453 e 4-54, em que DE representa os dados experimentais, PM a predição do 
modelo e ICM o intervalo de confiança do mesmo. Na Figura 4-54, observase a mesma curva extra, antes visualizada na decomposição térmica. Apesar disso, o modelo prevê bem tanto o comportamento, quando a perda de massa decorrente da desidratação.

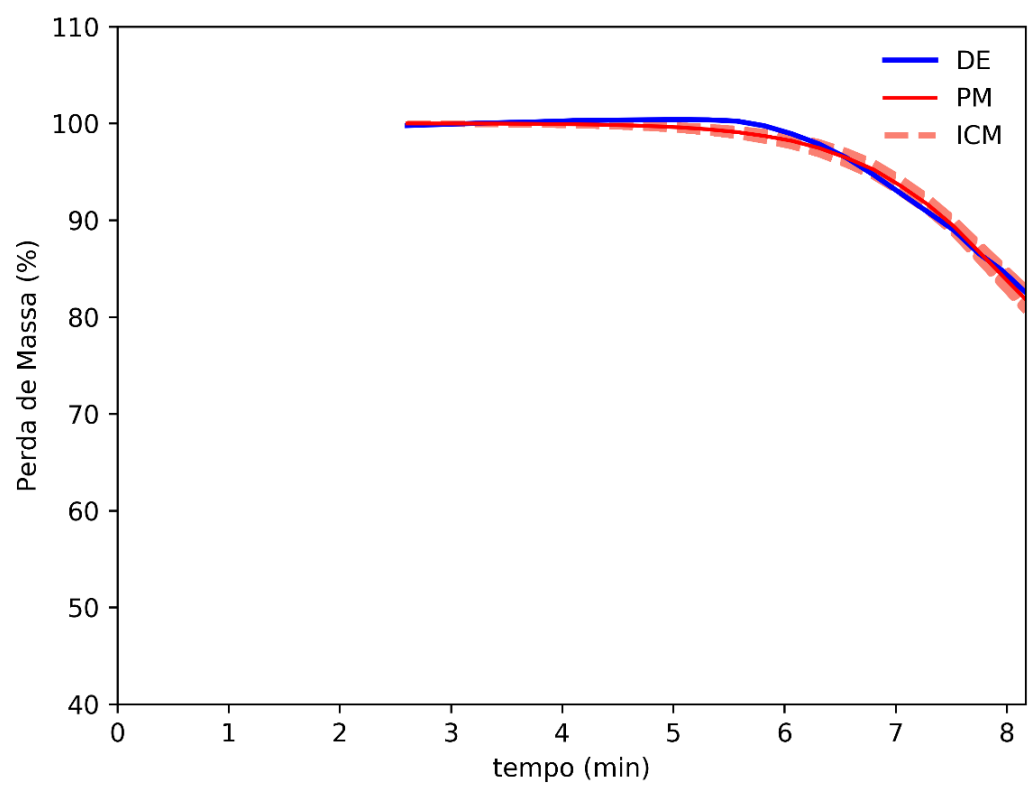

Figura 4.53: Comparação dos dados experimentais com o modelo, a partir dos parâmetros estimados, para a primeira reação da segunda etapa da decomposição redutora. 


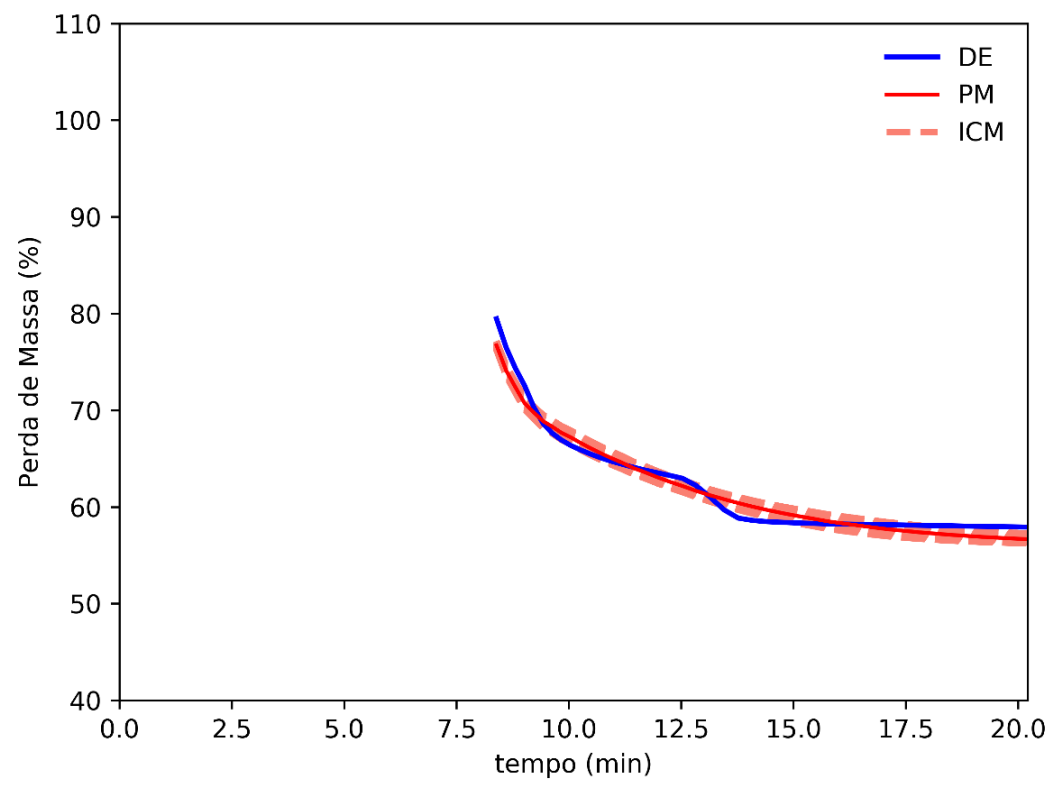

Figura 4.54: Comparação dos dados experimentais com o modelo, a partir dos parâmetros estimados, para a segunda reação da segunda etapa da decomposição redutora.

Assim, tem-se os gráficos das taxas de velocidade específica pelo tempo, $k_{1}$ e $k_{2}$, para as duas reações de desidratação nas Figuras 4-55 e 4-56.

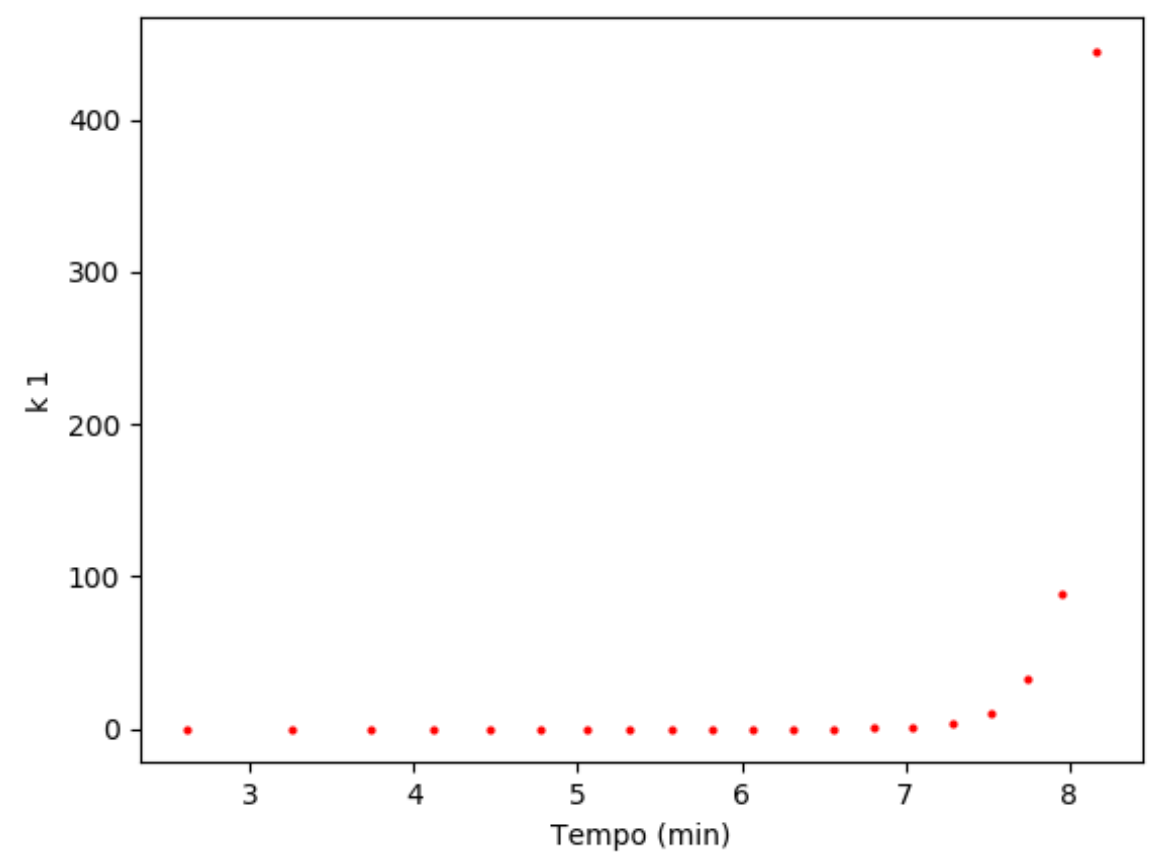

Figura 4.55: Taxa específica da primeira reação referente à primeira etapa da decomposição redutora. 


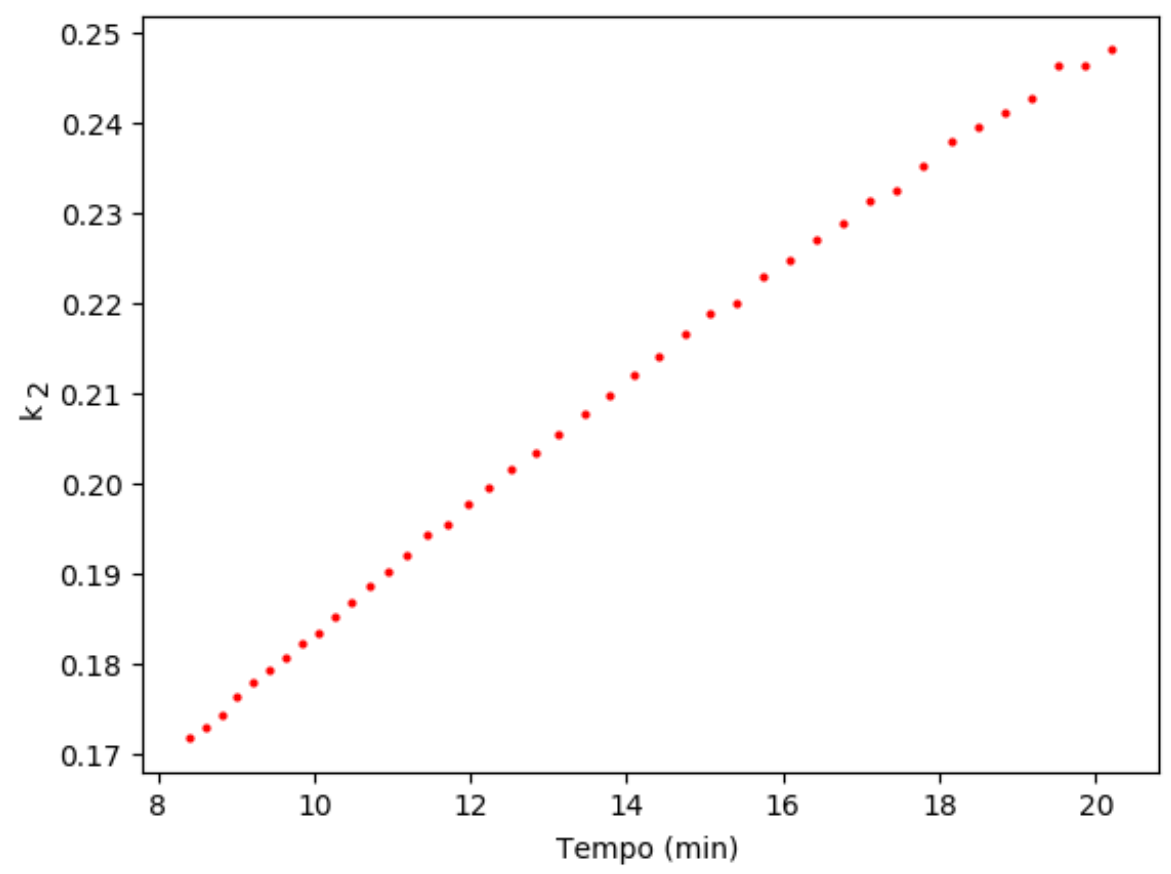

Figura 4.56: Taxa específica da segunda reação referente à primeira etapa da decomposição redutora.

A matriz de covariância dos parâmetros estimados e a sua matriz de correlação estão apresentadas nas Equações 4-21 e 4-22 respectivamente, para os parâmetros $A_{1}$ e $B_{2}$, e 4-23 e 4-24 para os parâmetros $A_{2}$ e $B_{2}$.

$$
\begin{aligned}
& V_{1}=\left[\begin{array}{ll}
1,254 * 10^{-03} & 1,101 * 10^{-05} \\
1,101 * 10^{-05} & 5,081 * 10^{-04}
\end{array}\right] \\
& A_{1} \quad B_{1} \\
& V_{\text {correlação }}=\begin{array}{lll}
A_{1} & 1,000 & 0,014 \\
B_{1} & 0,014 & 1,000
\end{array} \\
& V_{2}=\left[\begin{array}{cc}
3,817 * 10^{-03} & -5,871 * 10^{-03} \\
-5,871 * 10^{-02} & 1,988 * 10^{-02}
\end{array}\right] \\
& A_{2} \quad B_{2} \\
& V_{\text {correlação }}=A_{2} \quad 1,000 \quad-0,674 \\
& B_{2} \quad 0,674 \quad 1,000
\end{aligned}
$$

A matriz de correlação dos parâmetros $A_{1}$ e $B_{1}$ mostra que os parâmetros estimados são independentes e, portanto, significativos, dado que a correlação entre eles é muito pequena. Já para os parâmetros $A_{2}$ e $B_{2}$, temse uma correlação maior, da ordem de 0,67. Esse resultado indica que os parâmetros separadamente não podem ser medidos, visto que são muito interligados.

Em seguida, as Figuras 4-57 e 4-58 apresentam as regiões de confiança dos parâmetros $A_{1}$ e $B_{1}$, e $A_{2}$ e $B_{2}$ respectivamente, e posicionados no centro das mesmas estão os valores ótimos fornecidos pelo enxame. 
Para os parâmetros $A_{1}$ e $B_{1}$, vê-se a nuvem em forma de cruz, mostrando como dito antes, a convergência do método. Para o desenho em formato alongado tem-se a grande correlação entre os parâmetros.

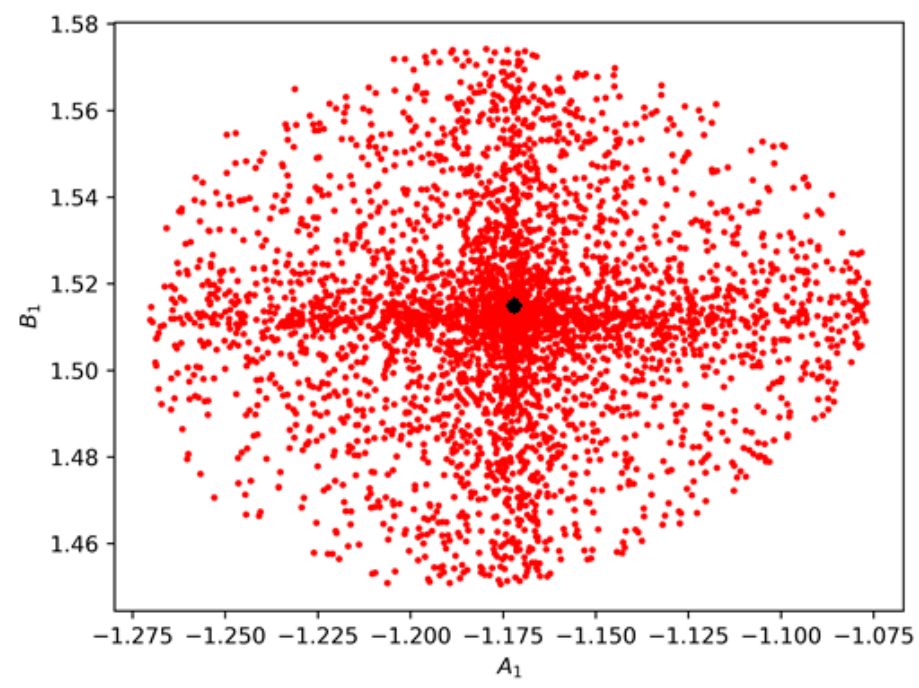

Figura 4.57: Região de confiança dos parâmetros $A_{1}$ e $B_{1}$ para a decomposição redutora.

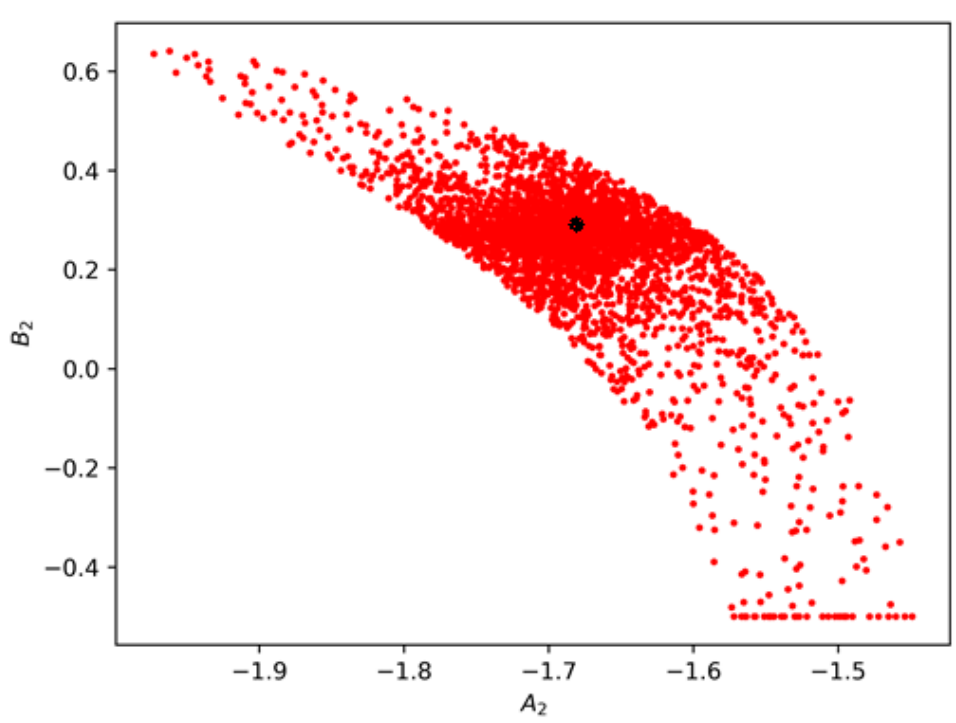

Figura 4.58: Região de confiança dos parâmetros $\mathrm{A}_{2}$ e $\mathrm{B}_{2}$ para a decomposição redutora.

Por fim, os parâmetros de Arrhenius, fator pré-exponencial e energia de ativação, foram recuperados (usando as Equações 3.35 e 3.36) utilizando os 4 parâmetros estimados. Esses resultados encontram-se na Tabela 4-18. 
Tabela 4.18: parâmetros estimados para a primeira etapa da decomposição redutora

$$
\begin{array}{llll}
\mathrm{k}_{01}\left(\mathrm{~min}^{-1}\right) & \mathrm{Ea}_{1}(\mathrm{~J} / \mathrm{mol}) & \mathrm{k}_{02}\left(\mathrm{~min}^{-1}\right) & \mathrm{Ea}_{2}(\mathrm{~J} / \mathrm{mol}) \\
4,169 * 10^{+13} & 104988,5 & 1,199 & 7652,4
\end{array}
$$

\subsubsection{2}

\section{Etapa}

A Tabela 4-19 apresenta quais parâmetros foram estimados para a $2^{\underline{a}}$ etapa da decomposição redutora do alúmen de potássio, as equações das constantes cinéticas em função desses parâmetros e quais reações essas constantes fazem parte. Para essa etapa, como demonstrado pelo Modelo 5, o processo ocorre em uma única reação, e portanto, uma única estimação de parâmetros.

Tabela 4.19: 2 Parâmetros estimados, correspondentes constantes cinéticas e suas respectivas reações para a Etapa 2 da decomposição redutora do alúmen de potássio

\begin{tabular}{ccc}
\hline Parâmetros estimados $^{a}$ & Constantes cinéticas & Reação \\
\hline $\mathrm{A}_{3}$ & $k_{3}=e^{A_{3}+10^{B_{3}}\left(\left(T-T_{\text {ref } 3) / T)}\right)\right.}$ & Equação (4.4) \\
\hline $\mathrm{B}_{3}$ & \\
\hline
\end{tabular}

O parâmetro $B_{3}$ foi estimado na sua forma logarítmica, como anteriormente.

O valor de $T_{r e f 3}$ é $1021,15 \mathrm{~K}$, e foi determinado pela visualização da curva de decomposição na análise de TG da amostra R15In.

O resumo dos resultados da estimação para a segunda etapa da decomposição térmica do alúmen de potássio na presença de agente redutor se encontra na Tabela 4-20.

Tabela 4.20: Resumo dos resultados da estimação da segunda etapa (decomposição) da decomposição redutora

\begin{tabular}{|ccc|cc|c|}
\hline Valores Estimados & $\mathrm{F}_{o b j}$ & \multicolumn{3}{|c|}{ Intervalo de confiança } & $\mathrm{R}^{2}$ \\
\cline { 5 - 6 } & & & Limite Inferior & Limite Superior & \\
\hline $\mathrm{A}_{3}$ & $-1,33287$ & \multirow{2}{*}{99,41} & 0,574574 & 0,762607 & \multirow{2}{*}{0,999} \\
$\mathrm{~B}_{3}$ & 1,495468 & & 1,64091 & 1,66115 & \\
$10^{B_{3}}$ & 31,2945 & & & & \\
\hline
\end{tabular}

A Figura 4-59 apresenta a simulação do Modelo 5 , com os parâmetros estimados, e comparando as predições do mesmo com os dados experimentais a partir de 20 minutos até o final da análise térmica. Pode-se observar nessa figura a existência de uma diferença maior no valor final das perdas de massa, em que o modelo registrou uma perda de massa menor que o real (em torno de $3 \%$ ). Ainda assim, dado o alto valor de $\mathrm{R}^{2}$, tem-se que o modelo ajustou bem aos dados experimentais. 


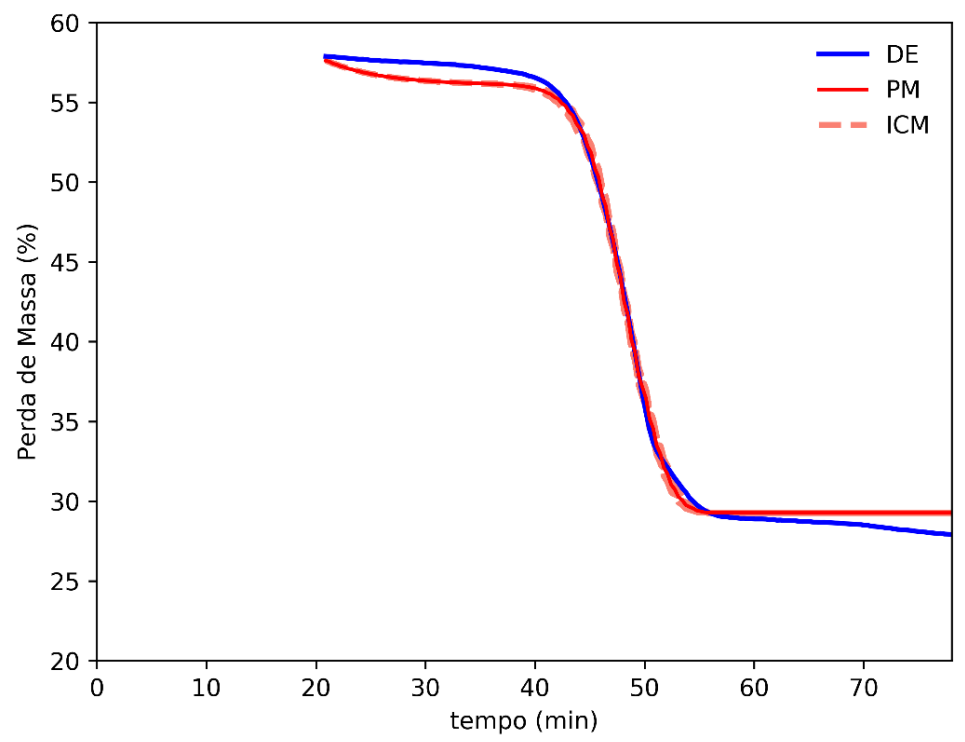

Figura 4.59: Comparação dados experimentais com o modelo, a partir dos parâmetros estimados, para a segunda etapa da decomposição redutora.

Assim, expõe-se o gráfico da taxa específica da reação (Figura 4-60). Onde nota-se novamente o seu aumento em função da temperatura.

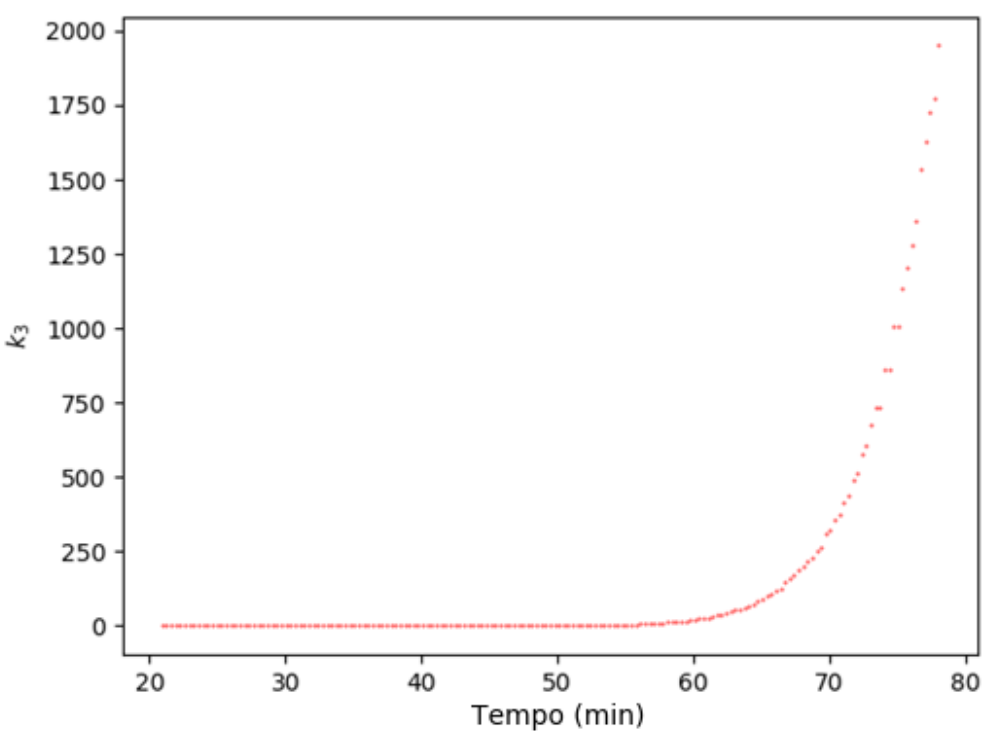

Figura 4.60: Taxa específica da reação, referente à segunda etapa da decomposição redutora.

Dessa forma, a matriz de covariância dos parâmetros estimados e a sua matriz de correlação estão apresentadas nas Equações 4-25 e 4-26 para os parâmetros $A_{3}$ e $B_{3}$. 


$$
\begin{aligned}
& V_{3}=\left[\begin{array}{ll}
7,575 * 10^{-04} & 9,039 * 10^{-05} \\
9,039 * 10^{-05} & 9,806 * 10^{-05}
\end{array}\right] \\
& A_{3} \quad B_{3} \\
& V_{\text {correlação }}=A_{3} \quad 1,000 \quad 0,331 \\
& B_{3} \quad 0,331 \quad 1,000
\end{aligned}
$$

A matriz de correlação dos parâmetros $A_{3}$ e $B_{3}$ mostra que os parâmetros estimados são independentes e, portanto, significativos, dado que a correlação entre eles é muito pequena, da ordem de 0,3.

Finalmente, tem-se a região de confiança dos dois parâmetros na Figura 4-61, em que a forma indica a convergência do modelo em torno do ponto central.

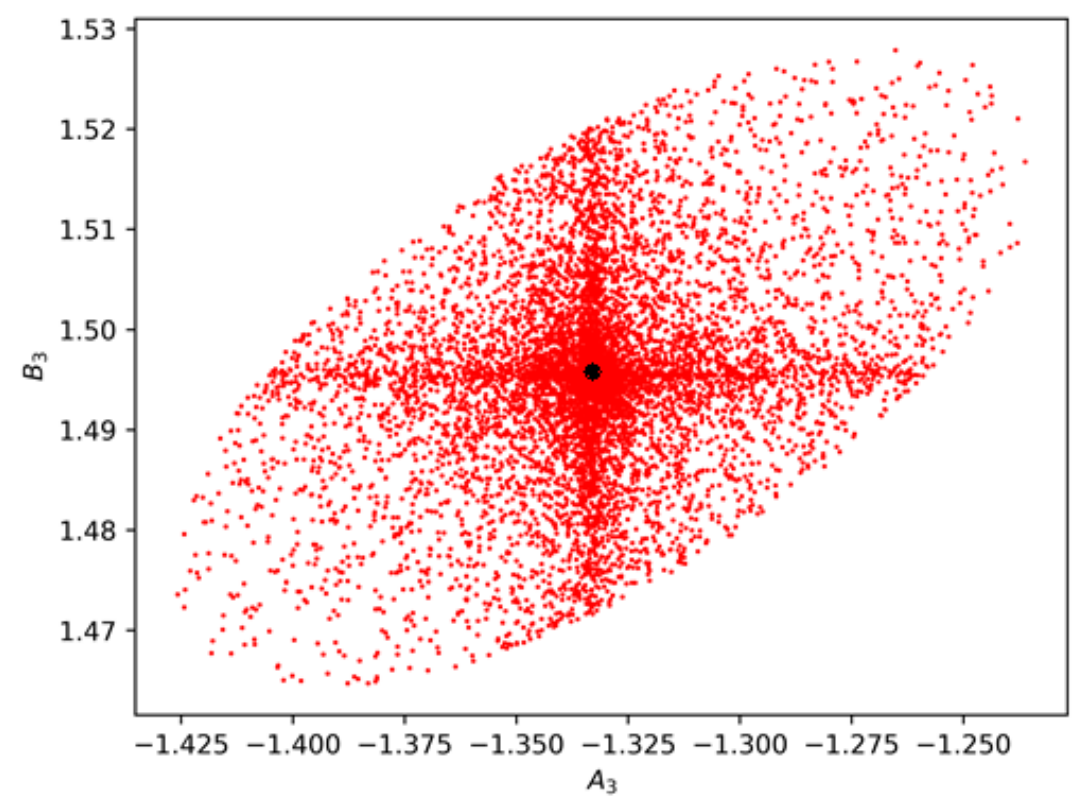

Figura 4.61: Região de confiança dos parâmetros $A_{3}$ e $B_{3}$ para a decomposição redutora.

E, portanto, na Tabela 4-21 os parâmetros de Arrhenius, fator préexponencial e energia de ativação, a partir dos 2 parâmetros estimados.

Tabela 4.21: Parâmetros de Arrhenius para a segunda etapa da decomposição redutora

$$
\begin{array}{ll}
\mathrm{k}_{03}\left(\mathrm{~min}^{-1}\right) & \mathrm{Ea}_{3}(\mathrm{~J} / \mathrm{mol}) \\
1,028 * 10^{+13} & 291963,8
\end{array}
$$




\section{5}

\section{Comentários Finais}

O Modelo 4 de quatro etapas foi escolhido como o que melhor prevê o comportamento da decomposição térmica do alúmen de potássio. É possível observar que os dados experimentais e os resultados do modelo tiveram bom ajuste, confirmando que o Modelo 4 é um modelo adequado para representar esse processo. Já para a decomposição redutora, se fez necessária a formulação de um novo modelo, o Modelo 5, que descrevesse corretamente o comportamento da decomposição na presença de agente redutor.

A partir dessas informações, se fez as estimações dos parâmetros, dividindo cada uma das decomposições (térmica e redutora) em duas etapas. A primeira etapa, a desidratação, teve bom ajuste para ambos os casos, em ambas as reações. A segunda etapa, da decomposição, foi operada como duas reações para a decomposição térmica, e com uma reação para a decomposição redutora, e ambos os casos tiveram bom ajuste, indicando que os dois modelos descrevem corretamente o percurso e o resultado do processo. 


\section{5 \\ Conclusões}

Neste trabalho, foi investigada a cinética de uma nova rota de obtenção de sulfato de potássio a partir do alúmen de potássio. O uso do agente redutor coque breeze mostrou ser de grande vantagem, tendo em vista que houve a diminuição da temperatura do processo e, consequentemente, da energia gasta. Além disso, utilizar o coque breeze é benéfico ao meio ambiente tendo em vista que ele é um resíduo e, aumentar a vida útil do mesmo contribui para a manutenção da economia circular e preservação do meio ambiente.

Os resultados de TG para a decomposição térmica mostraram duas regiões de forma que o modelo escolhido as descreveu em quatro reações: duas de desidratação e duas de decomposição. O mecanismo cinético do modelo adotado conseguiu representar bem os dados experimentais e é considerado bem sucedido no que se refere à predição de resultados.

Para a decomposição redutora, o modelo adotado descreve três reações: duas de desidratação e uma de decomposição, de forma que o mecanismo cinético do modelo adotado é similar ao modelo da decomposição térmica para as duas reações de desidratação. O modelo representou bem os valores medidos e por isso representa uma possibilidade no que se refere à predição dos dados experimentais.

Uma utilidade importante do uso de modelos é o monitoramento online de um processo. Em aplicações industriais, onde uma análise pode interromper o processo, comprometer o material, ou apenas custar caro, a utilização de um modelo confiável, com boa capacidade preditiva, elimina esse tipo de problema.

O método de Osawa para estimação dos parâmetros cinéticos não mostrou ter grande eficiência, para o presente trabalho. Desse modo, optouse por representar os dados por modelos não lineares e estimar seus parâmetros cinéticos desconhecidos pelo método de otimização enxame de partículas.

Assim, os parâmetros estimados pelo Enxame de Partículas para a decomposição térmica foram os seguintes:

Tabela 5.1: Parâmetros de Arrhenius para a decomposição térmica do alúmen de potássio

\begin{tabular}{|c|c|c|c|c|c|c|c|}
\hline \multicolumn{4}{|c|}{ Região de desidratação } & \multicolumn{4}{c|}{ Região de decomposição } \\
\hline $\mathrm{k} \$ \_\{01\}(\mathrm{min}-1)$ & $\mathrm{Ea}_{1}(\mathrm{~J} / \mathrm{mol})$ & $\mathrm{k}_{02}(\mathrm{~min}-1)$ & $\mathrm{Ea}_{2}(\mathrm{~J} / \mathrm{mol})$ & $\mathrm{k}_{03}(\mathrm{~min}-1)$ & $\mathrm{Ea}_{3}(\mathrm{~J} / \mathrm{mol})$ & $\mathrm{k}_{04}(\mathrm{~min}-1)$ & $\mathrm{Ea}_{4}(\mathrm{~J} / \mathrm{mol})$ \\
\hline $1,524 * 10^{+14}$ & 108804,4 & 0,899 & 4261,8 & $5,138 * 10^{+19}$ & 417279,4 & 1,315 & 16304,2 \\
\hline
\end{tabular}

Os parâmetros para a decomposição na presença de agente redutor, por sua vez, foram os seguintes: 
Tabela 5.2: Parâmetros de Arrhenius para a decomposição redutora do alúmen de potássio

\begin{tabular}{|c|c|c|c|c|c|}
\hline \multicolumn{4}{|c|}{ Região de desidratação } & \multicolumn{2}{c|}{ Região de decomposição } \\
\hline $\mathrm{k}_{01}($ min-1) & $\mathrm{Ea}_{1}(\mathrm{~J} / \mathrm{mol})$ & $\mathrm{k}_{02}(\mathrm{~min}-1)$ & $\mathrm{Ea}_{2}(\mathrm{~J} / \mathrm{mol})$ & $\mathrm{k}_{03}(\mathrm{~min}-1)$ & $\mathrm{Ea}_{3}(\mathrm{~J} / \mathrm{mol})$ \\
\hline $4,169 * 10^{+13}$ & 104988,5 & 1,199 & 7652,4 & $1,028 * 10^{+13}$ & 291963,7 \\
\hline
\end{tabular}

Desse modo, foi possível representar por meio de dois modelos distintos os processos de decomposição térmica do alúmen de potássio e decomposição redutora do mesmo com o uso do coque breeze. Ambos os modelos responderem muito bem frente aos dados experimetais e foram validados com sucesso. Futuramente, esses modelos, após adaptações, podem ser usados para monitorar online a perda de massa e as quantidades ou composições de cada espécie presente no processo implementado em escala industrial.

\section{1}

\section{Trabalhos Futuros}

Para trabalhos futuros, sugerem-se algumas adições para um maior aprofundamento e aprendizado já propostos por esta Dissertação de Mestrado, como as mostradas a seguir.

- A modelagem da decomposição do alúmen de potássio em processo contínuo, de modo a traduzir mais fielmente o ocorrido na indústria.

- Realizar mais análises de TG em diferentes taxas de aquecimento, para que, com mais pontos, o método de Osawa possa ser testado novamente.

- Realizar análises de TG isotérmicas, selecionando temperaturas de reação específicas, como uma temperatura antes da queima do coque e antes da decomposição do sulfato de potássio.

- Caracterizar por DR-X os resultados das análises, bem como em diferentes momentos da reação, entre eles no platô intermediário entre as duas regiões, e no fim do processo.

- Realizar a estimação de parâmetros pelo método do enxame de partículas para as outras taxas de aquecimento, de $10 \mathrm{~K} / \mathrm{min}$ e 20 $\mathrm{K} /$ min e comparar com os resultados obtidos no presente trabalho. 


\section{Referências bibliográficas}

[1] CAMARGO, M. S.. A importância do uso de fertilizantes para o meio ambiente. Pesquisa e Tecnologia, 9(2):4, 2012.

[2] FAQUIN, V.. Nutrição mineral de plantas. 2005.

[3] DEPARTAMENTO NACIONAL DE PRODUÇÃO MINERAL. Anuário Mineral Brasileiro: Principais Substâncias Metálicas, 2017.

[4] BRASIL RURAL. Brasil ainda importa a maioria dos fertilizantes usados na agricultura, 2018.

[5] SILVA, A.; MEDEIROS, M.; SAMPAIO, J. ; GARRIDO, F.. Verdete de cedro do abaeté como fonte de potássio: caracterização, tratamento térmico e reação com cao. Revista Matéria, 17(3):1061-1073, 2012.

[6] O ESTADO DE S. PAULO. Fertilizantes: Brasil continuará dependente de importação de Potássio, 2011.

[7] LAPIDO-LOUREIRO, F. E.; NASCIMENTO, M.; NEUMANN, R. ; RIZZO, A. C.. Tecnologias de aplicação de glaucomita como fonte de potássio na agricultura: o caso brasileiro e a experiência indiana. In: CONGRESSO BRASILEIRO DE ROCHAGEM, volumen 1, p. 111-119, 2009.

[8] FRAGOSO, C. L.. Processamento químico e caracterização de um concentrado de glauconita visando a produção seletiva de K2SO4. PhD thesis, PUC-Rio, 2014.

[9] NEEFT, J. P.; MAKKEE, M. ; MOULIJN, J. A.. Catalysts for the oxidation of soot from diesel exhaust gases. $i$. an exploratory study. Applied Catalysis B: Environmental, 8(1):57-78, 1996.

[10] OZAWA, T.. Thermal analysis-review and prospect. Thermochimica Acta, 355(1-2):35-42, 2000.

[11] NEEFT, J. P.; HOORNAERT, F.; MAKKEE, M. ; MOULIJN, J. A.. The effects of heat and mass transfer in thermogravimetrical analysis. a case study towards the catalytic oxidation of soot. Thermochimica Acta, 287(2):261-278, 1996.

[12] DU, Z.; SAROFIM, A. F.; LONGWELL, J. P. ; MIMS, C. A.. Kinetic measurement and modeling of carbon oxidation. Energy \& Fuels, 5(1):214-221, 1991. 
[13] GILOT, P.; BRILLARD, A. ; STANMORE, B.. Geometric effects on mass transfer during thermogravimetric analysis: application to reactivity of diesel soot. Combustion and flame, 102(4):471-480, 1995.

[14] STRATAKIS, G.; STAMATELOS, A.. Thermogravimetric analysis of soot emitted by a modern diesel engine run on catalyst-doped fuel. Combustion and Flame, 132(1-2):157-169, 2003.

[15] LIU, J.; ZHAO, Z.; XU, C.; DUAN, A.; ZHU, L. ; WANG, X.. Diesel soot oxidation over supported vanadium oxide and k-promoted vanadium oxide catalysts. Applied Catalysis B: Environmental, 61(12):36-46, 2005.

[16] YEZERETS, A.; CURRIER, N. W.; EADLER, H. A.; SURESH, A.; MADDEN, P. F. ; BRANIGIN, M. A.. Investigation of the oxidation behavior of diesel particulate matter. Catalysis today, 88(1-2):1725, 2003.

[17] NASCIMENTO, M.; MONTE, M. B. D. M. ; LOUREIRO, F. E. L.. Fertilizantes e sustentabilidade: o potássio na agricultura brasileira, fontes e rotas alternativas., 2004.

[18] EPSTEIN, E.; BLOOM, A. P.. Princípios e perspectivas. Editora Planta, Londrina, Brazil, 2006.

[19] GOMES, M.; DE SOUZA, M.; BOEIRA, R. ; DE TOLEDO, L.. Nutrientes vegetais no meio ambiente: ciclos bioquímicos, fertilzantes $\mathrm{e}$ corretivos. Embrapa Meio Ambiente. Documentos, 2008.

[20] MAPLES, R. L.; THOMPSON JR, W. ; VARVIL, J.. Potassium deficiency in cotton takes on a new look. Better Crops Plant Food, 73(1):6-9, 1988.

[21] DE ASSIS PRADO, C. H. B.; CASALI, C. A.. Fisiologia vegetal: práticas em relações hídricas, fotossínteses e nutrição mineral. Manole, 2006.

[22] BORGES, A.; JUNIOR, S.. Jf da.(2010) nutrição, calagem e adubação. Sistema de produção de banana para a Zona da Mata de Pernambuco. Aracaju: Embrapa Tabuleiros Costeiros, 139p.(EmbrapaCPATC. Sistema de produção, 3), p. 25-34.

[23] HABASHI, F.. Handbook of extractive metallurgy. Wiley-Vch, 1997.

[24] VIOLA, D. H. L.; OTHERS. Produção de sulfato de potássio a partir de cloreto de potássio e sulfato de amônio: estudos de equilíbrio sólido-líquido e desenvolvimento de processo. 2016.

[25] WILBUR, S.. Process for upgrading crude alkali metal sulfates, Oct. 31 1961. US Patent 3,006,726. 
[26] DAVE, R. H.; GHOSH, P. K.. Efficient recovery of potassium chloride from liquid effluent generated during preparation of schoenite from kainite mixed salt and its reuse in production of potassium sulfate. Industrial \& engineering chemistry research, 45(5):15511556, 2006.

[27] KÖNIGSBERGER, E.; ERIKSSON, G.. Simulation of industrial processes involving concentrated aqueous solutions. Journal of solution chemistry, 28(6):721-730, 1999.

[28] PENNELL, R. E.. Production of potassium sulphate fertilizer material, June 8 1937. US Patent 2,082,809.

[29] SCHULTZ, H.; BAUER, G.; SCHACHL, E.; HAGEDORN, F. ; SCHMITTINGER, P.. Ullmann's Encyclopedia of Industrial Chemistry: Potassium Compounds, 2000.

[30] LIPPMAN, J. A.; COMSTOCK, R. L.. Manufacture of sodium or potassium sulphate and hydrogen chloride, Dec. 7 1943. US Patent $2,336,180$.

[31] SCHARF, H.. Environmental aspects of k-fertilizers in production, handling and. Development of K-Fertilizer Recommendations, p. 395, 1990.

[32] SENDEROWITZ, H.; PARISH, C. ; STILL, W. C.. Carbohydrates: United Atom AMBER PArameterization of Pyranoses and Simulations Yielding Anomeric Free Energies. Journal of the American Chemical Society, 118((37)):8986-8996, 1996.

[33] MAJUMDER, A.; GOVINDARAJAN, B.; SHARMA, T.; RAY, H. ; RAO, T.. An empirical model for chloridising-roasting of potassium in glauconitic sandstone. International journal of mineral processing, 43(1-2):81-89, 1995.

[34] YADAV, V.; SHARMA, T. ; SAXENA, V.. Dissolution kinetics of potassium from glauconitic sandstone in acid lixiviant. International Journal of Mineral Processing, 60(1):15-36, 2000.

[35] YADAV, V.; SHARMA, T.. Leaching of glauconitic sand stone in acid lixiviants. Minerals engineering, 5(6):715-720, 1992.

[36] CASTRO, L.; TOURN, S.. Direct application of phosphate rocks and glauconite as alternative sources of fertilizer in argentina. Exploration and Mining Geology, 12(1-4):71-78, 2003.

[37] YEAR, C. G. N.. Bayer's process for alumina production: a historical perspective. Bull. Hist. Chem, 17(18):15, 1995.

[38] HABASHI, F.. A short history of hydrometallurgy. Hydrometallurgy, 79(1-2):15-22, 2005. 
[39] SILVA FILHO, E.; ALVES, M. ; DA MOTTA, M.. Lama vermelha da indústria de beneficiamento de alumina: produção, características, disposição e aplicações alternativas. Revista Matéria, 12(2):322338, 2007.

[40] ANTUNES, M.; CONCEIÇÃO, F. ; NAVARRO, G.. Caracterização da lama vermelha brasileira (resíduo do refino da bauxita) e avaliação de suas propriedades para futuras aplicações. In: INTERNATIONAL WORKSHOP ADVANCES IN CLEANER PRODUCTION, volumen 3, 2011.

[41] COllaZO, A.; FERnÁNDEZ, D.; IZQUIERDO, M.; NÓVOA, X. ; PÉREZ, C.. Evaluation of red mud as surface treatment for carbon steel prior painting. Progress in Organic Coatings, 52(4):351-358, 2005.

[42] LIMA, M. S.; THIVES, L. P. ; HARITONOVS, V.. Damage induced by moisture in bituminous mixtures fabricated with red mud and stone dust as filler: Methodology for environmental analysis.

[43] NUNN, R. F.. Advances in red mud dewatering and disposal technologies. LIGHT METALS-WARRENDALE-, p. 107-114, 1998.

[44] LIMA, F.. Utilização da lama vermelha e do resíduo caulinítico na produção de pigmento pozolânico para argamassas e concretos de cimento portland. UFPA, Brazil, 2006.

[45] KAVAS, T.. Use of boron waste as a fluxing agent in production of red mud brick. Building and Environment, 41(12):1779-1783, 2006.

[46] YANG, J.; XIAO, B.. Development of unsintered construction materials from red mud wastes produced in the sintering alumina process. Construction and Building Materials, 22(12):2299-2307, 2008.

[47] MANFROI, E. P.; OTHERS. Avaliação da lama vermelha como material pozolânico em substituição ao cimento para produção de argamassas. 2012.

[48] MACÊDO, A. N.; PEREIRA, D. H.; DOS SANTOS TRINDADE, S. R.; DA SILVA SOUZA, J. A.; CARNEIRO, R. J. F. M. ; OTHERS. Comportamento de blocos cerâmicos estruturais produzidos a partir da mistura de lama vermelha e argila. Ambiente Construído, 11(4):2536, 2011.

[49] PALMER, S. J.; NOTHLING, M.; BAKON, K. H. ; FROST, R. L.. Thermally activated seawater neutralised red mud used for the removal of arsenate, vanadate and molybdate from aqueous solutions. Journal of Colloid and Interface Science, 342(1):147-154, 2010.

[50] COOLING, D. J.. Improving the sustainability of residue management practices-alcoa world alumina australia. Paste and Thickened Tailings: A Guide, 316, 2007. 
[51] GALWEY, A. K.; MOHAMED, M. A.. Structure and function of the nuclei developed during dehydration of the alums kal (so4) 2. 12h2o and kcr (so4) 2. 12h2o. Thermochimica acta, 121:97-107, 1987.

[52] GALWEY, A. K.. Structure and order in thermal dehydrations of crystalline solids. Thermochimica acta, 355(1-2):181-238, 2000.

[53] PYSIAK, J.; GLINKA, A.. Thermal decomposition of basic aluminium potassium sulfate. part ii. kinetics of the reaction. Thermochimica Acta, 44(1):29-36, 1981.

[54] SOUZA, R.; NAVARRO, R.; GRILLO, A. V. ; BROCCHI, E.. Potassium alum thermal decomposition study under non-reductive and reductive conditions. Journal of Materials Research and Technology, 2018.

[55] HECK, N. C.. Metalurgia extrativa dos metais não-ferrosos ia. UFRGS/DEMET.[Links], 2001.

[56] PACEWSKA, B.; PYSIAK, J.. Thermal decomposition of basic aluminium potassium sulphate (baps) in hydrogen atmosphere. Thermochimica acta, 179:187-193, 1991.

[57] PACEWSKA, B.; PYSIAK, J.. Influence of carbon and water vapour on the thermal dissociation of a basic aluminium-potassium sulfate. Journal of Thermal Analysis and Calorimetry, 33(2):511-517, 1988.

[58] ASSOCIAÇÃO BRASILEIRA DO CARVÃO MINERAL. Siderurgia.

[59] ROINE, A.. Outokumpu hsc chemistry for windows: chemical reaction and equilibrium software with extensive thermochemical database. Pori: Outokumpu research OY, 2002.

[60] PERNICKA, E.. Provenance determination of archaeological metal objects. In: ARCHAEOMETALLURGY IN GLOBAL PERSPECTIVE, p. 239-268. Springer, 2014.

[61] DANNATT, C.; ELLINGHAM, H.. Roasting and reduction processes. roasting and reduction processes-a general survey. Discussions of the Faraday Society, 4:126-139, 1948.

[62] UNIVERSIDADE FEDERAL DO RIO GRANDE DO SUL. Termodinâmica Metalúrgica II.

[63] APTE, N.; KIRAN, E. ; CHERNOSKY, J.. Thermal decomposition of aluminium-bearing compounds. Journal of thermal analysis, 34(4):975-981, 1988.

[64] PIRES, D. C.. Estudo cinético do perclorato de amônio por calorimetria exploratória diferencial e termogravimetria. $\mathrm{PhD}$ thesis, Instituto Tecnológico de Aeronáutica, São José dos Campos., 2004. 
[65] PIMENTEL, A. S.; ARBILLA, G.. Thermal analyasis kinetics for nonisothermal reactions of solids. Química Nova, 21(3):263-266, 1998.

[66] NAGAI, T.; TAMURA, S. ; IMANAKA, N.. Thermal decomposition behavior of the rare-earth ammonium sulfate $\mathrm{R2}(\mathrm{SO})$ 3.(NH4) 2S04. Journal of Solid State Chemistry, 183(7):1504-1509, 2010.

[67] GHASRI-KHOUZANI, M.; MERATIAN, M. ; PANJEPOUR., M.. Effect of mechanical activation on structure and thermal decomposition of aluminum sulfate. Journal of Alloys and Compounds, 472(12):535-539, 2009.

[68] ANDRADE, J.; IHA, K.; ROCCO, J. A. F. F.; FRANCO, G. P.; SUZUKI, N. ; SUÁREZ-IHA, M. E. V.. Andrade, J., Iha, K., Rocco, J. A. F. F., Franco, G. P., Suzuki, N., \& Suárez-Iha, M. E. V. Eclética Química, 32(3):45-50, 2007.

[69] SEYE, O.; CORTEZ, L. A. B. ; GÓMEZ, E. O.. Estudo cinético da biomassa a partir de resultados termogravimétricos. Proceedings of the 3. Encontro de Energia no Meio Rural, 2000.

[70] OZAWA, T.. A new method of analyzing thermogravimetric data. Bulletin of the chemical society of Japan, 38(11):1881-1886, 1965.

[71] MACCALLUM, J. R.; TANNER., J.. A comparative study of some methods of assessing kinetic parameters from thermogravimetric analysis. European Polymer Journal, 6(6):907-917, 1970.

[72] ALVAREZ, V. A.; VÁZQUEZ., A.. Thermal degradation of cellulose derivatives/starch blends and sisal fibre biocomposites. Polymer degradation and stability, 84(1):13-21, 2004.

[73] YI-CHE, S.; DING-RU, Y. ; FENG-CHIH, C.. The Kinetics of B-a and P-a Type Copolybenzoxazine via the Ring Opening Process. Journal of Applied Polymer Science, 95:730-737, 2005.

[74] TONIOLO, F. S.; BARBOSA-COUTINHO, E.; SCHWAAB, M.; LEOCADIO, I. C.; ADERNE, R. S.; SCHMAL, M. ; PINTO, J. C.. Kinetics of the catalytic combustion of diesel soot with MoO3/Al2O3 catalyst from thermogravimetric analyses. Applied Catalysis A: General, 342(1-2):87-92, 2008.

[75] SCHWAAB, M.. Análise de Dados Experimentais: I. Fundamentos de Estatística e Estimação de Parâmetros. 2007.

[76] BRANDÃO, A. L. T.. Discriminação de modelos cinéticos de ramificação usando dados de distribuição de massa molar em sistemas de polimerização. PhD thesis, UFRJ, 2014.

[77] SCHWAAB, M.. Avaliação de algoritmos heurísticos de otimização em problemas de estimação de parâmetros. PhD thesis, Dissertação de Mestrado, COPPE/UFRJ, Rio de Janeiro, RJ, Brasil, 2005. 
[78] DOWDY, S.; WEARDEN, S. ; CHILKO, D.. Statistics for research. wiley. New York, NY, 1983.

[79] HIRSCH, R. P.. Introduction to biostatistical applications in health research with microsoft ${ }^{\circledR}$ office e xcel ${ }^{\circledR}$. Wiley StatsRef: Statistics Reference Online, p. 1-7, 2014.

[80] DRAPER, N. R.; SMITH, H.. Applied regression analysis, volumen 326. John Wiley \& Sons, 2014.

[81] SCHWAAB, M.; BISCAIA JR, E. C.; MONTEIRO, J. L. ; PINTO, J. C.. Nonlinear parameter estimation through particle swarm optimization. Chemical Engineering Science, 63(6):1542-1552, 2008.

[82] BEALE, E.. Confidence regions in non-linear estimation. Journal of the Royal Statistical Society. Series B (Methodological), p. 41-88, 1960.

[83] BRANDÃO, A. L.; ALBERTON, A. L.; PINTO, J. C. ; SOARES, J. B.. Copolymerization of ethylene with 1, 9-decadiene: Part i-prediction of average molecular weights and long-chain branching frequencies. Macromolecular Theory and Simulations, 26(1):1600059, 2017.

[84] BRANDÃO, A. L.; OECHSLER, B. F.; GOMES, F. W.; JR., F. G. S. ; PINTO, J. C.. Modeling and parameter estimation of step-growth polymerization of poly(ethylene-2,5-furandicarboxylate). Polymer Engineering and Science, 58(5):729-741, 2018.

[85] SCHWAAB, M.; PINTO, J. C.. Optimum reference temperature for reparameterization of the arrhenius equation. part 1: Problems involving one kinetic constant. Chemical Engineering Science, 62(10):2750-2764, 2007.

[86] AGARWAL, A. K.; BRISK, M. L.. Sequential experimental design for precise parameter estimation. 1. use of reparameterization. Industrial \& Engineering Chemistry Process Design and Development, 24(1):203-207, 1985.

[87] ESPIE, D. M.; MACCHIETTO, S.. Nonlinear transformations for parameter estimation. Industrial \& engineering chemistry research, 27(11):2175-2179, 1988. 